$$
\begin{aligned}
& \text { FLNCTONALNERVOUS } \\
& \text { DISORDERS IN } \\
& \text { CHLDHOOD }
\end{aligned}
$$

LEONARD G.GUTHRIE 
$P=0, x$

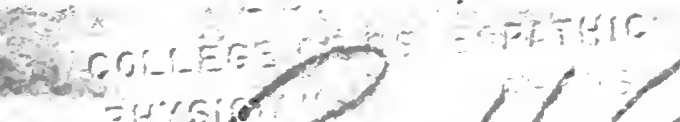

GOOKVAS DOPATED TH:15EOOKVAS DOPATED

mons - 
Digitized by the Internet Archive in 2007 with funding from Microsoft Corporation 
OXFORD MEDICAL PUBLICATIONS

\section{FUNCTIONAL NERVOUS \\ DISORDERS IN CHILDHOOD}



OXFORD MEDICAL PUBLICATIONS

\section{FUNCTIONAL NERVOUS \\ DISORDERS IN CHILDHOOD}

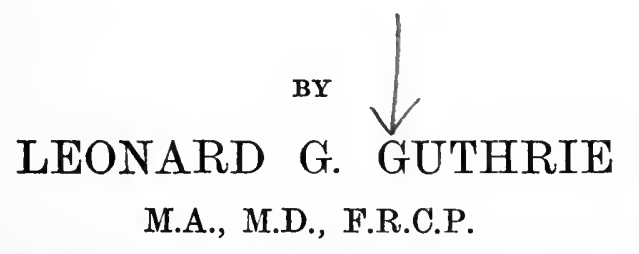

genior physician to paddington green chILdREN'S hospital. pHysician TO THE HOSPITAL FOR EPILEPSY AND PARALYSIS, MAIDA VALE

\section{LONDON}

HENRY FROWDE HODDER \& STOUGHTON Oxford University Press Warwick Square, E.C. 


$$
\begin{aligned}
& \text { WS350 } \\
& \text { G984f } \\
& 1907 \mathrm{f}
\end{aligned}
$$




\section{PREFACE}

THE object of this book is duly set forth in the introductory chapters. In brief, it is to emphasize the truism that the neurotic child is the father of the neurasthenic adult. Many nervous and other ailments are the outcome of the neurotic or emotional temperament, and all are aggravated thereby. It is held that early recognition of these simple facts by medical men may help to lessen the prevalence of neurasthenia in the rising generation.

The contents of the volume consist chiefly of lectures and addresses delivered at various times before provincial branches of the British Medical Association, and the Postgraduates' College of London.

The majority of them have hitherto been unpublished, but some have appeared in substance in the Clinical Journal. Parts of the section on "Night Terrors" are taken from an article on that subject in Vol. viii of Clifford Allbutt's System of Medicine.

My thanks are due to the Editors and Publishers of the System and Journal named, for permission to make use of the materials in their present shape.

In all cases the matter has been re-arranged, re-written to a great extent, and considerable additions have been made.

The illustration which faces Chapter vi on "Fears of Neurotic Children,". is reproduced by favour of the Royal Medical and Chirurgical Society from Jerome Cardan's De Utilitate ex Adversis Capiendâ (ed. 1672), now in the Society's 
Library. It depicts a philosopher in the act of introducing a frightened boy to a hideous hag with cloven hoofs, barbed tail and snake-like hair, and it seems to represent the Platonic method of testing children's courage by exposing them to witcheraft.

I may at once disclaim all pretensions to scientific treatment of my subject. The lectures were not didactic when delivered, nor are they ex cathedrâ now ; they were intended to promote discussion and to excite interest in the medical aspect of the twentieth century neurotic child. That they succeeded in this respect is no tribute to their merits. A better book than this would have resulted, had it been possible to include therein the discussions which the lectures raised, and the valuable personal experiences and views of those who spoke upon them.

But as this could not be, I can but trust that those who will read them, like those who listened to them, may find food for thought as well as criticism in these pages. Should criticism be severe and the reviewer, quoting Merlin, say that-

None can read the text, not even $I$,

then, misquoting Merlin, I must hope that

None may read the comment but myself, 


\title{
CONTENTS
}

\author{
CHAPTER I
}

\section{INTRODUCTION}

Importance of acquiring knowledge of Children as well as of their Diseases-Medical advice now sought on cases formerly dealt with by Disciplinarians.-Tendency to ignore the Personality, Ancestry and Environment of the Child in treating his Ailments.

\section{CHAPTER II}

\section{EFfects of Emotions on Health . . . . . . 7}

- George Eliot on the Sorrows of Childhood-The Neurotic Temperament-Physiological Effects of Excessive Emotions-The Neurotic Temperament a Matter of Inheritance-Results of Training and Environment--The Unemotional Person.

\section{CHAPTER III}

\section{Nervous System in Chindhood.}

Functional Neuroses not solely caused by Reflex Irritation-Not due to Normal Physiological Instability of the Nervous System common to all, but to Nervous Instability peculiar to the Individual-Individual Instability shown in : Disorders of Co-ordination-Defective Control of Higher over Lower Centres.-Explosiveness and Exhaustion of Nerve Centres-Hysteria-Neurasthenia.-Neurasthenia the Outcome of the Neurotic or Emotional Temperament.

\section{CHAPTER IV}

\section{Types of Neurotic SubJects . . . . . . .}

The Restrained and Unrestrained Types-Complaints to which they are liable-Various Sub-types of Neurotic Persons-The Neurotic Tem. perament not necessarily morbid, but may result in NeurastheniaImportance of recognizing it early-Medical Advice on the point a Modern Necessity-Most Neuroses of Psychical Origin. 


\section{CHAPTER V}

Hypersenstitiveness of Spectal Senses . . . .

Hypersensitiveness to Sound, Colour, Taste, Smell-Remarks on Diet-Appetite and Dislikes-Cutaneous Hyperaesthesia.

\section{CHAPTER VI}

The Fears of Neurotic Childoren . . .

Ancient Methods of dealing with Fear in Children-Results of FearCauses and Examples of Fear-Fear of Inanimate Objects-Of the Supernatural-Religious and Moral Emotions-Unnatural Remorse, Worries and Apprehensions-Fear of Corporal Punishment.

\section{CHAPTER VII}

Fretting and Home-Sickness . . . . . . .

Fretting a Genuine Source of Ill-health-May be due to Homing Instincts-Fichte-De Quincey-Gautier-Junod-Trollope-Coleridge-De Balzac-Descartes-Should he be sent to School?

\section{CHAPTER VIII}

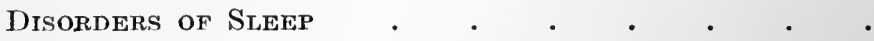

Normal Hours of Sleep-Causes and Consequences of SleeplessnessHours of Sleep for School Children-Night Terrors: Symptoms-No Essential Distinction between Idiopathic and Symptomatic Night Ter. rors-Nightmare and Night Terrors only Differ in Degree.-Day Terrors: Relation to Epilepsy and Migraine-Treatment.

\section{CHAPTER IX}

\section{Moral Fatlings}

As Evidence of Ill-health-Influence of Heredity and Environment -Acute and Chronic Illnesses-Mitigating Circumstances-Cruelty -Passionateness--Screaming Fits-Infant Murderers-Dishonesty -Untruthfulness-Suicide-Moral Imbecility-Sexual InformationSexual Aberrations-Modern Methods of Moral Instruction-Teaching on Heredity-Alcohol-Tobacco-Pathological Penalties-Tendency to Overstate the Case.

\section{CHAPTER X}

\section{Mental and Educational Overstrain}




\section{CHAPTER XI}

Palpitation-Tachycardia-Disorders of Sympathetic SystemEnterospasm-Splenic Pain at Puberty-Flushing-Pallor-Dead Fingers-Treatment-Hypertrophic Stenosis of Pylorus-Congenital and Acquired-Hyperchlorhydria-Treatment-Headaches-Causes -Migraine-Treatment.

\section{CHAP'TER XII}

Enuresis, Cyclical Albuminuria, Cyclical Pyrexia, Cyclical Voming . $\quad$. $\quad$.

\section{CHAPTER XIII}

Disorders Associated with Primary Dentition . 166

\section{CHAPTER XIV}

\section{Spasmodic Affections}

Neuroses Associated with Rickets-Convulsions-Tetany-Laryngismus.

\section{CHAPTER XV}

Spasmodic Affectrons (continued) Convulsions . .

Definition-Instability of Cercbro-Medullary Centres-Instability Peculiar to the Individual-Eclampsia Noonatorum-Convulsions Before, During and After Primary Dentition-Reflex ConvulsionsTreatment-Prognosis. Epilepsy and Eclampsia of Similar Nature-Etiology-Idiopathic and Symptomatic Epilepsy-" Accidental" Epilepsy-Heredity-Petit Mal and Dreamy Mental States -Paroxysinal Screaming-Examples of Dreamy Mental States-Jules Breton, Jerome Cardan, Henry Morley-Treatment of Epilepsy.

\section{CHAPTER XVI}

\section{Spasmodic Asthma}

Age-Neuropathic Inheritance-Reflex Causes-Central OriginAlternation with Skin Affections-Migraine-Dead Fingers-Periodicity-Pathology-Analogy with Mucous Colic-Diagnosis-Treatment.

\section{CHAPTER XVII}

\section{Chorea}

Definition-History-Duration-Sex and Age-Etiology-Relation to Rheumatism - To Fright - To Shock-Rheumococci-Reflex Chorea-Site of Lesion and Morbid Anatomy of Chorea-Varieties of Chorea; Sthenic-Asthenic-Subvarieties-Description of Sthenic Chorea-Residual Chorea-Description of Asthenic Chorea-Mutism in Chorea-Psychical Conditions-Treatment of Chorea. 


\section{CHAPTER XVIII}

\section{The Tics}

Definition-Varieties-Etiology-Descriptions of Various FormsThey may be neither Habits nor Spasms-Treatment-Differential Diagnosis from Chorea.

\section{CHAPTER XIX}

Delayed Walking-Loss of Acquired Walking Power - Hysterical and Functional Paralysis

\section{CHAPTER XX}

Stammering and Other Defects of Speech . . . 262

\section{CHAPTER XXI}

IDIOGLOSSIA • • • • • • • • • •

Definition-Examples-Defective Visual and Auditory MemoryComparison of Six Cases-Not "Baby Language," nor Invented Language, nor an example of Atavism, but English rendered Unintelligible by Substitution of Consonants and Vowels for each otherAn Exaggerated Form of "Lalling," not associated with Mental Deficiency-Probably due to Defect of Auditory Perceptive Centresand not to Defective Articulation-Treatment. 


\section{CHAPTER I}

\section{INTRODUCTION}

IN days gone by, our training as medical students did not include more than a text-book acquaintance with the diseases to which children are subject. It is true that at every teaching hospital there was a department devoted to the diseases of women and children, but this was usually in charge of a gynaecologist who naturally confined his attention and that of his pupils within the bounds of his own specialty. Many students therefore obtained the highest possible qualifications and entered practice in a state of "complete and exhaustive ignorance" of all but the most obvious of children's ailments. The recognition even of these depended upon a theoretical acquaintance with physical signs and $s y$ mptoms which often failed in an emergency.

One speaks, of course, of many years ago, with vivid recollections of defaults-when babies were uncanny mysteries-when the cry of pain, bad temper, passion, and the wail and whine of desperate illness were all alike to us ; when the character of respirations conveyed no meaning if physical signs of pneumonia and bronchitis were absent; when urgent dyspnoea only suggested laryngeal obstruction and tracheotomy; when a temperature of $104^{\circ}$ filled us with alarm, although the child might be placidly sucking its thumb at the time; when every infant squalling with colic seemed a likely victim to appendicitis or intus-susception. Sometimes, if no physical signs of either of those fell diseases could be discovered we may have felt a wild impulse-like the Veneering's waiter in Dickens' Our Mutual 
Friend-to suggest "wind," and throw up our situation. We laboured, in short, under a sense of incapacity due as much to ignorance of the signs and symptoms of health as of disease in infants and children. It was difficult, even after careful examination, to decide whether a child was seriously ill or had little or nothing the matter with it.

Within recent years a change for the better has arisen. Many of the large hospitals have wards set apart for children. Children are no longer dispersed amongst adult patients to torment them by their wakeful moans. Students are taught by lectures and practical demonstrations that the inner parts of babies are not such sealed mysteries as they at first appear to be. They learn that the baby's facial expression, its frown and look of pain, and above all, its smile, the character of its voice, the movements of its limbs, chest, and abdomen, are as significant as the condition of its tongue and pulse. If it can smile its life cannot be in imminent danger.

Herodotus tells in a story how the life of the infant Cypselus was saved by a timely smile. In consequence of an oracle it was ordained that the infant should undergo a major operation, a crude sort of cranioclasty. It was arranged that ten surgeons or Bacchiadae, as they were termed, should call at the house to see the child, and that the first to receive it in his arms should dash its brains out on the floor. But when the babe was handed to the first, it smiled at him, so he had not the heart to destroy it, but passed it on to the next. He was similarly irresolute and did the same, until finally, all had handled the babe and examined it, and it.was then restored to its mother. But the operation remained unperformed.

Then the surgeons went outside and consulted together. They agreed that, in spite of the baby's smiles, the operation was necessary, and even urgent. However, the mother was listening behind the door, as mothers will do when 
consultations are proceeding, and she hid the child in a chest. So Cypselus escaped and lived to do some major operations on his own account. He began on the Bacchiadae.

Doubtless, since the days of Cypselus many a surgeon has been disarmed by a baby's toothless smile, although the smile may have been entirely thrown away on the anxious and less experienced practitioner who had doubted if the babe could possibly live through the night.

To cultivated ears, screams described beforehand as those of agony, and warranting immediate operative interference, may resolve themselves even when heard outside the nursery door into those of peevishness and passion, although the patient's bowels may not have acted for four days and the temperature is $103^{\circ}$.

Enough has been said to show the importance, long neglected, of acquiring knowledge of children as well as of their diseases. There is no excuse now for entering practice in a state of dark mental chaos with regard to the manners and customs of infants. In addition to special tuition now afforded at general hospitals, a number of children's hospitals has arisen within the last twenty years, where further knowledge may be obtained, whilst, still more recently, London has followed, far behind, in the footsteps of all other civilized countries, and founded a Society for the Study of Disease in Children, from which it may be hoped that valuable information may be propagated.

It is difficult to explain why a subject so important to the welfare of the community as the study of children should have been so long neglected in this country. Perhaps the public as well as the medical profession are to blame. For from time immemorial the upbringing of children has been regarded from an economical rather than a medical point of view. Many an elaborate treatise on methods of training children to be healthy, virtuous and brave has seen the light, but has emanated from moral educationalists and not from physicians. In fact, medical 
men were not supposed to interfere in matters considered to be outside their province. If children were ill or ailing, the doctor was called upon to prescribe for their diseases, but advice on their management in general was neither sought nor welcomed. $\mathrm{He}$ was not asked to see a child because it was wayward, but because it was wasting, not because it was dainty, capricious in appetite, refusing food considered good for it, and craving for all that is unwholesome, but because it had pains in its stomach. Advice was not asked for peevish, passionate children, nor for those who were afraid of the dark, and unnaturally timid, absent-minded, or brooding and morose, jealous, spiteful, or cruel, nor for mischievous, untruthful, dishonest, or immoral children. All such defects were regarded as moral rather than morbid, and were treated as such. It was long before it was recognized that a child might be dull and stupid in consequence of defects of sight or hearing.

If such stupid children were neglected, the precocious were in a still worse plight. For although the saying "So wise so young do not live long" might be quoted, it was not considered that medical advice might lead to such children's longevity.

Of late years this attitude of the public has changed. They have formed Parents' Unions and Childhood Societies, and have learnt that morality is largely a question of health and temperament and environment; that vice to a great extent depends upon disease, hereditary or acquired. Hence medical men are frequently called upon to advise in cases which formerly were dealt with by disciplinarians. Even at Board schools children are no longer caned as of yore for having chorea. The pendulum has perheps swung too far in the opposite direction, but it is a fault on the right side. Parents are perhaps too apt nowadays to look for stigmata of degeneration in their offspring, and to suffer tortures of remorse when their little ones are naughty. Peccadilloes are magnified into enormous misdemeanours suggestive of moral insanity. Petty ailments, especially 
if combined with a vile temper, are regarded as evidence of a gouty inheritance.

A child who shows signs of intelligence above the average is thought to be in imminent danger of over-taxing his brain; whilst one is asked to give hopes that thumb and finger exercises or Swedish drills may stimulate activity in the brain of a semi-imbecile and render his intelligence normal.

As I have said, a reaction has taken place; we are called upon to advise in cases which formerly did not come within our cognizance. Our knowledge of diseases and ailments of children has been considerably widened of late; there is yet a tendency to lay too much stress upon the actual complaint from which a child suffers and not enough upon the child's personality, his ancestry and environment.

We are apt to attribute an enormous variety of symptoms to one cause in particular instead of to many different factors, and when we have removed or treated the presumed cause, we are much concerned because the patient is not materially better.

For instance, a child has night terrors, and, as indigestion will certainly give rise to bad dreams, we think to stop the night terrors by treating the child for dyspepsia. Or headache is the complaint, and having observed a slight error in refraction we are disappointed that the headaches do not disappear when suitable glasses have been provided. Or we are surprised that epilepsy is not cured after the evacuation of a few thread-worms.

Some believe that epilepsy and chorea and most functional disorders in children are due to auto-intoxication, and are curable by disinfecting the alimentary tract; others that eye-strain, decayed teeth, or a tight prepuce, or adenoid vegetations are chiefly to blame; whilst it is hardly necessary to mention the uric acid specialist, who attributes all known ailments, and several more, to excess of biurate of sodium.

One may sum up by saying that although facilities for 
acquiring knowledge of diseases in childhood have been greatly increased of late, the value of such knowledge would be enhanced were it combined with the study of childhood itself. 


\section{CHAPTER II}

\section{EFFECTS OF EMOTIONS ON HEALTH}

In the case of adults the effect of mental troubles on the course and origin of illness is well recognized. Galen, when called to see a Roman lady who was supposed to be in a decline, divined that the sickness was merely that of love, for, on the mention of the name of Pylades the actor, the lady's pulse at once became hurried and irregular.

We are all aware that medical treatment alone will not cure insomnia in a clerk who has been robbing the till, or dyspepsia in a wife who is jealous of her husband. Yet where children are concerned, we often forget that the influence of their mental troubles may be as greatas, or greater, than our own, in causing and prolonging their complaints.

George Eliot says of the sorrows of childhood: "We can no longer recall the poignancy of that moment and weep over it as we do over the remembered sufferings of five or ten years ago. Every one of those keen moments has left its trace and lives in us still, but such traces have blent themselves irrecoverably with the finer texture of our youth and manhood; and so it comes to pass that we can look on at the troubles of our children with a smiling disbelief in the reality of their pain"* George Eliot refers to the effect of children's mental sufferings upon their happiness, not upon their health. Yet health and happiness go together. If a child is miserable, its health, like that of an adult, suffers. The cause of the misery may seem trivial, but its effect upon health may * Mill on the Floss, p. 66. 
be prolonged through after life. We do not find instances of this in medical text-books, but in the autobiographies of many literary persons. It might be thought that such cases are exceptional, and that the effects of their early sorrows are exaggerated by the vivid imagination and emotions of the writers, and that the various complaints of mind and body which many of them graphically describe, are merely part of the eccentricities of genius. But the tale is none the less true for being clothed in picturesque language which all of us have not at command. And therefore one need not hesitate to use illustrations from nonmedical literature which seem to be in point.

My purpose is to speak of neurotic children and to consider the bearing which their temperament has upon their diseases.

To speak of temperament in relation to disease carries us very far back in the history of medicine; to the days of the Humoralists who followed the doctrines of Empedocles, and held that there were four elements : fire, air, earth, water ; four qualities : hot, cold, dry, moist ; and four humours: blood, phlegm, yellow and black bile. Their fantastic theories as to the causation of disease have long been dead. Yet even now we speak of sanguine, phlegmatic, choleric and melancholic dispositions, though without attaching such medical importance to the terms as the Humoralists did.

The Neurotic Temperament. A neurotic temperament means a disposition in which the emotions are easily kindled, strongly felt, and restrained or controlled with difficulty. Emotional excitability may apply to all, or to only one or more sets of possible emotions. For instance, capacity for emotions such as fear, anger, and the like, may predominate in one; love and sympathy in another; self-love, sadness, melancholy in a third. Together with emotional excitability in one or other of these directions, there may be deficient development of control, deficient powers of judgment as to the weight of the cause which excites the emotion, which cause is ex- 


\section{EFFECTS OF EMOTIONS ON HEALTH}

aggerated by process of imagination and want of experience. Unrestrained emotions of any kind will lead to mental and bodily exhaustion. On the other hand, a similar result follows a constant struggle between the will-power which seeks to control and the emotions which seek display.

The physiological effects of excessive emotion of any kind, whether restrained or unrestrained, are to produce lowered vitality and prostration, enfeebled circulation, and disorders of the whole processes of metabolism and elimination. Hence the importance of recognizing the presence of emotional excitability in early childhood.

The emotional temperament is largely a matter of direct inheritance. Apart from a family history of neuroses, a glance at one or other parent will often give a clue to the disposition of the child, and in some cases when placid and commonplace parents cannot understand where their children get their temper from, a "wicked uncle," or an aunt "who was always considered queer," may be found amongst collaterals. The emotional temperament may be modified, though it cannot be eliminated by training and environment. The child is father of the man, and on looking back to early days we must all agree that our dispositions, our likes, dislikes, and passions have not altered much. Experience has taught us to modify our actions, but has not changed our impulses. And again, those of us who are neurotic will agree with George Eliot that our emotional sufferings in early childhood were very great indeed, that they were intensified by being neglected or ignored, that they affected our health as well as happiness, and that we bear their traces still.

The Unemotional person. The person who is not neurotic bears a charmed existence in comparison with one who is. Emotions he must have, of course, but they are mainly pleasurable, and no one of them is too keen; all are easily controlled. Theoretically, he is the offspring of a long-lived race of sturdy and somewhat commonplace people. None of his ancestors has been in any way 
distinguished, except for unimpeachable respectability and orthodoxy. They have been methodical, businesslike, plodding, industrious, and successful. His birth will be normal and easy, his infancy uneventful. He will take the breast readily and not cry for more when he has had sufficient. He will, however, cry lustily and kick vigorously when hungry, or when a pin is running into him, but not otherwise. He will sleep the sleep of the just, and so will his parents and nurses. He will not show undue precocity, except in physical strength, and will stand and walk long before he can talk. He will be a little slow in taking notice, but when he begins he will win much popularity by his affable reception of complete strangers. He will tolerate all novel experiences, except painful ones, with the greatest composure. In very early days he will regard all toys merely as things to suck, but later he will show marked preference for those which make most noise. His teeth will be cut before the nurse has time to discover that he is fretful and "must be about" them. Of course he may not escape measles and scarlatina, but will take them so mildly that they will probably be diagnosed as rose rash or "fourth " or " fifth disease." He may, when just able to walk, excite consternation by his inveterate habit of risking his neck and limbs on every possible opportunity, but otherwise there will be no reason for anxiety respecting his health during early childhood. As regards digestion, he will be capable, like the unfortunate Dean Swift, of consuming a hundred golden pippins at a time; but, unlike that most miserable of men, he will be none the worse for doing so. As a boy, he will be fond of all kinds of sport. Under the guidance of friendly gamekeepers he will acquire a stock of knowledge of the habits and customs of birds and beasts, solely with the object of killing them, not with the instincts of a Waterton or White. Not that he is wilfully cruel ; he is only incapable of conceiving that animals have feelings worth respecting. Like Tom Tulliver, he will believe that worms do not feel, or if they 
do it doesn't matter much. He will readily swap the terrier which adores him for a better ratter, and will be capable of fattening tame rabbits in order to increase his pocket-money by selling them for his own dinner. A horse to him is merely a thing to be tamed, ridden, and driven. At school he will not shine in lessons, but will pass muster. Classics and foreign languages he will abhor, but he will be fairly good at simple arithmetic, and he will like practical chemistry because of the evil smells which he will be allowed to perpetrate and the general suggestion of fireworks which that interesting study conveys. His taste in literature will be confined to tales of adventure, particularly concerning pirates. Anything of the imaginative or romantic order he will relentlessly condemn as " rot." He will naturally excel at school games, and the 'Varsity Blues, engaged at his parents' great expense to form his mind, will deal leniently with his Latin in consideration of his prowess as a "forward" at "footer." He will infinitely prefer a caning to an imposition, and will think the fun of breaking bounds well worth the handsome recognition which it entails at the hands of the head master $\mathrm{He}$ will enjoy fighting, but, far from being a bully, will champion the cause of small nervous boys against those who illtreat them. But he will have a hearty contempt for his protégés, and will probably cause them more discomfort by his boisterous disregard for their sensitive nature than the bully ever would by physical ill-usage. In short, he is the type of what is called a manly boy without any nonsense about him ; good-tempered, honourable, easy-going, not highly intellectual, but with a fair amount of common-sense of a rather narrow order. He can obtain a pass degree at almost any university without much trouble. He makes an excellent clergyman of the muscular order, though perhaps a little intolerant of conscientious doubters of creeds which he never dreamed of questioning. In the army he is the idol of his men, who readily follow his leadership of a forlorn hope without blaming him for 
having made it so. In commerce he conducts a safe and never risky business, and, with capital and competent managers to guide him, will be prosperous. If wealthy, he may develop a taste for art, and become renowned as possessing the finest collection in the country of pictures of the early Victorian British or "Baby's birthday" school. In politics and religion he will stick to his party. No misfortune, pecuniary or otherwise, will ever lose him an hour's sleep or interfere with his appetite. Perhaps he may eat and drink rather more than would be good for most people, but with no apparent ill effect. He may have illnesses, of course, but will always flatter his medical man by the wonderful manner in which he rallies under remedies skilfully prescribed. Indeed, he will be regarded by his doctor as a standing proof of the efficacy of medicine. Ultimately he will die of old age after many false alarms.

This rough and over-drawn sketch may serve to convey the idea of a person without any very keen emotions. Throughout his existence he has no strong passions to battle with, cares sit lightly on him, and his ambitions are never thwarted, for he is perfectly satisfied with the state of life into which it has pleased God to call him.

Before proceeding to further consideration of neurotic children it is necessary to say a word on the nervous system in childhood. 


\section{CHAPTER III}

\section{NERVOUS SYSTEM IN CHILDHOOD}

THE various functional neuroses of childhood have been explained by theories based on the normal development of the cerebro-spinal system in infancy. Some think that exuberance of energy is responsible; others speak of the comparative instability of the nervous system in early life, the imperfect development of the higher centres, the defect of inhibition or of control by the higher over the lower centres, and the want of clearness in the paths which conduct various impulses, in order to explain defective co-ordination, spasmodic muscular actions, and unchecked reflex excitability. Then we are told that rickets and gastro-intestinal catarrh are responsible for the nervous affection of early infancy, e. g. tetany and convulsions, whilst rheumatism is at the bottom of the neuroses of later childhood-for instance, chorea, habit-spasm, and night terrors. Others find a gastro-intestinal source such as constipation, auto-intoxication, or parasites for all the latter ailments.

I venture to think that none of these theories fully explains the facts. It is true that the higher centres are not fully developed, and that inco-ordination and want of control of the higher over the lower centres exist in normal early life. It is true that the brain is soft and diffluent at birth, and only one-third of the size which it attains in adult life, and that during the first year it grows at the rate of about $1 \mathrm{cc}$. a day, and therefore must be unstable. It is true also that association paths between different cell 
groups and tracts are only formed by degrees, and that myelination of nerves on which their function depends is not complete at first. But this is not the whole matter. All children who suffer from indigestion or rickets do not fall a prey to tetany, laryngismus and convulsions, but only comparatively few. Chorea practically always occurs in rleumatic subjects, but many children will go through repeated attacks of rheumatism, and yet never have chorea ; whilst worms, unless in large numbers produce, as a rule, no symptoms at all. It is only occasionally that nervous symptoms appear to be due to internal parasites. The same may be said of the various disorders of digestion which occur in children and adults alike. So other factors must be at work.

Chief of these factors is the emotional temperament of the child-an individual instability of the nervous system rather than the nervous instability common to all. Any illness may bring this individual instability into prominence, whilst in itself it may be responsible for the occurrence and perpetuation of various complaints.

Normal or physiological instability and immaturity of the nervous system will not fully account for the neuroses of early life. For practically all the neuroses of infancy and childhood may occur in adults whose nervous system has long been fully developed. Tetany, laryngismus, chorea, tics of every kind, and eclampsia may be seen in adults and infants too.

One must regard instability which gives rise to various neuroses as peculiar to the individual and not the common inheritance of all young subjects.

Special instability and immaturity may be manifested :-

1. In derangement of co-ordination between higher and lower centres.

Thus may be explained in part, such complaints in early infancy as nystagmus and head nodding; some cases of strabismus ; of congenital stridor ; dysphagia ; enuresis ; stammering of vocal organs, and of the bladder. Some would 
include under this heading such diseases as spasm of the pylorus (hypertrophic stenosis) or of the cardiac sphincter.

Even hypertrophy of the bladder associated with dilatation of the ureters and hydronephrosis, and idiopathic dilatation of the colon, have been attributed to incoordination in the action of sphincters and detrusors of hollow viscera; an inco-ordination dependent on derangement of cerebral function.

2. Individual instability may be shown in defective control by higher over lower nerve centres. Thus have been explained motor symptoms such as chorea, the tics, and habit spasms, and certain cases of recurrent pyrexia and cyclical vomiting.

3. Individual instability may again appear as abnormal "explosiveness" or " exuberant energy" of higher centres. Epilepsy and eclampsia are held to be the resultants.

4. Explosiveness combined with readily induced fatigue and exhaustion of the psychical, sensory, and motor realms reveal innate or acquired instability manifested in hysteria.

5. Neurasthenia is characterized by irritability and exhaustibility of all parts of the cerebrospinal system.

As the foundation of neurasthenia there is an abnormal capacity for feeling emotions and sensations of all kinds. Emotions are powerfully excited by stimuli which would appear totally inadequate to cause them in normal subjects.

Similarly, trivial physical stimuli give rise to grave nervous disturbance. The effects of common ailments are far more prostrating and more lasting in neurotic than in normal individuals. Emotions and symptoms of disease seem set as it were on hair triggers in sufferers from neurasthenia.

Hysteria and neurasthenia are often met together. Neurasthenia may be defined as hyper-sensitiveness of higher centres with proneness to general exhaustion of nervous energy, mental and physical ; whilst hysteria is characterized by excitability and explosiveness of higher centres, associated with local sensory and motor paralysis, and deficient powers of control of emotional display. 
The well-known stigmata of hysteria-anaesthesia of the conjunctiva and pharynx, and cutaneous surfaces, constriction of visual fields, loss of plantar, pharyngeal and superficial reflexes, motor paralysis and contractures of limbs, are absent in neurasthenia. Also the explosions of nervous energy known as hysterical fits are replaced in neurasthenia by dreamy mental states and intellectual torpor implying exhaustion, rather than heightened energy of higher centres. Moreover, hysteria is less chronic than neurasthenia. The onset of hysteria is usually sudden; complete and speedy permanent recovery is not uncommon, at all events in childhood. It is compatible with perfect physical health and nutrition, whereas neurasthenia is usually gradual in onset, chronic in course ; recovery is never sudden, and is often incomplete. Neurasthenics are always ailing more or less, or on the borderland between indifferent health and prostrating illness. Nutrition is almost always impaired in neurasthenia.

The anatomical site of hysteria is usually admitted to be the cortex cerebri. That of neurasthenia seems to be more widely spread throughout the cerebro-spinal system. The well-known observations of Hodge on the changes found in the nerve cells of pigeons and honey-bees after fatigue, suggest that similar changes may be similarly induced in man, and that in neurasthenics the neuronic structures are more easily exhausted and less capable of recuperation than in normal persons.

Pitres said of hysteria_- "En réalité on nait hystérique, on ne le devient pas." The same might be said of neurasthenia. In both cases it is the tendency to develop palpable symptoms rather than their actual development which is congenital.

This tendency is inherited. There are few neurotic subjects whose parents, collaterals or ancestors are not or have not also been neurotic.

Neuropathic inheritance is most apt to show itself in the offspring of parents both of whom are of neurotic temperament. 
Neurasthenia probably causes more misery and pain than any organic disease. It is not a novelty of the twentieth century. Under other names it has always flourished. It is not confined to any class or any district. It may be met with in the castle and in the cottage, in the highlands or in city slums. It is not monopolized by jaded politicians, harassed business men, society dames, anxious housewives and mothers, pallid students and highly-strung musicians and artists. Nor is it solely met in victims of railway accidents and in pleaders for compensation under the Employers' Liabilities Act.

Children may from very early years be neurasthenic in the highest degree.

It is important to recognize the early symptoms and tendencies towards the disease; to deal with them and check them if possible in order to save such children from the life-long ill health which has been the lot of many endowed with the highest order of intellect and genius.

The exciting cause of neurasthenia may be traumatism, or an illness of any kind, but the perpetuation of the mischief may be largely brought about by domestic mismanagement.

It should be remembered that the neurotic person is by no means necessarily neurasthenic, though always on the high road to become so.

Neurasthenia is the outcome or result of the neurotic temperament when subjected to unfavourable conditions and surroundings. The environment of the neurotic child as well as his personality have always to be considered in relation to his ailments. 


\section{CHAPTER IV}

\section{TYPES OF NEUROTIC SUBJECTS}

RoughLY speaking there are two types of neurotic children : (1) The unrestrained emotional type; (2) the restrained emotional type.

In the first type, intelligence is normal or above the average. The characteristics are: marked timidity and restless energy. The subjects are high-spirited but easily discouraged; imaginative and often superstitious; apprehensive of trouble; apt to exaggerate difficulties and slow in making efforts to meet them ; worried by trifling causes; demonstrative of affection, but such affection is often due to sheer selfishness. They are often immensely vain and burdened by a sense of being unappreciated; passionate at times, but more often querulous and depressed. They crave for sympathy and think themselves ill-used if every one does not give way to them. They resent all discipline and argue instead of obeying. They are quick at learning, but forgetful of facts. They will work with feverish energy in fits and starts, but are soon exhausted. They are enthusiastic but impetuous, and wanting in judgment. They suffer agonies of remorse for trifling offences. Many eventually become the main stay of "Rest-cure" institutions. Some achieve brilliant success in art or literature in after life, but frequently fail from lack of industry, method and common sense. Their saving grace is sometimes a sense of humour and of the ridiculous, which may be cultivated to their advantage.

They are usually thin, slightly built, and we are asked 
to see them because they are wasting. They are pale and sallow with dark circles round their eyes, dilated active pupils and puffy lower eyelids. Their attitude may be limp and dejected or constantly changing and restless. Slight movements of the fingers (mikrokinesis) may be observed on extension of the hands and arms. These are evidence of nerve exhaustion, but not of feeble-mindedness. Their expression is animated ; their colour changes rapidly. Their appetite is capricious; they suffer from attacks of abdominal pains, diarrhoea and vomiting, without special cause, or chronic constipation. They are liable to repeated night terrors, headaches, and migraine, urticaria, and other forms of erythema exudatativum, poorness of circulation, dead fingers, cold extremities, sweatings, cardiac palpitation. Habit spasm and rheumatic chorea, recurrent tonsillitis, cyclic albuminuria are common. Epileptiform seizures are met, but true epilepsy is rare. They may develop all forms of hysteria or neurasthenia in after life; may become alcoholics or drug takers ; suicidal, homicidal, and insane.

In the second type, emotions are very strongly felt, but the powers of control are equally strong. Such children are observant, intelligent, but so reticent that they often pass for being dull, sullen, and obstinate. Their expression is lowering, their attitude statuesque, or stooping, their gait is slouching, slow and clumsy. They are often extremely sensitive, shy and proud. They appear wanting in affection, but really yearn for it, and brood over slights, imaginary or otherwise, until they become morose, gloomy and revengeful. Being slow to take or give offence, they are often shamefully bullied at home and school, but suffer all with apparent stolid indifference, except for occasional outbreaks of fury They are solitary in habits, introspective, prone to selfanalysis, imaginative, superstitious, with morbid love of horrors, and equally morbid dread of them. They may harbour various kinds of "Phobia," and sometimes develop abnormally conscientious scruples of moral and religious 
nature. They take all things seriously, and have little or no sense of humour. This disposition, with its characteristic suppression of outward display of emotions, is as exhausting as that of the other type in which emotional excess is obvious, and is associated with many similar complaints. It is apt to lead to dreamy mental states and intellectual torpor, or to hysterical melancholia. The digestive powers may fail, and the sufferers may develop into sexual neurasthenics, or soured, discontented hypochondriacs, full of selfish woes and disappointed ambition, or in time they cease to use their powers of self-restraint, and become vixenish, mischief-making old spinsters, or crusty and crossgrained old bachelors.

In addition to the above types, in which intellectual powers are above the average as a rule, there is a class which deserves notice. In this the intellect is by no means brilliant, and the subjects are painfully conscious of the fact. But they are consumed with ambition to excel, and are envious of their superiors. By sheer force of exertion they manage to keep abreast of, or even to exceed their competitors. But the mental strain is too much for them in the long run, and they break down in health as well as mind in consequence, particularly if placed in positions of responsibility for which they know themselves to be unfitted in after life. These are usually, but not invariably, of the female sex. Needless to say, the sub-varieties of neurotic types in either sex are endless. Of such are developed the fiercely fond and fiercely jealous women who capture mild husbands and dominate them by developing symptoms of functional heart disease. Some dabble in medicine, despise doctors, live chiefly on antipyrin, coca wine, and cake, and change their religion if they happen to give birth to a club-footed infant. Amongst them are pioneers in various directions (often unsavoury)-shriekers, faddists and "antis" of all sorts, whose views on every subject are precisely the opposite of those entertained by the majority of their fellow creatures. They are more 
impressed by exceptions than by rules, and would alter rules to meet exceptions. There are those whose hearts throb in painful sympathy with suffering humanity, but still more in indignation because distress is not at once relieved by the drastic measures which they dictate. Some of these neurotic moral reformers hold that ends justify means, however questionable such means may be, yet are at once prostrated by anger, grief, and self-pity, when their suppressions and distortions of facts meet with plain speaking. Others become dour fanatics, religious, social and political, more desirous to punish than to reform, grimly relishing the fact that the sins of fathers are visited upon their children. Some from early life seem to start in an aggressive and defiant attitude towards everything which is sanctioned by law, tradition, custom, convenience or science. Some are womanish men and some are mannish women in type. Each acquires the least admirable qualities of the opposite sex, whilst losing the most attractive features of its own.

There are neurotics who are only sensible of the sorrows and trials which affect those outside their own kith and kin ; and neurotics who hug other people's grievances and their own by turns. There are dull neurotics who worry incessantly over trifles-cannot decide whether to shortcoat baby or not, lie awake because a bib has gone astray in the wash, and go downstairs in the dead of the night to hunt for sparks in the tea caddy. They are full of aches and anxiety, take medicine by the gallon, and love doctors, but frequently change them at the bidding of strong-minded friends.

All these, by reason of their emotional temperament, suffer, as Swift said, from "the imaginary ailments with which our female Yahoos are always infested"; and he might have added " male." In addition, they have many ailments which are genuine, though heightened by imagination.

We would save their children from their fate, and it is possible that much may be done for an incipient neurasthenic 
when caught young. For the neurotic temperament is in no sense morbid unless fostered and indulged beyond measure. Every neurotic child is a potential neurasthenic of one extreme type or another, but he need not, under judicious management, become a neurasthenic at all.

No one would deny that a certain proportion of the neurotic temperament is the spice of life. Without it all would be reduced to the same dead level of dulness and mediocrity. The creative faculty in art, science and literature depends upon imagination and upon emotional susceptibility. It is probable that no advance and no reform since civilization began has ever been effected by any one bereft of emotional capacity, and therefore if on recognizing the neurotic temperament in early childhood when emotions are most keenly felt and their effects are indelible, we are able in any way to guide and modify it by cultivating reason and commonsense, and by intelligent sympathy, we may do good service to mankind.

The lives of men and women such as Wagner, Berlioz, Charles Lamb, Charles Dickens, Carlyle, George Eliot and many others were embittered and their genius trammelled by cerebral and gastric neurasthenia. Whenever they have lifted the veil we can trace their sufferings and often the faults of character which distressed those who loved and admired them most, to want of sympathetic and judicious treatment in their youth.

It should not, however, be assumed that unfortunate parents and guardians are always to blame. The neurotic child may disagree with his surroundings and not the surroundings with the child. In all cases our plan of action must depend on our powers of observation, inference and ability to sift evidence; and our success must rest on the measure of tact, patience and sympathy which we employ.

Parents being nowadays fully alive to the influence of mind upon disease expect to be told how ill-health may be averted by mental as much as by medical therapeutics; they desire to know how hereditary tendencies to moral 
failings as well as to disease may be counteracted, and how the stigmata of degeneration-real or imaginary-may be effaced.

Hence our professional armamentarium is no longer completed by a set of infallible prescriptions for coughs, worms, stomach ache and fits; we must often be obliged to dispense more platitudes than pills. Yet platitudes impress when uttered with an air of authority. If based on commonsense and common knowledge, they need not be despised.

We are chiefly called upon to use them in the case of neurotic children, who may be so from inheritance and from circumstances. We are expected to use the knowledge which we share with the public as to the characteristics of such children, and to back our medical advice with commonsense in treating them. Most functional neuroses are of psychical origin. The science of psychology does not help us much in treating them, for psychology deals solely with the normal mind. Yet abnormalities are only appreciated by comparison with normal states, and so a few words on the normal development of special senses are neces sary before considering peculiarities of which psychology takes no heed. 


\section{CHAPTER V}

\section{HYPERSENSITIVENESS OF SPECIAL SENSES}

Taste is congenital. According to Kussmaul's experiments the normal newly-born infant distinguishes between sweet, sour and bitter. Sweet excites sucking movements, and bitter produces grimaces.

These distinctions are, however, crude and common to all infants, whereas in some, hypersensitiveness to taste seems to be present from a very early period.

The ordinary healthy infant will swallow anything which is sweet and warm. But the infant whose taste is hypersensitive soon detects and resents the slightest variations in the taste and temperature of its food. It readily appreciates the difference between the sweetness of its mother's milk and that of milk sweetened by cane sugar. It will notice and rebel against difference of sweetening agents used-for instance, the substitution of maltine for lactose.

It is probable that this nice power of discriminating between differences of taste is responsible for many difficulties in weaning an infant, and in finding a diet which agrees with it. It may prefer the food which disagrees, and therefore fail to thrive on that which seems more suitable.

Hypersensitiveness of taste may be regarded as one of the earliest characteristics of a neurotic infant.

Appetite and Dislike.-The mother of a hospital patient lately described her child's appetite as "very fictitious." The good woman meant " capricious," but the word she used describes not inaptly the appetite of some neurotic children, which is ravenous, yet soon sated, which craves for indigest- 
ible and unsuitable diets, and is banished by the sight of things wholesome. Milk and milk puddings are often detested, and the child sometimes seems wholly carnivorous.

A curious characteristic is that food, especially if minced, is critically sucked, not masticated, and if any small particle of harder consistency than the rest is discovered, it creates the strongest expression of nausea and disgust.

At first the child is supposed to be in danger of assimilating a bone, and amidst general consternation it is exhorted to eject the mouthful, which it usually does, and then flatly declines to eat any more. When the alarm has proved false, the child is reproved for daintiness and forced to eat whatever is put before it. The result is a confirmed habit of bolting food lest it should be tasted, and this leads to disastrous consequences to digestion. The habit of scraping the platter clean is enjoined in schools and families where Spartan discipline is maintained, with results resembling those which befel the Lacedaemonian boy whose vitals were gnawed by the fox beneath his little girdle. Indeed, this story may be an allegory intended to convey the ill results of foodbolting. A child can no more be persuaded to masticate substances which raise its gorge than we ourselves can try to chew a rhubarb pill.

Our tastes and distastes with regard to food are generally formed in early life, and what we do not like is almost certain to disagree with us. A healthy child's meat may be a neurotic child's poison.

The diet suitable for neurotic children is indeed always a matter of perplexity. No fixed rules for all are possible. Some abhor milk in any form and would live on meat and pickles only; to others meat and fat in almost any shape are abominable; some can only relish bread and butter, sweets and jam; some can hardly be induced to touch fresh vegetables or fruit, others would live on nothing else. Some regard with suspicion the slightest variation and innovation in their diet, others will not eat the same food twice. 
Some again shun all fluids, whilst others would drink with avidity water from the nearest kennel.

It is difficult to explain these curious idiosyncrasies. Sometimes a particular food is hated because it raises memory of past illness. A single egg which is slightly stale or a smoked milk pudding will create unending dislike for such comestibles.

A lasting distaste for wholesome articles of food is sometimes inspired by the custom of administering medicine in them. It is long before the memory is effaced of a certain gruesome half-inch of cold-drawn castor oil floating in odious superiority on the surface of a wineglassful of warm milk. And unfortunately it is the milk which sustains perpetual disgrace for having once kept evil company.

To spring an unwelcome surprise upon a child in the shape of cake, jam, or raisins in which a powder has been artfully concealed, is to take an unfair advantage over youthful simplicity. The powder may be "unsuspected," but it certainly "animates the whole." Medicines are necessary, but the suggestion of their presence should be kept out of the menu of the daily meals. Milk and medicine are incompatible.

Aversion to Fat.-Neurotic children are mostly thin and need fat, but usually hate it, in the shape of beef and mutton fat, the most unattractive forms of hydrocarbons. If compelled to eat it they swallow it whole, and suffer martyrdom accordingly. Their only hope of salvation is in the school "gag eater," who may come to the rescue provided that his lessons are done for him in return.

Butter, and even oleo-margarine, are the best substitutes for beef and mutton fat, and are usually welcome to the most fastidious children. In schools one is usually told that bread and butter are allowed à discrétion, but the amount of butter supplied is singularly disproportionate, as a rule, to the quantity of the bread.

Fat in the shape of suet pudding is excellent for robust schoolboys, but its pallid greasy homeliness, even with a 
treacly dew upon it, renders it unacceptable to queasy stomachs.

I cannot enlarge here on the subject of school dietary. It usually looks better on paper than it does on a dish, for the school cook is rarely a "cordon bleu," and as Jerome Cardan said more than 300 years ago: "Trust a schoolmaster to teach, but not to feed your children."

I suppose that cod-liver oil is given to all thin children. Although cod-liver oil is of the greatest value, the sensitive palate of neurotic children often revolts against its taste and smell. This is sometimes due to attempts to administer it in its crude state or in an ineffectual combination with sickly orange wine or milk. It should always be given in the form of an emulsion, with iron, hypophosphites, or bromides, as indicated.

Adult patients will often recoil with horror at the bare suggestion of cod-liver oil ; they will give us graphic accounts of childhood rendered miserable by its ancient fish-like smell ; of meal-times haunted daily, and appetite destroyed by the thought of the grim dose which was to follow; of constant gallant efforts to get it down and keep it down, and of its subsequent ill-timed reminders of its hateful presence No wonder they say that it never did them good and resent it, for however skilfully the preparation is made, the scent of the oil will cling to it still. If disliked it does no good but harm, for cod-liver oil is food, and food to be digested must not nauseate. Its liability to cause diarrhoea has also to be considered, but when it does so the effect is probably due to psychical rather than physiological action. Fat, unless relished, does not fatten.

A friend of the writer who suffers from nervous diarrhoea whimsically attributes his affliction to the enormous quan. tities of cod-liver oil which he was forced to swallow in his early days. He says that the oil "permanently lubricated his works."

In some cases, excess of carbohydrates may give rise to enuresis, periodic pyrexia or "Food Fever" as Dr. Eustace 
Smith calls it ; whilst in others toxaemic disorders, headache, migraine, cyclical vomiting result from eating too much meat and fat.

Without urging that whims and daintiness should be fully indulged, a certain allowance should be made for the capricious tastes and distastes of neurotic children with regard to food.

Oatmeal porridge, for instance, may suit the majority, but a child who dislikes it should not be forced to consume a large plateful of it " under doctor's orders."

It may be necessary to order a diet free from fat, sugar, starch or "purins," as the case may be, for a time, but such a diet should not be prescribed indefinitely.

It is usually sufficient to warn against excess in any form of food which is found to disagree without excluding it altogether.

Pica or "dirt-eating" is not uncommon as a neurosis in children during the first year or later. They will eat earth, cinders, paper, hair, plaster, wool off the blankets, or the " paint off purple monkeys till it makes them deathly sick." All babies will do so occasionally, and it is only when the practice becomes inveterate that it indicates a morbid perversion of taste. In such cases the children are thin, sallow, and unhealthy looking, and suffer as might be expected from colic and diarrhoea with evacuations of which the contents are often surprising. In rare instances the habit has ceased after riddance of worms.

It is of course common in imbeciles, but unless signs of mental deficiency are apparent the habit is not of serious import.

Sight.-Except in premature infants, sight, or at all events perception of light, is congenital. During the first few weeks bright sunlight causes evident discomfort, though even as early as the sixth day it is said that an infant may follow a light in the room with its eyes and even turn its head for that purpose.

Such manifestations are, however, precocious and ex- 
ceptional. Until the third month co-ordination of ocular movements is not established, whilst it is not until the sixth month, as a rule, that infants seem to recognize objects and persons seen.

Earlier perception and recognition of familiar objects and persons, and discomfort or alarm at the sight of things strange, are again indications of hypersensitiveness of brain and acuity of visual centres, which again is characteristic of the neurotic and precocious child.

Hearing.-Infants are deaf for twenty-four hours after birth, and may continue to be so for several days. The deafness is attributed to swelling of the tympanic mucous membrane and absence of air in the tympanum. The swelling subsides, and air enters the middle ear as a rule within a few days of birth.

Even at the end of the first fortnight an infant appreciates loud and even moderately loud sounds. By the end of the second month and almost always by the end of the third it recognizes the direction from which the sound comes, and will turn its head towards it.

Hypersensitiveness to sound, with fear and shock occasioned thereby, are perhaps the most common of all indications of a neurotic temperament in infants.

Hypersensitiveness to Sounds.-Unnatural timidity and hypersensitiveness of hearing may be shown in early infancy and may persist as the infant grows into the child. The fibres of the auditory tract leading from the nervus cochlearius to the first temporal gyrus can be traced at the end of the second month. But acuteness of hearing is developed far more quickly in some than in others.* Some babies are awakened by the slightest sounds ; others would sleep through an earthquake.

Adults with a sensitive ear dislike loud discordant noises, but nervous children fear them.

Most of us who have any ear for music envy the com-

* Ireland, Mental Affections of Childhood, p. 70. 
placency with which a saw-sharpener endures the excruciating sounds which he produces, and wish that he would ply his necessary but exasperating calling out of hearing. The imperturbable driver of a cart full of empty milk cans, hung upon shrieking wheels over a macadamized road is blandly unconscious of the torture which he inflicts upon sensitive ears. To many the mere thought of a saw being ground or of a pencil squeaking on a slate, or of a cork being cut by a blunt knife, produces a momentary rigor, goose-skin, and a more or less lasting sense of discomfort.

Placid and sentimental people eulogize (at all events in theory) the merry voices of children just let out of school. But it is otherwise with the musician or neurotic brainworker whose house adjoins a Board school playground. The relentless piano-organ, the newspaper yeller, the trumpeting motor car, all make a neurotic adult's life well-nigh unendurable, and we sympathize with his infuriated letters to The Times on the subject.

Yet I believe that the sufferings of neurotic children from noise are quite as poignant as his.

They will start and jump at the slightest sound, and loud noises drive them nearly crazy. I have seen a small boy run shrieking down a railway platform in imminent danger of falling on the line, beside himself with fright, at the noise of the engine blowing off steam. Dr. Still mentions a similar case of intolerance of the noise and smoke of a train. Habit spasm and excessive timidity in a boy aet. 7 whom I knew were produced by an unusual cause. In the dead of night the cord by which the weight of a "grandfather's clock" was suspended broke and the weight fell to the floor, whilst the clock ran down with a prodigious whirring commotion.

Dr. Ashby has mentioned a child aged two years who would say "Church bells make baby sick" when the bells of a church close by began to ring for evening service, and sometimes she would actually vomit on such occasions. 


\section{HYPERSENSITIVENESS OF SPECIAL SENSES 31}

In later years she suffered from migraine and hysterical half-blindness. *

The instance need not be noted as one of annoying caprice on the part of a spoilt child. It would serve as an advertisement for the Society for the Prevention of Street Noises.

There can be little doubt that dread of noise accounts for shyness and unsociableness in many cases. At children's parties one often notices that some thin and pallid infant is discovered in a corner weeping and bewildered by the noise. Good-natured attempts to make it join in the general hilarity only lead to floods. of tears, and it is dismissed to the care of its nurse by the much-annoyed hostess, who cannot understand why the "stupid little thing" will not enjoy itself like her own sturdy urchins. Such children cannot romp. They instinctively seek peace and quiet in the society of adults, and soon acquire a precocity and old-fashionedness which make them unpopular in the nursery and with their schoolfellows.

In some young children dislike to certain sounds seems to depend on an early development of the musical sense. Thus one child, aged three, of parents who are both musicians of the first rank, delighted in hearing them perform, but whenever he heard a street organ he would cry, "Bad, bad music! Take it away!"

Some children are soothed by the gentle tinkle of a musical box, but cannot endure a toy cow which "moos." These are probably disconcerted by the uncanny incongruity in a thing which being dead yet speaketh.

They may like the toy but cannot stand the "squeak," whereas to the ordinary child the toys which make most noise are most acceptable.

Sensitiveness to Colour.-A medical friend recently drew my attention to a curious dislike for the colour red, displayed by his little daughter, aged seven months. If offered a scarlet geranium or piece of scarlet cloth, she

* Wightman Lecture. Rep. Soc. for Study of Disease in Chilren. 1905. 
would make no effort to take it, but would shrink back, and hide her face on her mother's shoulder. She readily grasped and seemed pleased with objects of any other colour. At this age she showed unusual readiness to make friends with strangers, and was not timid in any respect. Six months later she showed the same dislike for red and yellow too, with other signs of timidity. She could not be induced to approach a pair of yellow-coloured slippers, and was frightened when strangers made advances to her, whilst she had been terrified at the sight of her grandfather clothed in a dressing-gown instead of his ordinary habiliments.

Red is the stimulant among colours, and according to Havelock Ellis yellow is almost equal to it in popularity among savages. These are the war colours of savage races, and are probably used with the intention of intimidating their foes, rather than from aesthetic preference.

During the epidemic of Dancing Mania which prevailed in the Middle Ages, the dancers are said to have been excited to paroxysms by the sight of red objects which they held in horror. . . . Many of those afflicted thought they waded in blood.* Dr. Ling's hysterical patients at La Charité Hospital, Paris, when under hypnotic influence affected to be horrified by the red and attracted by the blue flames which they had been taught to associate with the North and South magnetic poles respectively. It is true that the late Ernest Hart proved that the same results ensued when the poles of the magnet were substituted for each other without the patients' knowledge, but this does not disprove that the patients were repelled by red and attracted by blue when the presence of the colours was suggested to them. The visual aura which sometimes precedes epilepsy and the visual hallucination of certain forms of night terrors, are not infrequently red in colour.

Finally, it is well known that red excites certain animals to fury.

* Parish, Hallucinations and Illusions, 1897, p. 37. 
Probably therefore in certain abnormal mental conditions, a primitive and instinctive dislike and fear of this colour is aroused. On the other hand in normal civilized races most young children have a decided preference for red and yellow over any other colours, but it has been shown that the love of yellow diminishes with age. Even between the ages of four and seven, though yellow is still one of the most favourite colours of boys, it ceases to be in any degree a favourite colour among girls. Lobsien at Kiel, investigating the colour preference of a large number of schoolgirls between eight and fourteen, reached congruent results. He adopted the method of offering the colours in pairs, and found that while orange was never preferred to any other colour, there was a tendency at all ages to prefer yellow to green and usually to violet, but never to red or blue. In comparing the colour preferences of male and female students, it is found that with age there is a shifting towards the violet end of the spectrum, which is the favourite end of men, red being that of women.

Audition Colorée.-In connexion with abnormal sensations produced by colours may be mentioned the peculiar condition known as "Colour hearing" or "Sound seeing "which in some individuals is developed to a remarkable degree.

In "audition colorée" there is an arbitrary association of a definite subjective colour sensation with the hearing of an actual sound. In those who share this peculiarity, the association of a particular colour with a sound is constant in the individual but similar sounds do not produce similar colour sensations in all.

One person, for instance, on hearing the vowel " $a$ " sees white, whilst another always sees light blue.

Generally speaking, however, deep tones and vowel sounds seem to be associated with dark, and sharp high sounding vowels with the lighter colour sensations.*

The kind of sound which produces these colour sensa* Parish on Hallucinations and Illusions, 1897, p. 223. 
tions also varies in different individuals. In one case they may be related to vowel sounds, in another to the timbre of the speaker's voice. In some cases the tones of various musical instruments are associated with definite colour sensations, and also with peculiar hallucinations of sight. The chromatisms to which sounds give rise may in fact, be definite and fully developed objective sensations, and not merely mental associations of certain colours with certain sounds.

The faculty seems to be hereditary and familial. It dates from a very early period of life and cannot be traced simply to learning the vowels and consonants from coloured alphabets, for instances are recorded in which members of the same family who were all taught to read from the same coloured alphabet yet associated different colours with the same letters.

The constant involuntary association of a certain image or subjective sensory impression with an actual sensation belonging to another sense is termed "Synaesthesia."

Synaesthesia, that is to say simultaneous excitation of visual and auditory senses, is not confined to these. Particular tastes or smells, sensations of temperature, and even the exercise of muscular sense are said by Parish to arouse sensations of colour in some people. To a certain extent synaesthesiae are physiological and not morbid peculiarities. Even the thought of certain sounds and sights will make one's flesh creep.

In young children, grotesque mental pictures are often excited by the imperfect hearing or misunderstanding of words, and expressions which are reserved for use in private and public divine worship.

Memory in some people depends, especially in the case of numbers, dates and names, on arbitrary association with mental diagrams, in fact on Synaesthesia.

If, sometimes, memory, recognition and appreciation of one set of sensorial impressions are enhanced and intensified by simultaneous excitement of another set, namely that of 
colour sensations, the condition may be regarded as a normal abnormality.

At the same time, the existence of synaesthesia in a marked degree is a sign of hyperaesthesia of special senses and of an emotional temperament.

It has been suggested that possession of the faculty of colour hearing or sound seeing might be turned to practical account for educational purposes. Musicians are said to have found colour sensations helpful in enabling them to pitch a key and tune their instruments. But few musicians need such aids. In one case it is stated that a lady relied on the tint excited, in order to decide whether she had spelt a word correctly, and thus, one may presume, she was enabled to dispense with a dictionary. Yet such assistance in orthography is not vouchsafed to all, and the lady is to be congratulated on the possession of superior advantages over the majority of her sex.

Dr. W. S. Colman concludes that the faculty of colour hearing may assist in simple processes such as spelling, singing at correct pitch, learning by rote and mental arithmetic, but for higher work such as expressive singing, musical composition, abstract speculation and higher mathematics, colour sensations must be a hindrance rather than an assistance and therefore systematic development by any deliberate education of the faculty is hardly desirable.*

Hypersensitiveness to Odours.-It is well known that individual susceptibility to certain odours exists in adults. The scent of roses, or even the sight of an artificial rose, will produce a paroxysm of asthma in certain people.

Evelyn mentions in his diary that Viscount Stafford at a banquet got up in some disorder from the table when roses appeared amongst the fruit at dessert. He also mentions Sir Kenelm Digby's story that Lady St. Leger had so great an antipathy to the flower that when one was placed on her * Lancet, Vol. I. 1898, p.24. 
cheek whilst she was asleep it raised a blister. $\mathrm{He}$ adds, however, "that Sir Kenelm was a teller of strange things."

A man of my acquaintance would turn faint and presently vomit on perceiving in the street a smell imperceptible to others. Probably we all have idiosyncrasies in this matter, dating from infantile experiences, sometimes pleasurable, and sometimes painful. The scent of honeysuckle or other flower may raise a flashlight picture in the mind of some green country lane, seen in early infancy but never since. The heavy penetrating odour of thick pease-soup creates an appetite in some, in others nausea, with memories of school fare, and Wightman's Multiplication Tables.

The smell of linseed which pervaded surgical wards in preListerian days, must have recalled to others, as it did to me, successive crops of boils, and weeks of poultice-clad existence which we loathed.

Dr. Hughes Davies in an interesting letter to the Lancet* describes attacks of faintness with actual syncope in his wife and son-a boy aged thirteen-produced by the scent of eucalyptus.

Cutaneous Hyperaesthesia. - Hypersensitiveness to common sensations of touch, pain and temperature are also most important signs of a generally abnormal susceptibility of mind and body to external and internal impressions.

The skins of neurotic children are frequently as irritable and sensitive as their brains, as Tennyson said of his own. As mentioned before, neurotic children are prone to various skin eruptions of the urticarial or erythematous type, and also of the eczematous type, which resist elaborate treatment and disappear as mysteriously as they arrived. But apart from these, they are subject to intolerable itching or formication without manifest eruptions. A tight or frayed collar, or arm-hole, a shrunken vest, close-fitting sleeves or inelastic stockings, the pressure of a narrow shoulder-strap and often

* Feb. 10, 1906, p. 403. 
of flannel next to the skin, will induce such discomfort that the child will fidget and fret itself ill. Any but the softest underclothing acts upon them like a hair shirt. It may be that a considerable number of cases of habit spasm and even rheumatic chorea are partly due to constant irritation of the kind.

A child under the writer's care insisted on wearing his braces so long and his waistband so loose that his mother feared to take him in the streets lest a dénouement should put her to shame. His father and several uncles, she said, had a similar distaste for close-fitting garments and could hardly be induced to don conventional garb.

The curious attire of the neurotic Bohemian is often not an affectation but a necessity for his comfort.

There is more than a grain of truth in the fairy tale of the tender Princess and the Pea.

The principles to be observed in the clothing of neurotic children are that the garments should be light, warm, loose and non-irritating. Clothes should be made to fit the child ; the child should not be forced to fit the clothes.

Leo Tolstoy thus describes his early resentment at his swaddling clothes: "Here," he says, "are my earliest reminiscences: I am bound. I wish to free my arms and I cannot do it, and I scream and cry, and my cries are unpleasant to myself, but I cannot cease. Somebody bends down over me; I do not remember who. All is in a halflight. But I remember that there are two people. My cries affect them ; they are disturbed by my cries, but do not unbind me as I desire, and I cry yet louder. They think that this is necessary (i.e., that I should be bound) whereas I know it is not necessary, and I wish to prove it to them, and am convulsed with cries, distasteful to myself, but unrestrainable. I feel the injustice and cruelty, not of human beings, for they pity me, but of fate, and I feel pity for myself. This was my first and most powerful impression in life." *

* Life of Leo Tolotoy, Vol. I., Heinemann. 


\section{CHAPTER VI}

\section{THE FEARS OF NEUROTIC CHILDREN}

Children show considerable variability in their capacity for fear.

In former generations fear was considered essential to morality, and if a child naturally showed no signs of awe in the presence of his betters he was thrashed into a becoming state of reverence. This process was called "breaking his will " and its practice was peculiar to the age of Puritanism. On the other hand the treatment of children who were obviously timid consisted in attempts to strengthen their nerves by deliberately frightening them. Thus Plato proposed to test children's courage by exposing them to the horrors of witcheraft.

Mr. Day, author of Sandford and Merton attempted to teach young girls to be brave by firing pistols at their skirts, and by dropping hot sealing wax on their bare arms, without much success.

The causes of fear in children can hardly be enumerated. Fear does not necessarily imply cowardice in presence of physical pain or danger. A timid child may bear having a tooth extracted with the utmost fortitude, yet be utterly cowed by a harsh word or look, or by ridicule, by ordinary sounds and sights, or by the effects of its own vivid imagination.

Fear, whether of the supernatural, or of physical ill-usage, or of ridicule may have disastrous effects on mind and health. Much of the self-consciousness, introspection, hypochondriasis, neurasthenia and hysteria which is noticeable in adults may be traced to the effects of fear in early life. 


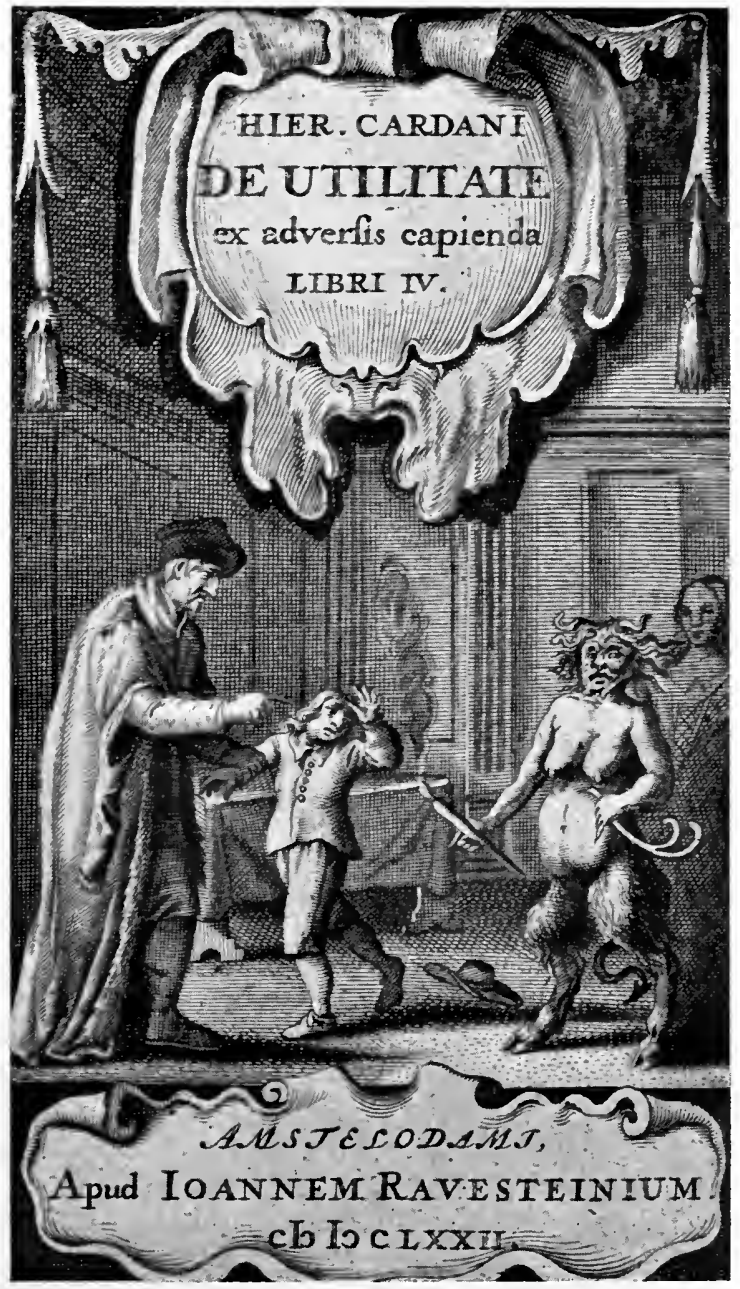

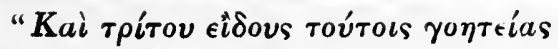

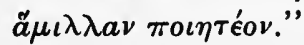

Plato's Republic, Bk. iii. §113. 

In young children the earliest indications of fear should be recognized and should meet with sympathy, encouragement, explanation and removal of its causes if possible, and never with badinage or contemptuous nonchalance.

Fear in a child may be the end and not the beginning of wisdom.

It is of all emotions the one most calculated to produce lasting effects upon a neurotic child. Fear is natural to all sentient beings, and is the essence of self-protection. A child who fears neither God, nor man, nor danger, nor the devil, is next door to an idiot who sets the house on fire, then claps his hands and crows with delight at the flames. Fear implies powers of imagination, and the child who suffers most is the most imaginative. It is impossible to foretell what may suggest a sense of the supernatural to an imaginative child and therefore alarm it. The childish mind may invest inanimate bodies with the most malignant qualities. I have known a child who attributed any number of horrifying visitations and persecutions to the spite of a fur footwarmer, which he was wont to describe as a "bomp". Another child was obsessed by fear of a talc ventilator. The "Flapper," as he called it, seemed ever present in his "dreams and he resented being taken to strange places by day unless reassured that no "flapper" would be there to upset his peace of mind. Another was haunted by houses with "blind eyes," i.e. with windows blocked in order to evade the window tax.

Oliver Wendell Holmes speaks of a certain glover's sign in the shape of a huge hand which terrified him night and day in early life.

Judicious treatment and management probably saved Sir Walter Scott from many a midnight qualm. He says "at the age of four I had acquired, I know not how, a kind of superstitious terror for statuary of all kinds. No ancient iconoclast or modern Calvinist could have looked on the outside of the Abbey Church (if I mistake not, the principal church at Bath is so called), with more horror than the 
image of Jacob's ladder, with all its angels, presented to my infant eye. My uncle (Captain Robert Scott) effectually combated my terrors, and formally introduced me to a statue of Neptune, which perhaps still keeps guard at the side of the Avon." *

Harriet Martineau in her essay on "Fear" (Household Education, ed. 1876) says : "I was as timid a child as ever was born; yet nobody knew or could know the extent of this timidity; for though abnormally open about everything else I was as secret as the grave about this. I had a dream at four years old which terrified me to such an excess that I cannot now recall it without a beating of the heart. I could not look up at the sky on a clear night, for I felt as if it was only just above the tree tops, and might crush me. I could not cross the yard except at a run from a sort of feeling, with no real belief, that a bear was after me. The horrors of my nights were inexpressible." Her particular terror was of a magic lantern. "I never saw," she says, "the white cloth with its circle of yellow light without being in a cold perspiration from head to foot." Even at the age of thirteen she turned so faint that she could not stand but by grasping a chair, on seeing a lantern slide of a dragon vomiting flames. She says again: "Some of my worst fears in infancy were from lights and shadows." Her blood ran cold at the sight of the shadows cast by the window frame on the ceiling when the lamplighter went his rounds in the street. The prismatic colours on the wall caused by the sun shining through glass lustres filled her with alarm, although curiously enough she says she knew enough of optics to have taught any child how such colours came there. "Under all this," she says, "my health was bad; my behaviour was dogged and provoking, and my temper became for a time insufferable." She only began to improve in the year when she obtained some release from habitual fear, and during the whole critical period she misled everybody by concealing with apparent apathy the terrors which beset her.

\footnotetext{
* Lockhart's Life of Scott, Ed. 1898, p. 20.
} 
Charles Lamb, in his well-known essay on Witches and other Night Fears, says of himself : "I was dreadfully alive to nervous terrors. The night time and solitude and the dark were my hell. . . . I I never laid my head on my pillow I suppose from the fourth to the seventh year of my life, so far as my memory serves in things so long ago, without an assurance, which realized its own prophecy, of seeing some frightful spectre." The form of his visitations he attributes to the picture, in Stackhouse's History of the Bible, of the raising of Samuel by the Witch of Endor.

Leigh Hunt's fears, like those of Charles Lamb, were induced by horrid pictures. One of a fabulous wild beast called the "Mantichora" unspeakably shocked him. His brother cruelly worked on his fears by imitating the creature, which was half man and half tiger, and was suspected of devouring small boys. "Such things," he writes in his Autobiography, "are no petty ones to a sensitive child. My brother had no notion of the mischief they did me. They helped to morbidize all that was weak in my temperament, and cost me many a bitter night."

The profound results of fright from sufficient causes upon all sentient beings need no comment. In nervous subjects similar consequences follow causes which seem insufficient to produce them. Excessive and unnatural timidity in a young infant is a forerunner of neuroses to come. It is shown in starts and screams, and trembling at sights and sounds which only excite curiosity or amusement in normal children who are beginning to take notice. Everything which is new and strange to them begets alarm. Their mothers often are unwilling to take them out because they become so frightened at common objects which they see and noises which they hear.

Fear of the Supernatural.-Neurotic children are not altogether dependent on what they see or hear for the scenes in their dreamland theatre. Nurse's tales and awful pictures are but matches which fire the train of their imagination. They share with savage aborigines the dread of the 
great unknown; they seize with avidity on suggestions that mysterious unseen influences affect them, and will invest all that is taught them on such subjects with a fearful embroidery of their own.

The possible results therefore of certain forms of religious and moral teaching upon nervous, imaginative and superstitious children need careful consideration.

In former generations children were taught that wickedness was bound up in their hearts, that careful notes were made of all their sins, and dreadful punishments awaited them in after life even if they escaped them in this-which they could seldom hope to do. For instance, when little Mary Mills expressed the hope that Dick, who had defied his mother, and who died of sunstroke in consequence, was with God, her godmother laid her hand over Mary's mouth.*

And when the youthful Augusta (Fairchild Family), disobediently played with the fire and was burnt to ashes her young companions were told that her conflagration would last for ever in the flames of Hell.

The stern and grim religion of the Puritans was perhaps suitable to the age in which they lived, and probably many children brought up under it grew callous in ti e. Perhaps, for purposes of discipline, when the fires of Hell seemed a long way off, the birch was always handy. But it is not adapted to the requirements of the present generation. Neurotic children nowadays are only too apt to suffer from morbid remorse and apprehensions on account of their misdoings, and need a religion more cheering, and treatment more lenient towards their moral defects than were thought suitable by our forefathers.

Children have probably been, in days gone by, quite as susceptible to religious emotion as some are at the present time.

Saint Theresa of Castile at the age of seven having been told by her father, somewhere about the year 1522, that martyrs went straight to Heaven without suffering any of

* Stories from the Church Catechism. 
the inconveniences of Purgatory, took her little brother with her and wandered forth to seek martyrdom at the hands of the Moors.

This was but an indication of the neurotic temperament which in after life led to chronic ill-health, paroxysmal pains, swoonings and hystero-epileptic visions. The latter doubtless added to her reputation and influence in the sixteenth century, as they would do were she with us now.

Many instances might be adduced to show how strongly impressionable children are affected by gloomy religious doctrines and how lasting is their effect upon them in later life.

The late Frederick W. H. Myers, mystic and spiritualist, was overcome with grief as a child on finding a mole crushed by a passing cart wheel, and learning from his mother that as it had no soul it could not live again. The suggestion that those who lived bad lives on earth were annihilated at death filled him with horror.

Myers went through the usual course of fervent Christianity, Hellenism, Paganism, Agnosticism and Pessimism in search of a religion which could bring him peace without pain. Less stern doctrines than his mother's might have spared him endless mental suffering.

Although we may entertain doubts ourselves as to the immortality of moles and pet canaries, there is no occasion to allow our reservations to distress our children. The Red Indian believes that his dog will live with him in Paradise, and why should he not if it comforts him to think so?

The doctrine of annihilation is hardly less repulsive to sensitive minds than that of eternal punishment. Both are associated with the unamiable desire that the wicked should not escape scot-free.

The prospect of watching sinners frying in Hell made good old Tertullian laugh, he tells us, but so keen a sense of humour is hardly appreciated now.

One may not be justified in expressing any opinion on the 
quality and quantity of religious instruction which is suitable for children in general. But solely from a medical point of view it may be urged that only the brightest and most comforting side of religious faiths should be presented to children who are by nature timid, imaginative and apprehensive.

The same remark applies to the teaching of all moral, social and political questions. Exaggerated statements and extreme and biassed views on any topics such as the evils of drink, tea and tobacco, the land and poor law questions, are in the highest degree injurious to neurotic emotional children.

Unnatural remorse for misdemeanours is a feature in neurotic children. When cautioned, as they often may be, against the danger of bringing their parents' grey hairs with sorrow to the grave, they are apt to take the warning literally, and daily watch for the commencement of the process with the utmost anxiety and self-reproach.

Thackeray speaks of his agonies of contrition for having spent fourpence of his parents' money on coffee and toast when famished with hunger on his way home from school. Leigh Hunt believed himself irretrievably lost as a child for having once said " $\mathrm{D} \_\mathrm{n}$ it !" A friend of mine once told me that at the age of six he thought he must be doomed to eternal perdition after using an unparliamentary expression during a spirited altercation with his nurse.

Dr. Langdon Down met with five cases of good and studious children who became moody, with conscientious scruples as to their motives, morbid views as to what was right and wrong, and extreme anxiety to be strictly truthful. One child thought that he had contaminated his mother by thinking of her immediately after seeing a dirty beggar man. Such cases occasionally lead to a permanent breakdown, and their tendency is towards melancholia and self-inflicted injury.*

Worry and Morbid Apprehensions.-Children, like

* Mental Affections in Childhood and Youth, 1887, p. 94. 
adults, are prone to worry over trifles and if neurotic are particularly liable to morbid apprehensions.

Leigh Hunt said that as a child he could not see his mother bite off the ends of her thread when sewing "without being pained lest she should swallow them." Doubtless he had been told that ends of threads, if swallowed, entwine themselves around the heart with fatal results, which is a popular superstition.

A boy aged eleven recently under treatment for many functional neuroses, including cyclical albuminuria, conceived the idea that his mother was in danger of death. He would wake her night after night in order to make sure that she was still alive, and told her that he frequently dreamed of seeing her walking on a narrow plank amidst moving machinery and being drawn in and turned to mincemeat.

Moral and Religious Emotions.-Within recent years we have had a surfeit of child evangelists. In this country little Willie Powell, aged twelve, has roused all Wales to a high pitch of wonder and excitement by his sermons in the Baptist Chapel of Porthcawl, whilst Master Nicholas, only six years older, has vied with him in Cornwall.

In America the Rev. Henry Banta, described as "a frail, sickly-looking lad of twelve," started at the mature age of nine to convert the United States, and actually received a unanimous call to the ministry of the Church of Shallotte in North Carolina soon after his tenth birthday.

The States can also boast a "picaninny preacher," a coloured girl, Clerita Nora Avery, who when aged eleven preached to crowded congregations in the leading cities.

Even more remarkable is the case of Laurence Dennis who drew crowds to hear his little sermons at the age of three. "Laurence," said the reporter, "has all the natural equipment of an orator ; and when one listens to his sermons, with their happy flow of words, their clearness and their logic, and when one watches his appropriate and quite unconscious gestures, it seems impossible that the preacher should be, as he is, a child of three." 
Laurence T. Dennis is now at the tender age of ten. Some months ago his preaching created a great sensation in the North of London, and during the summer months he was conducting missions at various places in the Isle of Man. He has travelled thousands of miles and preached to over a million people in America, Canada, Egypt, the Holy Land and England.

It would be premature to discuss the future of infant prodigies of this description. Provided that their talents consist purely in a retentive memory, ready and spontaneous utterance requiring no elaborate preparation for delivery of their simple creeds, it is probable that any exhaustion produced will at most be physical rather than mental. But a combination of such qualities with a highly emotional temperament may of course prove disastrous to mind as well as body.

Fear of Corporal Punishment.-The ancient tradition that the birch is the tree of knowledge is dying out. Yet the theory may not be altogether devoid of scientific" basis. Griesbach, Vannod, Bolton and others have demonstrated that mental fatigue in children causes a diminution of cutaneous sensibility which can be estimated by means of the aesthesiometer.* Therefore it may be that by stimulation of certain cutaneous areas, the sensibility of which is blunted, the higher centres of the brain may be invigorated and refreshed.

But experience proves that equally good results may be produced by methods more humane than those of " plagosus Orbilius." In the modern treatment of dulness, inattention and other signs of mental fatigue in school children, the rod has been discarded in favour of shortened lessons with frequent intervals for refreshment by active exercise, games and drills, and by frequent change of subject.

The use of corporal punishment as a means of brightening intellect is practically extinct; whether it should be retained as an incentive to morality is still a vexed question.

* International Congress of School Hygiene, Nürnberg, Feb., 1904. 
Roger Ascham argued that a child would hate sport, pastime, dancing, and learning equally if beaten for remissness in all. There is a good deal of truth in this, but he adds :-

"God forbid but all evil touches, wantonness, lying, picking, sloth, will, stubbornness and disobedience should be with sharp chastisement daily cut away."*

Yet there seems to be a logical flaw in the supposition that children will love virtue if chastised for not practising it, but hate games and learning if treated on the same principle. It may be doubted that corporal punishment is ever remedial in any sense. If it acts as a deterrent it is merely through fear of physical pain and from no higher motive. It cannot ennoble character but may degrade it by the loss of self respect which it entails.

Hans Andersen when threatened with a flogging ran away from school and flatly declined to return. Conscious of his own superiority, filled with vanity and a sense of dignity and self-importance, he regarded the punishment as an intolerable affront to his pride and almost as an act of sacrilege. His education was sacrificed owing to lack of discernment of his genius on the part of his early teachers.

It is maintained of course that what the school boy feels more than the degradation of corporal punishment is the acute pain. As a matter of fact the ordinary boy does not in the least feel a degradation which is the common lot of all, and he soon forgets the pain, so there does not seem to be much use in inflicting either.

But it is different with the neurotic timid child who is sent to schools where it is said that only cherubs can escape the rod. The writer has known not only one but several highly intelligent but nervous children whose want of progress at school was traced to haunting terror of the cane. Schoolmasters do not always realize that this may be so. It is pleasant to recall that one of them when the fact was brought to his notice took the utmost pains to disarm a

* The Schoolmaster, p. 41. 
little fellow of his fears on this account, and with the best results.

Many must remember the sickening horror with which they witnessed public executions at school-their pity for the victim, the miserable certainty that sooner or later they were bound to share his fate-above all, I think, they felt unmeasured disgust and resentment towards the "sworn tormentor" unmingled with any feeling of respect.

If such anticipation is harmful, realization must be worse still in sensitive nervous children. We cannot expect schoolmasters to discard their cherished birch at once. Not a hundred years have elapsed since the poet Southey was expelled from Westminster for his impiety in publishing in the school magazine a protest against the indiscriminate flogging then practised at that ancient institution. But in time schoolmasters may be brought to realize that corporal punishment is a brutal and indecent degradation for all except those of simply brutish intelligence.

The father in the street may say that he was often flogged at school, and that it never did him harm. But this may only mean that he did not realize the extent of the affront put upon him; it is no excuse for allowing his children to be similarly degraded. Their minds may be more refined and delicate than his own. Reforms have usually been started from below, and the frequent cases in which one hears of assaults made on board-school masters and mistresses by infuriated parents, show that a feeling against the corporal punishment of children by their teachers is rising, and may in time spread upwards.

One may not be prepared to deny that such awakenings of parental solicitude are sometimes inspired by beer, yet sympathy is due to parents who bring their half-starved, neurotic, white-faced children to hospital and complain that they are always being caned at school. In time it may be hoped that the public and our educational authorities will cast aside tradition and insist that children who 
are able to think and reason should be treated as intelligent beings, not as brutes.

Corporal punishment should be unhesitatingly condemned, at all events in the case of emotional children. It may damage both mind and body. Neurotic children are usually keenly alive to their own imperfections, which indeed are often many-and the mental punishment which their sins entail is often greater than they can bear. In the case, however, of little healthy, wilful children up to the age of three or four, the occasional application of "a satin palm with a sting like steel," is the easiest and perhaps the kindest method of control.

Some schoolmasters paralyse the brains of nervous pupils by an absurd trick of shouting their commands and admonitions at them. The ordinary callous schoolboy is quite undismayed, but the pedagogic thunder never fails to reduce the more sensitive pupils' energies to nil. Shouting schoolmasters cannot teach neurotic children. 


\section{CHAPTER VII}

\section{FRETTING AND HOME-SICKNESS}

MANY of us may remember the pangs of nostalgia in childhood ; the dead cold weight at the epigastrium, the feeling of intense depression, of nausea at the sight of food which seemed tasteless and like to choke us when we forced it down; the lump in the throat and tears which came at every thought and suggestion of those who seemed far away, though perhaps within a stone's throw.

We did not as a rule exhaust ourselves with weeping and rolling on the floor like Ulysses, but in acuteness our sufferings may have been as his. We kept them to our-" selves, or at most alluded to them as " belly ache," to friends with whom we were sufficiently intimate to exchange confidences. In time our troubles passed away, but Thackeray's remark to the effect that little boys only cry when sent to school because it is a very uncomfortable place, does not apply to all.

Children in hospital, though convalescent from various ailments, will often fail to thrive. They are dull, listless, silent, fretful and constantly in tears. They waste, and no food will tempt their appetite.

Experienced nurses recognize that they are merely fretting or suffering from "hospitalism."

One cannot doubt that in most children home-sickness is but a passing pang. Many Rachels waste their tears. Their offspring are soon cheered, and it is only the mother's heart which aches. It was not Hannah's voice which Samuel thought he heard in the dead of night, but Eli's. 
But Samuel must have been a child of considerable strength of mind. He told his aged easy going master the bitterest home truths, and when he grew up he "hewed Agag in pieces before the Lord" (1 Samuel xv. 33). It is true, and perhaps fortunately true, that most children bear bereavement lightly.

Did not Dick Steele, a child of five, beat his father's coffin with his battledore all heedless of his mother's sorrow? Thackeray pictured young George Osborne as a typically healthy child rejoicing in his newly acquired affluence and oblivious of his yearning mother's vigils at a corner of Russell Square.

Yet it is an undoubted fact that fretting is not always solely on the mother's part. Sensitive children may suffer far more than stern male parents think from loosening of apron strings. It does not always follow that sending a child to school makes a man of him. The sorrows of a child amongst strangers may be very present, and not, like those of the young bear, to come. It is not always unkindness nor want of sympathy, but homing instincts, which give rise to grief. The slum child discharged from hospital, where all have tried to make him happy and comfortable, will scream with rage and terror when his drunken mother who starves and knocks him about threatens to leave him there again. The latest fashionable and kindly custom is to receive poor children after they have been duly washed, anointed, and clothed, into the mansions of the rich to spend a happy holiday in refined and luxurious surroundings. I do not know from the children's point of view how far this experiment has proved a success. But I venture to think that in some instances, marble halls may have echoed with dismal wails for home and " muvver." In this connexion one recalls an incident in the life of Fichte the Idealist, related by G. H. Lewes. This precocious, dreamy and ultra-conscientious child could repeat sermons which he had once heard with almost verbal accuracy, and so useful did this accom- 
plishment appear to the worthy Baron von Mittiz on wet Sundays, that he translated the boy from a humble village home to his stately castle of Siebeneichen. But, Lewes says: "The heart of the poor village boy sank, as he beheld the gloomy grandeur of the baronial hall ... his first sorrow, his severest trial had come in the shape of what a misjudging world might regard as a singular piece of good fortune, and so deep a dejection fell on him, as seriously to endanger his health." *

* History of Philosophy, vol. iv., p. 141. Johann Gottlieb Fichte lived to the age of fifty-two and died then of fever contracted from his wife who had nursed the sick and wounded in hospital. Fichte was a singularly precocious child. He showed many of the traits of the neurotic child, of the self-controlled type. He was imaginative, dreamy, and prone to seek solitude. Sensitive and timid, he yet possessed moral sense and conscientiousness to a degree which is quite exceptional in a child.

Finding himself becoming careless and neglectful owing to the powerful hold which a book, Siegfried the Horned, presented to him by his father, had upon his imagination, he deliberately threw the book into a stream and endured severe punishment rather than confess his motives in doing so. He was at the age of thirteen rendered so miserable at school by the persecution and bullying which he received from his schoolfellows, that he resolved to run away and live like Robinson Crusoe on a desert island, yet he scorned to do so by stealth, and informed his arch-tormentor-." The Obergesell "-of his intention beforehand. Having made his escape, he felt impelled whilst trudging along the road to ask the blessing of Heaven on his wanderings, and as he knelt in prayer he remembered that his disappearance would cause grief to his parents. Immediately, like a young Regulus, he returned to face all penalties in store for him. But fortunately the rector of Schulpforte was humane; he not only remitted Fichte's punishment but chose for him among the elder lads a master who treated him with the greatest kindness and to whom he became warmly attached. (Lewes's History of Philosophy, vol. iv., p. 145, Ed. 1853.)

Had less consideration been shown for him at so critical a period of his life, it is conceivable that his career would have been blighted by the bitterness of despair.

In after life indeed, a tendency to mental overstrain is shown in the extract from his diary: "September 12. I wanted to work to-day, but could do nothing. How will this end ? What will become of me a week hence?"

But at this time his resources were at their lowest ebb, and he discovered that low living is not conducive to high thinking. 
Fortunately his approaehing failure was reeognized in time, and he was removed to the more eongenial surroundings of a eountry parsonage, where he speedily reeovered.

Have ehildren ever died of grief alone? The evidenee may be slight, yet the possibility that the lives of feebly constituted children may have fliekered out under medieal eyes whieh have seen symptoms only indieating need af prosaie medieal treatment, eannot be ignored.

De Quineey, in his noble essay "Levana and our Ladies of Sorrow, wrote :-

"Now I am far from saying that ehildren universally are eapable of grief like mine. But there are more than you ever heard of who die of grief in this island of ours. I will tell you a common ease. The rules of Eton require that a boy on the Foundation should be there twelve years: he is superannuated at eighteen, eonsequently he must eome at six. Children torn away from mothers and sisters at that age not infrequently die. I speak of what I know. The eomplaint is not entered by the Registrar as grief, but that it is. Grief of that sort and at that age has killed more than have ever been eounted amongst its Martyrs." *

Théophile Gautier mentions in his sketeh of his own life that removal, at the age of three, from the south of Franee to Paris gave him sueh intense home-siekness as to bring him to the verge of suicide. "I had already thrown my toys out of window and was on the point of following them when by good or ill luek I was seized from behind."

He deseribes himself as "a gentle, sad and sickly ehild with a curiously dark skin." At eight years old he was sent to the Collége Louis le Grand, where he was seized by despair which nothing could overeome.

"The noise and coarseness (brutalité) of my little fellow prisoners filled me with disgust and horror. I was dying of cold, boredom and isolation behind those dismal high walls. I eould eat nothing and was visibly wasting away.

* De Quincey, Camelot Classics, 1886, p. 106. 
My work gave my masters complete satisfaction and I promised to be a brilliant pupil if I lived .....

There was nothing to be done but to take me home and let me finish my school days as an "externe libre."

Madame Junot* records an interesting conversation between hersclf, the First Consul, and the physician Corvisart, on the cause of her little nephew's dcath.

This child, when under two years of age, was separated from his father, whereupon his grief bccame ungovernable. For some days he cried without cessation, perpetually inquiring where his father was. "At length his useless tears were intcrmitted, but his sighs, his pallid cheeks, and constant recurrence to the subject uppermost in his thoughts showed that his grief was not abated. His mother ... seeing that the uniform answer to his question that his father had gone away only increased his distress, at last replied that he was at Bussy, a small estate the family possessed, a few miles from Dijon. The family made a rule of indulging all his wishes and affording every diversion that could be supposed to alleviate his sorrow, and a journey to Bussy was undertaken; but the disappointment here experienced added to the malady which had now taken deep hold of him. In turn, a removal to the houses of all his relatives was tried, but in vain. At the end of a twelvemonth this extraordinary infant, who at the time of his father's departure was one of the finest, most healthy and animatcd of children, expired with the dear name of Papa still on his lips."

Napoleon threw doubt upon the story as related by Mdme. Junot and appealed to Corvisart, who replied : "Affection, distressed by absence as that of Mdme Junot's ncphew had been, might cause death, and the case is not even of very rare occurrence." "I have in my portfolios," he added, " a multitude of notices relative to the affections of children;

* Memories of Napoleon, his Court and Family, transl. Bentley, 1836, ch. xl., p. 237. 
and if you should read them, General, you would find not only that the germs of the passions exist in their young hearts, but that in some children these passions are developed in an alarming manner. Jealousy as well as poison will kill children of three years of age and even younger."

"You think then that this little Junot died of grief from ceasing to see his father?" asked the First Consul.

"After what Mdme. Junot has just related I cannot doubt it; and my conviction is confirmed by her having, without being aware of it, described all the symptoms of that malady of which only beings endowed with the most exquisite sensibility are susceptible. The child is happy in its early death, for he would have been to be pitied throughout his existence, and could have met with only a perpetual succession of disappointments."

The instances recorded in his note books to which Corvisart referred seem to have remained unpublished, and doubtless for political reasons. Corvisart, the fashionable and popular physician to Napoleon's court had passed through the reign of terror. No doubt he had in mind the fate of many a small aristocrat-from the Dauphin downwardsorphaned by the guillotine, despised, rejected, and ill-used by the brothers and sisters of "Liberty." One likes to think that Corvisart had sympathy with such, and wonders how he dealt with them.

It may be questioned whether grief alone is capable of causing death in children. But no doubt can be entertained that it may render them an easy prey to disease of many kinds. De Quincey's statement was no mere fancy bred of opium. Deaths which he ascribed to grief would have been attributed to "decline" by Registrars in former days, whilst now tuberculosis would be the cause assigned. The signs of grief are not discoverable post-mortem : in life they are sufficiently obvious and should be recognized.

I remember seeing a little girl aged 9, who for a fortnight had complained of constant headache. She had refused food, vomited, was wasting, and looked pale and ill. Her 
temperature rose irregularly, and it was feared that she might be in an early stage of meningitis. I could discover no cause for the symptoms nor did I know what was the matter with her until, some time later, I was told that she at once began to mend on hearing that a nurse to whom she was greatly attached, and who had given notice to leave, had changed her mind, and consented to stay.

Nostalgia.-Fretting and homing instincts in animals. The homing instinct probably is developed in all animals to some extent. It is more prominent in some varieties than in others and also is more marked in some individuals of the same species than in others.

Doubtless in the majority of cases it is but a blind impulse, and if thwarted no ill effect is produced upon the animal concerned. It would be interesting to know whether carrier-pigeons suffer in health when in confinement far from home. It is a fact that in many cases the homing instinct in human beings proceeds from desire to revisit places and not persons. It is not always evidence of an affectionate disposition. The exile's longings may be for his native land or even for a hovel in it, and not for the sight of his kith and kin. In some, a change of domicile or even a change of residence begets nostalgia, although the change is obviously for the better. In the old days of transportation there were many stories of convicts who became prosperous and respected, contracted new ties of relationship, and could have passed their lives in affluence and comfort abroad yet returned to England to pass a hunted harassed existence with the certainty of being hanged eventually.

Nostalgia is not solely the longing as of a cat for the warm fireside. Circe must have made Ulysses extremely comfortable in many ways, yet he pined for home.

I would not suggest that desire is always for the home alone and not for its inmates. But it may be so in some cases, and the reason why I mention this is that children who bear with equanimity the departure or death of relations 
may nevertheless fret if sent from home. Perhaps Gautier's may be a case in point.

Personal experiences of grief in children ending fatally must be rare, but some of us may have witnessed in our school days the downfall of a certain type of " new boy "from this cause. He arrived usually after term had commenced, clad in deep and spotless mourning clothes. He treated us with old-fashioned and ceremonious politeness, and used far longer words than were wont to enrich our own vocabulary. This naturally lowered him in our eyes, but he might have atoned for it by the unusual splendour of his playbox, which contained a complete and brand new assortment of bats, balls, rackets and boxing gloves, had he shown the faintest conccption of the use for which they were intended.

Tears sprang readily to his eycs; he was often found wceping silently in dark corners. Some of us despised him openly as a snivelling little brat. Others concluded that he was probably crying for his mother, but after a few rough attempts to console him, decided that the matter was outside our simple sphere of usefulness, and so left him alone.

At first his Form master was inclined to favour him, for he was uncommonly well informed, even in out of the way subjects. But his brilliancy of questions and answers was quite counterbalanced by his blotted, hastily scrawled and unfinished exercises. Sometimes indeed he had none to show.

There was a simple cause for this apparently gross idleness. Hcalthy schoolboys of ordinary type do not like the precocious urchin, whom they could thrash with one fist in the playground, to put them to shame in class. At the same time they are not above turning his acquirements to practical account. So, having appropriated his exercises with slight variations for their joint and several use, they were careful to destroy them five minutes before class time, lest he should be able to complete another set which 
they might be accused of eopying. The humour of the proceeding was further enhanced by hearing him denounced for purloining from their own stores of knowledge.

His descent was then rapid. In the course of a few months all his original neatness of costume and evidence of refinement disappeared. He became a dirty, dishevelled and shrinking little object; disdained and constantly punished by masters for idleness, deceit and obstinacy; fagged and subjected to all the ingenious modes of torment, mental and physical, which the human boy can devise. He met his unmerited punishment in sullen despair, his selfrespect was gone and his hope of justice destroyed. He added zest to his juvenile persecutors' sport by giving vent to torrents of blasphemy and foul language, which indeed were his sole methods of defence.

One remembers an incident in his Harrow life mentioned by Anthony Trollope. The Head Master once stopped him and asked whether such a disreputable, dirty little boy could possibly be a member of so aristocratic a community. Trollope, who had had many a private interview with the Head, remarks, "I suppose he had never seen my face !" *

I have known timid, homesick children to pass through years of misery at school, not produced of necessity by physical ill-usage, but by constant dread of undergoing it. The powerful, loud-voiced and quick-tempered schoolmaster, who lashes little nervous boys with his tongue for trifling misdemeanours, may harm them even more than if he lashed them quietly and temperately with his cane. The knowledge that unintentional breaches of unwritten law will be regarded as most heinous crimes, and visited by lengthy and scathing denunciation, if not by castigation, renders life an intolerable burden to such children.

* Trollope was "despised and persecuted by masters and scholars alike, and so neglected that after nearly twelve years' schooling he left unable to work an ordinary sum, or write a decent hand." Nat l. Dict. of Biography, Vol. lvii. p. 238.) 
This constant dread of impending trouble and powerlessness to avert it plays havoc with any seeds of moral sense already sown. Children of this kind have no sense of proportion between degrees of guilt. If told that trivial faults are deadly sins, they readily believe it, and are reduced to abysmal depths of gloom and despair in consequence. Reckless misconduct is often the outcome of reaction from such moods.

I do not pretend that all these common causes of childish unhappiness and ill-behaviour are unfamiliar. Yet it is well to bear them in mind when confronted with children reported to be " beyond control."

Schoolmasters as a rule are not best qualified to be judges in the matter. One cannot justly blame them if the standard at which they aim is one of convenience rather than of perfection.

The boy who gives least trouble in and out of school may often be their model. So, naturally, they do not favour one whose indolence, sullenness and carelessness in class are only rendered more exasperating by occasional indications of unusual mental ability; and the boy who is neither good at games nor at work is obviously an undesirable alien. It is less trouble to blame and chasten him for his delinquencies than to inquire minutely into their remote causes. It is-or was in my own younger days-common knowledge that schoolmasters are in some respects singularly shortsighted. We knew that the most industrious and plodding of us was disheartened by being made the butt for satire, that the tongue of the nervous was tied and his wits dissipated by a teacher's hastiness and irascibility, that the glib and self-assured was shallow-pated, that the one regarded by the master as a pattern of straightforwardness was justly dubbed by us a sneak and liar. We scented hypocrisy by instinct, just as we knew that the unfortunate who was in perpetual hot water was often not responsible for such immersion. We called him "Crazy Jane," and caused him to make sport for us young philistines, yet made 
allowances for his imperfections which our master never seemed to do.

We heard deafness and myopia stigmatized as " mulish obstinacy" and inattention, but could not interfere. Perfectly natural attempts at explanation of charges brought against us were stormed at as paltry excuses, prevarication and lying, or, worse still, trcated with savage buffeting on the "Dare you set your wits at me, sirrah ?" principle.

I do not think that nowadays little boys at preparatory schools are cowed by shecr brutality as they used to be. The time-honoured method of making an example now and then of some luckless wight, pour encourager les autres, I hope is falling into abeyance. For a time, no doubt, it made discipline more easily maintained. But the example of a burly, powerful man, felling a small boy to the floor, picking him up by his waistband, dashing him on to a desk and belabouring him with a heavy horsewhip until his heart-rending howls made us faint with horror, was more shocking than the culprit's misdemeanors. Such scenes were fairly common in my own school days. The officiator usually attributed their occurrence to the necessity of trying to save our little playmate's soul from hell; but the more prosaic of us traced them to the advent of blue letters by the post, or to other domestic events which need not be particularized. "For when," says Roger Ascham, "the schoolmaster is angry with some other matter, then will he soonest fall to beat his scholar."

Coleridge said that he dreamed of his schoolmaster all his life, and that his dreams were horrible. Brutes of the type of the Rev. James Boyer, of Christ's Hospital, are now happily extinct; but, without being guilty of his gross and wanton cruelty, some schoolmasters of the present day produce similar effects on timid children by storming at them. Some of us, like Coleridge, have been haunted many nights by visions of our early guide to learning, grown bigger, grimmer, bristlier, and altogether more alarming than ever. He is not in the least moved by our appeals 
to him as fathers of families and respectable men of business. We are only saved from painful and ignominious submission to his will when outraged Nature wakes us.

The case of Honoré de Balzac may be taken as an example of genius misunderstood and unappreciated in childhood, and more especially during life at school. At home he was alternately spoilt by an indulgent father, and harshly used by a stern and narrow-minded mother; at one time he would be merry, lively and talkative, at another, morose and wrapped in silent reverie, or passionate and irascible beyond measure. Brave and generous as in after life, he would take his sister's faults upon him in order to shield her from punishment.

Sent to school at eight his faults only were recognized, his talents and intellectual promise were unperceived. $\mathrm{He}$ was banned as the idlest, most callous boy in his division, and caned, abused and confined in the school dungeons in consequence. The Fathers of the Seminary never knew that he welcomed imprisonment in the cells in order to satisfy his craving for reading books which he secreted from the library.

In addition to other persecutions, he endured tortures from ill-fitting school boots, and discomfort from stuffy, illventilated class rooms. Apparently the dreamy mental condition to which he had always been subject grew upon him. He would sit for hours head on hand, not attempting to learn, but gazing out of the window at the clouds or the foliage of trees in the courts below. The signs of brain fatigue culminated at the age of fourteen in an attack of coma with "feverish symptoms." He was hastily removed home, where he arrived "thin, wasted, like a somnambulist sleeping with open eyes, hearing hardly anything that was said to him." His mother, sensible for once in her life, roused him from his reveries, made him take part in games with the rest of the family, and in time, with the help of fresh air, he regained his health and spirits.*

* Life of $H$. de Balzac, by M. F. Sanders : pub. by J. Murray. 
Descartes probably escaped Balzac's fate at school through the wisdom of the Jesuit Fathers of La Flèche. Marking that his mind was " naturally disposed to meditation," they allowed him to lie late in bed, excused his attendance at lectures, and relieved him of much routine work done in common with other boys.

The question, "should he be sent to school ?" is often asked of medical men concerning delicate neurotic boys by anxious mothers, and unless one is sure of the facts it is a difficult question to answer.

The father in such cases has usually no grave doubts in the matter. He is quite ready to accept the slightest encouragement for believing that a boarding school will in a very short space of time knock the nonsense out of the child, whose petty ailments and demands for constant attention deprive him of much of the charms of his wife's society. But at the same time the male parent must be prepared to find his connubial bliss alloyed by frequent maternal misgivings.

So the responsibility for sending spoilt effeminate urchins to school has to be shared by the family's medical adviser.

In the majority of cases the risk is fortunately not great. If effeminacy, and all the traits of character and conduct and habits which render a boy unpopular with his schoolfellows are simply the natural results of being spoilt and pampered at home, the chances are that after a few weeks of teasing and rough usage he will learn the error of his ways, adopt the manners and customs of his associates, and all will go well with him ; or he will suddenly assert himself when bullied, and be thereafter treated with respect. I have known a new boy who, night after night, was whilst fast asleep rudely awakened by finding himself deposited on the cold floor with all his bedding on top of him. At last he had a happy thought, he took his heaviest boot to bed with him; then lay pinching himself to keep awake until he saw white figures stealing towards him in the gloom. One stooped to seize his bedding, when down came the 
heavy boot heel well on the crown of an ungodly head. The ghostly figures fled with muttered curses. My little friend never discovered their identity, but henceforth his nights were spent in peace.

Yet there are some whose timidity, abnormal shyness, inability to acclimatize themselves to new surroundings, yearning for home comforts and kindness, desire for solitude, want of social instincts, render them, like Gautier and Fichte, unfit for ordinary school life. These traits are innate in some-they are not always the outcome of indulgence and unwholesome petting-but are natural conditions which cannot be altered or removed. They may be found to co-exist with mental capacity of the highest order which may never bear fruit in uncongenial climes. Perhaps such cases are uncommon, yet medical men, particularly those who are attached to schools, should know of their existence.

There are no well established rules for recognizing them. Certainly a mother's apprehensions lest her offspring suffer cruelly on account of sensitive disposition and exquisite refinement are often as unfounded as her touching faith in his virtues and talents. The shrewd suspicion of fathers, uncles and guardians that all the boy requires is to have the nonsense knocked out of him may often be correct. But it is not always so, and when the experiment is tried in doubtful cases, the effects need careful watching by all concerned. 


\section{CHAPTER VIII}

\section{DISORDERS OF SLEEP}

Tне normal infant up to the fourth quarter of its first year spends most of the 24 hours in sleep. Towards the end of the second year, about 12 hours at night, and from $1 \frac{1}{2}$ to 2 hours by day are given to sleep. Up to the end of the fourth year a healthy child sleeps about 12 to 13 hours at night, or somewhat less if allowed-as it should be-a nap of an hour or so by day.

From the fourth year until puberty 9 to 11 hours of sleep at night is an average allowance.

But healthy children, like adults, vary considerably in their requirements of sleep, and it is necessary therefore to pay attention to their individual peculiarities. Some need far more sleep than others. Habit and ill-health no doubt have much to do with abnormalities. Even the healthy infant unless trained to sleep at proper times may give trouble by not doing so. Habits of waking at inconvenient hours and declining to go to sleep again are readily set up. Common causes of sleeplessness are indigestion, over-feeding, hunger due to unsuitable food, earache, painful dentition, irritating skin affections, and pain of any kind. A frequent mistake of nurses and parents is to use all artifices to procure sleep without attention to the causes which prevent it.

The neurotic infant is proverbially a bad sleeper. $\mathrm{He}$ awakes at the slightest noise, and when once wakened is difficult to soothe. The most trivial ailment renders him feverish and sleepless. For his special needs, comforters, rockers, and lullabies have been invented, and, to his special 
detriment, elixirs and soothing syrups and "teething powders."

Disturbed sleep or sleeplessness in infants should not be treated by anodynes and hypnotics, but by methods aiming at detection and removal of the cause.

An infant's habit of awaking at the slightest sound may often be traced to excessive precautions against his being disturbed. When the whole house is hushed and every one walks with noiseless footfalls and speaks with bated breath because the baby is asleep, it is not surprising if the babe resents any relaxation of such domestic discipline. Healthy infants will sleep through any ordinary noises if accustomed to them from the first.

The neurotic infant's ear, however, is highly sensitive to loud noises even in waking hours, and therefore quiet is essential to its repose.

In children who are no longer infants in arms, disturbance of sleep by Night Terrors is very common; the causes and treatment of Night Terrors are discussed under that heading. True insomnia is however very rare under the age of puberty; cold feet, palpitation, and indigestion are perhaps the most common causes. Healthy children will always secure their quantum of sleep if allowed to do so, provided that pain does not render sleep impossible.

The healthy normal child that "feels its life in every limb " expends much energy during the day, but makes up for the lost quantity in sleep at night. But the restless, active-minded, neurotic child sleeps least when most excited and tired by his mental and physical exertions in daytime. The recuperative effects of sleep are denied to him. In consequence of fatigue of mind and body his temperature may rise to $103^{\circ}$ or $104^{\circ} \mathrm{F}$., he spends the first part of his night in babbling deliriously of visions, hallucinations, and recollections of events of the day, but then sleep follows, from which he is too often rudely awakened because it is time to get up, and finds himself cross, fretful, peevish and unrefreshed with "a day of misfortunes" before him. 
It is a scnsible rulc to allow children who have been disturbed in this manncr overnight, to sleep as long as they will in the morning. This may to some extent counteract the effects of emotional excitement by day which cannot always be prevented in the case of neurotic children," though all attempts to do so should be made. "Early to bed" is a good principle, but "early to rise" is not always so.

As previously mentioned the amount of sleep required varies in individuals. Adults are often obliged to restrict themselves in sleep from imperative necessity, or they do so from conscientious motives. Nervous breakdown is the inevitable consequence - with the symptoms of headache, lassitude, irritability, mental confusion, loss of memory, inability to concentrate the mind, uncontrollable drowsiness by day, and wakefulness at night.

All these symptoms are common results of insufficient sleep in children too, and can be remedied if their cause be suspected, and further opportunities for sleep are afforded.

The old rule, six hours' sleep for a man, seven for am woman, and eight for a fool, is no longer acceptable. It was applicable only in days when time was no object, hasty work was unnecessary, and leisure for naps during the day was always obtainable.

Modern education imposes an increasing mental strain on children, particularly on those who are industrious but slow. Recently there has been a general outcry that the school-child's sleeping hours are too short. But long hours in bed are not good for all alike. Early wakers should be early risers, or should be trained to occupy their minds with books or playthings directly they awake. For enforced idlencss in a warm bed may give rise to dreamy mental states and sexual instincts. Some children's brains grow more active, and some less active, as the day wears on. Those who are difficult to rouse in the morning have difficulty in getting to sleep at night. Those who wake early, go to sleep quickly.

Such peculiarities may be the result of habit, but are not 
always so. Within limits they should be studied and allowance made for them. As much harm may be done by keeping a drowsy stupid child out of bed at night as by making him get up early in the morning. Lessons cannot be learned by a child who is only half awake.

School rules for getting up and going to bed cannot perhaps be made to meet each individual case, but whenever the signs of insufficient sleep are manifest in special cases, no time should be lost in making up the deficiency. Many a nervous collapse might thus be averted.

Hypnotics, except in some cases of acute illness and pain, should not be given to children. This does not, however, apply to bromides, which are invaluable in the case of neurotic excitable children whose sleep is disturbed by Night Terrors.

\section{NIGHT TERRORS}

Symptoms of Night Terrors.-The attacks are usually described in children aged between three and eight years. Older children suffer from them, but one is comparatively seldom called to treat them on this account.

Typical night terrors occur almost always within half an hour to two or three hours of going to bed. Except in cases of febrile disturbance, recurrent attacks in a single night are rare, but they may be repeated for many nights on end, or at weekly, monthly, or longer intervals. Piercing screams are heard, and the child is found sitting up in bed, or crouching in a corner of the room, with hands outstretched as if to shield himself. Sometimes he is trying to get out of the window, or to open the door. He may escape from the room, and run screaming down the staircase with fearwinged feet. His face expresses wildest alarm, his eyes are widely opened, with pupils dilated, and he gazes intently at the ceiling, or some quarter of the room in which he locates the apparition which frightens him. He often 
gives a clue to its nature by shrieking, "Black faces!" "Black dogs!" "Horrid man!" or some such exclamation.

He may cling instinctively for protection to any one within reach, but he does not at first look at or recognize persons. His attention is fully taken up by the imaginary object of his fear. The period of terror lasts from a few moments to half an hour. The child usually then recognizes his surroundings, but he sweats and trembles, turns pale, and seems utterly shocked and exhausted. He will beg not to be left alone in the dark again, or that his hand may be held. He soon dozes, but sobs and starts for a time before sleep becomes sound. Sometimes at the end of an attack he passes a large quantity of pale urine, but more frequently he has wetted the bed or the floor during the stage of excitement.

Next day there is usually complete recollection of what has occurred, but, in some cases, even when the child has sprung out of bed, and may have answered questions more or less rationally, he has never been really awake, and he seems to remember nothing subsequently.

The foregoing is a general account of the symptoms, but subtle distinctions between the attacks and between the patients have been drawn.

Night terrors have bcen divided into "Idiopathic and Symptomatic," by Silbermann.*

The characteristic of the idiopathic variety he holds to be a transitory hallucination of sight, due to an abnormally increased irritability of the brain, whilst the characteristic of the symptomatic form is a sensation of distress arising from digestive disturbance acting through the agency of the vagus nerve, and giving rise to dyspnoea.

This distinction is not altogether satisfactory, because it is too narrow. Although visual hallucinations are commonest in young children, other hallucinations, such as those of hearing, and of common sensation, besides those of sight 
may occur in night terrors of idiopathic origin, and also in those of symptomatic origin.

A classical instance of auditory as well as of visual hallucination in night terrors is given by Jerome Cardan, the famous mathematician, philosopher and physician of the sixteenth century. From his seventh to his twelfth year he says that he was haunted nightly by visions of a cock with red wings which frightened him lest it should speak, which it always did, uttering in human voice, "verba plerumque comminatoria." * As an instance of hallucination of common sensations, Dr. W. S. Colman mentions a case of a child aged two years who woke screaming that some one was hurting his finger. He pointed out where the person seemed to be, and insisted that his finger was bleeding.

Hallucinations of all kinds may be due to reflex irritation of the brain by local disorders, and hence may be regarded equally as idiopathic and symptomatic in nature. Moreover, Silbermann's symptomatic variety of night terrors should include those occasioned by local disorders other than digestive, and should not be confined to those which give rise to dyspnoea. Nevertheless, it is a fact that dyspnoea from various causes is a potent cause of night terrors.

It is probable that all dreams and night terrors are symptomatic in that they arise from some dimly felt bodily sensation. They are idiopathic in the sense that the interpretation of the sensations which give rise to them is entirely the dreamer's own.

Distinction between Nightmare and Night Terrors. Dr. Coutts in an able article $\dagger$ distinguishes between "night terrors" and "nightmares." The latter he regards as due to reflex disturbances, the former, he thinks, cannot be thus explained.

Like Silbermann, he regards it as essential to night terrors that the child should see visions, whilst in nightmare he only dreams dreams.

* De Vitâ Propriá.

† American Journal of Medical Science, Vol. I., 1896. 
Other points of distinction which he makes, are :-

(1) That night terrors seldom occur in children over eight years of age, whilst nightmare may happen at any age.

(2) That night terrors occur during the best of health, whilst nightmare attends chronic ill-health.

(3) That in the course of a night there is usually but a single attack of night terrors, although there may be several of nightmare.

(4) That in night terrors there is a family history of neuroses, such as epilepsy, chorea, hysteria, etc. In nightmare there is no such history.

(5) That infantile convulsions usually precede night terrors, but not nightmare.

(6) As regards the differentiation of symptoms, he mentions that in night terrors the child seems wide awake, but is not so. He still sees the vision which has terrified him, and is unconscious of his surroundings. In nightmare he is actually wide awake, only partially demented by recollection of a troubled dream. He is fully conscious of the presence of others in the room.

(7) In night terrors there is no recollection of the event, whereas in nightmare there is a perfect recollection, and dread of recurrence.

(8) In night terrors the nature of the vision never varies, in nightmare the objects of apprehension have generally been met in waking hours, and are not invariably the same.

These distinctions are clearly and well defined, yet they seem to be too hard and fast. Hallucinations of vision, as part of night terrors, are not confined to children under eight years of age. They may occur at any age. They are frequently symptoms of febrile delirium.

The unvarying nature of the vision does not constitute a distinction between night terrors and nightmare. The same dream hallucinations which terrified us as children may haunt us as adults till we die, and may be our last as well as one of our earliest emotional disturbances. A dream which has once powerfully affected us is apt to recur 
as a habit under slight provocation. Its recurrence cannot be held to distinguish night terror from nightmare.

The statement that night terrors (visionary hallucinations) occur in the best of health, whilst nightmare (terrible dreams) attend chronic ill-health is perhaps too sweeping. Both may be indications of ill-health, shronic, acute, or temporary, affecting brain or body, or both.

A distinction between night terrors and nightmare cannot be based on the presence or absence of visionary or other kinds of hallucinations. The statement that night terrors occur usually only once, whilst several attacks of nightmare may be repeated during the night, is not in accordance with the writer's experience. There may be several repetitions of an alarming visual or other hallucination in a single night, especially in cases of pyrexia.

The recollection or non-recollection of the event next day can hardly be relied on as a basis of distinction between night terrors and nightmare. It is doubtful if the essence of a vivid and alarming dream is forgotten. But many children will give no information on the subject, because the horror of it is too complex for their powers of verbal expression, or they will deliberately conceal it lest they should be laughed at, as in the case of Harriet Martineau. There seems to be little reason for regarding frequent repetition of the same dream, or non-repetition of its occurrence, or peculiarity in its nature as indications of night terrors rather than of nightmare. The difference is merely one of degree. A nightmare in one child is a night terror in another. One child may be merely frightened, another may be driven temporarily insane by his dreams. A stolid, commonplace child may over-eat himself and wake screaming in the night. Next day he will be none the worse, and will only vaguely remember that he has had a bad dream.

It is far otherwise with the emotional, imaginative and neurotic child. To him, the prospect of his "witchridden pillow," as Charles Lamb called it, is one of unutterable terror and dismay. If he keep his mental torment 
on this account to himself, as he often may do, there can be no doubt that mind and body will suffer, it may be for a lifetime.

Night terror may therefore be regarded as nightmare exaggerated by the emotional disposition of the sufferer. As Dr. Coutts points out, in cases of night terror there is usually a family history of neuroses such as epilepsy, chorea, hysteria. In nightmare there is no such history as a rule.

The Psychology of Dreams.-It is perhaps difficult at first to reconcile a reflex theory of dreams with the fact that the tenor of the dream in many cases bears no relation to the presumed stimulus which excites it. For instance, why should a child dream night after night of a horrible red-winged cock because he has a pain in his stomach ? The apparent difficulties may be reduced by a psychical explanation.

The child has seen a red-winged cock by day and has not liked the looks of it. Its image is firmly impressed on certain neurons of his brain. In sleep these neurons are dissociated, that is to say, their paths to consciousness are disconnected. Pain in the stomach partially awakes the child to consciousness of what Jolly calls the "self light of the retina." The "self light of the retina " awakes the neurons which contain the image of the red-winged cock, and they convey the perception of it to higher centres, which misinterpret and distort the vision. For these are unrestrained by judgment centres, and so the cock attains formidable and even gigantic proportions and utters "threatening words."

In dreams we are all mad, because our sense of judgment, of proportion, of humour, and the ridiculous deserts us. Insanity with all its delusions is but a waking dream. Most delusions have a physical basis in fact, which the mind misinterprets because the centres of judgment slcep. The dream hallucinations of very young children are mostly due to wakened memory of objects which they have seen, and which have terrified them-we may not know when 
or why-by day. Many children have cause to remember the fifth of November, with its hideous effigies and masks, although at the time they may have shown no signs of perturbation.

In one sense all bad dreams are symptomatic, that is to say, their exciting cause is a peripheral stimulus arising internally or externally. The nature and origin of the stimulus may to some extent be explained by the tenor of the dream. For instance, partial asphyxia due to close atmosphere, or to covering the face with bed-clothes, or to obstruction of respiration by adenoid vegetations, will give rise to a dream in which a sense of impending suffocation causes terror. Hence arise dreams of being engulfed by tidal waves, or buried alive by avalanches. Again, dreams of being pursued, yet unable to stir, may be occasioned by actual restraint of movement from heavy bedclothes or pressure of one leg upon another. Dreams of flying or of falling into a bottomless abyss may depend on labyrinthine vertigo. Dreams of the Inquisition and of tortures at the stake by Red Indians may be produced by dimly-felt bodily pain. Dreams of being exposed on an iceberg in the midst of a vast frozen sea may arise from feeling cold.

Below the age of five or six the tenor or content of the dream is usually simple, and there is seldom any difficulty in divining its nature from the child's exclamations.

Early school tasks, and especially initiation into the mysteries of simple arithmetic, will cause children to babble scraps of hardly acquired learning and do sums in their heads all night long. Just as in adults who are mentally overworked, the trivial events of the day are woven into distressing dreams at night.

Children who suffer from educational night terrors are often precocious and learn with ease, but the symptom indicates cerebral activity which may readily end in exhaustion. And this is even more likely to affect dull conscientious children who dream of lessons during the process 
of "being brought on" by teachers of Dr. Blimber's type.

Complex Dream Hallucinations.-In children from the age of six or seven upwards, the dream hallucinations are often complex and difficult for them to describe. It is not till childhood has passed that one learns what the child's sufferings in this respect have been. If we knew their nature at the time, it would often be possible to relieve them.

The prominent feature in this class of night terrors seems to be an elaborate visual hallucination. The phenomena are purely subjective, they do not represent any objects which have been seen in waking hours, and are therefore distinguished from the early simple hallucinations which occur in younger children.

They are of colossal skeins of wool, or mazy webs in constant intricate movement, now approaching, now receding from the eyes, and the terror culminates as the thing draws near. An excellent example of this form of night terror is given by Charles Dickens * who writes : * "Sauntering among the rope making, I am spun into a state of blissful ignorance, wherein my rope of life seems to be so untwisted by the process that I can see back to very early days indeed, when my bad dreams-they were frightful, though my more mature understanding has never made out why - were of an interminable sort of rope making, with long minute filaments for strands, which, when they were spun home together close to my eyes, occasioned screaming." †

* Uncommercial Traveller, Essay on "Chatham Dockyard," p. 283.

$\uparrow$ Dickens, from the time when he describes himself as a sickly and not particularly well-cared-for little boy, was subject to attacks of what I take to be enterospasm. He says that his nurse, a ghoullike young person who told him tales of "Captain Murderer," and "Chips the Carpenter," and of a huge spectral dog whose size he feebly attempted to explain away-not that he deemed it in the least improbable, but because he felt it " to be really too large to bear "- "impaired his digestive powers for life." Dickens also suffered from hemianopia and migraine in after life. 
Other examples of the kind are as follows:--In one patient, when a child, the vision took the form of a ball, of no particular colour, and at first small. It quickly rolled towards him, growing to monstrous size, and seemed about to overwhelm him. This ball was apt to make its appearance in the course of any variety of dream. $\mathrm{He}$ knew the dream stage at which it was likely to appear, and would make frantic endeavours to wake himself in time to avoid it. He would awake screaming with all his might, but would never confess the reason, only saying, "It was nothing," or that he did not know why he cried. $\mathrm{He}$ usually found that he had wetted the bed on such occasions. He would try to keep awake afterwards, for fear the dream should recur. $\mathrm{He}$ is of neurotic disposition, markedly myopic, and a great sufferer from migraine.

Another patient thus described his early hallucinations :His personality consisted of a head only, or, at all events, his body was immobile. He was in the midst of a vast white, undulating plain, on which some dark, indistinct object kept moving in concentric, narrowing circles around him. The terror culminated when the thing passed behind him during its gyrations, and he could not see it, but felt that it was there.

In another of his dreams there was a wall of thick darkness in front of him, on which a huge spider, as large as a Newfoundland dog, span an endless web, which somehow threatened to involve him.

In both cases he was always conscious of being in a dream, but the hallucinations and the fear of them continued. $\mathrm{He}$, again, is of highly nervous temperament, and is subject to migraine.

The fact that this type of dream frequently occurs in those who suffer from migraine, suggests that the hallucination may be induced by the visual aura which so commonly precedes an attack of migraine, also that as errors of refraction and astigmatism are sometimes the cause of migraine they may perhaps account for the complex visual form of night 
terror to which attention has been drawn. It is true that typical migraine with its various well-known aurae is seldom complained of before the age of puberty. But the aurae may neverthcless occur in young children and frighten them to distraction whether by day or by night. Adults often experience the aura of migraine without the headache, and when this happens for the first time they are often greatly alarmed by the amblyopia, hemianopia, giddiness, and other sensations which they take to indicate serious cerebral disorder.

It is impossible to enumerate all the different local causes of irritation which may give rise to night terrors in one case, and nightmare in another. They include ocular, aural, nasal and faucial troubles; pain of any kind may cause night screaming. Suspicion of hip disease or calculus always leads to inquiry as to night screams, but night screams do not usually arouse suspicion of hip disease or calculus. Yet the possibility of this cause and effect should be borne in mind. Hyperacidity of the urine, is often associated with enuresis and night terrors. Catarrhal appendicitis, mucous colic, intestinal parasites, may act as reflex causes. In some cases, cyclical albuminuria is met, with all its curious vaso-motor disturbances. In many, delirium caused by pyrexia accounts for terrifying visual and other hallucinations. An indigestible meal will undoubtedly produce a nocturnal "incubus," but dyspepsia is not so frequent a cause as has generally been supposed. Nor are night terrors in neurotic subjects often cured by attention to digestion alone. In many cases it seems that chronic nervous dyspepsia and a variety of neuroses may be traceable to repeated but unsuspected night terrors.

Night terrors consisting in a feeling of impending suffocation are most commonly attributable to partial asphyxia due to naso-pharyngeal obstruction. Close bedrooms, heavy bedclothes, and the common custom of tucking children up in bed so that they cannot freely move their limbs, may account for this and other forms of nightmare, especially 
the paraplegic variety. The dream in which one is pursued, but cannot run away, is probably due to actual restriction of movements. But another explanation may be offered, namely, that deficiency ${ }_{i}^{\circ}$ of oxygen is the exciting cause.

Mr. Glaisher, when at a height of 29,000 feet in Coxwell's balloon, found himself unable to execute any muscular actions, although his volition to perform them remained intact. Paul Bert had a similar experience after exposing himself to low atmospheric pressures in a closed chamber.*

Professor Marcet concludes from these incidents that " the conception of volition does not require oxygen, but the manifestation or response of volition cannot be carried out without it."

Night sweats and irritating cutaneous eruptions may be productive of night terrors in some. The present writer attributes to this cause a peculiarly horrible dream to which he has been liable from early life. The dream is that he is taken prisoner by captors who with fiendish malignity slowly tickle him under the arms whilst he is unable to stir hand or foot or even to cry out. Its horrors are still unabated after many repetitions, and it never fails to wake him, and others within hearing, by his stifled groans and cries.

Night sweats are the probable exciting cause, but the story of Simon de Montfort who tickled the Albigenses to death may be responsible for the interpretation.

The "tabula rasa" of the neurotic infant's mind readily receives permanent impressions. Dreadful pictures, and ghastly tales of ghosts, witches, martyrs, tortures and hideous modes of death, all subjects which are terrible and uncanny, afford irresistible fascination to those who are by nature timid and imaginative. They will pore and gloat over spectres and devils whose existence they will tremulously deny by day, but at night, as Charles Lamb expressed it, " they awake into sleep and find the visions true."

* Marcet, "History of the Respiration of Man," Lancet, Vol. ii., 1895, p. 77. 


\section{DAY TERRORS}

In rare cases precisely the same symptoms which attend night terrors occur by day, and when this is the case the suggestion that the attacks are those of masked epilepsy has to be considered. At the time of an attack the child is apparently wide awake, and Dr. Still has suggested the terms "sleeping" and "waking" terrors to convey the distinction. It may be doubted, however, whether the child is really wide awake, or only in a dreamy mental state such as that which occurs in adults who see ghosts of departed friends and are firmly convinced that they are not dreaming.

In "day" terrors of children the hallucinations may be visual as well as auditory. Consciousness of surroundings does not seem to be lost, but the child is beside himself with fear of what he thinks he sees or hears, and rushes to his mother for protection.

In some cases, as has been suggested with regard to certain forms of night terrors, the hallucination may be due to an aura of migraine, although the aura may be far more remote from the headache than is customary in ordinary migraine.

Sometimes both "sleeping " and "waking " terrors occur in the same subjects. A girl of six, for instance, would stop in the midst of play and shriek "There's something black," with every appearance of the livelicst terror-shuddering and shrinking back as though something were following her or being thrown at her. Then she would scream piteously, "I can't help it!" over and over again. These attacks lasted ten minutes or so and were followed by exhaustion, sleep, and headache. Sometimes at the commencement of an attack she would shriek "I am giddy!" or "A fly is buzzing in my ear!" but as a rule the hallucination was visual, and took the form of something black. She had been subject to them both by night and day for upwards 
of three years. They formerly occurred about every third day, and she would have as many as three in one day. On one occasion, three years ago, an attack culminated in general convulsions with unconsciousness lasting several hours. This child had an excessively timid and hunted expression, as though full of dread apprehensions, which she doubtless was. She had slight naso-pharyngeal obstruction from adenoids, but no other sign of disease. Under bromide of ammonium, the attacks rapidly disappeared. She has had no severe attacks for nearly two years, but is still hysterical and emotional. A brother suffers from "day-somnambulism."

This lad, now aged nineteen, was brought to the writer in 1897 on account of occasional attacks in which he would stand still, and stare fixedly for a few moments, seeming not to know where he was. He never had " night terrors," nor ordinary epileptic fits, but during his school life, on several occasions he arrived home, rang the bell, although the door was open, and when his mother came to see who was there, he seemed not to recognize or see her, but walked upstairs and went to bed, and slept. On waking some hours later he had no recollection of what had happened since starting home from school. These attacks of somnambulism happened at rare intervals, and had been attributed to over-work at school. They ceased after leaving school five years ago but have returned within the last year, and have caused him to lose several situations. He has sensations of things passing in front of his eyes which he cannot describe, or a feeling as if his eyes were drawn to the left side. He usually knows where he is at such times but says he is only "half sensitive." Sometimes, however, he is quite unconscious of surroundings, but he never falls, bites his tongue, micturates, nor is he convulsed. Once an attack came on just as he was beginning to write at dictation in Sunday school. He went on writing automatically for at least ten minutes and must have partly heard what was dictated, for although most of the words are illegible, 
and the result is unintelligible, such expressions as "suffer for us," "Our Lord," "free dying" are written clearly enough-and words such as " redenmentane," "dempstry" and "redepts" obviously indicate attempts to write "redemption" or "redeemer." Some of these words are written several times over in succession.

Apart from these attacks of dreamy mental states his health is perfect, and he is a bright looking and highly intelligent lad.

There is no other history pointing to epilepsy or any form of insanity in the family.

Another girl aet. five years had for six months almost weekly attacks, both by day and night, in which she would suddenly begin to scream. When her mother called her she would shriek, "I cannot see!" or, sometimes at night, "A pig is after me!" or " Things are dancing on the walls !" On going to her assistance her mother would feel her at first rigid, then quivering and quaking from head to foot. The child was never unconscious, but always much terrified. An attack would last about ten minutes, after which she would seem exhausted, and sleep, waking subsequently with a bad headache. During a month's treatment by bromide of ammonium she had no more day attacks, and only one occurred at night. Enlarged tonsils and adenoids were removed by operation, and the attacks then ceased. In both girls large tonsils and adenoids might have been the exciting cause of "sleeping" and "waking" terrors. But in both the improvement took place under the use of bromides, and in the first the nasal obstruction was but slight and an operation was not advised owing to the extreme nervousness of the child.

In two out of three of Dr. Still's cases the hallucinations were auditory. Each one would stop in the midst of play, look terrified, and run to his mother screaming sometimes "Some one is after me," or sometimes unable to explain why he was frightened.

Children may become quite maniacal in these attacks, 
as Dr. Goodhart says, and as in the first case mentioned may be driven into convulsions by such intense paroxysms of fear, but the convulsions are rather of the nature of hystero-epilepsy than of true epilepsy.

In younger children, aged about three years, the place of such attacks seems to be taken by fits of paroxysmal screaming without adequate cause. The children shed no tears, but seem wildly agitated and scream incessantly for half an hour or longer until exhausted. Paroxysmal screaming should not be mistaken for a fit of temper. It is sometimes associated with constipation arising from atony of the bowel in a neurotic child (cf. pp. 91-4).

Mucous Disease as Cause of Night and Day Terrors. -Dr. Still lays stress on the rheumatic history of his cases of day terrors, and also on the condition present which Dr. Eustace Smith has described as "mucous disease." In this, the patient is languid, irritable, pale and sallow, with puffy eyelids, the bowels are constipated rather than relaxed and the motions contain an excess of mucus. Complaint is often made of abdominal pain or discomfort, and threadworms may be present.

It may be doubted whether either rheumatism or the " "uric acid diathesis" or "mucous disease" is the fons et origo of night or day terrors. Any or all may be the result rather than the cause of the neurotic symptoms which prevail. Perhaps it would be more correct to say that the phenomena are part of a vicious circle.

Relation between Night and Day Terrors to Epilepsy.-Epileptics may suffer from night terrors but the subjects of even exaggerated forms of night terrors are rarely epileptics.

The analogy between night terrors and epilepsy is no closer than that which some suppose to exist between epilepsy and migraine.

Migraine and night terrors are extremely common affections, and are apt to occur together in nervous, activeminded subjects. They cannot be intimately related to 
epilepsy, for were they so epilepsy would be far more common than it is.

At the same time, fright and emotional shock, both sudden and prolonged, may excite epilepsy, and so the occasional sequence to night terrors may be explained.

The significance of day terrors whether, as suggested, they may be caused by vertigo or by a migrainous aura in a highly neurotic child or not, seems to be more grave than that of night terrors alone. Yet even in such severe cases of day terrors, as have been mentioned, true epilepsy has not made its appearance. Day terrors are more closely allied to hystero-epilepsy, and hysteria, dreamy mental states and narcolepsy than to epilepsy itself. The coincidence of day terrors and day-somnambulism in the sister and brother to whom reference has been made on p. 79 illustrates this relationship.

The following case is an example of narcolepsy, night terrors and somnambulism occurring in the same subject.

Narcolepsy and Night Terrors.-A boy, aged twelve,"after an attack of influenza suffered from headaches and somnolency. He would fall asleep suddenly in the midst of a meal, or whilst dressing or undressing, or at any other inconvenient time. Once he slept from 3 p.m. until 11 a.m. the next day. After an ordinary night's rest, he would sleep steadily through the forenoon or afternoon, if allowed to do so. At first sleep was natural, but later on it was disturbed by screaming, muttering, and violent struggling, somnambulism, slowness, and irregularity of the pulse. Once he split his nightdress from top to bottom and overset the table by the bedside during the night, but had no recollection of what had occurred the next day. The attacks of sleepiness, at first infrequent, became of common occurrence. In the intervals he seemed well at first, but gradually his moral nature changed, and he went through what his mother called "a phase of quite grave deceitfulness." He became timid, and afraid of the dark. He had no actual epileptic fit, but was subject to sudden 
attacks of convulsive, grasping movements of the right hand and twitchings of the right side of the face. All these alarming symptoms disappeared after removing him from school, and sending him to vegetate in the country for eight months. An elder brother of his, after gaining a scholarship at a public school, suffered from fits of daze or giddiness, with other symptoms of grave cerebral exhaustion, whenever he worked for more than an hour or so at a time. $\mathrm{He}$ always improved after a few weeks' holiday, but return to school work produced so many relapses that the parents wisely gave up all attempts at ordinary education. He was sent to do outdoor work on a farm for two and a half years. This effected a complete cure.

Treatment of Night Terrors.-Night terrors being the result of dimly felt external or internal impressions upon a morbidly excitable brain should be treated by correction or removal of exciting causes, and by endeavouring to quiet the emotional temperament of the child.

The sleeping room should be well ventilated, soft feather beds and heavy bedclothes should not be used. Nasopharyngeal obstruction from enlarged tonsils and adenoid vegetations are perhaps the most frequent exciting causes. Eye strain from errors of refraction and astigmatism are also occasional causes. Many subjects of night terrors are of the rheumatic or so-called uric acid diathesis. In some, cyclical albuminuria, in others, mucous colic is asssociated with night terrors whilst pyrexia from any cause may be attended by terrifying visual and other hallucinations.

All these conditions need appropriate treatment, but it should be remembered that neither one nor all of them constitute the whole cause.

Removal of adenoids, scybala, intestinal mucus, threadworms, correction of refraction errors, anti-rheumatic remedies and tonics will not in all cases provide a cure. It is necessary also to correct morbid tendencies to brood over terrors seen and unseen, to protect active and sensitive as well as dull brains from educational over-pressure, and 
to shield nervous children as far as possible from thoughts, words, sights, and deeds which are calculated to increase emotional proclivities.

The fear of darkness cannot be dispelled by enforced exposure to it. Confinement to the dark cell in prisons has been abandoned as a punishment too severe even for adults to endure. Yet many parents and guardians persist in thinking that a neurotic child's plea for a night-light should be met with derision and scorn.

Treatment By Drugs.-Bromides are always essential. A dose of 5-10 gr. bromide of potassium, given an hour or so before bedtime, is often sufficient to secure a night's rest. Chloral hydrate, $2 \frac{1}{2}-5$ gr., may be added. Fright usually upsets digestion, gastric and intestinal, and indigestion of either kind excites night-terrors. When it can be ascertained that chronic fear and dread complete the vicious circle, bromides, besides wholesome consolation, suitable diet, and drugs which aid digestion and elimination, are needed. Bromides may be combined with bismuth, = gentian, rhubarb, castor-oil emulsion, in gastro-intestinal troubles; with ferri et ammonii cit. in anaemia; with strophanthus, digitalis, citrate of caffeine, when cardiac stimulants are required ; or with nux vomica and hypophosphites in emulsion of cod-liver oil in debility. In rheumatic cases, salicylate of quinine is a valuable drug. Quinine as a rule is not well borne by highly neurotic children; when given, it should be with hydrobromic acid.

In cases of mucous diarrhœa, citrate of potash often acts well, and is also useful when night terrors are associated with enuresis and the presence of concentrated, highly acid urine.

Somnambulism is often associated with night terrors but may occur independently as a habit in children upwards of five or six years of age. Sleep-walking in any case is indicative of an overwrought brain. It occurs in epileptics, and in their families, but there is no necessary relationship between somnambulism and epilepsy. It is proverbial. 
that sleep-walkers rarely come to any harm unless suddenly awakened. They are more apt to alarm others than themselves.

Sleep-walking may best be prevented by wearing a belt at night fastened at the back, and having a ring attached through which a bandage should be passed and tied beneath the bed.

The bandage should not be tight enough to restrict movements in bed nor loose enough to allow excursions outside. 


\section{CHAPTER IX}

\section{MORAL FAILINGS OF NEUROTIC CHILDREN}

"Puer robustus malus," is an old saying and formerly, as stated elsewhere, disciplinarians dealt with children who were unruly, passionate, dishonest, untruthful, cruel, spiteful, and otherwise immoral, but now medical men are often called upon to decide whether such children are morbid or vicious. At present the tendency is to regard bad conduct as evidence of ill health, and it is true that after exhausting illnesses such as enteric fever, pneumonia, scarlatina, diphtheria, rheumatism and chorea, nervous children who have been well brought up and well behaved hitherto often seem to lose moral control and give great anxiety by their provoking delinquencies. But in the majority, health and moral sense under judicious management are re-established in time.

Moral lapses are again not uncommon at the age of puberty and may be simply signs of nervous instability not to be regarded too seriously.

In all cases we have to consider mitigating circumstances -the age, ancestry, and environment of the child, the nature of the alleged acts of immorality, and the child himself. A child of three has little or no moral sense; it is purely selfish. At six it should show some consideration for others. At eight it should have definite notions of what is right and wrong.

The importance of a bad family history of neuroses such as hysteria, epilepsy, alcoholism, and insanity, can hardly be over-estimated in a case of persistent and gross mis- 
conduct in any direction occurring in a child aged upwards of eight, whatcver its upbringing and surroundings may be.

Environment.-We have to bear in mind the effects upon a child of parents or guardians who are stupid and narrow-minded, intellectual but highly strung and emotional, careless and unobservant, or over-anxious, well-meaning, and fussy. Some parents are too sympathetic, some not sympathetic enough; some belong to "Parents" Unions" and seek a warranted system of management, others think the system which suited them must be good enough for their children; some are too indulgent, some are too harsh. In any case, we may find a clue to children's ill-health, or bad behaviour, in the character of their parents, nurses, teachers, and companions. Needless to say, discretion and tact are necessary in following up the clue in the interests of the child. A neurotic child may be one of a family whose other members are as like to each other and as commonplace as a set of plain jugs. The exception may be as Sévres or Dresden in comparison, but regarded by his family as simply flawed; misunderstood from the first; checked, reproved, and punished until goaded by despair of regenerationfor neurotic children are often extremely remorseful for their misdoings-he rebels, commits some really flagrant offence and is branded as wholly vicious. Sometimes the outbreak may be occasioned by boredom, monotony, and want of sympathy. Most schoolmasters are familiar with the sullen child who is tractable enough for half the term, and then suddenly defies all attempts at discipline.

Some years ago, a girl aged fourteen was brought to hospital for the following reasons:-She had been discharged in disgrace that morning from her situation as nursemaid in some petty tradesman's family for having slapped the baby's face and bruised its cheek. She was also accused of having maliciously pricked it with a pin. Her father had intended to beat her severely, but 
being a just man he sent her to hospital first to inquire whether she was "right in her head." There was nothing wrong with her head, but a look of entreaty in her eye induced a search for extenuating circumstances, although, on general principles, nurse-girls who slap babies and run pins into them should not be encouraged. On inquiry it appeared that she had been removed from school, where her conduct had always been good, and progress satisfactory, and sent to this situation against her will. She did not like babies, probably from having seen too many of them at home, but preferred dressmaking. Discontent with her position as household drudge seemed to have caused her revolt, for which she appeared penitent. So, small doses of bromides and a situation to her liking were prescribed instead of punishment. It was satisfactory to learn some months later that she had given no further anxiety with regard to the state of her mind, and was doing well in a situation which was no longer that of a nursemaid.

A schoolboy, aged twelve, of highly neurotic antecedents, after having several fits, apparently epileptic, in term time, suddenly took an inveterate dislike to school, although previously he had worked well there, and had been tractable and well behaved. He soon became utterly lawless, lied and stole, and made a furious attack on a brother for no reason that could be ascertained. He spent most of the day under his bed, only creeping out at mealtimes, when he would snatch food off the table and return with it to his bedroom refusing to sit down or have any intercourse with his family. His conduct went from bad to worse, punishment and persuasion were useless, and the fits became frequent. I shared his family's belief that he was insane. However, after some weeks, the School Board regulations were disregarded, and the boy was sent to work at a tobacco factory with an elder brother, as an experiment. This succeeded perfectly; his behaviour became model at once, except for occasional passing moods of obstinacy and self-will, 


\section{MORAL FAILINGS OF NEUROTIC CHILDREN 89}

and he had no more fits till three years later, when one occurred after exposure to the sun during a heat wave. He has had none now for six years, and is doing well in business.

Highly strung, emotional parents, as well as dull and narrowminded ones, are morbidly distressed by their children's delinquencies. The former because being well up in doctrines of heredity they regard their naughty children as discreditable reflections upon themselves; the latter because they cannot conceive why a child after being taught the Catechism and whipped for telling lies fails to become effulgent of morality.

Neurotic mothers may learn to dislike their neurotic children as a standing reproach to themselves. Dislike leads to severity, for which the parent is not altogether responsible. Sometimes refined and educated women are prosecuted for ill-using one of their children, although they are known to lavish all fondness and affection on the rest. The parent in such cases is usually as neurotic as her child, and is quite as much in need of treatment, though not in the Criminal Law Court.

Bromides are good for all neurotic children, but in some cases they act better still when given to the parent.

Cruelty.-Kindness to animals has only recently been raised to the dignity of a virtue. In former generations it was only inculcated as a matter of policy. One's own parents and grandparents learnt from Mrs. Turner's Cautionary Stories, that if they saved puppies from being drowned, the puppies, when grown up, might possibly return the compliment; whilst if " they loved to plague and fret every animal they met," they might meet with disasters, "like Jack, who got a fractured skull from bellowing at a furious bull."

Cruelty seems to have been a venial offence compared with untruthfulness. One of Mrs. Turner's poems is headed "Falsehood Corrected," and relates that "When Jacky drowned our poor cat Tib, he told a very naughty fib, and 
said he had not drowned her." ... "His parents being very sad to find they had a boy so bad, to say what was not true, determined to correct him," etc. Obviously, drowning the cat did not count.

Although children, presumably, are taught to be kind to animals from higher motives now, they must often be puzzled by inconsistencies between precept and practice which they observe. An intelligent child will want to know why he may not smash a blue-bottle on the window pane whilst his elder brother is allowed to poison butterflies in a "stink pot" and transfix them with pins on a cork. Or why it is cruel to make a worm wriggle by treading upon it, but not cruel, and even meritorious, to impale it neatly on a fish-hook. Why should his father boast of the bag he has made at a battue, whilst if he himself catapults a robin his mother's indignation is such that the very egret plumes quiver in her hat? If unsolicited litters of kittens are sentenced to be drowned, why should not the office be assigned to him ? Why is it cruel to pelt ducks in a pond with stones, but not cruel to worry rats in a barn with a terrier?

In all cases of alleged cruelty in children, the above considerations should be borne in mind, and also the child's age, upbringing and surroundings. Cruelty in children is not always evidence of morbid neurosis, unless it is persistent, ingenious and obviously induced by sheer delight in inflicting and witnessing pain. The child of three or four who throws a kitten into the fire is not necessarily a youthful Nero. On the other hand, the child of ten who deliberately casts an aged pet dog down the well of a staircase, and laughs at its pain, or the child described by Dr. Still as being found smothered in blood and amusing himself by cutting up a live rabbit with scissors, bids fair to become a candidate for a criminal lunatic asylum.

A German prince was recently acquitted of a charge of atrocious murder on the ground of insanity. Evidence was given that as a boy he delighted in destroying the 


\section{MORAL FAILINGS OF NEUROTIC CHILDREN 91}

eyes of live fish with a stick, and in cutting off the feet of cats and setting dogs upon them. Once he hung a badger up by its hind legs for two days, then gagged and baited it with dogs. Such acts of fiendish cruelty in children seem to indicate precocious and abnormal sexual impulse, or psychopathia sexualis, which may end in "Sadism."

Children will not necessarily learn to be kind by being taught that many people are cruel. Not long ago a lady visited a certain children's hospital, and distributed to the little patients leaflets which informed them that some doctors are wicked and cruel men who delight in tormenting dumb animals. The children were instructed to preserve these leaflets and keep them clean for the edification of their parents when they were sent home cured of their complaints.

The well-known and well-worn woodcuts of disembowelled rabbits on racks which embellish anti-vivisectional literature may produce undesigned and undesired effects on youthful neurasthenics, by inspiring them with pious hopes that if they are good, they may, when grown up, be permitted to become physiologists. Neurotic subjects are fascinated by thoughts of pain and torture, and in some the sight of suffering begets desire to cause it, in others an equally cruel desire to avenge it. A cruel child may turn out either a ruffian or a reformer burning with indignant zeal and desire to persecute all transgressors.

Neurotic children should not be brought up in the idea that all the world is cruel. Nor should class prejudice be fostered by the teaching that bearing reins are always too tight, that seals and birds are invariably skinned and plucked alive. After all, "Hearts just as pure and fair may beat in Belgrave Square as in the purer air of Seven Dials."

Passion and Screaming Fits.-Fits of violent temper and fury are common enough in emotional children and often call for medical advice. "Good babies who never cry," are seldom healthy. The lusty normal infant will 
squall with rage in order to cxpress its desires and resentments. It is only when such ebullitions of passion occur in children at the age when some amount of self-control might be expected, that fits of temper are abnormal or morbid. Such absence of self-control may be due to injudicious management, and habitual indulgence; or as the result of chronic repression and rankling slights and grievances. Frequently, passionateness is an indication of nervous instability resulting from severe illness. More rarely it may precede epilepsy.

Children vary greatly in their capacity for feeling emotions and also in the degree of self-control to which they attain.

One cannot expect a child to exercise any control over its passions unless it is inspired by the force of example.

Not long ago a lady brought a perfectly healthy-looking little boy aged five, who suffered from incontinence of urine, to see me. On attempting to make his acquaintance the child screamed with rage, hit furiously at my face, and executed a kind of war dance in the corner. When I ventured a mild remonstrance, his mother flew into a passion hardly less violent than her child's, and told me roundly that if I had known anything about my profession I should have seen at a glance that it was not temper but uric acid which was flooding her poor little boy's system.

Petty ailments even when regarded as evidence of gouty inheritance are no excuse for indulging a vile temper.

On the other hand, the policy of continuous repression of emotional display, as practised by Mrs. Wesley who prided herself on having taught her baby to " cry quietly," is not altogether commendable.

As applied to adults we all know the line: "She must weep or she must die," yet the relief afforded by a good cry to the pent-up feelings of a little child is often ignored.

The " nurse of ninety years" would probably regard the child's display of emotion merely as an indication for corporal punishment. 


\section{MORAL FAILINGS OF NEUROTIC CHILDREN 93}

But fits of passion and hysterical weeping in young children are often the culmination of a long course of selfrepression under petty provocations, and this is apt to occur in nervous children during convalescence after illness.

Overbearing sisters and brothers, who call them "names they disapprove of," may be a source of endless irritation to their sensitive juniors.

Nicknames should be avoided in the family circle, especially in the case of neurotic children who often possess a strong sense of dignity and self-respect. Even a pet name bestowed in early infancy is strongly resented by a child who regards itself as no longer a baby, whilst a nickname suggesting some personal peculiarity of habit, manners or appearance is regarded as the grossest insult.

It is dangerous also to joke with children unless one knows them well and is acquainted with the style of humour which appeals to them. Thackeray says somewhere"The facetiae of a dull man are mostly cruel." The ponderous chaff of well-meaning but stupid grown-ups seldom amuses sensitive children.

A shy child hates being badgered by ridiculous questions and having its answers met with loud indulgent laughter. At best it deems the questioner a fool, at worst it thinks itself one.

Few things provoke an emotional child more than drawing attention in public to its faults, particularly when, as often is the case, it has tried its best to overcome them. The following case is in point : A mother was showing to her boys, aged seven and twelve, a well-known picture of an angel bending over a sleeping child. The mother drew attention to a resemblance between the child in the picture and her younger boy who received the compliment complacently. But the elder brother remarked maliciously: "The angel is looking to see if he has washed behind his ears." In an instant the younger boy was at him tooth and nail, scratching and fighting, howling and spluttering with rage, nor could he be pacified until passion had exhausted 
him. The exciting cause of this and other similar fits of uncontrollable passion seems absurd enough. But the boy had been left unduly sensitive by a severe attack of dysentery which had also been followed by various habit spasms. He recovered eventually, but for a long time his ungovernable temper caused considerable anxiety as to his future.

Fits of crying for no apparent reason are very common in neurotic children. It is very unwise to press them for the cause of their tears, they are usually quite aware that it is trivial and inadequate, and are heartily ashamed of themselves for giving way. If pressed for a reason they will often give a wrong one rather than be dubbed "cry baby" and thereby lead themselves into further troubles.

Allusion has been made elsewhere to the curious attacks of maniacal screaming which are not uncommon in children at about three years of age. They may in some cases be due to "day terrors," and sometimes are associated with constipation from atony of the bowels. They are not fits of temper.

The following is an example.

Late one night, a mother arrived at hospital bearing a little girl aged three whose piercing screams were audible long before she reached the gates. The child was struggling violently, she had scratched her mother's face, torn down her hair, and created havoc in her bonnet. She was flushed in face and the pupils were widely dilated, no tears were shed, but for some minutes she continued to shriek and struggle, and appeared quite unconscious of her surroundings. Suddenly she became quiet, looked dazed and pale and trembled, then regained her senses, drank some water and spoke intelligently. The mother who at first was too agitated to do more than ejaculate: "The child's out of her mind. Do something for her!" then explained that the child moped and had been dull and silent during the day. When her father, of whom she was very fond, came home, she seemed not to recognize him and when he spoke to her, she had suddenly commenced to scream. No pre- 


\section{MORAL FAILINGS OF NEUROTIC CHILDREN 95}

vious attack of the kind had occurred, and the child had always been considered healthy in every way, docile and good-tempered. She was, however, much constipated, and under treatment of castor oil and bromides no similar attacks ensued during the few weeks she remained under observation.

Infant Murderers. - Not a few instances of murder by children have been recorded within recent years.

At New York, in 1904, a child aged two and a half who became jealous of his baby sister aged one month, being left alone with her, seized a bronze statuette and battered in her face, causing fracture of the skull and immediate death. He showed no remorse, but afterwards expressed his gladness that the baby had gone.

The Bonhomme Normand, August 26, 1904, contains an account of a little girl aged two who got a large knife and with it cut the throat of her baby brother aged four months.

The Petit Parisien, in the same year reported a case of a boy aged nine who lured a girl of six to the river and deliberately pushed her in. She was rescued and the boy was confined to his room for three or four days as a punishment. $\mathrm{He}$ escaped at the first opportunity and did precisely the same thing with a baby girl aged three, being seen from a distance gloating over his drowning victim and repulsing her feeble attempts to regain the bank.*

In yet another case the corpse of a girl aged six was found at Le Havre and at the inquest it was proved that a boy aged eight had enticed her to the digue and pushed her into the sea.

These cases fall into two distinct groups. In the first two, the motive was presumably jealousy, and one may doubt whether any underlying pathological factor need be invoked to account for them.

It may be observed, however, that the act of cutting a baby's throat with a knife, implies more premeditation and

* British Journal of Children's Diseases, Nov., 1904, p. 510. 
more knowledge of the result to be gained than the act of striking the victim with any handy object. One may assume, therefore, that the French girl was more precociously wicked than the American boy. Children of the age of two will often strike and attempt to injure others, but are seldom acquainted with the use of a knife for this purpose.

The new baby is often regarded as a supplanter by the child accustomed to regard itself as the sole recipient of petting and affection. Unrequited affection may be as galling to the child as to the adult, and if the natural instinct of jealousy be regarded as evidence of vicious disposition unworthy of sympathy in a child, the seeds of spite, gloom, moroseness and discontent may be sown, with lasting ill-results on health and happiness. Fortunately the more tragic consequences of an infant's jealousy are rare. It is only to be wondered that they do not occur more frequently.

The second class of cases is of far graver significance and yet more difficult to understand, except on the assumption that such cases indicate true moral insanity. As moral imbeciles such children must be secluded from society. Yet one cannot deprecate too strongly the tendency which prevails in certain quarters to regard all children who are spiteful, passionate, and cruel, as destined for our criminal lunatic asylums.

Children whom slight provocations goad to fury, may be regarded as potential murderers and irresponsible decadents by persons versed in Lombroso's and Naudau's dicta, and skilled in detecting modern "devil's marks." Yet, neurotic instability and not inherent vice may account for their misconduct. Moral imbeciles exist and must be protected for their own and for the public's sake. But care should be exercised that the decision whether children are such moral imbeciles should not be left to extremists predisposed to regard all children-except their own-as possible degenerates.

Dishonesty.-Offences against property being con- 


\section{MORAL FAILINGS OF NEUROTIC CHILDREN 97}

sidered more serious than those against persons, cases of theft by children are more often brought under our notioe than of other forms of immorality. A child who steals sugar or sweets need not be regarded as a saccharomaniac, nor is he so culpable as one who steals money in order to buy them. Some children will annex what they regard as unconsidered trifles merely to enjoy the pride of possession, although they would not dream of taking money or anything which they consider really valuable. They are horrified when told they have been guilty of theft, and will suspect long afterwards that they are wanted by every policeman they meet in the street. The most curious instances of dishonesty are those in which children will steal money, not to spend upon themselves, but to give away, or to buy presents for others. In some cases the habit arises from a hysterical desire to gain affection. Thus a girl of fourteen would spend all her pocket money on buying presents not only for her own family, but for people with whom she was only slightly acquainted. When her money was spent she would pester her parents for more, and if not gratified would steal it even from the servants in order to satisfy her altruistic tendencies. She would admit the thefts at once when taxed with them, but seemed to think that the end justified the means. She would also order bouquets and expensive articles from the shops to be sent to comparative strangers, to whom she would write effusive letters begging to be invited to stay with them. Subsequently she went through the opposite phase of hysterical melancholia and moroseness, but eventually she made a complete recovery.

Eden Phillpotts, in his humorous and life-like studies of the "Human boy," tells a story, which I believe is based on fact, of a schoolboy, aged twelve, who stole large sums of money from his schoolfellows in order to support an indigent charwoman and her family, on the principle that "Charity covereth a multitude of sins," including breakage of the eighth commandment. 
The key to the boy's neurotic temperament is ingeniously given in an earlier story in which he appears as the possessor of a piebald rat, which he regards as a familiar spirit sent to help him in gaining a scriptural prize.

Such cases come under the heading described as the unrestrained emotional type, in which impulses which may be moral in themselves are not controlled by a sense of proportion between them and the means by which they take effect.

Untruthfulness.-It should be remembered that one lie does not make a liar. Timidity is often the cause of apparent untruthfulness. Some nervous children have been so impressed by the virtue of truth that they live in constant fear of telling a lie. And so, when the opportunity arrives, they lose their heads and blurt out "no" when they mean "yes." Others appear to lie from absentmindedness or because the question put to them does not admit of a direct answer, although they are too frightened to say so and therefore seem to prevaricate.

I mention these simple facts because I know that a child may suffer cruelly from the feeling that its word will not be believed. Neurotic children are ready enough to brood over imaginary grievances and slights, and their misery may be increased tenfold when the grievances are genuine. Romance-weaving is common in all imaginative children who have not learnt to distinguish between the truths of allegory and fact. Sometimes it is due to vanity or desire to create an impression. Darwin says that as a child he was cured of this habit by having his most startling narratives received with chilling silence. Sometimes little children believe implicitly in their own inventions which may in some cases be inspired by vivid dreams. Thus a bright intelligent boy of five seemed firmly convinced that he possessed a hansom cab and horse. He would take his friends down the mews, knock at a stable door and ask for his cab, and become much annoyed when told in jest that it had gone out. He would worry because he said he should 


\section{MORAL FAILINGS OF NEUROTIC CHILDREN 99}

not get fares unless supplied with a man's collar and tie. On one occasion he told his parents untruly that a boy had been killed by a motor car just outside their door. In other respects he was well behaved. He had always been a nervous excitable child and was subject to various kinds of "habit spasms."

Romance-weaving, however, may, even in young children, be due to hallucinations and delusions, and may be a sign of impending illness, such as meningitis, or follow in the wake of fevers. I remember a schoolfellow more than thirty years ago-a nervous, delicate, stammering boywho had an amusing gift of improvising humorous dramas by aid of a pen-wiper and the knotted corner of a handkerchief. He was a day boarder, and one morning he arrived at school full of a thrilling and circumstantial account of a burglary which he said had taken place at his father's house overnight. His father, he stated, had shot two of the burglars dead on the lawn. The story soon reached the ears of the headmaster, who was much impressed, and went off at once to pay a visit of condolence to the boy's father. He soon returned in a towering rage at finding the story was pure invention. His address on the fate of liars was so impressive that many small boys were prepared to see this youthful Ananias consumed in fire and brimstone on the spot. He was, however, only " removed by request" from the school. Some weeks later the headmaster announced that the unfortunate boy was dying or dead, I forget which, of so-called "brain fever," and expressed regret at having dealt hardly with him. No doubt the boy laboured under delusions.

Dr. Francis Warner mentions a boy who went to school looking distressed and said he must return home as his baby brother was dead. He had no baby brother. This child often had illusions and saw what existed only in his imagination ; he soon after became subject to epileptic fits.*

Some time since I saw in a weekly paper an account of 


\section{FUNCTIONAL NERVOUS DISORDERS}

two little children who came home from school with a graphic story of a funeral which they said they had seen at a neighbouring church. No such funeral had taken place, so the children were punished for telling lies. A week later both were dead of scarlatina. The story was related as an instance of second sight, but obviously the children were in the invasion stage of the fever and were subjects of collective hallucination.

Delusional Insanity Following Enteric Fever.-A boy aged eleven, after recovering from enteric fever, went to the police-station and said that all his family had been asphyxiated by coal gas. When I saw him he was full of suspicion and pregnant hints of something wrong at home. I asked him what he complained of, and he said, "Well, there's the cat, it goes about sniffing like this" (here he imitated the cat); "then there's a loose board in the kitchen floor and a heap of old bricks in the yard. That's not right, anyhow." He obviously believed that he and his family were exposed to dangerous conspiracies. In a few weeks he recovered entirely. It is usually easy by a little cross-examination to discover whether children are victims to delusions and hallucinations or not, for children are rarely consummate actors.

Suicide.-Jerome Cardan relates in his De Vitâa propriâ (ed. 1643, p. 31 ) that as a boy of seven he contemplated suicide when in the heroic vein. He adds that he suspects others of similar thoughts, though those who write do not refer to them in their books.

The impulse to self-destruction in neurotic children is probably far more frequent than is generally supposed. It may arise from melancholy and physical pain, as in Cardan's case, or from the sense of banality and boredom of existence, or from curiosity as to the mysteries of death. But more frequently, I believe, it proceeds from a feeling of being unappreciated.

I have heard a little boy of four cry in the bitterness of his sorrow when chidden for some fault: "I'll tumble head 


\section{MORAL FAILINGS OF NEUROTIC CHILDREN 101}

first out of the window, I will !" No doubt he saw no other way of convincing the community of the importance of his small personality at the time, but proper arguments induced him to reconsider his alarming resolution.

Neurotic children are as a rule too timid to make a deliberate attempt to destroy their lives, but they are quite capable, when in disgrace, of endeavours to make themselves ill as a penance or in order to excite sympathy. For instance, to lie on the floor on a winter's night until the cold overcomes their fortitude, and they creep back to bed, though not to sleep, for thoughts of the misery of the morrow.

Sometimes mere curiosity to see how it feels may lead to apparent attempts at suicide. A boy of nine was said to have attempted to hang himself, but I found on questioning his parent that, having been warned against the danger of putting his head in a round towel, he promptly did so, swung himself round, and nearly succeeded in strangling himself.

I have only met with one case in which a boy of fourteen made a determined attempt to throw himself out of window. But it is a sad fact that instances of child-suicide seem to be increasing of late years. It is said that in Germany suicides among children are by no means rare. In September of the present year, 1906, a schoolboy of Hamburg, aged thirteen years and two months, committed suicide because after the summer holidays he was not moved from his former class into a higher class. He hanged himself from a peg on the wall of his bedroom.

According to statistics given by a Frankfort newspaper, no fewer than fifty-six boys under sixteen years of age have committed suicide since the beginning of the present year. In the majority of cases the cause of suicide was connected in some way with the lads' school studies, so that there appears to be no doubt that overwork was in most cases primarily responsible for the loss of these young lives. Saenger * mentions the significant fact that such suicides occur chiefly in schools for backward children.

* Neurasthenie bei Kinder. 
"Complaints are general among German parents that the course of study in all the German State schools is far too exhausting for the boys. They are overloaded with theoretical knowledge, without being adequately trained for the practical necessities of life. And to make matters worse, there is a criminal neglect of healthy outdoor exercises. The result is that the products of German schools are not so well equipped to fight the battle of life as English boys, who have received a far inferior theoretical education." *

Limitation of Development of Moral Consciousness. -After making due allowance for possible exaggeration of supposed immorality in children, there are yet cases in which, no doubt, moral offences are due to congenital failure in development of moral consciousness or to more or less sudden loss of the faculty already developed.

In some cases normal development of the moral sense seems to be arrested by congenital cerebral lesion or by disease in early infancy, such as birth-palsy, or infantile paralysis or hemiplegia. But even in these we must remember that the moral training of such children is apt to be deficient. The family cripple is often the family pet, and may be spoilt and indulged in every whim to such an extent that the necessity for exercising moral control has never dawned upon him. On the other hand, the lesion producing deformity may have been far more widely spread than is indicated by the extent of the paralysis of the limbs, and may have affected the higher centres, in which, presumably, the capacity for moral control is generated. From time immemorial dwarfs and misshapen persons have been credited with spiteful and malicious instincts. But their unfortunate physical condition and up-bringing may explain their moral failings. Their innate capacity for moral development need not necessarily be limited.

In the Middle Ages, uncanny, ill-conditioned, black-haired, neurotic children were regarded as devil's changelings, or " Kill crops," and Martin Luther could only suggest, when

* From a daily paper. 
asked to prescribe for one of these, that it should be drowned in the river Moldau.

True moral imbecility can only be diagnosed after most careful consideration of facts-including reference to ancestry, environment and personality of the child. Moreover it must be proved that acts of immorality are persistent, that they are unprovoked, or occur on the slightest provocation or temptation, that the culprits cannot be brought to realize why their actions are wrong, or that they are wrong at all. Penitence has to be distinguished from its simulation by fear of punishment.

It is possible to attach too much value to the stigmata of degeneration. Some children show them who cannot be regarded as either mentally or morally deficient, whilst they may be absent in others who are both. They are only presumptive evidence of degeneracy.

There may be considerable brain power behind an undersized and ill-shapen skull, just as a philanthropist may wear the mien of a prize-fighter. Similarly the ungainly attitudes, slouching gait, deficiency in attention and other characteristics exhibited by many children are not necessarily proof of defective intelligence, moral or otherwise. They may be due to want of training, or they may be part of the curious but harmless eccentricities which are noticeable in many estimable and intellectual persons throughout their lives.*

Although apparent limitation of moral sense may be associated with general impairment of intellect, both in the presence and absence of physical disease, there is no constant relationship between impairment of intellect and defective moral sense. In some cases the latter only seems affected, as Dr. Still has pointed out in his interesting Goulstonian Lecture for 1902.

These cases of moral imbecility coupled with mental superiority form the most dangerous class of the community. Plato's method, or perpetual sequestration from society seems to be the only mode of treating them.

$$
\text { * Cf. p. } 128 .
$$


Sexual Information. Medical men are not infrequently asked by anxious parents to prescribe the amount of sexual information which should be given to children and the shape in which it should be conveyed.

Mothers are harrowed in mind by tales of innocence betrayed by ignorance, yet hesitate to open children's eyes lest purity be sullied.

It is assumed of course that children learn nothing but what they are taught, and must therefore be profoundly ignorant of all that pertains to sexual relationship, unless purposely enlightened. This assumption is not always correct. In former times innocence was not a synonym for ignorance. Maidens knew the precise meaning of their designation and openly alluded to it. Indelicacy of expresssion was quite consistent with consummate virtue. Miranda's "No wonder, Sir, but certainly a maid," implied that Mirandas of the period were no unsophisticated damsels, whilst Juliet before the age of fourteen must have acquired an extensive fund of knowledge from her garrulous old nurse and that "merry man" her husband.

Even one hundred years ago, subjects not mentioned in present polite society were probably openly discussed before children.

Sir Walter Scott's little friend Marjorie Fleming at the age of seven wrote in her diary :- "I would rather have a man-dog than a woman-dog because they do not bear like women dogs." Other entries in her diary show that the young lady knew a great deal more than children of her age are nowadays supposed to know. Had she lived in the succeeding generation some of her most quaint observations would never have been recorded.

For then came the era of "prunes and prisms," when prudery passed for refinement, when all reference to our internal structure was connected, as George Eliot said, with " a general sense of secrecy and obscenity;" when it is said that even table legs were shrouded in brown holland.

The age of false delicacy is passing, although we are 
still regarded by the French as a race of prudes and hypocrites. Yet most of us were brought up in it, and the silence which children soon learn to observe, like their elders on matters not usually discussed, is held to proceed from ignorance.

It is without dispute that individuals of both sexes, either from deficient powers of observation in this particular direction or from inability to draw inferences, may reach maturity and yet remain ignorant of the methods of procreation.

Hence the question is not infrequently asked of medical men :-Should set and deliberate instruction be given to children on their mode of origin, on the chance that ignorance on the point may lead them astray, or lest late enlightenment should fill them with loathing and disgust ?

Personally, I see no objection to the use of time-honoured and harmless evasions of awkward inquiries by little inquisitive children as to whence they came. Stories of their origin in a parsley bed or through the offices of a friendly stork are sanctioned by antiquity. If I have a prejudice, it is in favour of the theory that they emerged from the doctor's pocket. It is plausible, seems consistent with circumstances, and moreover it tends to inspire the youthful mind with a respect for our profession, which, alas, wears off too soon in later life.

This applies of course to very young children. Older ones, yet still under the age of puberty, may be trusted to use their powers of observation and of inference without drawing attention directly to the future functions of their reproductive organs.

There can be no objection to instructing children in the mode of reproduction of plants, fish and birds and on the nature of eggs. Indeed such instruction should form part of general education.

An intelligent child (like Marjorie Fleming) will learn all that it needs to know by observation of domestic relationship and its consequences in a rabbit hutch. A judicious 
hint may be given on occasion, that the child's mode of birth resembles in essentials that of the newly arrived kittens. But I think that further information is unnecessary and inadvisable at all events before the age of puberty. Even at that time, unless there is reason to suspect precocity of instinct, details should be avoided. The child should be left to draw inferences rather than have them thrust upon it. So long as sexual instincts are dormant it is a mistake to wake them.

No good purpose can be served by deliberately exciting thoughts and emotions which only too readily become predominant in neurotic children.

It is necessary to forewarn a child against the grossness and impurity of conversation and conduct which it may hear and witness amongst its associates. But explicit details may be harmful. The parting advice given by the Squire to Tom Brown :- "Never listen to, or say things you would not have your mother and sisters hear," can hardly be improved upon.

However, such views are now considered old-fashioned and out of date.

Books are now widely circulated which claim, according to advertisements, to inspire young children with "purity born of knowledge " by " scientific yet simple, plain-spoken yet delicate statements of facts, too often wrapped in silence."

The plain speaking is, I venture to think, more apparent than the delicacy of verbiage. In spite of their strong ethical and religious basis, which may be held to disarm criticism of such books, one cannot but fear that morbid precocity may result from the teaching which they advocate,

The information given is complete as far as it goes, but neccessarily stops short when the crucial point at which further curiosity must be excited is reached.

Curiosity has been excited and yet remains unsatisfied. The purity of childhood-like its " chaste indecency," as Victor Hugo called it-consists in ignorance. Children are 


\section{MORAL FAILINGS OF NEUROTIC CHILDREN 107}

pure minded because they do not think of things impure. If we set them thinking of them, purity may vanish.

Dirty corners are easily established in children's minds When they exist their contents may be forgotten. It is therefore dangerous to stir them up by a kind of moral spring-cleaning which aims at making them appear less filthy than they seemed. I do not think that sexual information is divested of prurient suggestiveness by being clothed in an atmosphere of "sacredness and self-reverence," as averred.

Indeed it is well known that intensely religious and sexual emotions are closely allied.

Neurotic children are often in the highest degree susceptible to both.

Early Loves.-A great deal of harm may possibly be done by teasing children whenever they show indications of being attracted by others of opposite sex. I think the distressing bashfulness, gaucherie and blushing self-consciousness which often beset young men in feminine society may be in some cases traced to badinage on infantile attachments. Romantic episodes of the "Holly Tree Inn " variety are not to be encouraged in every household, but free social intercourse between the sexes should be promoted, under supervision, to a far greater extent than is usual in this country. The American system of co-education of the sexes is certainly preferable to our own.

Nevertheless, it should be remembered that "calf love" is not devoid of danger in highly emotional children.

Berlioz thus describes the effects of his innocent enslavement to his "Estelle" at the age of twelve :-

"The vertigo took me," he wrote, "and never left me from that hour. I hoped nothing. I knew nothingbut my heart was full of a profound pain. I passed entire nights in a state of desolating self-torment. During the day I hid myself in the maize fields, in the farthest corners of my grandfather's orchard, mute and suffering, like a wounded bird. ... My heart panted in an empty Space. 
It seemed as if it must burst-must dissipate itself. All my skin became painful, it burned, I blushed from head to feet, I wanted to scream, to call my .friends, or even strangers, to help, console, guard, defend me, to save me from destruction, to retain the life which I felt escaping to the four winds of heaven. . . .

"One does not dream of death during these crises. The thought of suicide is not even supportable; one does not wish for death, but for life, for a thousand times the life we can ever know ; it is a prodigious aptitude for happiness, exasperated by lying idle, an aptitude only to be satisfied by an immense, a devouring, a furious possession, a possession on a level with the incalculable superabundance of sensibility of which the heart is full." *

Such hysterical transports, in which the heart is filled with "incalculable superabundance of sensibility," may indeed be exceptional, but the possibility that we may meet with them cannot be ignored.

Rousseau, also, if we can believe in his "Confessions," was subject from the age of eight to similar attacks of passionate devotion to his numerous mistresses. We may take for granted that neither he nor Berlioz realized the true import of such frenzies. However harmful in other respects, they were innocent in point of fact, though innocence was solely due to ignorance.

Rousseau explains that a little more effrontery on his part, combined not only with encouragement but instruction from others in certain matters, would have led to still more disastrous consequences than those which befell him.

These instances seem once more to accentuate the perils of giving set instruction on sexual matters to emotional children.

Sexual Aberrations.-Masturbation. It is necessary to be on the watch for bad habits in young children of both sexes, and to check them at once if they are found

* Hector Berlioz et la Société de son Temps, par Julien Tiersot. Paris: Librairie Hachette. 


\section{MORAL FAILINGS OF NEUROTIC CHILDREN 109}

to exist. Small children from the age of two or three years and upwards commonly indulge in manipulations of the sexual organs without giving rise to anything approaching orgasm. Such reprehensible tricks are physically harmless, although detestable from a moral point of view. They are dangerous because they may result in definite masturbation, and because neurotic subjects, who remember practising them in early life, may readily believe that they have thereby ruined themselves body and soul. To these latter cases further allusion will be made.

The minor habit can soon be checked by a watchful mother or nurse. It need not be regarded as a moral offence in little boys, nor as directly deleterious to mind or body. Some consider the habit as akin to thumb-sucking, but, needless to say, there is no analogy between thumb-sucking and true masturbation.

Local irritation-balanitis, for instance-may give rise to the lesser or the graver evil. Sometimes either or both are traceable to an unscrupulous nurse's tuition, or to corruption by older and unchaste children.

Except in cases of idiocy and imbecility, signs of orgasm are rarely seen in little boys. It is otherwise with female infants. In these the practice of "thigh rubbing" is not uncommon at the age of one or two years, or even earlier. The child will cross its thighs and sit rocking to and fro, the breath is held, the face becomes flushed, then pale, perspiration breaks out and considerable exhaustion follows. Local irritation is the usual cause. The nature of the actions is seldom recognized at first in infant girls, and therefore the habit becomes difficult to eradicate. In extreme cases it may be necessary to confine the child in a Phelp's spinal box for a time.

In infant boys the habit in its grosser form can hardly escape detection. It happens far more rarely than in the other sex, and seldom requires treatment by forcible restraint.

When practised openly, frequently, and in spite of cor- 
rection, true masturbation in male infants is almost always in association with imbecility, idiocy, or feeble-mindedness. But it is extremely doubtful whether any of the latter mental affections are directly caused thereby.

In the case of older children it is unwise to excite curiosity by uttering warnings against bad habits, unless they are known to exist, or to suggest that they are practised when they may not be. Evil practices may follow good precepts.

Much mischief may be done by well-meaning schoolmasters and non-medical teachers who think it is their duty to hold up awful pictures of the pathological consequences of self-pollution before shuddering neurotic children who may or may not have been impure.

The pathological information given in certain popular handbooks and "straight talks" is chiefly gleaned from the most pernicious form of quack literature. The details have been grossly and wantonly exaggerated in order to work upon the imaginations of wretched young hypochondriacs and to draw them into the charlatan's net.

The public deserves sympathy in the matter, for the medical profession has, as a rule, been reticent on the subject, because, except in rare instances, the harmfulness of secret vice is moral rather than physical, and therefore it has seemed unnecessary and even reprehensible to seek to palliate it. And so the public has been brought to believe that a host of dreadful nervous ailments, including idiocy, imbecility and insanity, are commonly due to onanism, whereas onanism is often but a symptom of them. Isolated instances scattered sparsely in medical literature have been skilfully compiled and combined to form one loathsome picture in order to terrorize mankind.

Sir James Paget, I believe, has been the only writer who has ventured to extenuate the supposed disastrous results of such vice. Most medical men have followed his example in practice, but have often failed to reassure the tortured minds of those who deem their sins unpardonable.

Sexual neurasthenics are the most miserable creatures on 


\section{MORAL FAILINGS OF NEUROTIC CHILDREN 111}

earth, and any teaching which tends to add to their number should be discountenanced.

It is unwise as well as untrue to tell children indiscriminately that they may be recognized as self-polluters by their hollow eyes and pale cheeks, weariness, aches and pains, tenderness of the spine, moping, dislike for games, reverie, loss of memory, inattention, disinclination to look at one in the face, irritability, and unnatural appetite for pickles and spices.

All these physical signs and symptoms may be those of ordinary neurasthenia. There may not be the slightest justification for attributing them to the cause assigned by amateur experts in psychopathia sexualis.

It is disquieting to think of the misery which may be inflicted upon delicate and sensitive children by some malicious youngster who has been taught to look for signs of moral depravity in his companions. The writer has met with a boy who, after sending a series of frantic letters and telegrams begging his parents to remove him from school, ran away and arrived home in a state of hysterical collapse. It was ascertained that for weeks he had undergone persecution from his school-mates on account of supposed moral delinquencies. There may have been some ground for suspicion in this case, but the boy's mental breakdown was due to abuse heaped upon him by others, not to any which he may possibly have inflicted on himself.

A still sadder instance is that of a youth aged nineteen who was admitted to hospital with classical symptoms of cerebral tumour. After death a glioma was found in the optic thalamus. During his last illness, the callous want of sympathy and ill-concealed contempt shown for him by his relatives were striking, and subsequently it transpired that all the poor lad's symptoms had been attributed to secret self-indulgence.

A child who suffers from habit spasm, or happens to be dreamy, shy and miserable, is not necessarily addicted to secret sins. 
Aristotle said, "He who seeks solitude is either a God or a beast." Reverie does not necessarily proceed from pruriency. A child who mopes is usually miserable. It is not advisable to add to his grief by insulting him. Bashful children may not be able to meet one's eye, though brazen ones can do so.

Great injury may be done to a nervous imaginative boy by the belief that physiological occurrences at puberty are the outcome of disgusting habits.

He will probably bear his grief and remorse in silence, and not be "good at games," which seems to be a modern "shibboleth."

One cannot dispute the good intention of school masters who conduct their schools on the espionage system, disallow cubicles, sew up trousers pockets, insist that boys must always either be working or playing, regard all boyish friendships with suspicion, and the gathering of two or three together as evidence of conspiracy against morals. Yet such systematic and determined campaigns against vice w in schools are not altogether free from objection-especially when supported by frequent public and private admonitions given to all alike on the subject of self-pollution.

Healthy-minded and high-spirited boys resent constant supervision as an insult to their intelligence and degradation to their self-esteem.

Ribald little sinners with a turn for cynicism will by a few humorous comments dissolve most of the effects of ponderous harangues against their vices into laughter.

Thus they may sometimes save the more timorous, impressionable and neurotic of their comrades from serious inward misgivings and false alarms, which otherwise may end in sexual hypochondriasis.

Fortunately, healthy school boys of the ordinary type possess a keen sense of the ridiculous, and are not in the least impressed by exaggerated and extravagant statements which they briefly stigmatize as "jaw." 
So, perhaps, the actual dangers of straight talks are slight except in certain cases.

Yet school masters, parents and guardians would be well advised to confine themselves to the moral, and to ignore the medical side of the question.

Treatment in young children consists in removal of local causes of irritation, and in prevention of the habit. In some cases, bromides may be useful.

In older subjects, as already implied, treatment is rather of the mind than of the body. The ordinary healthy school boy who has been led by curiosity or misled by companions into evil habits, soon abandons them when he finds they unfit him for football. He need only be told that if he continues to abstain he will suffer no ills from past delinquency. But the neurasthenic, who believes that he has ruined himself body and soul by even minor offences, requires much consideration, assurance of recovery, and encouragement to occupy his mind and body in healthy pursuits and recreation. Cold baths, hard bed, early waking and rising, regular exercise, except riding and climbing poles and ropes, plain unstimulating diet, should be enjoined. Quinine with hydrobromic acid, and iron if anæmia is present, are the best drugs to give. The bowels should be regulated, and digestion attended to if impaired. No pains should be spared in endeavouring to convince the patient that his recovery is certain.

The sexual neurasthenics who imagine themselves to be the victims of former self-indulgence are almost invariably in good general health, their manifold complaints are entirely imaginary.

Although onanism is common amongst the inmates of asylums, it is only stated to be the direct cause of insanity in under 2 per cent. of cases, and even this percentage may be too high.* Inveterate and excessive masturbation is

* According to statistics taken from the L.C.C. Asylums Boards during the years 1903-5 $1 \cdot 38$ per cent. of cases were attributed to this cause. 
almost unknown, except in those who show obvious stigmata of degeneracy and feeble mindedness, acquired or of congenital origin.

Ill Effects of Exaggerated Statements on Neurotic CHILDREN.

Teaching on Heredity.-The modern neurotic child labours under disadvantages which its parents were happily spared. It is led by books of the class to which allusion has already been made to take a far more serious view of life than they were wont to do. Life to it is no longer a trivial round, but a task of most appalling magnitude. Children are now taught to attach the utmost gravity and importance to everything they say or think or do, not only on their own account but on account of the far-reaching effect which their words and thoughts and deeds may have on posterity. They are told that they inherit not only the features but the faults of their parents, and that they may transmit the latter and the former; that their moral failings are due to w their mother's neglect to train herself in all good qualities which they would have inherited had she done so.

A kindly child on hearing this may perhaps repress all open criticism, yet at times she cannot but feel saddened when confronted with her parents' obvious frailty. This may lead her to hope that by taking them in hand herself, she may yet effect their reformation. But such hopes are rarely justified. Very good little boys and girls who aspire to the rôle of household reformer succeed better in story books than in actual life.

Unless such ideas in neurotic emotional children are gently checked at once, they may become obsessional and expand until notions of amending the universe in general are prematurely fostered. Such individuals soon attain years not of discretion but of irremediable indiscretion. We can only then unsafely leave them to their own devices, until they have shrieked themselves into conditions demanding a "rest cure." It is then that the medical man's thankless task begins. 


\section{MORAL FAILINGS OF NEUROTIC CHILDREN 115}

Parents who give themselves away by lamenting that "their chance is gone" of giving birth to highly moral infants because in early youth they were not actuated by desire to improve the coming race, may, after all, afflict themselves with needless discomposure. Heredity is a complex resultant of forces. Common experience shows that moral action is an acquired habit and not directly transmissible. The best of good little girls and boys may not hereafter enrich the world with others like them. It is surely unnecessary for parents to depreciate themselves in their children's eyes. To the ordinary child the desire to benefit posterity may not be an all-powerful incentive to be good. But neurotic and emotional children may readily cling to the idea that their lot is to reform our race. Such lofty views may hamper their efficiency in humble spheres of usefulness. When, like Olivia Primrose, they deem themselves "perfectly qualified to make converts," they can no longer be content "to help mother make a gooseberry pie." Nor indeed is it wise to bid them do so, lest " a most abominable pie," such as Lady Jane served to Sir Pitt Crawley, be the consequence.

But such results are trivial compared with the effects on mind which the awful doctrines of heredity may produce in nervous children. The notion that they inherit moral failings from their parents is not conducive to filial piety, but to teach them that physical ill-health and deformity are results of parental folly, vice and indiscretion, is, to say the least of it, disastrous policy. Scorn and contempt for the afflicted and their progenitors may be inspired in those who are physically strong, whilst hypochondriasis with all its miserable self-communings may be set up in those who ail.

The forces of heredity are mysterious, complex and little understood. It is therefore unjust to parents and children alike to exaggerate the scanty knowledge we possess.

"Neither hath this man sinned nor his parents, that he was born blind," is a statement which might be remembered with advantage. 
The tendency to overstate the case against all habits which may be deleterious is a prominent feature in modern moral education.

Teaching on the evils of tobacco.-We all agree that smoking is bad for little boys. It sometimes lessens their appetite and often makes them sick. They spend their pocket-money on cigarettes instead of on sweets, which practice, however, may be more damaging to the sweet-stuff trade than it is to them. It compels them to lurk in dark corners and under damp hedges, which deprives them of light and exercise, or under haystacks, which is dangerous to the stacks. It makes them deceitful because they are bound to lie when charged with the offence, and bold because their school master, who usually reeks of tobacco himself, is unlikely to detect them.

Smoking makes little boys impudent because they chiefly practise it in order to annoy their elders, and in this they succeed because their favourite brands of tobacco are simply intolerable.

All these reasons are good and sufficient to make us abolish smoking by the young if we can, and therefore it seems unnecesssary to add other evil results which are more or less problematical.

For instance, smoking is commonly said to stunt the growth, but evidence on this point is inconclusive. Comparisons between the relative heights, weights and dimensions of athletic undergraduates who do not smoke and those of sedentary bookworms who do, are not proofs that the difference is solely due to smoking or non-smoking.

It is doubtful whether the most inveterate non-smoker can add an inch, much less a cubit, to his stature.

Nor is it true, as taught in certain manuals for the young, that "very many children die of infantile paralysis because the father is a tobacco user."

Very many children do not die of infantile paralysis. The disease is so rarely fatal that even now its exact pathology is undetermined. In any case it is quite certain 


\title{
MORAL FAILINGS OF NEUROTIC CHILDREN 117
}

that tobacco has no share in producing it whether used by the father or by the infant.

But children cannot be expected to know this, and may learn to look upon the parents of the many cripples whom they see as monsters of depravity.

Similarly it is untrue that "General Grant and Emperor Frederic both died with throat difficulty which physicians unite in believing was caused by the use of tobacco."

Physicians are not united in believing that malignant disease of the larynx is solely caused by the use of tobacco.

It seems cruel to desecrate the memory of the dead in children's minds, even in order to enforce a moral principle. It is dangerous to steel the hearts of children and alienate their sympathy by teaching them that sufferers from a terrible disease are victims of unbridled self-indulgence.

Let us admit at once that tobacco smoking in excess is injurious to the eyes, heart, digestion and nervous system. Yet it is not seemly that children should learn :-

How they who use fusees All grow by slow degrees, Brainless as chimpanzees, Meagre as lizards ;

Go mad and beat their wives, Plunge (after shocking lives) Razors and carving knives Into their gizzards !

without being also comforted by Calverley's reflection :-

\author{
Yet know I five or six \\ Smokers who freely mix \\ Still with their neighbours.
}

Children may be out of place in the smoking room, but need not be taught to regard it as a den of vice.

It is assumed that smokers are slaves rather contemptible than pitiable. It is stated that the man who "uses tobacco" when under its influence does not realize that he is tired or ill simply because the nerves that should tell him of 
his fatigue or illness have for the time being become paralyzed."

To most of us who smoke in moderation these effects are unfamiliar; our chief grievance is that if we are ill we cannot smoke at all. The most that we can say in defence of our evil habit is that to some extent it soothes us and facilitates quiet thought. If moderate smokers were more numerous there would be fewer shriekers.

We all agree that young boys should not be allowed to smoke, but how to stop them? I believe it would be best prevented by the boys themselves, at all events in schools. If school masters allowed smoking in moderation (during certain hours, and with some supervision of the quality of tobacco used) as a privilege to boys upwards of sixteen, we may be sure that the favoured ones would jealously guard their privilege from being shared by their juniors.

The curious etiquette and customs which are inexorable laws at schools would render any small boy's life a burden to him if he were guilty of what is known as "cheek." $\mathrm{He}$ " would no more dare to smoke than to wear a stick-up collar or sport a "swagger" cane, before such emblems of virility were his by right inalienable. It is total prohibition which creates the offence.

The climax of absurdity is reached in certain American states where non-smokers have made it a penal offence to be found in possession of even a cigarette paper, although it seems allowable to smoke "long nines" with impunity.

I submit that exaggerated statements as to the results of social evils, and indeed the teaching of any extreme views on moral, religious and political topics are in the highest degree injurious to neurotic and emotional children.

Views on Alcohol.-All are agreed that children in health do not require alcohol, but in illness it may be otherwise. In spite of experiments held triumphantly to prove that alcohol is neither a food nor a stimulant, but is simply a poison, I for one believe that I have seen the moribund restored to life by it. And so I cannot approve of 
teaching children " that alcohol may be banished not only from food and from social parties but also from the medicine chest."

A young lady, enthusiastic in the cause of Temperance, once said to the writer: "If I were ill I'd rather die than take alcohol." It would seem that this is the frame of mind which enthusiastic extremists would induce in children. It is neither healthy nor reasonable. It is readily developed in neurotic children whose fears, imaginations and emotions are swayed by every painful suggestion. A few ugly pictures of post-mortem digestion of the stomach, and grossly inartistic lantern slides representing the horrors, vice and crime produced by drink, may suffice to cause them lasting misery.

Neurotic children should be spared all teaching which tends to inflame their emotional and excitable temperament. For this reason I deprecate the scheme at present on foot for teaching young children throughout the land the so-called physiological effects of alcohol. One fears that no teaching will be countenanced or tolerated by promoters of the movement except that which represents their own biassed views.

The ordinary Tom, Dick and Harry-with whom, however, I am not concerned-will giggle at the ugly pictures and be frankly bored by the awful stories, in spite of being regaled on a plenitude of tea and buns. No further ill effect on them need be anticipated. But it is otherwise with the neurotic. They are only too prone to seize and dwell upon the dark side of human nature, to gloat fascinated over all things that are horrible and repulsive.

Yet it cannot be too strongly urged that all neurotic, high-strung, emotional people, and therefore, par excellence, children who resemble them, should abstain from alcohol. These are the people who are constantly on the verge of brain exhaustion-from the exuberance of their emotions. They may be lost if ever they take stimulants, for having once begun they are unable to refrain.

$M_{\text {any being conscious of their weakness in this respect }}$ 
wisely abstain from alcohol, and would therefore enforce total abstinence on all in general.

Similarly they would lay an embargo on tea and coffee. It is perfectly true that tea or coffee in excess may be almost as injurious as alcohol. People who are in danger of becoming slaves to any form of stimulant are infinitely the better for avoiding it. Yet it must be remembered that the devil which they spy in the bottle or in the teapot is in reality lurking in themselves.

I repeat that alcohol is in the highest degree dangerous to emotional, high-strung, neurotic individuals. Children of this description should never be allowed to have it except in a case of serious and critical illness. Alcohol has no tonic effects, and therefore should not be ordered to brace and strengthen them when weakly.

Hygienic Rewards and Pathological Penalties. -There are in certain circles indications of reaction against scourgings, dark cupboards and bread-and-water treatment which were the lot of our forefathers' naughty children, whether neurotic or otherwise.

In the place of such treatment we find a new system of teaching which offers health as the reward of good conduct, and disease, mental and physical, as the penalty of wrongdoing.

I have already alluded to the most aggravated example of this teaching in the case of sexual aberrations. But the principle is applied more generally for the correction of many faults of children. Here are some instances derived from books in general circulation :-

Effects of Attitude on the Mind and Body.Our grandmothers were taught by means of stocks and back-boards to hold themselves erect, to stand and walk with elegance, and this was called "deportment," a social rather than an ethical grace.

But now, little girls are urged not to stoop or stand on one leg "because of the effects that wrong positions have not only upon body but upon mind." 
They learn that wrong positions will cause them to grow crooked and asymmetrical, with their noses on one side, and one eye more widely opened than the other. They are told that their internal organs will become displaced and crowded, so that the "little room in which the little baby must live hereafter for three-quarters of a year may not develop as it should, or grow out of shape."

These statements are misleading. It may be that the uterus in such cases will become affected, but I see no reason for telling a child so. The information will only add to the unhappiness of those few unfortunates who find their noses awry, their mouths on one side, their cheeks fallen in and one eye larger than the other.

Neurasthenic Deformities.-It is not strictly true that stooping, and standing on one leg, are the sole causes of flat chests, round shoulders, lateral curvatures and such like deformities-nor is it fair to assume that faulty attitudes are simply bad habits.

A child may stand on one leg because he finds rest and relief to weak back muscles by doing so. The spinal curvature which may ensue is the result of the muscular weakness rather than of a reprehensible trick. Similarly flat chests and rounded shoulders depend more on disease than habit-although it must be admitted that these defects will be intensified by habit.

We shall do more good by detecting the weak muscles, giving them rest, and strengthening them by appropriate exercises, than by forcing the unfortunate child to stand at attention when its weak and exhausted muscles require relaxation.

Faulty attitudes are not moral failings.

The healthy, muscular and active child rarely, if ever, needs drilling, unless its movements have been restricted by tight and heavy clothing, and by long and weary confinement during school hours.

Children may stoop because their eyesight is defective, but stooping is not a common cause of defective eyesight. 
Weak backs and weak vision are often associated. Both should be corrected and treated before a child can be expected to sit and stand squarely and erect.

It should not be forgotten that physical exercises fatigue both the mind and body of a weakly subject.

It is quite a mistake to suppose that a child rendered limp and exhausted by mental efforts will be resuscitated by commanding its attention to a new form of drill.

I do not doubt the utility of drills and exercises but it must be remembered that periods of rest are quite as important in weakly neurotic children.

The late Mr. Noble Smith, amongst other excellent observations on Growing Children, their Clothes and Deformities, * drew attention to the production of rounded backs, depressed chests and crooked spines by wearing ill-shaped clothes. He pointed out the ill results of narrow-chested clothes with the same space between the arm-holes back and front, which prevent the child from throwing its shoulders back and its chest forward. He also complained of the ill effect of suspending all clothes by shoulder-straps. I quite agree with him as to the production of deformities in this manner.

* London, Smith, Elder \& Co., 1899. 


\section{CHAPTER X}

\section{MENTAL AND EDUCATIONAL OVERSTRAIN IN CHILDHOOD}

IN considering mental overstrain as the result of educational over-pressure, we must still remember that the effects of emotional excitability cannot be ignored. Quite apart from the actual amount of mental work done, fear of failure may in one case produce overstrain; in another ambition to succeed may lead by easy steps to exhausting emotions such as jealousy, hatred and all uncharitableness, towards competitors; whilst in a third, disappointment at want of success accounts for brain exhaustion. Girls are perhaps more apt than boys to break down under such conditions.

We hear much of the effects of overstrain in school life, but it is equally apt to occur in the nursery. Parents will readily accuse masters and mistresses of overworking children at school; without the faintest suspicion that the preliminaries to a breakdown have been arranged long beforehand at home.

The symptoms of mental overstrain in children probably do not vary greatly from those of adults, whilst the physical signs are also much the same. But in children we may have difficulty in eliciting the mental sensations which adults readily confide. A child, for instance, will not or cannot describe the difficulty he feels in concentrating his attention, in grasping and taking in what he is told or taught. He will not mention the distressing mental confusion, irrelevancy of thought, the sense of general incapacity and inaptitude of which adults complain. The utter weakness and exhaustion, giddiness and dreamy feeling of un- 
reality in surroundings, which result from the slightest attempt to exert the mind and the subsequent excruciating headaches, are all set forth with the utmost fidelity by adults, but with the exception of headache, children do not draw attention to these symptoms. Again, the adult tells us of his unconquerable irritability, his disposition to sudden fits of rage over trifles, his hyper-sensitiveness to noise and sudden sounds, his moods of gloomy depression and forebodings, his nights in which the traffic of his mental trains is that of a railway junction without the sense of underlying order which prevails therein and gives sccurity in the midst of apparent confusion. His vigils, in which he tingles with shame and self-reproach for imaginary defaults and errors, and dreads to meet the simplest duties of the morrow, are part of his tale of woe, but we only know in the case of the child that he is irritable and passionate, or querulous and depressed, that in one school class he is brilliant in flashes, in another he is voted incorrigibly idle, dull, and stupid; that he screams at night, and babbles scraps of Greek and Latin and simple arithmetic by turns.

Does intellectual precocity in itself tend to induce exhaustion? Is the child with five talents more apt to break down than the child with only one?

Idiots Savants.-In connexion with precocious intelligence must be mentioned cases in which curious ability in strictly defined directions is associated with general mental enfeeblement. Thus we may meet a schoolboy who on railway systems is a walking Bradshaw's Guide, but to whom all other avenues of learning seem barred; or one whose mind seems unable to contain anything but a complete and detailed account of all the ocean liners, their tonnage, rate of speed, number of passengers and captains' names.

In some instances, these strange faculties are found in idiots. Thus Dr. Langdon Down has met with some feeble minded children who showed extraordinary aptitude for mental arithmetic. Others possessed an astonishing mem- 
ory for figures, dates and past events. One could recite all the answers in Magnall's Questions without an error, and repeat from memory anything he had read, simply by a process of verbal adhesion. Another knew tune, words, and number of nearly every hymn in Hymns Ancient and Modern. Another could tell the time to a minute at any part of the day, although not understanding the use of a clock face. Others showed extraordinary capacity for music, or such skill in mechanics that hopes of turning it to account were entertained.

Sooner or later it is discovered that these unwonted developments of a solitary faculty are associated with general mental enfeeblement not previously suspected, and end in early decay or possibly in death.

This may account for the prevalent belief that the wise die young.

Intellectual Precocity.- "Immodicis brevis est aetas et rara senectus" is an old saying, and allowing for obvious exaggerations in the records of infantile prodigies, in some instances it seems true. Thus, Christian Heinecken, the learned child of Lübeck, was born in 1721. He had mastered the Old Testament by his first birthday (!), and in another month he had added the New Testament to it. Long before he had reached his third birthday he was familiar with the religious history of the world, and could discuss abstract questions of dogma with marvellous eloquence and learning. He was intimately acquainted with history and geography, ancient and modern, sacred and profane, besides being able to speak French and Latin.

He died at the age of four (Encyclopedia Britannica).

John Philip Baratière was born in the same year as the above. Before he was five he had mastered Latin, French, Dutch, and Greek, and three years later could translate the Hebrew Bible into Latin and French. At thirteen he became M.A. at Halle, and was received into the Royal Academy at Berlin. At nineteen he died.*

* Tissot, "De la Santé des Gens de Lettres." 1769. 
John Evelyn's "most deare child Richard," who died January, 1658, aged five years and three days, "was both in shape and countenance and pregnancy of learning next to a prodigy." Evelyn in his diary gives a most pathetic and interesting account of this little boy's piety and extraordinary acquirements. He attributed his death at the time to the over-zealous treatment of women and maids, who baked him in a cradle near an excessive hot fire in a close room, whilst suffering from quartan ague. But thirty years later he seems to have thought that precocity had a share in causing the child's untimely decease, for in $\mathbf{1 6 8 9}$ he warned Dr. Clench, the father of another learned infant, " not to set his heart too much on this Jewell." *.

Evelyn, sagacious in this as well as in other matters, was quite alive to the dangers of over-pressure in such cases. After mentioning in detail the accomplishments of young Clench, then aged under twelve years, and the searching examination to which Mr. Pepys and he subjected the child, he says that Dr. Clench assured them that "he never impos'd anything to charge his memory by causing him to get things by heart, not even the rules of grammar; but his tutor (who was a Frenchman) read to him first in French then in Latin, that he usually played amongst other boys four or five hours every day, and that he was as earnest at his play as at his study."

I have been unable to trace the further history of this precocious lad. But had he died young, Evelyn would certainly have recorded the fact in his Diary, which he kept up until 1705.

Evelyn mentions another child, William Wotton, who at eleven years of age was looked on as a miracle. He both read and perfectly understood Hebrew, Greek, Latin, Arabic, Syriac, and most modern languages ; disputed in Divinity, Law, and all the sciences ; was skilful in history, both Ecclesiastical and Profane, and in politics. ... "But what was more admirable than his vast memory, was his judgment

* Evelyn's Diary, p. 527, Chandos Classics Ed. 
and invention, he being tried with divers hard questions, which required maturity of thought and experience. . . . He was also dexterous in chronology, antiquities and mathematics."

He took his B.A. degree at Cambridge when twelve years and five months old.

$\mathrm{He}$ died in 1726 at the age of sixty-one without attaining any remarkable distinction beyond a Fellowship at Cambridge and a country living.

A Prodigy of 100 Years Ago.-The Times recently reprinted from its columns of a century ago the following account of the death at Margate, at the age of sixteen, of "Mr. T. P. Oldfield, a youth of most extraordinary genius, and too generally known to suffer an idea of the following account of his life to be discredited":-

"At the age of five years and a half he had a scarlet fever, which brought on him a paralysis of the lower extremities, and debilitated his body for the rest of his life, but his mind presented the finest display of human perfection. Whatever he read he instantly had by heart; his favourite pursuits were the mathematics, philosophy, astronomy, geography, history, and painting, in all of which he had made a great proficiency.

"His favourite authors were Locke and Newton; and his retentive faculties were so strong, that he never forgot a single incident with which he had been once acquainted. He could relate every circumstance of Grecian, Roman, and English History; was master of astronomy, and had pursued it up to all its recent discoveries; had the finest taste for drawing and painting, and would frequently take admirable likenesses of persons who struck him, from memory. He wrote a hand like copper-plate; and at a very early period of his life had made himself master of arithmetic. He was never known to be out of temper; and though he suffered an illness of ten years, which terminated in a dropsy and bursting of a bloodvessel upon the lungs, he was never once known to repine or be impatient. His wit was brilliant 
and refined; and his loss will ever be regretted by those who had the happiness to know him."

With regard to some of these infant prodigies, one is reminded of Uncle Toby's quaint comment upon Mr. Shandy's reference to the precocity of the "learned Lipsius, who composed a work the day he was born."

Longevity of Genius.-Many distinguished men have been "wonder children," but genius does not seem to have shortened their lives.

Lord Bacon 1561-1626, died aged sixty-five, of a chillprobably pneumonia-caused by stuffing a fowl with snow on a very cold day in order to test the effects of freezing in delaying decomposition.

Kant, 1724-1814, enjoyed eighty years of calm and happy existence.

Locke, 1632-1704, although always delicate, lived till he was seventy-two.

Berkeley, 1684-1753, died of sudden heart failure at sixtynine.

Descartes, a "sickly young philosopher" at the age of eight, died of phthisis at fifty-three.

Spinoza, who puzzled learned rabbins and philosophers by his questions at fourteen, succumbed to phthisis in his forty-fifth year.

Many other instances might be mentioned of precocity in early life which did not tend to early decay. Bidder, the celebrated calculating boy, became a distinguished engineer and his length of life was above the average. Tasso was famous at the age of eight and lived till he was fifty.

Lord Macaulay read incessantly from the age of three. At four he was taken to see the Oxford collection, and remembered the whole of the catalogue ever after. At seven he began $A$ Compendium of Universal History, at eight he wrote a Treatise to convert the Natives of Malabar to Christianity. He died of sudden heart failure, aged fifty-nine.

Poets are not long lived as a race, but in most cases their 


\section{MENTAL AND EDUCATIONAL OVERSTRAIN 129}

early deaths have been due to disease, accident or irregularities, and not to mental strain or overwork.

Keats died at twenty-six, but from phthisis contracted probably from his younger brother, whom he nursed till death, not from a "broken heart" for which heartless reviewers were responsible.

Byron expired when he was thirty-six, but of Roman fever, although excesses may have accelerated his end.

Burns died at thirty-seven, chiefly from alcoholism.

Poe at forty from a similar cause.

Coleridge, in spite of being a confirmed morphino-maniac, lived to the age of sixty-two. He became addicted to the drug in order to relieve the pangs of chronic dyspepsia, induced, he believed, by the atrocious food supplied at Christ's Hospital. Charles Lamb bore witness to its execrable character.

Southey, who began to write dramas before he was eight, expired from senile dementia at sixty-nine.

The poet's existence and also that of the philosopher is far less likely to tend to mental overstrain than the musician's. The philosopher's or poet's life is one of contemplative laziness. He instinctively seeks quiet and solitude for inspiration. He will not, and cannot be hurried. He may, it is true, spend weeks or months in polishing his lines until they satisfy his fastidious taste, but his labours are in no sense obligatory.

On the other hand the musician - that is to say the creative musician, not the mere executant-has not only to conceive his ideas but to carry them out with infinite labour and minute attention to the elaborate intricacy of orchestration, and above all he is subject to endless annoyance from performers, managers and patrons. He must occupy himself with sordid business details which are foreign to his nature and most irritating to one of his excitable disposition.

Mozart, Schubert and Mendelssohn all died under the age of forty. But perhaps grinding poverty, slights, insults, 
and disappointment had as much to do with Mozart's and Schubert's early deaths, as the overwork of brilliant intellect. Mendelssohn's death seems to have been accelerated by grief at the loss of his favourite sister. Wagner lived to be seventy, yet his life was one chronic course of neurasthenic misery; one prolonged wail and unavailing protest against the physical prostration which followed mental exertion.

It may be concluded that " wonder children " are no more liable than dullards to die young. Neither the possession nor the exercise of talents of exceptionally high order is necessarily exhausting. Clever children who devour and assimilate knowledge readily and retain it with ease, seldom show signs of mental fatigue. It is absurd to stint their cravings for fear of overburdening them with information. Yet it should be remembered that genius is often one sided and limited to certain fields. Injudicious attempts to brighten dulness in one direction may tarnish brilliancy in another.

Genius of a highly emotional order is not of necessity exhausting to its possessor, but it is in the attempt of great minds to give birth to their own creations-to represent their activity on paper-that they are most frequently brought to nought.

Genius has been defined as an infinite capacity for taking pains. The definition is faulty, for it only applies to genius recognized by the world at large. Many possessed of the highest mental qualities bear little fruit, because the energy spent in forcing it proves too much for them.

The only way to secure the best results of the powers that are in them, is to regulate the hours of irksome drudgery spent "in taking pains."

The case of Richard Wagner is a typical one of a brain exhausted by its own output. His early tendency to brain exhaustion was shown when as a "pale slim little boy" of six he woke his sister in the night by his sudden shouts, lauginter and tears in his sleep. 


\section{MENTAL AND EDUCATIONAL OVERSTRAIN 131}

In schooldays he was subject to attacks of some cutaneous malady preceded by depression, irritability and peevishness which led him to seek solitude. Before he was thirty he had acquired the look of weariness and suffering which never left him. People, he said, often thought him irritable when he was simply ill. His physical ailments were chiefly the cutaneous malady mentioned above, rheumatism and feeble digestion which caused him gnawing torments ; excruciating headaches which he compared to the sensation of knives cutting into the nerves of his brain, and insomnia. With these were fits of unconquerable gloom and depression and uncontrollable weeping, thoughts of suicide, but dread of sudden death, desire to flee away from all men, fear that work which he had in hand would never be completed. At thirty-five he felt himself too old to finish Siegfried.

These and many other mental and physical conditions which are graphically described in Wagner's life and letters, physicians vainly sought to cure by hydro-therapeutic measures, by teetotalism, strictest dieting and probably by innumerable drugs. But Wagner himself rightly attributed them to his " headlong method of working " in fits and starts, with feverish energy. The prose of Tannhäuser was turned into verse and the music composed, or rather written, in a fortnight. The second part of Rheingold was completed in ten days, the whole of Walkürie was finished in four weeks. No wonder that he said, "Rheingold is done, and I am also done for," and again, "Truly, writing is a misery and men like us should not write at all."

In time he was reduced to a condition in which writing even the shortest letter became a torture. He shortened his time to five hours and finally to two hours a day, but it was then too late. He should have realized earlier, as Darwin did, that he was only capable of " taking pains" for brief periods.

Had he done so, he might have spared himself years of abject misery. His genius would have erected a monument even higher than that which now stands. Wagner's condi- 
tion of chronic mental overstrain, with all its symptoms and suffering, has been the lot of many men of genius.

Recently attempts have been made to show that errors of refraction account for all their woes. Astigmatism, no doubt, may have its share but cannot bear the sole responsibility.

The case of Emile Zola illustrates again the penalties which emotional, strenuous and imaginative men of letters have to pay for their exertions. It is doubtful whether the conception of plots, characters and scenes is ever so productive of exhaustion as is the physical effort to give them birth in written words; together with the dread of failure and morbid sensitiveness to criticism which beset neurotic brain workers.

Dr. Toulouse . . . found that the novelist's doubt of himself was excessive and unreasonable. He frequently feared that he might be unable to accomplish his daily task, finish the book he had begun, or conclude the speech he was delivering. At one period, before he could go to bed he had to satisfy a peculiar craving to touch and retouch certain articles of furniture, open and re-open certain drawers. Arithmomania pursued him; he was for ever counting the gas lamps in one or another street, and the number of the houses. $\mathrm{He}$ long believed multiples of three to be of good augury, but later, as he told Goncourt, multiples of seven inspired him with most confidence. Moreover, he was so susceptible to thunder and lightning that whenever a storm burst over Medan all the shutters had to be closed and all the lamps lighted, after which he would bandage his eyes with a handkerchief. Even when there was no storm and he found himself in absolute darkness, he was occasionally troubled by what seemed to be luminous phenomena. A dreadful idea came to him now and then; it was that his heart had moved into his arm or thigh, and that he could feel it beating there. It must be said, too, that he was most sensitive to physical pain and extremely subject to emotion, which brought on attacks of a form of angina, from which he suffered, periodically, over a period of thirty years. The insults levelled at him by unscrupulous journalists, as much with respect to the alleged 


\section{MENTAL AND EDUCATIONAL OVERSTRAIN 133}

obscenity of his writings as to his share in the Dreyfus case, constantly led to such attacks, but his mind being always superior to his body, he never swerved from what he regarded as his duty-the enunciation of inconvenient truths-even though he knew that he would be savagely denounced for it and this ailment would necessarily return.*

Educational overstrain may result from,

(a.) The imposition of heavy tasks on memories which are naturally elusive.

(B.) Enforced concentration on uncongenial subjects.

( $\lambda$.) From exacting practical industry from those who are by nature contemplative, thoughtful and imaginative.

Strain of Memory.-Many clever children, early and without effort, grasp general ideas and principles, but are slow in committing to memory solid dry-as-dust facts, and are quickly forgetful of them. It is the attempt to cram them with arbitrary facts, and also to force them to disgorge them periodically on demand, which causes exhaustion. Facts have been called pegs on which ideas are hung. But if the pegs are driven in too hard, like nails till their heads touch the wall, nothing can be suspended from them.

An enormous amount of time and energy have been wasted in compelling children to learn the multiplication table by heart. Many of us must sympathize with little Marjorie Fleming when she wrote, "I am now going to tell you the trouble and wretched plague that my multiplication gives me. You can't conceive it. The most Devilish Thing is 8 times 8 and 7 times 7 is what Nature itself can't endure."

Some of us, like Leigh Hunt, never succeeded in learning it at all, nor do we know it now. But we vividly recollect the miserable hours spent in vain attempts to master it, and how we cursed the shade of Wightman.

Similarly the old-fashioned method of teaching history and geography by making children learn long lists of dates, and names of capitals and counties, destroys every vestige

* Life of Emile Zola, Ernest Vizetelly, John Lane. 
of interest in the subjects, and is irksome and exhausting to children.

No onc was more strenuous than Charles Dickens in denouncing the principle of "Gradgrinding," which he summed up as follows :- "Teach boys and girls nothing but facts. Facts alone are wanted in Life. Plant nothing else and root out everything else. You can only form the minds of rcasoning animals upon facts; nothing else will ever be of any service to them."*

Fact-cramming not only cramps the intellect and gives no scope for thought, but the child who is overburdened with dull facts may be reduced to a condition of mental chaos, in which, "whether 20 Romuluses make a Remus, or Hic, Haec, Hoc is Troy weight, or a verb always agrees with an Ancient Briton, or three times four are Taurus, a Bull, become open questions." $\dagger$

One is constantly seeing instances of such mental confusion reported in daily papers by school examiners possessed of a sense of humour. Perhaps the mistakes are humorous in their way, yet they are also pathetic as illustrating and suggesting the futility of the mode of teaching which crams but does not educate.

Some memorize best the things which they see, and others those which they hear. Memory in some is purely automatic and effortless, in others its exercise is a strangely laborious process, in which association of ideas, arbitrary and absurd, or logical as the case may be, takes part.

A bad visual memory is often due to deficient powers of observation, and this deficiency may be due to errors of refraction. Necdless to say, attempts to improve powers of observation, by insisting upon the child's using its eyes without correcting the errors of refraction, is the most common cause of prostrating headache, and indirectly may lead to mental overstrain.

Similarly, dulness and inattention owing to partial 


\section{MENTAL AND EDUCATIONAL OVERSTRAIN 135}

deafness due to enlarged tonsils and adenoid vegetations, may disappear when their cause is removed, but if dulness and inattention be treated by blame and punishment, the child's sense of injustice and subsequent exasperation may lead to mental breakdown, not to mention the other physical ill results which arise from neglected adenoid vegetations.

Harriet Martineau speaks of being " gradually borne down in health and spirits by the pressure of her trouble " (deafness), "her springs of pleasure were poisoned, her temper irritated and rendered morose, her intellectual pride puffed up to an insufferable haughtiness, and her conscience brought by perpetual pain of heart into a state of trembling soreness," with many other ill and lasting effects, all of which probably might have been lessened by removal of her adenoids in early life.

The overstrain due to taxing memories which are naturally deficient on the auditive and visual side; without the presence of actual ocular or aural defects, may be lessened by cultivating the practice of association of ideas. Also the use of "Memoria Technica" or artificial aids to memory in the shape of doggerel rhymes or rhythmical nonsense are not to be despised.

Most children are amused by them and learn them with ease. Such lines as :-

Billy Pitt took a cake and a raspberry jam

When he heard they had taken Seringapatam

(Meredith),

convey a considerable amount of easily retained information to a child. Some of us when learning Formal Logic must have blessed the gifted author of the verses beginning "Barbara Celarent," for without them we could never remember the different kinds of syllogisms. So the celebrated lines commencing, "Many nouns in 'is' we find," saved many of us from an inveterate tendency to make false concords.

Variety and Versatility.-The general complaint at 
the present time is that children are taught too many subjects, and that they know nothing accurately but have only a confused smattering of all-as the result of schooling.

The charge is true enough, yet I think a little information on a large number of subjects is better than none.

Most intelligent children seek variety. They devour knowledge indiscriminately but resent specialism. They soon tire of a single subject, and although they may continue to repeat automatically facts which they are taught, they cease to think about them.

The best specialist is always the one who possesses wide although perhaps superficial knowledge of other subjects than his own. General information can always be turned to account, even though its accuracy may be doubtful and need verification.

Unremitting concentration on special subjects may lead to brain exhaustion.

Darwin, whose symptoms resembled those of Wagner, confessed that his brain was not constructed for much thinking, and wisely gave up the attempt to use it in pursuance of his special subjects for more than an hour or so at a time. Had he not done so, much of his invaluable work might never have seen the light.

If a man of Darwin's gigantic intellect found it impossible to concentrate his attention for any lengthy period without fatigue, surely allowance should be made for children who doubtless suffer as he did. Yet bright intelligent children are often expected to concentrate their attention for many hours at a time, and when they fail are regarded as simply lazy.

Instances such as the following are not unknown in public schools.

A clever lad is sent, either to suit his parents' purse, or to gratify their ambition, to a preparatory school with a view to gaining some open scholarship at a public school. $\mathrm{He}$ is carefully crammed in all the subjects necessary, and receives special tuition out of school hours in those in which he appears weak. 


\section{MENTAL AND EDUCATIONAL OVERSTRAIN 137}

At the age of thirteen or fourteen he rejoices his parents' hearts by obtaining the coveted scholarship with high distinction.

For a time all goes well, but in the course of a few terms the school authorities begin to think that they have made a mistake in electing him. For he not only learns no more, but rapidly forgets much that he knew when he came. He is inattentive and even falls asleep in class. He breaks down ignominiously in repetition, and perpetrates blunders in his Latin prose which would disgrace a lower third class boy. $\mathrm{He}$ is in constant disgrace, he is punished and admonished daily by his masters, and receives periodically pathetic remonstrances from his parents on the unsatisfactory nature of the reports which reach them.

At last he is sternly told that the renewal of his scholarship will depend on the manner in which he acquits himself at a forthcoming examination.

This warning seems to spur him to almost superhuman efforts, for he achieves most brilliant success-only to be followed by a period in which his blunders are more gross than ever, and his idleness and dulness seem more exasperating than before.

$\mathrm{He}$ is penitent, and fully admits his laziness with many promises of future industry, for he regards the dull stupor and incapacity for thought which follow any attempt to work, as evidence of idleness which might be overcome by exertion. He thinks that if he pinched himself sufficiently he might be able to keep awake, and that if he got up an hour earlier in the morning his Latin verses might pass muster. But in this he is disappointed.

Except that he grows fast, nothing peculiar is at first noticed about him. He makes no complaint of feeling ill. Even headache may be absent, though its place may be taken by a feeling of tension or of emptiness, with sensation of unreality of his surroundings at times. But "migraine" headache is present as a rule; which is perhaps fortunate, because when severe, even the most unobservant of peda- 
gogues can hardly fail to detect it. In some cases his schoolfellows may notice that he does not answer at times when spoken to, or that he mutters to himself, grinds his teeth and exhibits slight convulsive movements during "preparation."

Sometimes mere drowsiness leads to narcolepsy. He falls asleep in and out of school and may be difficult to rouse. He may miss roll-call, or a meal, and after a hue and cry may be discovered fast asleep in a chair in his bedroom where he has gone merely to fetch something.

Sometimes a dénouement of his morbid condition is afforded by a so-called fainting fit (usually epileptiform in character) which occurs in class or chapel, and leaves him in such obvious mental and physical prostration that it is no longer possible to regard his former sloth and indolence as vicious.

In such cases the only possible treatment consists in removal from school at once, complete mental rest and vegetation in open country air for at least six months.

But such grievous disappointment of hopes and ambitions may sometimes be saved if the symptoms be recognized early and attributed to their real cause.

So, it would seem that in some cases, nervous prostration and brain exhaustion only follow attempts to pursue subjects on which much time and mental energy have already been spent. A public school head-master-wiser I think than many of his generation-gave me an interesting account not long ago of a classical scholar who broke down in the manncr described, but who soon recovered on being excused classics altogether and set to work at mathematics.

I do not suppose that such treatment would suffice in all cases, but it may be useful when exhaustion is produced solely by concentration on a single line of education, whatever that line may have been. And this is particularly the case when such concentration has been on lines laid down by parents and tutors without reference to the pupil's natural aptitude or inaptitude for following them. 


\section{MENTAL AND EDUCATIONAL OVERSTRAIN 139}

It is useless and dangerous to prescribe an exclusively classical, mathematical, scientific or commercial education for all alike.

No school lesson should last for more than forty-five minutes, and an interval of ten minutes to be spent in fresh air and exercise, not drill, should always elapse between each lesson.

Some advocate the abolition of home lessons and insist that preparation should take place in the afternoon and not in the evening. But this necessarily makes the hours by day too long, and shortens those which should be spent in open air by daylight. There can be no objection to home lessons in the evening provided that they are light and the hours spent upon them strictly proportioned to the age and capacity of the child.

The total number of hours of hard mental work should not exceed six daily, and there should be two, if not three, half holidays a week.

I ought no doubt to have dealt with the important bearing which school hygiene and sanitation have in lessening mental overstrain in children. But the subject is

- wide and I can only refer to the paramount necessity of seeing that our schools are well lighted, well ventilated, and well drained; that the children are well fed, well clothed, well exercised, well rested and that medical supervision is systematically exercised.

Summary.-The symptoms and physical signs of mental overstrain in adults and in children are much alikealthough the child seldom draws attention to them.

High intellectual quality does not necessarily lead to mental overstrain.

Educational overstrain is more frequently due to factcramming than to the imparting of general information.

Energy spent in application, or industry, is in itself exhausting in varying degrees.

A child incapable of prolonged mental concentration should not be regarded as culpably lazy. 
Over-taxing the memory is a fruitful source of mental breakdown.

In many cases the memory is weak on account of visual or aural defects.

Attention to the principles of school hygiene is all important in lessening the tendency to mental overstrain. 


\section{CHAPTER XI}

\section{DISORDERS OF THE SYMPATHETIC NERVOUS SYSTEM IN NEUROTIC CHILDREN}

Cardiac palpitation and rapidity, praecordial pain and oppression, dyspnoea, irregularity and quickness of pulse are frequently found in nervous children without evidence of organic heart disease. But repeated careful examination is needed before regarding the conditions as merely functional. Absence of evidence of cardiac enlargement, and of accentuation of the pulmonary second sound; the presence of anaemia, and an excitable emotional disposition, are in favour of functional disorder. As in adults, the symptoms of functional heart complaint are usually more distressing to the patient than those of organic disease. The child himself will often draw attention to the forcible beating of his heart, whereas children suffering from organic heart disease seldom complain of pain unless peri-carditis, or pleuroperi-carditis, or sudden failure of compensation occurs.

Attacks of palpitation and so forth are set up by indigestion, or by emotional disturbance of any kind. Sometimes they have been traced to excessive consumption of tea and cigarettes. An irritable heart is often the consequence of diphtheria, of the exanthemata, or of any acute illness.

Tachycardia may be paroxysmal. Periodic attacks in which the pulse rises to 150 or 200 , or becomes uncountable for several days in succession, may occur. These attacks are sometimes associated with constipation. The 
pulse becomes suddenly of normal frequency after the action of a purge. In some cases tachycardia is persistent; it seems to be an individual peculiarity. The writer has watched a patient whose pulse, on examination, has never been under 120 per minute for ten years. Yet the girl has never seemed to suffer any inconvenience, and no signs of cardiac enlargement have appeared.

Paroxysmal or persistent heart-hurry may, however, be the precursor of Graves' disease, instances of which are not altogether uncommon in children at the age of puberty or even younger.

Disorders of Sympathetic System.-Abnormal pulsation of the carotids or subclavians, or of the abdominal aorta, associated with floating kidneys, hepaptosis or splenoptosis, dilatation of the stomach, abdominal pain, mucous diarrhoea, and cyclical albuminuria, are all evidence of vaso-motor or sympathetic disorder. They may occur as part of true Graves' disease, but in the absence of thyroid enlargement and exophthalmos, one cannot say that they are attributable solely to disorder of the thyroid gland. The sympathetic system is at the mercy of the mind. Terror, fear, anxiety and worry all find part expression in distressing cardiac, respiratory, and abdominal sensations and functional visceral disorder. Long continued or repeated emotional disturbance seems to render the cardiac and splanchnic plexuses hypersensitive not only to cerebral but to local stimuli, and so "weak hearts" and "weak digestions" may be traced primarily to sensitive brains. Eventually it seems that the slightest indiscretion in diet is sufficient to irritate and throw the sympathetic out of gear, and so, timid and gloomy, masterful, impulsive and passionate people fall a prey to chronic dyspepsia and functional heart disease.

Enterospasm.-The existence of local spasm of the intestinal walls as an occasional cause of obscure, acute or chronic abdominal pain and discomfort, with obstinate constipation, sometimes attended by vomiting and signs of 
intestinal obstruction was, until lately, a matter of conjecture. But Dr. H. P. Hawkins, in a valuable paper* has proved by direct inspection of the intestines of patients subjected to laparotomy for the relief of such symptoms, that enterospasm is an established fact.

The spasm may affect any part of the intestine, but is most common in the first and last parts of the colon, namely, in the caecal region and in the sigmoid flexure. Hence a history of enterospasm may closely mimic that of appendicitis. But an attack of local appendicular peritonitis can usually be distinguished from one of appendicular or caecal colic by the absence of fever, and of signs of local inflammation in the latter.

There may be local or uniform tenderness of the abdomen on palpation, but rigidity of the muscles is less marked in enterospasm than in peritonitis, and the abdomen is hollowed or retracted as in meningitis rather than distended.

In one of Dr. Hawkins' cases-a girl aged twelve-the small intestine showed extreme local irritability when exposed to view. The mere handling of it or tapping with a scalpel was sufficient to excite active contractions.

When the sigmoid flexure is affected by enterospasm it may be felt as a hard sausage shaped body in the left iliac fossa.

Constipation is extreme in such cases. The stools consist of small hard marble-like scybala, or they may be pencil shaped.

Pellets of mucus or even membranous casts are not uncommon (mucous colic).

A severe attack may simulate one of intus-susception, but a rectal examination at once makes the diagnosis clear.

Anatomically, enterospasm must be regarded as evidence of exaggerated activity of the motor fibres of the splanchnic and vagus, or of a paralysis of their inhibitory fibres. But the altered nerve function may be not only in the intestine but in the centres governing intestinal innervation in the brain.

" "The reality of enterospasm and its mimicry of Appendicitis". (B.M.J. vol. i., 1906). 


\section{4}

FUNCTIONAL NERVOUS DISORDERS

Without disputing that enterospasm and mucous colic may be due in some cases to serious local mischief, such as dysentery, ulceration, and to metallic poisoning, it is a fact that the great majority of sufferers from these complaints are neurasthenic. Their symptoms are the outcome of an emotional disposition and an irritable and exhaustible nervous system. The analogy between spasmodic asthma. and mucous or membranous colic is mentioned elsewhere. In the treatment of enterospasm, the habitual use of purgatives and of enemata should be discountenanced.

Bromides, belladonna, hyoscyamus, with mild laxatives, and abdominal massage, are most likely to afford relief. But relief is only temporary unless freedom from emotional distress of any kind can be secured.

Splenic Pain of Puberty.-Thin, delicate girls, often at about the age of puberty complain of dull wearying pain in the splenic area. The pain is intensified by exercise, but also occurs during rest. The spleen is sometimes palpable and obviously tender.

The condition is probably due to splenic congestion, and seems to be a vaso-motor neurosis. It is most common in young girls who have not menstruated. As a rule it quickly subsides under rest and tonics.

Flushing, Blushing and Pallor.-Other circulatory disturbances associated with cardiac palpitation are sudden flushing and pallor. In boys and girls in their teens such symptoms of nervousness and awkward self-consciousness are regarded as normal indications of sexual maturity, though they often occasion much mental distress to those who are subject to them.

But in young children they are rightly considered, when pronounced, as morbid. They are not, however, as parents usually suppose, signs of incipient heart disease, but of an emotional temperament. It is not the fact that self-consciousness only arises at puberty. Many neurotic children, even before they can talk plainly, show evident signs of unnatural introspection by blushing, flushing or turning 
pale whenever notice is taken of them, or when they think they are being observed. Such self-consciousness is certainly abnormal and may be a forewarning of future nervous troubles.

Dead Fingers.-Except in cases of Raynaud's disease, which may occur at very early periods of life, " dead fingers" are uncommon before puberty. The digits, even in warm weather, though more frequently in cold, will become suddenly blanched or wax-like with numbness, tingling, and loss of power. Sometimes the condition alternates with migraine or asthmatic seizures, but it often occurs alone. The tendency to the affection is often hereditary; attacks may come on several times in the course of a day, and may last half an hour or so. The vaso-motor constriction which occasions them rarely results in gangrene or Raynaud's disease. They are of interest in suggesting the possible occurrence of similar vaso-motor constriction elsewhere in explanation of obscure conditions such as gastralgia, cardialgia, pseudo-angina, renal colic with haematuria from healthy kidneys, and of many abdominal pains which are regarded as purely hysterical. Many forms of erythema exudativum, urticaria, factitious or otherwise, and erythromelalgia are closely allied to Raynaud's disease, and may bear a similar interpretation. All may be looked upon as vasomotor neuroses, though doubtless toxaemia of some kind with lessened viscosity of the blood may play a part in producing them. Finally migraine and asthma have been attributed to vaso-motor disturbance in spite of the fact that vaso-motor nerves are less apparent in the cerebral and pulmonary vessels than elsewhere.

Treatment of Circulatory Disturbances.-So far as the heart is concerned no special treatment is necessary or useful. Digitalis and such-like remedies have practically no effect on irritable hearts. Any distal cause, such as indigestion, constipation, should be treated, and during an attack of cardiac distress and palpitation, rest in bed, bromide of ammonium with sal volatile, or valerian may be 
prescribed. In the intervals, tonic treatment, careful regulation of diet, study, sleep and exercise, should be adopted. A quiet life with absence of excitement and worry should be enjoined. Stimulants such as tea and coffee, and of course tobacco, should be eschewed.

It is important not to brand a child who suffers from palpitation with having a "weak heart." To parents this always means "heart disease" and the imminence of sudden death. Hence the danger of over care, anxiety and indulgence is especially great in such cases.

The circulatory disturbances caused by shyness, timidity and self-consciousness need moral rather than medical treatment.

The medical treatment of "dead fingers" by vaso-dilators, such as the nitrites, is not of much service. Friction, warmth and exercise soon shorten attacks, and they become less frequent when general health is well established. Cold baths and douches are not to be indiscriminately recommended. They may produce no healthy glow, but extreme dejection and languor, besides blanching the fingers for hours afterwards. The temperature of the bath should not be below blood heat, and the circulation should be promoted after bathing by rubbing the skin through a Turkish towel, and by a few minutes of dumb-bell or other exercises.

Congenital Hypertrophic Stenosis of the Pylorus ; Pyloric Stenosis, and Spasm.-Full discussion of these complaints, to which much attention has been drawn of late, would be out of place here.

The symptoms may occur within a few weeks, or even days, after birth, or they may be delayed for some months. They consist in bouts of vomiting, the contents of the stomach being ejected undigested with considerable force at varying intervals. Sometimes the vomiting occurs within a few hours after every meal, sometimes days or weeks intervene between the attacks. Obstinate constipation is present at first, but in time is replaced by diarrhoea. Extreme and 
progressive emaciation takes place, and death is due to starvation.

The physical signs in the abdomen are the presence of a hard, filbert-shaped tumour in the region of the pylorus, and of peristaltic waves, which may be seen and felt to pass from left to right of the epigastrium. The tumour is most palpable and the peristalsis most visible when the stomach contains food. The condition is due to more or less unavailing attempts of the stomach to force its contents through a firmly contracted and hypertrophied pyloric sphincter.

Post mortem the sphincter muscle is found greatly increased in size, the pyloric channel is stenosed, the stomach may be dilated and its muscular walls hypertrophied. The degree of stenosis found after death is not, however, evidence of its existence to a similar extent during life.

The etiology of congenital hypertrophic stenosis of the pylorus is undecided-some regard hyperplasia of the sphincter as the primary lesion, which increases after birth until mechanical obstruction to the exit of the stomach is produced. Others hold that the sequence of events is - due to inco-ordination of nervous gastric actions. Normally the pylorus relaxes when the gastric detrusors are at work, but here it is held that the pyloric sphincter becomes obstinately contracted when relaxation is required, and in consequence of spasmodic overaction, muscular hypertrophy ensues.

Some insist that hypertrophy cannot be the result of spasmodic contraction because the sphincters do not become hypertrophied in consequence of being in an almost constant state of tonic contraction. But tonic contraction is one thing and spasm is another. All muscles become hypertrophied in consequence of over-action. Spasm is over-action, and therefore there seems to be no reason why repeated spasm should not cause hypertrophy of the pyloric sphincter. At the same time it is difficult to explain congenital hypertrophy of the pyloric sphincter on the theory 
of spasmodic inco-ordination. It has been suggested that pyloric spasm and consequent hypertrophy may be the result of swallowing the liquor amnii in utero, and also that "a sort of intra-uterine developmental neurosis" may be responsible. The theory that pyloric hyperplasia is a freak of nature is not supported by analogous conditions

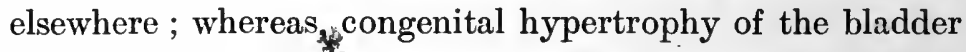
with dilatation of the ureters and hydronephrosis; idiopathic dilatation and hypertrophy of the colon existing in each case without mechanical obstruction to the outlet of the bladder and bowel respectively ; and finally, rare cases of dysphagia in infants apparently dependent upon spasm of the cardiac sphincter may all be explained on the theory of spasmodic inco-ordination (Thomson).

One must admit that congenital cases of pyloric stenosis are hard to understand, but there remains another class of case in which the condition seems to be acquired, and less obscure in origin, namely, purely spasmodic cases.

The symptoms and course are the same as in congenital cases, but occur most frequently in bottle-fed infants some weeks or months after birth.

In these the reasonable inference is that the sphincter is irritated directly by the contents of the stomach, and so becomes spasmodically contracted and in time hypertrophied.

The stomach contents may or may not be highly acid, but further investigations as to the presence in excess of free hydrochloric acid (hyperchlorhydria) are to be desired in all cases.

The complaint, however, resembles the hyperchlorhydria of adults, which is generally regarded as a neurosis chiefly confined to excitable, neurasthenic and melancholic people, who are often highly intellectual and highly educated. It is moreover associated with the "uric acid" diathesis, with various arthritic conditions, and in fact with the neurotic temperament in general.

Hence the spasmodic or acquired variety of pyloric steno- 
sis in children may in some instances be, strictly speaking, one of the neuroses of children and of adults too.

In the case of adults, hyperchlorhydria as a neurosis may be assumed to depend on secretory disturbance of cerebral origin. "Owing to the intimate connexion between the brain and the abdominal sympathetic nervous system it is easy to conceive that irregularities in over-worked or diseased brain centres may be the initial cause of corresponding irregularities in the discharge of nerve energy in, and their conduction to, the gastric mucosa." *

Treatment of Pyloric Stenosis.-In apparently congenital cases, in which the onset of symptoms is within a few weeks of birth, operative measures, such as pyloroplasty or Loreta's operation, are probably the only means of saving life. But operation should not be advised unless the hypertrophied pylorus can be clearly felt, and unless peristalsis is plainly visible, and unless the infant steadily grows worse under a few weeks' treatment by lavage of the stomach and careful fecding.

In acquired cases the results of lavage and skilful dieting are so successful that a patient trial of them, lasting it - may be for several months, should always be made. The surgeon's aid should only be sought as a late resource, though it is needless to say that operations should not be postponed until the infant is moribund.

Headaches.-Apart from those caused by tumours or other forms of gross cerebral or meningeal discase, persistent and recurring headache may be due to local causes such as hypermetropic astigmatism, nasal or naso-pharyngeal obstruction, and catarrh; disease of the middle ear or auditory meatus, and decayed teeth. The chief general causes are bad atmosphere and noisy surroundings at home or school, anaemia, dyspepsia, constipation and rheumatism.

In all cases of headache the above conditions must be looked for and treated if present by appropriate measures. But many headaches are purely of nervous or emotional

* David Sommerville, Polyclinic, Jan., 1907. 
origin. The locality of headache is not of great diagnostic value. Bitemporal or frontal headache is frequently due to astigmatism. Occipital headache may be caused by decayed molars; supra-orbital and frontal headache by disease of the nose or frontal sinuses. But headaches due to other causes may affect any site. Even in migraine the pain is not invariably unilateral.

The headache in migraine is characterized by its excruciating severity and by the physical prostration which accompanies it. In this respect it can only be compared with that which attends cerebral tumour or abscess, and incipient meningitis. The headache proceeding from the other causes mentioned is seldom so severe, but it is more lasting and more frequent than in migraine.

Migraine, again, is distinguished from other forms of headache by the disorders of vision and sensory disturbance which precede it. Macropsia or micropsia, hemianopsia, amblyopia, are common; surrounding objects may look steamy or misty and in movement; dark clouds, flickering lights, "fortification spectra" may be seen. There may be hallucinations of hearing, taste and smell. Numbness and tingling of the fingers, usually on one side, may occur. There may be difficulty in articulation. All these premonitory symptoms may perplex and alarm the child, and as previously mentioned they may give rise to "day" and perhaps to " night terrors" in young children in whom, as a rule, migraine is not suspected.

The prodromata last from a few moments to half an hour and subside as the pain comes on. Sometimes they may occur without subsequent headache. The headache itself usually increases in intensity for several hours until, at its height, the child lies groaning and whimpering, protesting against the slightest sound, hiding his face from the light. He will not speak above a whisper and sometimes not at all, so that he may be supposed to be unconscious. But he never is unconscious, nor does he ever shriek with pain and grate his teeth as when suffering from meningitis. 
The extremities are often cold and the patient may shiver. The pulse is weak and slow, the features are pale and haggard in some, flushed, with congested conjunctivae and throbbing carotids in others. Nausea and refusal of food are common, but vomiting is infrequent.

After persisting for about an hour or two the acute symptoms gradually subside, the patient usually falls asleep and wakes hungry, bright and well. He remains so until recurrence, which may be at weekly or monthly or longer intervals. It is only when frequent that migraine affects general health. Sufferers from migraine are often physically and mentally active. It is certainly a family affection and one of the neuropathic inheritances.

Pathology of Migraine.-The pathology of migraine is unsettled. Yet there seems to be reason to believe that whatever may be the exciting cause, the symptoms are associated with vaso-motor disturbance.

The difficulty is that the signs of vaso-motor disturbance vary. In one case the face may be flushed, the eyes suffused, the carotids and temporal arteries throbbing forcibly. This has been held to indicate hyperaemia of the brain.

In another case the face is pale and cold, the arteries small and contracted like whip cords. This has seemed to point to cerebral anaemia. The explanation which may be offered is that in all cases cerebral anaemia rather than congestion is the condition which gives rise to the symptoms.

For on the one hand, Hill has shown that congestion of face and throbbing of the carotids, and headache due to nitrite of amyl does not imply cerebral hyperaemia but anaemia, the condition being dependent upon general lowering of arterial blood pressure and consequent depletion of arterial cerebral circulation.

On the other hand, compression of the carotids, a condition which is analogous to the contraction of vessels met with in migraine, will also cause cerebral anaemia, and symptoms in many respects resembling those premonitory of migraine. 
Hence it may be that cerebral anaemia arising from opposite conditions may give rise to migraine; and this may explain the fact that in one case, e.g., when pallor and cordlike contraction of arteries prevail, nitrite of amyl affords relief, whereas in the opposite condition, in which there is flushing and throbbing of cervical and temporal arteries, such drugs as ergot and strychnia are beneficial.

Another hypothesis is that the nerve cells of the brain itself are primarily at fault, and that the condition is nearly related to, though not analogous to, epilepsy. Yet, epilepsy is certainly rare in the subjects of migraine, whilst vasomotor disturbances-shown in pulsation, relaxation, or constriction of accessible arteries-are of common occurrence.

Headache from Errors of Refraction.- "Eye Strain." It is only necessary here to mention that marked degrees of hypermetropia, myopia with astigmatism, may cause headache, photophobia, lacrimation and conjunctivitis from spasm of the ciliary muscles and fatigue of the internal recti muscles. Also eye strain in these cases may mean mental strain, for intelligent ambitious children, labouring under the disadvantages of defective eyesight, must make prodigious mental efforts in order to excel. This is particularly the case with the intelligent myopic child, who persists in taxing his eyes in spite of consequences. The same may be true of the intelligent hypermetropic, or astigmatic ; but more frequently the hypermetropic child passes as dull, lazy and stupid because he cannot clearly see. A common symptom is that whilst delighting in being talked to, read to and taught by ear, he cannot be induced to open a book for his own pleasure and instruction.

Major degrees of myopia and hypermetropia are, however, seldom overlooked at the present time, and the suggestion that they should at once be treated by suitable glasses is superfluous. On the other hand, minor conditions of these affections are of slight pathological significance, and their consequences upon health of mind and body have been greatly exaggerated. It is said that about 75 per cent. of school children 
suffer from errors of refraction, and enthusiasts have supposed that wits will be sharpened, morals regenerated, all headaches, habit-spasms and epilepsy be banished by supplying one and all with spectacles. Such optimistic views have slender basis. The idea that the cerebral and gastric neurasthenia, which embittered the lives of Wagner, Darwin, Carlyle, Lotze and others, was solely caused by unsuspected a-metropia cannot be accepted. One might woll wish it were true for future guidance.

Yet it may be granted that brain exhaustion may be accelerated and rendered worse by ocular fatigue in neurasthenics; and the weak are incapacitated by slighter causes than the strong. So, in rare instances brain-power may be preserved by glasses-especially when these are combined with rest for over-burdened minds.

Headaches which are solely due to errors of refraction can be cured by oculists, but not those due to other causes. One rarely meets a sufferer from migraine who is not wearing spectacles or pince-nez, or one who has been cured by wearing either.

However, I am far from denying that defective eyesight in children should receive appropriate attention, whether it be productive or not of headache and other nervous disturbances.

Treatment of Headaches.-All possible local causes, such as dyspepsia, constipation, anaemia and rheumatism, should be looked for and treated if present. Educational over-pressure, and the presence of worry and fretting from any cause should be thought of, and if found existent, relieved by suitable measures. Faulty hygienic conditions of sleeping and classrooms should be remedied, or the patient should be removed from such insanitary surroundings.

Treatment of Migraine.-All the above considerations apply to the sufferer from migraine, but the complaint is less dependent on accidental causes than on predisposition to the complaint. Attacks are as liable to occur in the playing field as in the schoolroom. 
When the circulation is poor, liq. strychniae m 1-2 with ext. ergotin liq. $m \times$ for a child of twelve, given three times daily, is sometimes of service in reducing the number of attacks. In some cases quinine with hydrobromic acid and nux vomica is of service; in highly emotional, excitable children with rheumatic tendencies, salicylate of soda with bromide of ammonium, sal volatile and inf. gent. co., may be given, whilst rest, quiet, and shortened lessons should be enjoined.

Citrate of iron and ammonium agrees as well as any patent preparation of iron, and may be given with ammon. brom., nux vomica, arsenic or both, according to circumstances, when anaemia is present. It should be remembered that quinine, strychnia, nux vomica and iron may give rise to headaches, particularly in neurasthenic persons, who often show remarkable susceptibility to their action.

The bowels should in all cases be carefully regulated. Fresh air, moderate exercise and healthy surroundings are essential. The diet should be plain and not over abundant. Excess in sugar and starch in some cases, and in others nitrogenous food, seem to increase proclivity to migraine. Strong tea and coffee should not be taken habitually, though in many cases they will ward off an impending attack. The same may be said of alcoholic stimulants.

During an actual attack of migraine the patient should be kept reclining in a quiet shaded room, and warmed if necessary. The less he is disturbed by pressing food and medicine on him, the better. But a dose of antipyrin or phenacetin with citrate of caffein should be administered at the onset. Guarana powder in 12 grain doses for a child of twelve has been recommended, but a cup of tea is perhaps as efficacious. 


\section{CHAP'TER XII}

\section{ENURESIS - CYCLICAL ALBUMINURIA-CYCLICAL PYREXIA- CYCLICAL VOMITING}

Enuresis.-Enuresis as a neurosis seems to be the result of hypersensitiveness of the lumbar centres of micturition, and of deficient inhibitory control on the part of the higher cerebral cortex over the lower centres in the spinal cord. It is one of the indications of general nervous instability. It may be hereditary, congenital, or acquired. Sometimes it is a familial affection. When nocturnal only, enuresis may be due to epilepsy.

Cases in which nervous instability is the sole cause are the most intractable ; but in the great majority some exciting cause is present as well.

In a few, want of proper training may keep up the habits of infancy. Every child has to be taught to control its bladder and make known its desire to empty it. It usually learns to do so before the age of two. If incontinence is habitual after the age of three, it is a morbid manifestation. It is most serious when it is constant, day and night, and is usually then associated with some form of mental enfeeblement, or with spina bifida occulta, in which case it is incurable. Sometimes it is due to pressure on the cord by tuberculous or other lesion of the vertebrae.

The chief exciting causes of enuresis are: (1) Adenoid vegetations ; (2) Local conditions, both within and without the bladder, which render it and the spinal centres irritable ; (3) Constitutional defects, such as anaemia and general debility, and, far more rarely, (4) Chronic interstitial nephritis. 
Adenoid Vegetations.-These are a most potent cause of nocturnal enuresis, but probably they never give rise to diurnal incontinence. Enuresis may be the result of night tcrrors, which are also common in the subjects of adcnoid vegetations. But night terrors in these cases are probably set up by partial asphyxia, which stimulates the respiratory centres and perhaps also the vasomotor centres in the medulla. Thus an increased flow of urine may occur into the bladder, which empties itself because the cerebral centres of control are inhibited by fright.

Causes of Irritation within the Bladder.-Stone, simple and tuberculous cystitis, and new growth need only be mentioned here. Vesical irritability may also be caused by hyperacidity of the urine, and by bacteriuria, and sometimes by polyuria.

Hyperacidity of urine.-Doubts have been recently cast on the reality of this cause of enuresis; but certainly, enuresis is associated at times with highly acid urine, depositing urates in large amount, uric acid, or oxalates. The enuresis in such cases may be diurnal and nocturnal too. It is usually readily cured for the time being, by a few doses of citratc of potash, especially if tinct. hyoscyami be added. Many believe that excessive meat diet is the cause, and it is true that, in some cases, incontinence seems cured by restriction in nitrogenous food.

Bacteriuria.-The urine on passing is rendered cloudy by swarms of bactcria, which come from the kidneys and bladder. The condition is common after enteric and other fevers. Urotropin is perhaps the best drug in such cases. It should be given in 5-10 gr. doses, well diluted with water. Benzoate of soda or ammonium is useful in larger doses.

Alkalinity of the urine in the absence of cystitis is also associated with enuresis. The urine may be alkaline from presence of triple phosphates. It may be of low specific gravity-1002-1005; it may contain a trace of albumin, and it is always marked by increase in quantity; 
in fact, polyuria is the condition present. A characteristic feature is, that the child, on being waked at night to pass water, does so in considerable quantities, but after a short interval is found to have passed as much again in bed.

In some instances the complaint has been traced to excess of farinaceous and saccharine food, and has been cured by supplying a rigid antidiabetic diet for a few days. (Percy Lewis.)

It must be borne in mind, however, that enuresis and polyuria with a similar condition of urine are strongly suggestive of chronic interstitial nephritis in children. Polyuria in itself is sufficient to cause enuresis. Diabetes mellitus, and insipidus are recognized causes of polyuria and enuresis.

Causes of Irritation outside the Bladder.-Of these may be mentioned balanitis and vulvitis; but in such cases the incontinence may be the cause, not the consequence, of the irritation.

Oxyurides and constipation sometimes give rise to enuresis. Phimosis is another cause.

Irritability of the bladder may still produce incontinence, -night and day, when the original cause of irritation has been treated or removed. The presence of very small quantities of normal urine in the bladder is sufficient to excite it to contract. At short intervals there is a sudden call to micturate, which must be obeyed at once.

Atony of the Sphincter is not a common condition, but occasionally gives rise to incontinence. The urine drips or trickles away without frequent and distressing desire to pass it. Such cases, in both sexes, may sometimes be cured by the passage of a sound.

Electricity, in the form of faradism, one pole being placed in the urethra or on the perineum, and the other to the back or suprapubic region, is sometimes of service when the sphincter is weak.

Direct massage of the neck of the bladder by a finger introduced into the rectum has been recommended; but 
the method is obviously objectionable, and should not be employed except as a last resource.

The treatment of an irritable bladder which will only contain small quantities of urine, consists in training it to hold more. The child should be kept in bed, and instructed to micturate at gradually increased intervals. The diet should be bland, without excess of starchy, farinaceous, saccharine, or nitrogenous articles. Water or barley-water may be given freely. It is a mistake to restrict fluids, except shortly before bedtime, in any case of enuresis. Tea and coffee should of course be prohibited.

Tincture of hyoscyamus, in doses of 10-30 min. or more, is a valuable vesical sedative. It may be given with citrate of potash and infusion of buchu.

In inveterate cases of irritable contracted bladder, gradual expansion of the organ by injections of weak boracic lotion is said to be successful, combined with local application of electricity.

Treatment by Epidural Injection has been advocated in France and America. It consists in injecting normal sterilized saline solution in quantities of one and a half to five and a half or more drachms into the sacral epidural space. It is supposed to act by irritating the cauda equina, and thus conveying impulses to the lumbar centres, which are thought to be incited thereby to exert tonic or inhibitory influences over the bladder. The injections are made with an ordinary syringe, having a needle of a length of $1 \frac{1}{2}$ inches. The patient stands, or lies on his side with thighs flexed. The site of injection is the membrane closing the lower end of the sacral canal, which is indicated by a triangular depression situated at the posterior termination of the intragluteal fossa, and between the posterior and inferior processes of the last sacral vertebrae. The needle is inserted at this point, and thrust forwards and upwards into the sacral canal. No anaesthetic is used. The operation is said to be free from danger if ordinary precautions to ensure surgical cleanliness are adopted. Success is claimed 
in a sufficiently large number of cases to warrant employment of the method when other means have failed. It is admitted that it is by no means uniformly curative. Occasionally, in purely nervous cases, treatment by hypnotic suggestion is successful.

General Treatment.-Whatever may be the cause, the inconvenience occasioned by nocturnal enuresis may be lessened by waking the child at set intervals, to pass water. Accidents commonly happen when the child lies on his back. Therefore he should be taught to sleep on one side. A "bobbin" or some hard object strapped to the small of the back will wake him should he turn over.

Restriction in fluids just before bedtime, and in stimulant diuretics such as tea, coffee, mustard, pepper, spices, meat-juices, sugar and starch (in some cases), should be enjoined.

Any of the mental and physical conditions which excite night terrors may cause ienuresis, and therefore require similar treatment. Punishment of any kind is rightly condemned in any case of enuresis occurring in a child upwards of three years. But few can have escaped a slapping in infancy for this particular crime, and the nurse's palm has taught many of us to control our bladders by night. Medical men only see cases in which such primitive treatment has failed.

Constipation should be relieved. Evacuation of the bowels in the evening before bedtime, will sometimes cure nocturnal enuresis.

Treatment by Drugs. - The utility of some has already been mentioned. It would be impossible to enumerate all the drugs which have been found invaluable by some, and useless by other practitioners. Consideration of the various causes of the complaint will suggest appropriate remedies.

Atropine and belladonna should not be given by routine in every case. Children who wet the bed occasionally should not be poisoned indiscriminately with belladonna for months together. The physiological action of bella- 
donna in full doses is to cause temporary paralysis of the bladder and to lessen secretion of urine. In some cases such results are beneficial, in others, not. Belladonna is useless when the vesical sphincter is weak, also in cases in which the tendency to enuresis is kept up by local and constitutional conditions. It is seldom useful in cases of both diurnal and nocturnal enuresis.

It is most valuable in cases of habitual nocturnal enuresis. The drug should then be pushed to full doses (10-40 min. of the tincture for a child of 10-12) and given at night only, with $10 \mathrm{gr}$. of one of the bromides. Or, atropine may be given in $1 \mathrm{~min}$. doses of the liq. atropinae sulph., $4 \mathrm{gr}$. to loz., gradually increased until the physiological effect is produced. If no good effects follow a few weeks of belladonna treatment, the utility of its continuance is doubtful. The disadvantage of keeping a child for months in a state of chronic belladonna intoxication is obvious. Few parents can be induced to persevere with the treatment after one or two experiences of children rendered half blind, staggering, * and delirious, in consequence. The ill effects can, however, be reduced by giving belladonna or atropine at night only.

The writer has found better results from giving hyoscyamus, citrate of potash, and buchu, than from the belladonna treatment alone.

Cantharides has been recommended when there is weakness of the sphincter. Lycopodium, in doses up to a drachm of the tincture, may be useful as a vesical sedative. Ergot for atony of the bladder; antipyrine as a general nerve sedative; rhus aromatica in doses of 10-15 $\mathrm{min}$. of the liquid extract as a stimulant diuretic and tonic, may all be useful when the conditions which indicate their use are present. Arsenic, strychnine, and nux vomica and ironmay be required.

Nervous retention of urine is not uncommon in boys. The writer has known it to occur in father and son. The father, throughout his life, could never use a public urinal, nor pass 
ENURESIS, CYCLICAL ALBUMINURIA, ETC. 161

water if any one was by. The son suffered much at school from the thoughtless teasing and practical jokes to which he was subjected by his schoolfellows on account of a similar failing. Fortunately, no further ill consequences ensued, but in such cases, as the affection cannot be overcome by drugs or strength of will, common sense instruction should be given, in order to enable the patient to conceal it.

Hysterical retention of urine in young girls never needs active treatment by passage of a catheter.

Albuminuria, Orthostatic, Cyclical, or Functional. -This affection, in which albumin is present in the urine whilst the patient is up and about, but disappears after rest in bed, may be regarded as one of the neuroses of childhood.

It occurs most commonly in children at the approach of puberty, but may be met with as early as the eighth year, The subjects are nervous, excitable, emotional, tearful, irritable, or passionate. They are peculiarly liable to night terrors, easily tired, lethargic and depressed; they suffer from migraine and from peculiar attacks of abdominal pain either epigastric or in the right iliac region, which suggest appendicular colic. The bowels are often confined or relaxed. The appetite is capricious. Evidence of disturbance of the vasomotor system is afforded by sweating, flushing, or fainting attacks, tendency to redness, blueness, and coldness of the extremities, and by passing erythematous eruptions. Epistaxis may occur; palpitation of the heart and tachycardia are met with sometimes, with tremors, and symptoms of Graves' disease. The kidneys may be movable, and there may be a condition of general enteroptosis. In appearance, the children are sallow, anaemic, with puffy lower eyelids and general appearance of chronic ill health. Their ancestry has been neurotic, gouty, or rheumatic. They answer to the description of children regarded as of the " uric acid diathesis," and are often the subjects of so-called "mucous disease." 
There is no evidence that the albuminuria is due to nephritis of any sort, nor that the condition ever leads to granular kidney or to any form of Bright's disease. Treatment by drugs, or by any means aiming at control of the albuminuria is unsatisfactory, but in some cases Chloride of Calcium has seemed to be of use. Careful dieting, exercise, baths, massage are generally inefficacious so far as the albuminuria is concerned, though valuable as means of improving general health.

Cyclical albuminuria is evidence of nervous instability, affecting chiefly the vasomotor system. It can be treated only on general principles, which should include a simple, regular course of life, lived as much as possible in the open air, wholesome ordinary diet, and freedom from emotional excitement, and overwork at school. The subjects tend to become valetudinarians and hypochondriacs, and therefore should not be treated as invalids.

Tonics, and sometimes sedatives, are necessary, if only to satisfy anxious parents that "something is being done."

Cyclical Pyrexia.-Recurrent pyrexia, with or without headache, is common in neurotic children, and has been regarded as a pure neurosis dependent upon instability and hyper-sensitiveness of medullary and higher nerve centres. In a certain proportion of cases, when no other cause can be ascertained, these curious periodic attacks are no doubt the outcome of an emotional temperament. But in some they are attributable to excess in carbohydrates. Eustace Smith claims that these are cured by supplying a diet free from starch and sugar, and describes them as instances of "food pyrexia."

Cyclical or Periodic Vomiting.-Acetonuria, Acute Acid Poisoning, Aciduria. The symptoms of acute acid poisoning, are profuse and persistent vomiting, constipation and the presence of acetone in the breath, with acetone and sometimes diacetic acid in the urine.

The attacks in simple cases tend to occur periodically 
at intervals of a few weeks or months. They usually last from two to five days but may be prolonged for two or even three weeks.

During an attack the patient is prostrate, the face becomes pale and drawn, the eyes are sunken and the abdomen is retracted. Epigastric pain and tenderness may persist throughout an attack or may be only present towards the end, in consequence of retching.

The tongue is usually clean, the temperature is slightly elevated, the pulse is frequently accelerated. The vomit consists of food and watery or bilious matter.

Thirst is intense, hunger is extreme, but nothing can be retained in the stomach. The patient wastes rapidly.

The odour of acetone in the breath and its presence in the urine are always unmistakable.

In simple cases, however, although the condition may appear extremely grave, complete recovery is almost invariable.

Fatal cases chiefly follow the administration of an anaesthetic, especially chloroform. In these, in addition to the symptoms mentioned there is commonly a period of delirium, restlessness and excitement alternating with apathy, which comes on some hours after recovery from the immediate effects of the anaesthetic. Vomiting is continuous and the vomit eventually resembles the dregs of beef tea. Airhunger is often present, drowsiness follows delirium and coma ends the scene.

In some cases jaundice and slight tenderness and enlargement of the liver may be found.

Etiology of Acute Acid Poisoning.-Acetonuria is met in diabetes, starvation, malignant cachexia, peritonitis and other septic abdominal complaints and sometimes in pneumonia. It may be produced by poisons such as phloridzin, morphia and salicylate of sodium. It may be induced by ingestion of fat, and in the dog it has been caused by fright.

Apart from the more serious conditions under which it 
occurs, acetonuria is regarded by some as a pure neurosis affecting metabolism.

If affects neurotic children. Gout, eczema, migraine and neuroses of various kinds are in their families. Sometimes periodic vomiting gives places to migraine at puberty.

Others hold that the attacks are due to hepatic incompetence to destroy or to prevent formation of acetone and its poisonous precursors, $\beta$-oxybutyric and diacetic acids. Such inadequacy may again be due to perversion of central nervous control over metabolism, resembling in origin the nervous form of glycosuria. Or it may depend on direct interference with the functions of hepatic cells by saprophytes and toxins.

The causes which may give rise to acute acid poisoning are, as stated, many. The point which is of chief importance is that acetone, diacetic and other noxious acids are derived from deficient metabolism or oxidation of fat. It follows that the more fat is present, the more likely are symptoms of its insufficient metabolism to appear.

The liver is an important seat of fat metabolism, and it is a striking fact that in practically all cases of acute and fatal acid poisoning which follow administration of anaesthetics, the liver has been found to be extremely fatty ; whilst in the rare instances of death from uncomplicated periodic vomiting, similar fatty changes in the liver have been noted.

It is possible, therefore, though non-proven, that in all cases of fatty acid poisoning, the source is from fat already stored to excess in the liver, which that organ is unable to metabolize, either in consequence of defective oxidation produced by an anaesthetic, or by disorder of central nervous influence on the hepatic functions, or by the action of toxing generated in the intestines and elsewhere upon the liver cells.

All the diseases and conditions associated with acetonuria are also associated with fatty liver, and finally, storage of fat in the liver may be the result of excessive ingestion of fat itself and fattening foods.

The treatment of fatty acid poisoning and periodic vomit- 


\section{ENURESIS, CYCLICAL ALBUMINURIA, ETC. 165}

ing, on these assumptions consists in endeavouring to neutralize poisonous fatty acids by alkalies such as bicarbonate or citrate of sodium in large doses.

As regards prophylactic treatment in uncomplicated cases of periodic vomiting with acetonuria, excess of fat and fattening food should be avoided.*

* Professor J. B. Leathes says: "In practically all forms of acetonuria, increasing the amount of fat in the food intensifies the condition. The disorder in acetonuria seems to consist in the failure of the organism to carry out the first steps in the progressive oxidation of the fatty acids, and brought about by overtaxing its powers."

"Fatty degeneration is not a degradation conversion of the proteids of the cells into fat, but in fatty heart and liver the fat has been transported from the connective tissues and dumped down, so to speak, for the purpose of supplying source of energy to the organ, from where it was only storage fat, to where it would be used up if the catabolic activity of the cells were normal, but the catabolic changes which liberate energy by the demolition of fatty acids fail, and the imported fat accumulates, because it cannot be used up." (Problems in Animal Metabolism.) 


\section{CHAPTER XIII}

\section{ON DISORDERS ASSOCIATED WITH PRIMARY DENTITION}

A HUNDRED years ago, the great majority of all ailments to which infants are liable were attributed to the effects of dentition. The mortality from this cause alone was placed as high as 50 per cent. About fifty years later, however, it was announced as a discovery that, after all, dentition was but a physiological process, and, as such, it could not very well be fatal, or even dangerous to life. This produced a reaction, and although infants continued to suffer and to die, as still they do, of convulsions, meningitis, pneumonia, pulmonary, gastric, and intestinal catarrh, during the period of first dentition, these illnesses were no longer attributed to " breeding of the teeth." Dentition rarely finds a place in death certificates now.

Yet the public-whose information on medical matters is usually a century behind the times-still persist in regarding all complaints in early infancy as due to teething. "Is it his teeth, or is it consumption of the bowels?"; "He always cuts his teeth with convulsions or bronchitis," as the case may be; "I thought it was only a teething rash"-are all common questions, and statements of which many of us must have grown weary, much as the Athenian tired of hearing Aristides called "The Just." Possibly, therefore, we may pay less attention to the phenomena of dentition than the subject merits.

Truth and fallacy, like poisons and their antidotes, often grow side by side. Dentition is a physiological process, and, as such, is often accomplished without any distur- 
bance to the infant's health. On the other hand, it is futile to deny that it is often associated with considerable pain, constitutional disturbance, and local signs of inflammation in the gums.

In inquiring why this should be, we are handicapped, at starting, by want of knowledge as to the exact method by which the eruption of teeth is effected.

Does the process resemble that which obtains in sharks, whose mucous membrane, to which the teeth are attached, and of which they are a part, is shed in layers, thus bringing successive rows of teeth to the surface?

At all events, the shedding of the temporary teeth in human beings seems analogous.

Do teeth arrive at the surface through successive additions to the length of their fangs? Against this view, it has been urged that, occasionally, unerupted teeth are found with perfectly developed fangs. Yet this condition may be but an exception to the rule.

We may safely say that the old view that teeth literally pierce the gums - as a blunt awl might be driven through a cowhide trunk-and that all troubles, which may accompany teething, are due to resistance afforded to a tooth by a tough unyielding gum, is erroneous.

No gum, even if as tough as a turtle's, could withstand the passage of a tooth.

The superstrata of the gum over a tooth are gradually absorbed, or atrophied, not pierced. The process has been attributed to the action of phagocytes, but on what evidence I do not know.

The idea that teeth may be "liberated," or their eruption hastened, by lancing the gums must be discarded.

We must, however, leave undecided the exact nature of the forces which are concerned in dentition. We know no more about them than we do of those which determine physiological processes elsewhere, such as the development of function in the salivary glands, the intestinal glands and the nervous system. 
What is the Immediate Cause of Painful Dentition?-Some have held that a tooth acts like a foreign body, and causes pain by forcing its way through its closely packed neighbours in a small and over-crowded jaw. I am not prepared to deny this altogether, for it is well known that an impacted wisdom tooth may give rise to much distress in after life. Yet, I think, an analogous condition in primary dentition must be rare, because, as a rule, the infant's pain arises when the tooth has out-soared its neighbours, and is nearing the surface of the gum.

I doubt again whether pain is produced by resistance to the passage of a tooth by the gum above, unless indeed the gum be inflamed, for surely the resistance offered to the permanent teeth by the deciduous teeth above them, must be far greater than any which the gum itself can afford. Yet eruption of permanent teeth is painless, unless the temporary teeth are carious, or the gums inflamed.

The inference, therefore, is that dentition is painful when the gums are so.

Symptoms of Painful Detention.-The normal healthy child may have none save salivation, and the satisfaction which he derives from biting and munching anything which he can put in his mouth.

If fretful, it is because he is not supplied with something to bite. A hard crust at once brings contentment. Mastication may accelerate the process of dentition, and Hippocrates was probably right in assuming that in these circumstances the gums itch. They are not, however, red or swollen, tender or dry. Pyrexia is absent.

The condition of a child in whom dentition may be really painful, is wholly different from the above. Here the gums are swollen, tender, and reddened. They are dry, or covered with thick and slimy mucus. Salivation seems suppressed. Frequently this condition of gingivitis affects the gums as a whole. Less frequently, it is most marked over the site of an erupting tooth. One cannot doubt that, under these conditions, dentition may be pain- 
ful. The child is restless, sleepless, or wakes at short intervals, screaming with rage and pain, and driving its parents to distraction. It ejects its "comforter," and the nipple of the breast, or bottle, with an angry cry. Evidently, pain and tenderness of the gums are increased by pressure. Often he pulls, and rubs his ears, or the back of the head, showing that his sufferings are referred to these parts.

The temperature is often alarmingly high, rising to $104^{\circ}$ or $105^{\circ}$. With pyrexia there are, I believe, almost invariably, signs of gastro-intestinal disturbance, such as vomiting, with diarrhoea, and loose, offensive, green and curd-containing motions, and griping colic. Sometimes there is obstinate constipation. Signs of pharyngeal, laryngeal, tracheal and bronchial catarrh are common enough. Nervous symptoms such as laryngismus, spasmodic coughs squint, muscular twitchings, tetany, convulsions may occur, but it is worthy of notice that these are far more prominent in edentulous, rickety subjects than in those who are cutting teeth.

The popular superstition that rickety children, who - suffer from any or all of these symptoms, "cut their teeth in their loins" was no doubt invented by some medical man in bygone ages, in order to account for the fact that the teeth, which he had confidently predicted, failed to make an appearance in their normal site.

Convulsions are far more common in infants before than during the teething age.

All the symptoms which have been mentioned, and many others, including so-called "teething rashes," which comprise every variety of dermatitis and exanthem; meningitis of every sort and kind; encephalitis, infantile paralysis, hemiplegia, paraplegia, diplegia, eye affections, such as keratitis, iritis, and optic neuritis ; ear affections, such as otitis media and mastoiditis; pulmonary diseases of every kind have been attributed to teething. In short, there is no disease for which dentition has not been held 
to account. Of pulmonary disease, perhaps lobar pneumonia, and particularly apical pneumonia, has most frequently been mistaken for teething, the reason being that until within recent years its existence was denied in infants under two. Yet of all complaints in infancy, lobar pneumonia yields most striking indications of its presence.

When, however, pneumonic delirium has been mistaken for meningitis, and a crisis has happened with the eruption of a tooth, or has followed lancing of the gum, no doubt the happy event has been held to justify both diagnosis and treatment. One can only thus account for the strange conviction, dear to our parents and their medical advisers, that infants' lives are saved by the timely use of lancets.

It would be strange indeed if teething did not often coexist with every illness in infants aged from eight months to twenty-four. Yet I am convinced that, in the vast majority of cases, teething is a mere coincidence. It is chiefly of importance when it occurs through inflamed gums.

One sees countless cases in which teeth are cut in the course of any kind of illness, but without influencing its duration, and without evidence of alveolar inflammation. On the other hand, it is equally certain that alveolar inflammation and, therefore, painful dentition, are associated with every kind of illness, and with gastro-intestinal disturbance in particular.

This fact is admitted even by those who are not disposed to regard dentition as the source of all evils-and the following explanations have been offered of coincident disorders :-

(1) The Reflex Theory.

(2) The Pyrexial Theory.

(3) Idiosyncrasy and General Nervous Instability.

The reflex theory is fascinating in its simplicity and plausibility. The trigeminal nerve, which supplies the jaws and teeth, has extremely wide anatomical connexions, as every one is aware. It would be tedious to enumerate 


\section{DISORDERS DURING PRIMARY DENTITION 171}

them. One need only allude to its communication with the facial, glossopharyngeal, and vagal nerves; with the sympathetic supplying the iris at the gasserian ganglion; with the nerve to the membrana tympani through the otic ganglion.

Moreover, the nerve is not far from its origin in the medulla, where its nucleus is in close proximity to other important nuclei, and also to the base of the brain. Such being the case, it seems natural to attribute all complaints of parts, however remote, to reflected irritation of the fifth nerve.

There may be a certain amount of truth in this, but it is not the whole truth. No doubt irritation of the dental branches of the fifth may produce otalgia, but it cannot produce suppurative otitis media. In rare cases, it may give rise to convulsions, but it cannot cause meningitis.

Spasmodic asthma, were the theory true, should be excessively common in teething infants, but it is of the utmost rarity. Pneumonia cannot be brought about by reflex irritation of the vagus; whilst, as before mentioned, laryngismus and tetany, complaints which might well be produced by reflex irritation, are practically confined to rickety children in whom dentition is delayed.

One may admit at once that pain in any part may be transferred elsewhere, yet disease is not set up in the remote part to which the pain may be referred. Pain, in early hip disease, is commonly referred to the knee, in renal colic, it may be felt in the testicle, yet neither knee nor testicle is actually diseased. John Hunter's usual astuteness forsook him when he attributed relapsing urethritis, exactly resembling gonorrhoea, to the effects of teething.

The reflex theory will not wholly account for all the complaints which exist with painful dentition.

The pyrexial theory, again, is not entirely satisfactory. It is held that dentition produces high temperature, the pyrexia predisposes the patient to chill, and that chill 
results in catarrh and inflammation of the pulmonary or alimentary system. Here again the explanation is not quite acceptable. Why should dentition be associated with pyrexia? It certainly is not so unless painful, and why is it painful unless the gums are unhealthy and tender? Modern experiments seem to show that chill is not the potent cause of catarrhs and inflammation, which it was formerly held to be. They are due to microbic invasions, and not to exposure to cold alone. At the same time protection from chill is important. Restless, feverish infants who are supposed to be " merely teething," should not be taken out of their cots to look at the moon on frosty nights.

Lastly, we have the theory that children at the dentition period are in a condition of exceptional susceptibility to various complaints, because not only their teeth, but the glands of the alimentary tract, and their nervous system are undergoing physiological development.

Such physiological processes, without doubt, are proceeding, but it seems unjustifiable to blame nervous, or intestinal instability, when other, and more obvious, causes of illness may be found. I doubt if any healthy child suffers by reason of the "instability" of its nervous system, or the development of its physiological functions. If there is any special susceptibility at this age, in a healthy child, it is to the ill-effects of sour milk and improper food, which susceptibility need not be regarded as an idiosyncrasy. This I believe to be the crux of the whole matter.

In my personal experience I can hardly recall a case of painful dentition which has not been accompanied, and usually preceded, by gastro-intestinal disturbance, or by naso-pharyngeal, pulmonary or bronchial catarrh.

It is in connexion with constipation or griping colic, diarrhoea, with offensive, green, curd-containing stools, that we find dry, tender, swollen gums, which, in my opinion, render the eruption of teeth painful. Over and over again, 


\section{DISORDERS DURING PRIMARY DENTITION 173}

mothers have complained that, whereas a child has previously cut several teeth without discomfort, on this particular occasion a tooth is being cut with diarrhoea, and all the familiar symptoms of feverish catarrh, fretfulness, insomnia, screaming, perhaps convulsions, and obvious pain in swollen, inflamed gums. In practically all such cases, improper diet or tainted milk is the cause, and the symptoms speedily subside under castor-oil and careful dieting.

One is compelled to regard the oral condition as part of the intestinal, rather than to consider the abdominal symptoms as due to reflex irritation from the gums.

In favour of such a view may be mentioned the wellknown fact, that, in adults, a raging toothache may often be relieved by a brisk purge. Sir Lauder Brunton explains this by supposing that "The state of the nervous system is so altered by the purge that pain is no longer produced by the irritation."

Yet I venture to think that a more reasonable explanation is that the cause, which irritates the intestines, irritates a tender tooth-and that this cause is removed by the - purge.

It must be a common experience that acute indigestion gives rise to tenderness of gums, toothache, and neuralgia. The mouth is part of the alimentary tract, and the teeth and gums are part of the mouth, and therefore share in the general disturbance caused by indigestible and irritant matter in the intestines.

I believe, therefore, that the ordinary phenomena of painful dentition are dependent on alimentary disturbance, associated with a "common cold," and that dentition is painful because the gums become unhealthy.

Assuming this to be true, it affords an explanation of many of the more serious complaints, which occur together with painful dentition.

If the oral mucous membrane is unhealthy, it must follow that it is unable to cope with the invasion of microbes. 
As previously mentioned, salivation seems suppressed during painful dentition, and healthy saliva has, no doubt, antiseptic properties. Hence we can easily see why infants, whose teething is painful, fall a ready prey to catarrhal inflammation of the ears or lungs, to pneumonia, and meningitis. A sore mouth readily becomes septic. With regard to ordinary infantile convulsions, attributed to teething, I am convinced that gastric, or intestinal disturbance, is far more frequently the cause than dental irritation. At the same time one may freely admit that in accordance with views already expressed, an infant who is neurotic by nature and inheritance, and whose nervous system is unstable in a pathological sense, is exceptionally liable to convulsions, and to the various neuroses which in a normal child cannot be attributed simply to dentition.

Treatment.-If the foregoing conclusions be correct, the success of ordinary methods of treatment in cases of painful dentition is explained, and, possibly, some of the more remotely associated affections may be prevented by attempts to render the mouth aseptic.

General preventive treatment consists in scrupulous attention to form and mode of preparation of diet. If the child's food is unwholesome, its alimentary tract will be unhealthy.

When sour milk in unclean bottles has set up diarrhoea and colic, the best remedy is castor oil in emulsion with a little tincture of rhubarb.

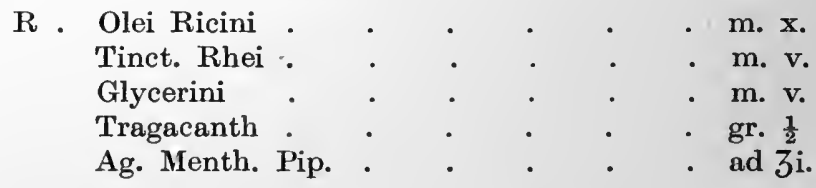

To this may be added Tr. Opii, in doses of 1 or 2 minims, if pain is extreme. The prejudice against giving laudanum to infants is groundless, except perhaps to those under the age of dentition. There is little danger in giving it even to these, provided that the dose be not too large, and that 
it be not repeated, until the drowsiness produced by it has passed off.

Salol may be added to the mixture, when the motions are peculiarly offensive, and bromide of potassium, when restlessness and sleeplessness are pronounced. Dover's Powder in doses of half a grain to a grain, with one or two grains of hydrarg. c. creta, is an ancient and excellent remedy for catarrh of any kind in children at the teething age.

Oral hygiene is of the utmost importance in teething infants. That which entereth the mouth defileth, and a teething baby puts everything therein which is possible of insertion.

Hence a reasonable discretion should be used in the selection of articles supplied for the purpose.

Rubber rings, "comforters," dolls' heads and the china ornaments on the mantelpiece should be washed before sucked. There is danger in the oft-sucked toy.

Nurses, who possess a very Baalbec of ruined teeth, should not indulge in preliminary suction of the bottle to make sure that the nipple draws, and that the milk is to the baby's liking.

Even "Walker-Gordon" milk should not be stored in the lavatory. The outside, as well as the inside of a feeding bottle should be kept clean. Every baby should possess its own pocket handkerchief, and a badger-hair gum-brush.

When the gums are painful, tender and congested, they should be brushed with a solution of 10 grains of chlorate of potash to the ounce of glycerine of borax.

Should ulceration be present, the addition of 20 to 30 grains of resorcin to the above, and of a few grains of chlorate of potash to the castor oil mixture, are most efficacious.

Finally, it should be remembered that a fretful, feverish infant is almost invariably overfed; thus its sufferings are aggravated, and convulsions may be induced by colic not by teeth.

A low diet of cow's milk well diluted with barley water should be prescribed. 
Earache from middle-ear catarrh is a common cause of symptoms (including convulsions) supposed to be those of dentition. Any infant, except a congenital idiot, will indicate the site of its pain by pulling its ear and rolling its head when suffering from otalgia. If recognized early, blistering to the mastoid process, and hot dry applications to the external ear, will often relieve. A leech to the mastoid process of infants who are robust is effectual. Puncture of the membrana tympani, even when the membrane is not bulging, but is merely congested, is sometimes strikingly successful in cases of apparent basic meningitis associated with fits.

Gum Lancing.-In the American Journal of Dental Science, it is said,* that: "Many lives of children are probably sacrificed yearly, because of the popular and professional prejudice against lancing." Such statements are pious opinions which lack confirmation.

Personally, I have grave doubts if painful dentition has ever been the direct cause of death, or that life has ever been saved by lancing the gums. Even the oft-quoted cases of fatal so-called "teething convulsions" are, in my experience, attributable primarily to gastro-intestinal disorder. It is difficult to believe that "threatened meningitis," whether tuberculous or otherwise, has ever been averted by use of the lancet, or that the crisis in pneumonia can be hastened, or diarrhoea cured, by such procedure. At the same time, there can be no doubt that local pain may be relieved by blood-letting.

Simple scarification of the gum is all that is needed. Such barbarous usage as the removal, between elliptical incisions, of a portion of gum over a tooth, supposed to be offending, is not to be commended. As well as being cruel, it is illogical ; for if the condition of the gum were merely that of tension over a tooth, a simple incision should gape at once, and so relieve the symptoms.

Gum-lancing should not be practised in the absence of 
local indications for its use, and merely in the blind hope of relieving " constitutional symptoms and distress not otherwise accounted for." * If unaccounted for, further investigation is required, not stabs in the dark. At the present time, it is hardly likely that the purple haemorrhagic swellings of the gums, met with in infantile scurvy, should be mistaken for signs of disordered dentition, requiring local venesection. Yet there is ground for suspicion that, in former days, many a case of scurvy was so maltreated and ended fatally.

* Op. cit. p. 237. 


\section{CHAPTER XIV}

\section{SPASMODIC AFFECTIONS}

Neuroses Associated with Rickets.-These are Laryngismus, Tetany, and Convulsions. Laryngismus consists in sudden spasm of the glottis occurring on excitement, on waking from sleep, on sudden changes in position, and on exposure to cold draughts.

The infant holds its breath, becomes livid, struggles for a few seconds, then spasm relaxes, a loud crowing inspiration is drawn, and the attack is over for the time. In the intervals of the attacks, respirations are quiet and noiseless; the voice is not hoarse, there is no clanging or brassy cough, nor is there inspiratory recession of the soft parts of the chest, nor stridor, nor pyrexia as a rule.

Laryngismus may thus be distinguished from the various forms of Laryngitis associated with spasm.

Prognosis as a rule is favourable when there is no laryngitis, catarrhal, inflammatory, or membranous.

Fatal cases of laryngismus are sometimes associated with enlargement of the thymus and lymphatic glands, the socalled Status Lymphaticus.

Tetany is met chiefly in children under two, or towards the end of the first year-50 to 60 per cent. ; less commonly between the third and sixth year, rarely thereafter until the time of puberty when in girls it is again seen in 25 to 30 per cent. of cases.

Tetany is characterized by carpo-pedal contractions. The wrists are flexed and the fingers and thumbs approximated in the form of a cone. The feet are extended, the 
toes are parallel and flexed at the proximal, and extended at the distal articulations.

The dorsa of both feet and hands are usually bluish red, tender and swollen. Other muscle groups of the extremities may be affected as well as the interossei.

When spasm affects the trunk there may be emprosthotonos. Opisthotonos is rare.

The spasm is tonic not clonic. It may be increased on compression of the limbs (Trousseau's sign). Chvostek's sign (facial-nerve irritability) is often present. A light touch in front of the ear produces immediate contraction of all the muscles supplied by the facial nerve, precisely similar to that induced by electrical stimulus. The electrical reactions are abnormally active.

Convulsions associated with rickets, laryngismus and tetany are not unusual, especially when laryngismus is severe. They are therefore probably asphyxial in origin. Laryngismus is included amongst "lowest level," or fits of medullary origin, but when general convulsions, accompanied by loss of consciousness occur, the higher levels no doubt share the explosiveness of the lower.*

Causation.-Rickets is not the sole cause of laryngismus, tetany and convulsions, for many rachitic children never suffer from any of these nervous affections.

Probably therefore, individual nervous instability is present when they occur. Yet signs of gastro-intestinal disorder are seldom absent, and there can be no doubt that the exciting cause of rachitic neuroses is a toxaemia induced by unwholesome food, which has also to a great extent given rise to rickets. For the nervous symptoms are, with few exceptions, speedily relieved by supplying suitable diet, and by giving a few doses of castor oil and bromides. There is little ground for attributing any of these nervous disorders solely to dentition or to intestinal parasites except in rare instances.

The treatment in general of these neuroses is that of * Cr. Chap.: XV. 
rickets. Potted milks and patent foods should be discontinued, and pure cow's milk, unsterilized and un-Pasteurized, should be given, if procurable. The child should be suitably clad, day and night, but not over-clothed. Fresh air is essential. Coddling in close rooms should be discouraged.

For the immediate relief of laryngismus a sponge wrung out of hot water should be applied to the front of the neck, and the chin should be drawn forwards. Hot baths have been recommended. But before a bath can be prepared the spasm in mild cases has subsided, and in bad cases, the child may be dead long before medical assistance can be procured, unless artificial respiration is adopted at once. In every case therefore of laryngismus, instruction should be given in this method of resuscitation to be used in case of emergency. The indications for its use are sudden blanching, cessation of struggling and of respiration, and wide dilatation of the pupils. Smelling salts may be held under the nostrils during artificial respiration, but not whilst struggles for breath? continue, for ammonia may increase the spasm. Children under these conditions are too often hurried to the nearest chemist, doctor, or hospital, and die before they get there.

Very few cases of ordinary severity resist treatment by suitable diet, and by castor oil suspended in mucilage with rhubarb and bromide of potassium. Belladonna may be added or chloral hydrate, especially if convulsions have occurred.

The treatment of convulsions associated with rickets, laryngismus and tetany is that of convulsions in general (q.v.).

Rachitic Tetany as already stated, is easily cured. There are, however, some cases in which tetany is associated with marasmus, dilatation of the stomach, or colon, vomiting and diarrhoea in infants and young children who are not rachitic. The symptom in such cases is of the gravest omen. Sometime it occurs only in the last 
stages of exhaustion, sometimes it is more chronic, it persists for weeks, and is eventually fatal. Lavage of the stomach should be carried out once or twice daily, and peptonized milk or albumin water and whey should form the diet. The addition of citrate of soda, gr. 1-2 to the ounce of milk, may render it more capable of absorption. Rectal alimentation is often necessary.

Treatment is, however, in such cases rarely successful.

A more tractable form of tetany is also seen in young girls at the time of puberty. It usually quickly yields to treatment by purgatives, tonics and attention to general hygiene.

Congenital Laryngeal Stridor.-Although in most cases due to malformation of the epiglottis, which causes obstruction to respiration, this complaint may sometimes depend on want of co-ordination between the muscles which close the glottis and those which are otherwise concerned in respiration. Whether the defect is of the higher cortical centres, or of those in the bulb, is unknown. In many cases the affection subsides towards the end of the second year. It is, however, persistent in some, but these - are usually the subjects of congenital spasticity or other forms of birth-palsy. Special treatment, unless nasal obstruction by adeaoids or catarrh be present, is unnccesssary.

Rachitic Hypotonia and Pseudo-Paresis are described in chapter XIX, p. 251. 


\section{CHAPTER XV}

\section{SPASMODIC AFFECTIONS (Continued)}

Convulsions in Infancy and Childhood.-Dr. Hughlings Jackson defines a convulsion as "a sudden excessive discharge of many nervous arrangements representing movements at once or nearly together, because the cells subserving such movements have become highly unstable."

When convulsions occur in the absence of injury to the brain or of actual cerebral disease, or of toxic conditions such as uraemia we are justified in assuming that instability of the nervous elements is the chief morbid condition which gives rise to the convulsions. For the large number of disorders and complaints peculiar to children only excite fits in a certain proportion of cases.

This instability may be (1) of the medullary centres (lowest level) when laryngismus stridulus, asthma, recurrent vomiting, pyrexial attacks may occur. Rigors which are certainly not confined to adults, are believed by some to be of medullary origin.

(2) The Rolandic centres may be affected, causing fits of Jacksonian type, which may happen without structural defects in that area (mid level fits). The instability of lower and mid-level centres may cause explosions of higher centres, and so produce general convulsions.

(3) The frontal cortical regions may be involved, giving rise to generalized convulsions, by spread of the discharge to other centres (highest level fits), or the discharge may be limited to the higher centres, producing merely a "sen- 
sory " aura, or a momentary interruption of consciousness, with only slight convulsive movements or none at all (Petit mal, dreamy mental states).

What are the causes of such instability? We may assume that it is not a normal and physiological instability common to all growing brains, but an instability either congenital and hereditary, or acquired.

For, an infant whose brain cells are normal, unless they are affected by some profound influence, for instance traumatism or inflammation, does not become a prey to convulsions. On the other hand the infant whose brain cells are abnormally unstable may suffer from convulsions owing to extremely trivial causes of irritation.

The distinction is important as regards prognosis-for if an infant who is properly fed and believed to be healthy by nature and inheritance suffers from convulsions, the probability is that the disturbance which excites them is of grave nature, whereas convulsions in an infant whose neuropathic inheritance is assured may be set up by slight causes which may readily be treated or removed. On the other hand when no such cause, trivial or otherwise, can be - detected, convulsions in early infancy may portend at best a speedy death, at worst a life of idiocy, imbecility, and epilepsy.

Convulsions in infancy and childhood may be considered under the following headings : (1) Eclampsia neonatorum; (2) Predentition convulsions; (3) Convulsions during the period of primary dentition; (4) Convulsions occurring between primary and secondary dentition.

1. Eclampsia Neonatorum. Convulsions in the newlyborn may be asphyxial, due to supervenosity of blood, and venous turgidity arising from prolonged and difficult labour, especially in the first-born. Cyanosis is frequently present in such cases, and the treatment then consists in the application of leeches-one to each mastoid process-or in actual blood-letting.

Willis, in the seventeenth century, having seen a scrics 
of infants die of convulsions shortly after birth, in a single family, bled the next arrival at once, and claimed that it escaped convulsions, and survived in consequence of his treatment.

Blood-letting is only justifiable when the infant is obviously healthy, though plethoric. Pallid, puny and anaemic infants who become convulsed shortly after birth should be treated by warmth, stimulants and saline injection sub cutem.

Convulsions from Cortical (Meningeal) Haemorrhage at Birth. Prolonged and difficult labour suggests this cause. Supra-cortical haemorrhage, if not fatal, causes various kinds of birth-palsy - spastic hemiplegia, paraplegia, or diplegia, with or without epilepsy, and mental deficiency. Hence, if diagnosed, operative measures are clearly indicated. Unfortunately focal commencement of fits is not an infallible guide to diagnosis, even when transient local paresis or paralysis of a limb or limbs follows the convulsions. Such paresis must be persistent, or there must be rigidity of the affected limbs, and the convulsions must be invariably of Jacksonian type, in order to justify the diagnosis of cortical hacmorrhage, and recommendation of craniectomy.

2. Pre-Dentition Convulsions. In the absence of traumatism, organic disease of heart, lungs or kidneys, congenital syphilis, otitis media, and the various forms of meningitis-simple, basic, purulent, and tuberculous-convulsions are usually traceable to improper food or overfeeding. A highly neurotic family history suggests predisposition to fits, which may be induced by very slight disorders of digestion.

Inward Convulsions are so called for the excellent reason that the infant is not outwardly convulsed, but merely rolls its eyes, moans or grins, clenches its fists, and draws up its legs at frequent intervals.

In some cases the infant suddenly lowers its head, doubles up its body, or straightens it out, the breath is held for a few seconds, and a scream or moaning cry of pain follows. 
Consciousness is not lost. Most of the above-mentioned seizures are due to colic.

A dose of castor oil, with a minim or two of laudanum in accordance with infant's age, usually puts a stop to them, and prevents recurrence, if suitable diet be supplied.

3. Convulsions During the Period of Primary Dentition have already been considered.

4. Convulsions between Primary and Secondary Dentitions. Excluding gross meningeal and cerebral diseases as causes, after the second year of life, colic from improper or excessive feeding is held to take the first place. Convulsions in such cases are usually regarded as produced by reflex irritation. But they may also depend on absorption of toxins produced by unwholesome and decomposing food. Toxaemic convulsions may also result from severe burns and scalds, and may occur as uraemic symptoms.

Reflex Convulsions have been attributed to diseased or impacted teeth, to errors of refraction, especially astigmatism, to diseases of the throat, nose, and ear, to the presence of foreign bodies in the various orifices of the body, to phimosis and balanitis, and to the presence of intestinal parasites.

It is the duty of every practitioner in a case of convulsions to search for any condition which may have lowered general health, and to rectify it if possible. But convulsions are more often the indirect than the direct result of any of the so-called "reflex irritations" enumerated. In many cases a hopeful prognosis based on the removal of threadworms, or of a prepuce, or on the correction of astigmatism, only leads to disappointment.

Fits, at the onset of an exanthem, are certainly rare, and when they occur it will usually be found that the child has had them before, or becomes liable to them afterwards.

Of psychical causes, fright or shock must be mentioned. The relation of rickets to eclampsia has been mentioned in the preceding chapter.

Acute Encephalitis as a cause of fits in children needs 
mention here-for it is only within recent years that acute encephalitis has been established as a distinct affection, which is not only attended at its onset by convulsions and grave cerebral symptoms, but may be followed by frequent attacks of epilepsy in after life.

Treatment of Infantile Convulsionsin General. -Treatment aims at stopping the fits, removing the exciting cause, and preventing recurrence.

Hot baths, with or without mustard, and mustard packs are of doubtful efficacy, but may relieve colic when present.

Ice to the head should be used when there is hyperpyrexia, and the patient should be placed in warm water, which should be gradually cooled to $50^{\circ} \mathrm{F}$, or even $40^{\circ} \mathrm{F}$. In all cases, the lower bowel should be washed out with saline solution ( 1 drachm to the half pint of warm water). Then, a rectal injection of chloral and bromide, 3 to 5 gr. of the former, and double or even treble the quantity of the latter, in $2 \mathrm{oz}$. of water, for a child of six months of age, should be given.

Inhalations of chloroform may be used to allay spasms whilst the injection is being absorbed.

Inhalation of nitrite of amyl is recommended by some, and hydrobromide of hyoscine in hypodermic injection of $\frac{1}{200}$ to $\frac{1}{100} \mathrm{gr}$. is said to be useful in protracted cases of convulsions. It is not, however, free from danger in debilitated infants. Injections of morphia ( $\frac{1}{20} \mathrm{gr}$.) for a child of six months, are preferable to those of hyoscine, but should never be repeated within twelve hours. When cyanosis is present, leeching, or even venesection, should be employed; provided that the infant is fairly strong, $\frac{1}{2}$ to 1 oz. of blood may be abstracted.

Emetics are never advisable, but the stomach should be washed out if there is any suspicion of its containing poison or irritants of any description. Of all emetics mustard is the most dangerous.

Whilst treatment is in progress, the probable exciting cause of the convulsions should be ascertained by observation 
and inquiry. Whatever this may be, a full dose of calomel or castor oil never does any harm. After-treatment consists in keeping the child quiet, and warm or cool, as indicated by the temperature. Attention to diet is of course all important, for the vast majority of infantile convulsions are set up by gastro-intestinal disturbance.

Reflex sources of irritation, such as nasopharyngeal obstruction, worms, local genital complaints, ear and eye troubles, should be attended to. Rickets should be treated in the usual manner.

Prognosis in Infantile Eclampsia. The inevitable questions asked in every case of infantile convulsions, are "Will he be an epileptic?" and "Will his brain be affected?"

The answer should always be cautious and based upon full consideration of the probable cause of the fits, and also upon their character and apparently local origin in different areas of the brain and its stem.

It is said that about 10 per cent. of infants who suffer from convulsions become epileptics in after life. This percentage is considerably raised if cases of convulsions due to organic cerebral disease are included, so in the absence of this, and of signs of defective intelligence and malformation of the skull, a hopeful prognosis is wisest. Bad signs are persistent unilateral or focal commencement of the fits, and the recurrence of momentary loss of consciousness, pallor, and slight twitching, in conjunction with a family history of epilepsy, insanity, eccentricity, narcomania, or alcoholism, which is present in from one-third to one half of cases of idiopathic epilepsy. The diagnosis of epilepsy is not usually made until after the third year of life ; yet it must be remembered that the distinction between eclampsia and epilepsy is but arbitrary.

It is true that babies do not bite their tongues in fits, nor is it possible to elicit from them any account of the various aurae which precede epileptic attacks in later life. Yet, eclampsia is only a synonym for epilepsy. The explanation of the fact that infants who suffer from fits become 
epileptics in after life in some cases, namely those of reflex or accidental epilepsy, lies in the old statement that "Epilepsy is a habit" - a habit which is induced by frequent repetition. If certain sets of cells in any of the cerebromedullary areas have once been rendered explosive by local or distal irritation of any kind they will continue to respond to stimulus with an ease which constantly increases.

Hence if the question be asked-whether infantile fits will end in chronic epilepsy-one can only answer that this will depend on our power to ascertain and remove the original source of the convulsion, and other exciting causes should they arise. When careful investigation reveals no physical cause of convulsions, the probability that the infant is an idiopathic epileptic, an idiot, or both, is great. Yet a prognosis of mental affection, idiocy, imbecility, or feeblemindedness arising in consequence of infantile convulsions should seldom be stated at the onset. It is usually most politic to give a hopeful outlook in the interests of parents and patient-except in cases in which a status epilepticus has continued for weeks on end in spite of all treatment which skill can devise, and in the absence of a special exciting cause. Such cases are comparatively rare, and can only end fatally, or in amentia of the most degraded type, and it is well to say so at once. But in the great majority of cases, even though a shrewd suspicion may be entertained on account of stigmata such as asymmetry of skull, illshaped and ill-placed ears, etc., that the infant may be an imbecile, such opinions, are best kept secret. The sorrow of the parent may be mitigated and the welfare of the patient secured by the assurance-which in all cases is kindly as well as true-that the future mental condition of the child will depend largely upon the measure of care and attention which may be lavished upon it. It is well to be reticent as to the bearing of a bad family history, whilst emphasizing the favourable importance of a good one upon the case. Few parents will admit that their infant is an imbecile until long after the fact has been apparent to outsiders. 
The discovery is less painful when made by degrees, and it should rather be confirmed than disclosed by the physician.

The prognosis must of necessity be unfavourable when evidence exists of structural damage to the brain, either from inflammation, blockage of cortical vessels or haemorrhage, and in cases of physical mal-development and uraemia.

The prognosis is far more favourable when convulsions, as so often happens, are directly attributable to digestive errors caused by improper food, and in rickets.

In cases of so-called "Reflex convulsions" the probability of permanent cure after removal of the presumed cause of irritation depends entirely on our having to deal with idiopathic or what has been termed "Accidental Epilepsy."

True idiopathic epilepsy is practically incurable, and to treat all cases of epilepsy as though they are symptomatic or reflex, only leads to disappointment. On the other hand it must be confessed that in many cases of reflex convulsions the irritant which causes them is so slight that a special susceptibility to fits must be assumed.

In such cases although the special cause be treated or removed, and the convulsions cease for the time, we must be prepared for their recurrence whenever a fresh source of irritation makes its appearance.

The prognosis in these cases depends rather upon our power to lessen instability and irritability of the brain cells than upon the correction of each minor cause which excites them.

Epilepsy.-As previously stated, no hard and fast distinctions can be made between eclampsia and epilepsy in children. The symptoms are the same, except that in eclampsia the tongue is rarely bitten. The most frequent aura in children old enough to mention it consists in sudden epigastric pain; but auditory, visual, olfactory, and gustatory aurae are sometimes experienced. These are of importance as indicating the probable focus of instability. 
As in infantile eclampsia, the nervous discharge which occasions epilepsy may have its origin in the nuclei of the spinal cord and ponto-bulbar areas-(lowest level); -in the Rolandic or sensori-motor area (mid-level);-or in the highest or psychical regions of the brain.

Instability or explosiveness of cells in any of these areas will give rise to characteristic seizures. If in the lowest level, there may be gross movements, chiefly of the trunk, and attacks of laryngismus; if in the mid-level there will be fits of the well-known Jacksonian type, perhaps without loss of consciousness, whilst if in the highest level there may be merely psychical conditions attended by loss of consciousness or perverted mental conditions, "petit mal" or dreamy mental states with only slight motor convulsions or none at all. In all cases the discharge may be localized, or it may spread to contiguous cells until a general explosion occurs with the phenomena of "grand mal."

Etiology of Epilepsy.-The etiology of epilepsy is that of eclampsia. Excluding all cases in which epilepsy is due to traumatism, to gross cerebral disease and toxaemic conditions such as uraemia, two classes may be considered -the Idiopathic and the Symptomatic or accidental. They are about equally divided in numbers.

In idiopathic epilepsy, fits occur without apparent cause -psychical or physical. The patient is usually in the best of health at the time of the first seizures. As a rule he is dull, stupid, and unemotional. One can only attribute idiopathic epilepsy to an inherent instability of the cerebral cells, which causes them to discharge energy from time to time, much as an automatic cistern empties itself periodically when full.

In symptomatic, reflex or " accidental" epilepsy one must admit an instability of nervous elements, comparable to that which obtains in idiopathic epilepsy, but the instability is manifested at first only in the presence of some definite local or distal cause of irritation-which renders the unstable cells explosive. 
One must admit again that in many cases the distal causes which bring about an explosion are often extremely slight in themselves, and quite incapable of causing convulsions in those whose brain cells are normal. Yet probably in every case some definite source of irritation will be found, either in the shape of painful dentition, gastrointestinal disorder, a foreign body in some orifice of the body, an adherent prepuce, or defective vision, or in the form of sudden shock or long continued emotional excitement.

The accidental epileptic is usually excitable, passionate and emotional, and unlike the idiopathic epileptic, his intellect is often much above the average. He may suffer from most of the ailments such as migraine, asthma, night terrors, enuresis, habit spasms, to which neurotic children in general are liable.

The part played by rickets in causing epilepsy in after life has, I think, been exaggerated. As mentioned above, the neuroses associated with rickets-laryngismus, tetany and convulsions - are usually attributable to improper feeding rather than to rickets itself. The convulsions in rickets are often associated directly with laryngismus, and are then probably asphyxial in type. At the same time children who suffer from rickets may also be epileptics of either kind.

The influence of heredity has already been referred to in the case of infantile eclampsia, and it applies equally to cases of both idiopathic and accidental epilepsy.

I am inclined to think that idiopathic epilepsy is more directly inherited than is the accidental type. The majority of the children of idiopathic epileptics are epileptic also, imbecile or both, whereas in the case of accidental epileptics it is more common to find a history of insanity, eccentricity, hysteria, asthma, migraine, drug taking, alcoholism, and suicide, than of epilepsy itself.

The effects of drunkenness on the part of the parents in producing epilepsy in their children have been variously 
estimated. Eccheverria found alcoholism in 17 per cent., but Wildermuth in less than 2 per cent of his cases.

Dr. R. O. Moon* found that in a fourth of his cases of epilepsy the parents (one or both) drank to excess; in another fourth they were teetotallers, while the remaining half were distinctly moderate drinkers.

With regard to mental weakness in epileptic children there were twice as many cases among children in whose parents there was no history of alcohol as among those whose parents were drunkards.

Petit Mal and Dreamy Mental States.-Petit Mal is usually regarded as "faintness" or syncope by lay observers ; temporary pallor and dazed look, and momentary loss of consciousness being the prominent symptoms. Their true significance is seldom realized, even when attacks of "haut mal" have occurred, and they are seldom mentioned except in answer to inquiry.

The importance of recognizing "petit mal" is great for it is associated with the most intractable cases of epilepsy, and it may precede "haut mal" by a period of months, or even years. Early recognition and treatment of the symptoms may perhaps prevent this minor affection from leading to the major.

Combinations of the two are always hardest to treat.

Dreamy Mental States are closely related to petit mal; they may result in or occur in conjunction with epilepsy.

But in many cases they are merely indications of exhaustion of an over-worked brain which is usually of highly imaginative and intellectual order. Probably most geniuses of the poetic, artistic, and literary type have been liable from early youth to fits of reverie and absorption in which they revel fancy-free in cloud-land scenery. Jules Breton (La vie d'un artiste) records the pleasure with which in his childhood he used to watch the pictures, charming, quaint, foolish or horrible, according to the mood of the moment, which he called up before him every night after the lamp had been put out. 
First came dim rays of light flecked with brown floating shadows, a perpetually moving chaos strewn with starlike spots. Gradually definite shapes appeared; great gloomy blood-coloured plains on which hideous serpents crawled with sudden movements corresponding to the beating of his pulse, grew suddenly light, full of sunbeams and the serpents turned into garlands of flowers.

Fabulous birds flew backwards and forwards. Windmills turned against the background of the sky, the whole scene flying past at an exciting, bewildering speed which almost drew him with it from his bed. Then it would be the sea which rolled and unrolled itself like an enormous canvas in whose folds he felt himself caught, carried off and luxuriously rocked-or an expanse of sky appeared with magnificent golden clouds on which St. Nicholas, St. Catherine, the Virgin and Child Jesus walked, whilst bluewinged angels whirled joyously about. At other times he saw rooms full of shadows and strange utensils, huge kitchens with great fires at which the devil turned the spits-or again the rooms would fill with crackling many-coloured lights like fireworks. Live playthings, or sometimes a religious procession such as he had really seen went by, and once to his great joy his dead mother suddenly appeared and clasped him in her arms.

Jerome Cardan mentions his indulgence in a similar habit of conjuring visionary hallucinations at will in early childhood.*

Between his fourth and seventh year he was not allowed to rise until the second hour after sunrise, as his legs never became warm in bed until the morning. Lying thusawake he said, but more probably betwixt waking and sleeping-he commonly saw colourless figures which seemed to be made of rings of mail rising out of the right-hand corner of the bed. The figures which followed each other in a long procession were of houses, castles, animals, knights on horseback, plants, trees, musical intruments, trumpeters in the act of blowing, groves, woods, flowers, and wild

* De vita propria, op. cit. Cap. $\mathrm{xxx}$ ii. 
shapes that resembled nothing which he had ever seen before. Rising from the right hand corner of the bed the figures described an arch, descended into the left hand corner and were lost.

Jerome enjoyed the spectacle but kept it secret lest if he revealed the mystery, whatever caused it would be offended, and he should see the show no more.

Henry Morley in his Life of Cardan commenting on this passage says: "During the same period of childhood I rarely fell asleep till $I$ had received the visit of a crowd of visionary shapes which were not by any means agreeable. I had also during that period holiday phantoms, in the beauty and the mystery of which I took delight and concerning which I had in the strongest degree the same childish belief that is mentioned in the text, that "Si fatebor indignabitur quicquid causam prebet hujus pompae, subtrahetque hoc festum."

Indulgence in this respect may be harmful, especially when unbridled, habitual and in association with signs of mental exhaustion. Irritability, passion, lethargy, forgetfulness and inattention, headache, disturbed sleep, spasms and involuntary movements, together with evidence of physical ill-health are often associated with dreamy mental states. When pleasurable they perhaps do little harm, but they are highly significant of danger when attended by ill-defined dread or an inexplicable horror of surroundings. Claustrophobia, agoraphobia, acrophobia ; a painful sense of unreality of personal existence and identity, a loss of sense of space, time, and orientation ; an equally painful feeling of banality, of pre-existence, and of prescience, and also hallucinations of sight, hearing, smell and taste, may all form part of the dreamy mental states of children and adults alike. Evidence of this in children is chiefly based on confession in later life. Children of the age of eight to twelve will not as a rule own to sensations of the kind, lest they should be called silly, whilst younger ones can only show that they are frightened without explaining why. 
Paroxysmal screaming fits, without apparent cause, and day and night terrors may be instances of painful dreamy mental states.

Fits of reverie and absent-mindedness should not be regarded merely as bad habits, although it is true that a sharp word or sudden shake may check them at their onset. Some therefore recommend that they should be treated by scolding, "wholesome neglect" and cold water. It may be unsafe as well as unjust to regard them as moral offences. Both petit mal and epilepsy may be arrested by a sudden peripheral stimulus, epileptics often say that they can sometimes ward off attacks by strong effort of will, but it does not follow that any epileptiform seizure is voluntarily induced. Many are quite unaware unless told that they are subject to epileptiform attacks of any kind.

Dreamy mental states are at times undoubtedly epileptiform in nature, though if recognized and treated as indications of a brain over-taxed, or on the eve of being so, they may never result in epilepsy.*

Schoolmasters should be made aware that pupils, hitherto bright, who at about the age of puberty become dull, inattentive and apparently wilfully obstinate, stupid, and lazy, are not always culpable. They should be familiar with the case of Balzac, already cited. Allusion has already been made to the monstrous error of imputing reverie, etc., to the effects of masturbation.

Treatment of Epilepsy.-The treatment of epilepsy associated with congenital mental enfeeblement, or gross congenital cerebral disease, can only be palliative.

Idiopathic epilepsy is said to be curable in about 10 per cent. of cases, and an epileptic who has been free of fits for ten years may be regarded as cured. The prognosis in a given case must be based largely on the family history. A bad record of epilepsy itself makes the outlook gloomy. A history of insanity, alcoholism, and other neuroses in past and present members of the family is less ominous. 
Were the results of treatment based on observation of idiopathic epileptics alone, the percentage of cures would be considerably less than 10 per cent.

But on the other hand, a large number of epileptic children, and adults too, have slight hereditary tendency to the disease, or none.

Many of them are above the average in intellectual capacity, although of highly neurotic or emotional temperament. They rank amongst the idiopathics, but should be classed by themselves - as " accidental " or symptomatic epileptics. I refrain from quoting the well-known historical example of such. In some, epileptic attacks only occur under acute, or in consequence of chronic emotional excitement-in others, physical ill-health and unsuitable surroundings induce fits, in others chronic reflex irritation from local mischief is the exciting cause. In all such cases treatment to be successful must extend beyond giving bromides and correcting minor abnormalities.

In early days of enthusiasm one is apt to wage war against all possible reflex irritation in every case of apparent epilepsy ; to correct refraction errors, remove tonsils, adenoids, nasal polypi, straighten deviating septa, stop or extract teeth, and reduce redundant prepuces ; to " rouse a torpid liver" (if one knows how to do it), stimulate a languid stomach, expel faecal accumulations and parasites; impose a scientific diet sheet, and attempt to purify the blood ; in fact to execute every kind of alteration and repair which seems desirable down to the evulsion of an ingrowing toe nail and the cutting of a painful corn.

Many of us on the strength of a few cases in which success seemed to follow one or other of the above named procedures, have formed the conclusion that all cases of epilepsy are to be cured by similar measures, and have rushed into print to say so. But wider experience shows that neither one nor all methods are infallible in the cure of the "accidental epileptic," whilst the idiopathic epileptic derives no benefit from any such measures. 
In the case of the neurotic emotional child who suffers from accidental epilepsy, obvious causes of reflex irritation should be removed if possible, but this avails but little so long as mental and emotional disturbance continue.

If such a child is unhappy from any cause, he will not be cured of fits by correcting his astigmatism nor by ridding him of threadworms.

The results of removing him from uncongenial surroundings are often better than those of attempts to treat the disease itself or its possible local and physical causes.

Indispensable adjuncts to treatment are a quiet emotionless existence, freedom from mental and physical fatigue, good food and pure air.

The distinction between accidental or occasional, and idiopathic epilepsy cannot be too strongly emphasized.

The Use of Bromides.-Bromides are invaluable in the treatment of all forms of epilepsy, but discretion in the manner of using them is necessary. A common mistake is to increase the dose every time a fit occurs-whereas the indications may have been to lower it.

For bromides, given for long periods, whilst lessening explosiveness in one cerebral area may reduce inhibition in another. The result of excessive bromide treatment is general decrepitude, mental and physical, and therefore fits increase in number though they may be reduced in severity.

One may do more harm by giving bromides in excess than by not giving them at all. It is a common experience in hospitals that accidental epileptics who have undergone a long course of bromide treatment outside without benefit, soon improve when admitted as in-patients, although mist. gent. alk. may be the sole remedy supplied.

As to choice of bromides, so long as small doses are given it does not seem to matter whether bromide of sodium, ammonium, or potassium be used. But when doses of 20 to 30 grains are given for any length of time, it is better to mix the salts rather than to give one exclusively. I have been unable to convince myself that one bromide salt is more 
lowering than another, but full doses of any are apt to disagree.

The reported efficacy of bromides of gold, strontium, lithium and zinc may be due to the fact that they are usually given in smaller doses than those commonly prescribed of other bromides, and that they are employed after large doses of the bromides of sodium, ammonium and potassium have deranged digestion.

The addition of arsenic to bromides undoubtedly lessens or even prevents acne, but arsenic should not be given habitually and for long periods. I have met with several cases of mild arsenical poisoning produced in this way.

Digitalis is a useful addition to bromides when the circulation is poor. Possibly it has some direct sedative action upon the central nervous system. Belladonna and atropin are valuable in cases of petit mal, especially in children.

Iron in the form of ferri et ammon. cit. may be given with advantage with bromide of ammonium, when anaemia. is present.

Tincture of cannabis indica is sometimes beneficial when complaint of persistent headache is made.

When bromides are ineffective, the addition of borax in doses of from 5 to 10 grains for a child of ten or twelve, or in the form of glycerine of borax m. 10 to half a drachm sometimes is beneficial.

The time at which bromides are administered is often of great importance-particularly when fits occur at regular intervals, for instance, within an hour or so of falling asleep or only whilst dressing in the morning.

No set rules can be laid down, but the best time for administration may be ascertained by experiment.

In cases of nocturnal epilepsy, a full dose may be given an hour or two before the fit is expected. But when fits occur only at night, some minor asphyxial trouble, caused by adenoids or nasal obstruction, or unhealthy modes of sleeping, or faulty hygienic conditions in the bedroom should be suspected. 
Fits on rising should be treated by giving a light meal and a dose of medicine half an hour before getting up.

In diurnal epilepsy when the fits occur indiscriminately the bromides should be given at regular intervals three or four times a day.

When it becomes obvious that we have to deal with an idiopathic and not an "accidental "epileptic, the bromide treatment must be kept up for at least two years. It may then be cautiously reduced.

All who have had any considerable experience with epileptics will be familiar with those who "always have fits when they try to do without the medicine."

There can be no doubt that in many cases fits may be prevented altogether by judicious use of bromides, and attention to general health. It is equally certain that patients who have been over-dosed with bromides often derive more benefit from strychnia and other tonics.

As regards food, a mixed simple dietary is usually best, without much meat, and without strong tea, coffee, and stimulants. Occasionally one meets with cases in which a vegetarian diet is advantageous, but these are few. Some - epileptics have a voracious appetite, and admit that repletion increases the number and severity of their attacks.

A salt-free diet has been recommended, but it is of doubtful advantage-indeed, chloride of sodium is an ancient remedy for epilepsy. 


\section{CHAPTER XVI}

\section{SPASMODIC ASTHMA}

Is this treatise it is impossible to deal adequately with asthma in all its bearings. Stress can only be laid on spasmodic asthma as a purely functional neurosis. In early infancy spasmodic asthma is rare, but, according to Hyde Salter, in 31 per cent. of cases, it has its onset during the first decade of life. The writer has seen one fatal case, to which further reference will be made, in an infant, aged eleven weeks. Henoch recorded two cases in infants aged eight months ; Baginsky, one at nine months; Moncorvo, one at two months; Comby, one at six weeks ; Hyde Salter, one at fourteen days, one at three months and three during the first year of life. W. Ewart, Ashby and Wright have each met with spasmodic asthma in infants aged seven months. Spasmodic asthma in early infancy may, however, escape recognition because bronchitis masks the symptoms.

Yet severe and acute bronchitis, such as is seen in adults, is so uncommon in infancy, that when an infant seems to be at death's door from the complaint, and recovers with almost miraculous suddenness, asthma may be suspected.

In rare instances an infant succumbs after several or even after a few severe attacks of dyspnoea and acute bronchitis, and subsequently, general emphysema of the lungs is the chief lesion discovered.

The following case, which Dr. G. A. Sutherland kindly allows me to report, is in point.

A male infant, aged ten weeks, was admitted to the Children's Hospital, Paddington Green, under Dr. Sutherland's 
care in 1903, for cough, wasting and dyspnoea of three weeks' duration.

The child had been weaned at six weeks of age and fed upon cow's milk, which he frequently vomited. The motions were green and offensive.

On admission he was small and thin, the skin was dry and loose. Respirations were hurried and laboured, and there was an occasional short cough. The sternum was prominent and there was recession of the epigastrium and supra-and-infra clavicular regions on inspiration. The sterno-mastoids were tense.

The percussion note was generally flat in tone but there was no dulness. On auscultation, râles and sonorous rhonchi were heard all over the lungs, but no tubular breathing. The tonsils and lymphatic glands were not enlarged. The temperature was normal.

After admission the dyspnoea was always present, but once or twice a day severe paroxysms occurred in which the child became cyanosed, and breathing was almost suspended. These attacks usually occurred after food, lasted about an hour, and seemed to be relieved by expulsion of flatus by the mouth.

The infant wasted rapidly, and died ten days after admission, apparently from exhaustion. The temperature was never above $99^{\circ} \mathrm{F}$. until just before death, when it rose to $101^{\circ}$.

Post-mortem, both lungs were extremely emphysematous, and so large that they quite concealed the heart. On section they were dry and crackled on manipulation. The bronchioles were thickened and stood out prominently from the cut surfaces of the lungs. They were filled with mucopus.

The larynx, trachea, heart and kidneys were normal. The thymus gland and the bronchial, mediastinal and mesenteric glands were not enlarged.

The symptoms and post-mortem findings leave little room for doubt that asthma was the cause of death. 
However, the characteristic symptoms of spasmodic asthma are seldom seen before the age of four years, and most commonly they make their appearance at the age of six, seven or eight years, - after, or (less frequently), without a history of repeated attacks of bronchitis.

Spasmodic asthma is attended by all the essentials of a functional neurosis.

Thus, a neuropathic inheritance of one kind or another was present in fifty out of 123 cases (Allbutt). In twentyfive there was direct transmission of asthma or of hay fever ; in other families, migraine, somnambulism and diabetes existed.

Predisposition to the complaint is a matter of inheritance and is an important factor in all cases. Other factors seem to be undue sensitiveness and irritability of the mucous membranes of the air passages, sometimes with, but more frequently without any deviation from normal structure which can be detected.

Abnormal irritability or instability of the medullary respiratory centres seems to be another factor. The presence of any source of local irritation, however remote it may be and however slight in itself, is sufficient to set up medullary "nerve storms" in the shape of asthmatic paroxysms. Sometimes irritability of the medullary respiratory centres appears to be solely responsible, for no source of reflex irritation is discoverable.

Hence spasmodic asthma has been regarded as an instance of " lowest level " or medullary fit, comparable to epilepsy, in which higher centres are affected.

Like epilepsy, spasmodic asthma is divided into symptomatic (or accidental) and idiopathic forms. The symptomatic shades off imperceptibly into the idiopathic in accordance with decreasing severity of the exciting cause.

Spasmodic asthma, like accidental epilepsy, may be described as a habit. At first it is excited by some definite and all sufficient cause, later, as the paths of reflex excitability become well worn, the provoking stimulus increases 
in potency whilst decreasing in actuality until finally it is infinitesimal yet all powerful.

The simile of the "hair trigger" applies to the mode of production of spasmodic asthma as to that of other paroxysmal neuroses.

In young infants, as previously mentioned, bronchitis or catarrh affecting any part of the upper or lower air passages is the commonest exciting cause of asthma.

The next most frequent cause is indigestion, which in one infant may give rise to eclampsia, in another is responsible for asthma.

In either case sensitiveness to gastro-intestinal irritants, or sensitiveness to catarrh increases, and with it a similarly ready response to irritation on the part of higher or lower centres in the brain and medulla respectively. Ultimately the most trivial catarrh and the slightest upset of digestion will induce asthma or eclampsia, as the case may be.

In children of three years and upwards in whom a predisposition exists, the onset of asthma may sometimes be traced to definite gross causes, such as nasal polypi, adenoids and enlarged tonsils, deviated septa and so forth. These - and other remote sources of reflex irritation are the same as those which have been enumerated in the case of eclampsia, epilepsy, night terrors and enuresis.

Spasmodic asthma, however, differs perhaps from other functional neuroses in the peculiarities and varieties of its exciting causes in individuals. Such causes include individual susceptibility to the effects of single articles of food, to tastes, smells, sights, to atmospheric conditions which defy definition, and to mental emotions which evade classification.

Idiosyncrasy of this kind cannot be explained, but can only be accepted as an authenticated fact. Sometimes, as in the much quoted instance of rose asthma excited by the sight of artificial flowers, the mental element is predominant, but in the majority there can be no doubt as to the purely physical effect of specific irritants on the air passages. 
Alternation with other Complaints.-A curious characteristic of asthma, and one which brings it into line with functional neuroses in general, is its tendency to alternate with skin affections such as eczema, psoriasis and urticaria ; with migraine " dead fingers" and other vaso-motor disturbances, and with attacks of cyclic vomiting, dyspepsia and flatulency.

A girl, for instance, until the age of two and a half years suffered from eczema of so severe a type as to lead to a diagnosis of Hebra's prurigo, and a hopeless prognosis. The eczema, however, then quickly subsided, only to be followed either by severe spasmodic asthma or by sudden outbreaks of urticaria, which occurred almost immediately after eating oatmeal in any shape.

Another case is that of a young lady who from early childhood had been subject to severe spasmodic asthma. Suddenly the attacks ceased for upwards of a year, but during the whole of that time she was so disfigured by acne rosacea that she was compelled to wear a thick veil to hide her features. The acne then rapidly disappeared but with simultaneous recurrence of asthma. This patient, again, would have attacks of "dead fingers" so severe as to prevent her from dressing herself on some mornings, and asthma on others, but she never had dead fingers and asthma at the same time.

Periodicity of Attacks.-Except in confirmed asthmatics in whom chronic dyspnoea is the result of structural pulmonary changes, and exacerbations become infrequent, spasmodic asthma is typically periodic. Putting aside cases in which periodicity in attacks is due to repetition of some special exciting cause peculiar to the individual, there are others in which periodic attacks occur at regular intervals, and seem to be independent of all external circumstances.

In this aspect one is reminded again of the periodicity which attends migraine and some cases of epilepsy, whilst the fact that sufferers from these complaints, like victims of spasmodic asthma, nay remain perfectly well in the inter- 
vals between attacks, favours the view that spasmodic asthma is a paroxysmal neurosis.

Finally, like epilepsy and migraine, spasmodic asthma is often preceded by premonitory symptoms such as drowsiness, for instance, or by warnings recognized sometimes only by the patient, and sometimes only by his friends.

Most nerve storms brew before they break.

It seems at first difficult to accept the theory that hypersensitiveness to stimuli, and conscquent explosions of misplaced energy on the part of the respiratory centres in the medulla, account for spasmodic asthma in face of physical signs which point to obstruction of the air tubes.

There is evidence that such obstruction exists either in the shape of spasmodic constriction of the bronchioles, or of an acute oedema, urticarial in type, affecting the mucous membrane of the air passages, or in the form of fibrinous exudation in the smaller bronchial tubes.

Yet the symptoms of spasmodic asthma cannot be explained by obstructions to the air passages alone. For the symptoms of obstruction do not resemble those of asthma.

In asthma there is a struggle between the inspiratory - and expiratory muscles, in which the former, although the weaker, seem to get the better.

The lungs are filled with air to their utmost capacity, the chest is enlarged to its full dimensions, as shown by the physical signs. Yet the patient strives to introduce more air into the lungs than they can hold, whilst unable to exhale that which they retain.

Were obstructions from spasm of the air tubes, or turgescence of their mucous membranes, the sole cause of asthma, it would be equally difficult for air to enter and to escape.

But air can come in, though it cannot get out. This cannot be explained by any valvular ball-plug theory, seeing that the bronchioles widen from the periphery towards the bronchi.

So the most probable explanation is that an asthmatic paroxysm is due to perverted action of the respiratory 
muscles and not solely to mechanical obstruction of the air passages. Moreover, such perverted action of respiratory muscles, in which the normal balance between inspiratory and expiratory forces is upset, probably depends upon reflex disturbance of the respiratory centres which govern respiratory movements.

It may again seem difficult to attribute turgescence and congestion of pulmonary mucous membranes, bronchorrhoea and fibrinous exudations to central nervous disturbance ; yet a certain parallel may be drawn between the lungs and the intestines in this respect. Every one is familiar with the nervous diarrhoea which in certain persons is set up by any worry or mental trouble, and it would seem that an even closer analogy exists between the local bronchial and pulmonary conditions in asthma and those of the intestines in certain cases of mucous colic, or membranous colitis, namely, entero-spasm, mucous diarrhoea with the presence of fibrinous exudations or casts which bear no distant resemblance to the fibrinous sputa of asthmatics.

Mucous colic may indeed be set up by constipation, abuse of aperients, and by local disease of the bowel, but most agree that it is in many cases a pure neurosis occurring in neurasthenics of the restless emotional type, and these are also fitting subjects for asthma.

The pathogeny of spasmodic asthma may be summed up as an inherent and often hereditary instability of the medullary respiratory centres, causing them to explode at intervals, spontaneously or at the bidding of stimuli of varying nature, into storms of misdirected energy.

To this may be added inherent or acquired sensitiveness and irritability of the whole or part of the mucous membrane lining the respiratory and alimentary tracts.

The differential diagnosis between spasmodic asthma and dyspnoea due to laryngeal obstruction, or to obstruction of the trachea and bronchi by foreign bodies or by enlarged glands and mediastinal growths ; and the distinction between true asthma and dyspnoea or "air hunger", 
miscalled cardiac, uraemic, and diabetic asthma, need not be emphasized here. It is only necessary to mention that a few-perhaps very few-cases of spasmodic asthma are traceable to definite naso-pharyngeal conditions such as polypi, deviations and spurs of the septum nasi, and to adenoid growths and enlarged tonsils.

Hay Fever, Paroxysmal Rhinorrhoea and Paroxysmal Sneezing are neuroses akin to spasmodic asthma and often associated with it. They are instances of individual susceptibility to special kinds of irritants.

Thymic Asthma so-called, is dyspnoea, associated with enlargement of the thymus gland, spleen, and of the internal lymphatic glands throughout the body (Status Lymphaticus). Sudden and unexpected death is apt to occur in these conditions. Some attribute these fatalities to pressure by the thymus gland upon the nerves and vessels of the heart or upon the heart itself, and similar pressure on the trachea is held to give rise to dyspnoea. Evidence of such pressure is, however, not found in all cases after death. Some therefore consider that the symptoms are due to autointoxication arising from faulty metabolism occasioned by the changes present in the lymphatic system. Others regard them as neuroses produced in a similar manner.

Yet the thymus is always found enlarged after death, and any increase in its size by sudden congestion or turgescence during life might well cause dyspnoea or sudden death by pressure, although after death such congestion may subside and no sign of pressure be seen.

As Jacobi points out, the distance between the sternum and the vertebral column is only about $2 \cdot 2$ c.m.

Treatment of Spasmodic Asthma.-Spasmodic asthma frequently begins in early childhood, and tends to become a habit which once formed may be impossible to eradicate.

The aim of treatment is to prevent formation of the habit, yet this is easier said than done.

The exciting causes are so many and so various and obscure, 
so dependent upon individual caprice, that they may remain unsuspected for half a lifetime, or never be discovered at all.

It is only by careful sifting of evidence that one can hope to hit upon the cause in individuals. It may be climatic, or dietetic, or due to morbid conditions which irritate. In the latter case should the morbid condition seem a "vera causa", that is to say, one calculated to produce discomfort and ill-health in a normal individual-for instance, nasal polypi or definite obstruction by adenoid vegetations and enlarged tonsils-the obvious course is to remove it. But even in such cases a guarded prognosis, so far as relief of the asthma is concerned, should be given. Crusades against all possible sources of irritation, however trivial they may be, are not to be encouraged in all cases, with definite hope of cure.

Treatment by Cauterisation of the Septum Nasi.-Francis's method consists in cocainising the septum and in applying cautery to the smallest possible area, with the lightest and gentlest touch at a spot just in front of the middle turbinal and a little below the tubercle of the septum.*

The success of this treatment appears to be in inverse ratio to the severity of the cauterisation.

If too much is done at one sitting, the patient is sure to be made worse. Hence it is possible that cures are effected more by mental influences induced by the treatment than by actual destruction of so-called " Asthma-Spots."

Dietetic Causes.-The fact that the healthy child's meat may be the neurotic child's poison is more clearly brought out in cases of asthma than in other neuroses.

The problem is to find out what the asthmatic can eat and what he cannot.

If single articles of diet, or at most a few, are found to disagree, it is easy to cut them out of the dietary, especially when such articles are unimportant from a nutritious point of view. It is simple, for instance, to exclude nuts, shellfish,

* C. A. Parker, The Nose and Throat and their Treatment, 1906, p. 367. 
sweets and cheese from the menu. The difficulty arises when asthma seems to be induced not by one but by many common foods suitable for children in general.

In such cases, however, it will often be found that it is the quantity of the food and the time at which the meal is taken, rather than its quality, which induces asthma.

A rigid diet-sheet should not therefore be prescribed on general principles. Foods should be mixed, good, plain and wholesome, excess in any kind of food should be avoided, meals should be small and the chief meals should be breakfast and early dinner. Any food taken late should be of the lightest and most digestible kind, and should not be consumed within three hours of bedtime, for it is indigestion during sleep which in most cases excites nocturnal asthma.

Climatic Causes.-Individual caprice with regard to climate and locality renders it impossible to foretell which place is likely or unlikely to agree with an asthmatic.

Examples of idiosyncrasy in the matter are too well known to need enumeration.

All that one can say is that if one place is unsuitable another should be sought until the right one is found.

It might be thought that by habituation a child would become inured to the effects of certain climates-but such a line of treatment is not practicable. Asthma in children is always associated with signs of bronchitis, and is invariably attributed to " catching cold." Every attempt to acclimatize the patient to his surroundings by sending him out leads to a fresh "cold" and to another attack of asthma and bronchitis.

No wonder, then, if the hothouse treatment is countenanced by anxious parents, baneful though it is, and productive of the "pale, moist, flabby, steamy thing, with big eyes, thin cheeks, protruding ribs, and a more or less general bronchitis "- to quote Dr. Goodhart's graphic description.

Change of air is essential for such as these, and when a place has been found in which the patient is free from the 
complaint, whether the place be high or low, dry or damp, inland or by the sea, in country or in town, the best plan is to let well alone, and keep him there. Meanwhile every attempt should be made to strengthen him by games and exercises and good food, to avoid cossetting and treating him as a delicate invalid. The neurotic spell may thus be broken.

The prognosis when spasmodic asthma starts in childhood is far better than when it begins in later life-especially if a congenial climate can be found before asthma has become a confirmed habit and the lungs are irreparably damaged by emphysema and bronchitis.

Given suitable surroundings, it may as a rule be safely predicted that a child will outgrow the complaint. It is doubtful, however, whether a tendency to asthma induced by effluvia, by roses, pollen, dust, ipecacuanha, cats and horses and by special articles of food is ever overcome. One must either remove such influences from the patient or the patient from them. The same may be said of paroxysmal rhinorrhoea, sneezing and hay fever, which are all commonly associated with asthma and must be regarded as instances of the same complaint induced by special causes.

Treatment of Paroxysms.-Early attacks of asthma in children may be cut short by an emetic, whether the asthma be due to an indigestible meal or to acute bronchial catarrh. Apomorphine given hypodermically in doses of $m 1-m 6$ of the injection according to the age of the child is most efficacious. It should not be given to infants under one year. It would seem from the accounts of sufferers from asthma that emetics relieve by their depressant effects rather than by vomiting.

In so-called peptic or dyspeptic asthma produced by indigestible food a smart purge should be given.

In children it is doubtful whether injections of morphia or inhalation of chloroform or amyl nitrite are desirable.

I have seen a child rendered so drowsy by a large dose 
of chloral and bromide that he could hardly be roused, yet the asthmatic breathing persisted.

As soon as the diagnosis of asthma is established in a child one may be certain that every kind of patent inhalation will be tried. Practically anything which produces thick smoke and promotes cough and expectoration gives relief in some cases-uncomplicated by bronchitis.

In purely spasmodic eases the fumes of burning nitre paper are perhaps as useful as more costly "Asthma Cures." The smoke of stramonium is uncertain in its action and may be injurious.

As internal remedies during an attack, spirits of nitrous ether with tincture of belladonna or of hyoscyamus, vinum ipecacuanhae and liquor ammon. acetatis may be given.

Hot fomentations to the chest are also useful.

In the intervals between attacks, arsenic with bromide of ammonium are of service, and when bronchitis persists, small doses of the iodide of potassium with carbonate and chloride of ammonium may be added.

Intra-nasal medication by means of sprays containing cocaine, adrenalin, and atropin, is not suitable for children. - Extensive operations on the nose and throat should not be undertaken unless clearly indicated on other grounds than the possible cure of asthma thereby. 


\section{CHAPTER XVII}

\section{ON CHOREA}

Chorea Minor, or St. Vitus's dance, or Sydenham's Chorea or Rheumatic Chorea as it is variously called, is a spasmodic nervous affection which is seen chiefly in young people.

The name St. Vitus's dance should be discarded as a synonym for chorea, for it was originally applied only to the epidemics of dancing mania which were prevalent in Germany early in the fifteenth century. Similar epidemics have occurred occasionally in more recent times, and the complaint is still represented in the corybantic orgies of sects such as the "Shakers." St. Vitus's Dance is, in fact an hysterical affection which bears no resemblance to the disease to which Sydenham in 1686 gave the name chorea.

In spite of Sydenham's careful and accurate account of chorea many other distinct spasmodic affections were subsequently included under the name, and even now one sometimes finds that children who exhibit various forms of habit spasms or tics are regarded as suffering from true chorea. The athetoid movements of paralyzed limbs which occur in the subjects of infantile hemiplegia are described as "hemiplegic chorea," but this disease, an incurable affection, is not strictly speaking chorea. True Sydenham's chorea is characterized by involuntary spontaneous movements, weakness and want of precision in voluntary movements, and by emotional instability, with, at times, more serious psychical disturbance.

Duration.-The average duration is said to be ten weeks, but the disease shows great variability in this respect. 
Generally speaking severe attacks last longest, but severe attacks may sometimes abort and come to an end in a week or two. On the other hand mild attacks may linger on indefinitely. Exacerbations, remissions, and relapses are common. The evolution is, with few exceptions, gradual. The movements increase in severity until a certain point is reached and then subside by degrees. They may be general and affect the whole body from the first, or start locally and become general later, or may be confined to the limbs of one side of the body throughout the illness (hemichorea).

Sex and Age.-Chorea affects girls three times as frequently as boys, but a larger number of boys than girls are attacked between the ages of five to ten, whilst more girls than boys are affected in the years from ten to fifteen. After this age, chorea is almost exclusively confined to girls.

Chorea is rarely seen before the age of five. The youngest child the writer has known to suffer from genuine chorea was a boy aged three years.

Etiology.-The predisposing causes of chorea are neuropathic temperament and the rheumatic diathesis.

A family history of hysteria, epilepsy and insanity is - not uncommon. Often there is evidence of heredity, both neuropathic and rheumatic.

Relationship between Chorea and Rheumatism.The view that rheumatism, cardiopathy and chorea are different manifestations of one and the same disease has been held in France for more than fifty years. But in this country it has been hotly contested, and has only recently met with wide acceptance. The arguments which have been advanced against the rheumatic origin of chorea have been :-

1. That the percentages in which acute rheumatism (arthritis) occurs, and in which rheumatic inheritance is probable are but small. Sturgis traced chorea directly to acute rheumatism in only $5 \cdot 8$ per cent of cases. But apart from arthritis, the other well-known manifestations of rheumatism,-recurrent tonsillitis, peliosis, nodules, mus- 


\section{4}

FUNCTIONAL NERVOUS DISORDERS

cular tenderness and "growing pains" are so common in chorea that the percentage of a rheumatic origin in the latter would be greatly raised were such symptoms taken into account.

Moreover, Dr. F. E. Batten has shown conclusively that, although signs of rheumatism may be absent before and during an attack of chorea, they are often subsequently developed.

Of 115 children suffering from chorea and treated at Great Ormond Street Hospital for Sick Children, he found that rheumatism had occurred in 32 per cent. Following up the cases that had not suffered from rheumatism, although unable to trace some, he found that $11 \cdot 3$ of the total number had developed rheumatism three years later; whilst a further $9 \cdot 7$ per cent of the total developed rheumatism within six years of chorea.

It follows therefore that statistics compiled from cases only at the time of the occurrence of chorea must considerably underestimate the proportion of those who are subjects of rheumatism.

As regards personal inheritance of rheumatism, the percentage of family predisposition to rheumatism in chorea cases compares favourably with that of acute rheumatism itself. Syers estimated rheumatic inheritance in chorea cases at 32.19 per cent., whilst Garrod found evidence of personal inheritance in a quarter of his cases of rheumatic fever.

2. It has often been stated as an argument against the rheumatic origin of chorea that rheumatism will not account for a large number of cases in which the disease follows fright or emotional disturbance, over-pressure at school, and traumatism, nor for cascs of so-called reflex chorea dependent on refraction errors, adenoids, worms, phimosis and other kinds of distal irritation.

The difficulty may be overcome by considering what is meant by fright and its results.

Fright is only shock under another name. The results of physical or mental shock are the same. They are extreme 
nervous prostration, lowered vitality, enfeebled circulation, disordered metabolism, and probably defective elimination. They may be due to physical injury or to emotion. The ill effects of chill or exposure to wet and cold are identical with those of shock.

Now the symptoms of chorea at once suggest a history of fright, and such a history is often provided because it is suspected, whereas acute rheumatism suggests exposure to chill or damp. Yet were the connexion established, it is probable that a history of fright or emotional disturbance in cases of acute rheumatism, and of chill in cases of chorea would be equally forthcoming in children.

Quite recently a girl was brought to hospital and found to be suffering simply from anaemia and debility. She had no signs of chorea at the time. A week later she fell into water up to her neck, and was much terrified in consequence. Three days subsequently she developed typical chorea. Was this the effect of chill or emotional disturbance? It is often said that symptoms of chorea have been present though unobserved before the fright or shock to which they have been attributed has been sustained. This may be so in some cases, though certainly not in the one cited.

The following may serve as examples of acute rheumatism following shock.

1. A girl aged ten, apparently in good health, was operated upon for cure of hernia. Whilst under chloroform she became collapsed. For a few days after the operation she passed large quantities of uric acid, then followed an attack of acute tonsillitis, succeeded by most severe peri- and endocarditis, and finally by an equally serious invasion of chorea. The operation wound healed by first intention.*

2. Another case is that of a little boy who had a tendon divided for cure of strabismus. He, like the girl, suffered from extreme shock whilst under the anaesthetic. Within a week he developed acute arthritic rheumatism.

* This case is reported by Dr. G. A. Sutherland, B.M.J., 1892. vol. i. 
Such cases seem to favour the view that in those who are predisposed to chorea or rheumatism, a shock of any kind may precipitate an attack of either or both diseases. $\mathrm{Mr}$. Clement Lucas has recorded a case in which a child, aged eleven, developed general chorea half an hour after being run over by a cart and sustaining fracture of the right humerus.*

Sudden shock alone, whether emotional or traumatic, is probably no more than the exciting cause of chorea and rheumatism. One must also presume the existence of individual susceptibilities to the rheumatic poison, a peculiar instability and weakness in the nervous system, and finally the presence of the poison itself in order to explain the occurrence of the attack of rheumatic chorea.

It is now held by many that the rheumatic poison is the result of the action of micro-organisms, though, at present, opinions differ as to the specific nature of the various organisms which have been found.

In chorea cases Pianese has isolated a bacillus and a coccus from the central nervous system, the former of which produced convulsions when inoculated into animals. Staphylococci have been found by many in the central nervous system.

Cocci have been discovered by Richter and Triboulet in the blood. Dana found a diplococcus in the meninges. In this country Drs. Poynton and Paine have obtained from the joints in acute rheumatism a diplococcus which, when injected into animals produced polyarthritis, endocarditis and symptoms resembling human chorea, and they have discovered similar diplococci in the neighbourhood of small vessels in the cerebral cortex.

Dana, Triboulet, Wasserman, Malkoff and others seem to have met with a similar diplococcus.

Dr. F. W. Andrewes and Dr. Horder, however, in a recent issue of the Lancet (Sept. 22nd, 1906, "Streptococci Pathogenic for Man ") suggest that the organisms cultivated by

* Soc. for Study of Disease in Children, vol. ii., 1901-2, p. 74. 
Drs. Poynton and Paine may have been present as terminal incidental infections, or that the cocci when isolated a considerable time before death were the cause of a malignant endocarditis. The results of their efforts to isolate the diplococcus rheumaticus from the heart's blood, pericardial fluid, and cardiac vegetations from fatal cases of acute rheumatism were in the majority of cases negative. Such streptococci as they were able to obtain they regard as being of the nature of "terminal infections."

They admit the possible etiological relation of intestinal or oral saprophytes to rheumatism, but conclude :- "It may be . . . that the primary cause of acute rheumatism is not streptococcal, perhaps not even bacterial, but that certain of its manifestations, e.g. endocarditis, may be due to a secondary invasion by streptococci of low virulence derived from the mouth and intestine." * It seems on the whole most probable that chorea is the result of an infective process, though it cannot be decided whether the symptoms are due to direct irritation of nerve elements by organisms, or to a general toxaemia induced by their action. The presence of micro-organisms in the immediate neighbourhood - of the cerebral cortical cells suggests local action, but a toxic condition of the blood may also play a part.

To return to the " modus operandi " of shock in producing chorea, it may be assumed that the effects of shock, whether due to injury, chill or emotion are to lower the vitality of our defenders the phagocytes, and so to give the battle to marauding micro-organisms-granting their existence.

In addition one must assume the presence of functional instability, hereditary or acquired, on the part of the nerve elements ; otherwise chorea would be a far more common manifestation of rheumatism than it is. Many go through

* In the Lancet (Dec. 1, 1906) Poynton and Alexander Paine reply that the diplococcus rheumaticus had been isolated from the blood and from the knee joint in two cases which recovered completely, and that therefore it cannot be of the nature of terminal infections. 
repeated attacks of acute rheumatism, yet never suffer from chorea. A definite history of a simple fright or shock is not obtained in all cases of rheumatic chorea. Yet it may be observed that just as articular rheumatism may result either from a single definite exposure to chill, or from repeated and prolonged exposure to wet and cold; so chorea may in one case be caused by a long course of overwork and terrorism at home or at school, whilst in another it follows immediately on the bite of a dog or an alarm by fire.

The interval which often elapses between a shock of any kind and the onset of chorea does not disprove that the shock was a "vera causa."

As regards so-called reflex chorea associated with the presence of worms, adenoids, eye strain, phimosis, etc., one may say that prolonged irritation of any kind may lower general health just as prolonged mental worry may do, and may produce chorea in rheumatic subjects. But a considerable number of cases of the kind are not true chorea at all but merely "habit spasms."

It has also been urged against the rheumatic origin of chorea that the fleeting character of the cardiac bruits heard in chorea is against thcir rheumatic origin. One may rejoin that in acute rheumatism the cardiac bruits are often similarly fleeting. Severe cndo- and peri-carditis may be present or absent in both chorea and acute articular rheumatism. The absence of cardiac complications does not disprove the rheumatic nature of chorea, nor does such absence preclude the diagnosis of acute articular rheumatism.

The common statement that chorea is not of rheumatic origin because it is not cured by salicylates may be met by rejoining that salicylates do not cure acute articular rheumatism. But the question as to the use of salicylates in chorea may be deferred until treatment of the disease is considered.

The evidence in favour of the rheumatic origin of chorea may be summarized as follows :-

A large proportion of children who suffer from chorea 
have developed, or develop sooner or later, manifestations of rheumatism. Apparent exceptions to the rule that chorea is rheumatism admit of the explanation that any condition which lowers general vitality may favour the onset of chorea in emotional subjects who are predisposed to rheumatism. Thus may be explained cases of chorea which follow shock of any kind, or illnesses such as pertussis, scarlatina, measles, variola, diphtheria and pyaemia, all of which are known to precede chorea occasionally.

The fact that a single attack of chorea may occur without other manifestations of rheumatism before, during, or after the event of chorea does not disprove its rheumatic origin. For similarly, a person may suffer once only in a lifetime from acute articular rheumatism. He may never, either before or after the illness, show further evidence of rheumatism. Yet no one would argue on this account that his illness could not have been acute rheumatism, but some other affection.

Bacteriologists may be left to fight out the question as to the specific nature of organisms found in rheumatism and chorea. It is only possible for clinicians to repeat that - chorea is part of the congeries of symptoms to which the name rheumatism has been given.

Until the essential cause of rheumatism is discovered that of chorea must remain unknown. Meanwhile, clinical symptoms and analogy with other diseases known to be of microbic origin suggest a similar cause for rheumatism. Specific germs need suitable soil in which to flourish. S. Salivarius and S. Faecalis may possibly be rheumococci in those who are predisposed to rheumatism.

Site of Lesion and Morbid Anatomy.-The quasivolitional character of the movements, their occasional hemiplegic distribution, their association with paresis in which the arm suffers more than the leg, and the cessation of the movements during sleep, all point to the cerebral cortex and especially to the mid- or Rolandic area of the hemisphere as the seat of mischief. The frequent occurrence 
of abnormal psychical states in chorea also suggests that the highest parts of the nervous system may be involved.

It must be remembered, however, that choreic movements may be caused, especially in children, by a lesion in the great ganglia or any other part of the brain. Yet the cortical origin of the movements is nevertheless assured, for in cases, for instance, of choreic movements resulting from gross lesions of the basal ganglia the movements do not occur unless the cortex be intact.

In some cases it would seem from the strictly local character of choreic movements that only a limited area of the cortex is affected. When, after commencing locally, the movements become universal, a spread of irritation from centre to centre may be suspected. The process scems to resemble that of Jacksonian epilepsy, in which a small focal lesion in the cortex has the power of communicating its explosiveness to contiguous centres until general convulsions ensue.

But more rarely the choreic movements are general from the first, and when this is so it has been suggested that some toxic condition of the blood exists which acts at once upon the whole of the cerebral cortex.

Such cases may be in a different category from the former, in which direct irritation of a limited group of cells by a colony of microbes may be suspected.

Although the cortex cerebri seems to be chiefly affected, it is possible that chorea may also involve different areas of the spinal cord; for the ataxy which prevails in some cases of chorea resembles in many respects that of tabes dorsalis. The absence of, or curious variations in the kneejerks, the presence of hyperaesthesia and pains and rigidity in the limbs, and perhaps the paresis and muscular wasting which occur, may indicate mischief in different spinal tracts and levels.

The morbid anatomy of chorea throws but little light on the precise conditions which cause the symptoms. Inflammatory and vascular changes which have been described are 
not constant, and when found are possibly the results of complications.

Various alterations in the appearance of the cells of the cortex and thalamus have been noted, but these again are inconstant and when present may be attributable to other causes. Yet the limitation of movements to a single limb or part of a limb is significant of a definite local lesion, the precise nature of which will probably remain unknown, for recovery in uncomplicated cases of chorea is certain.

Speculations on the point are therefore vain, but the theory which seems most plausible is that temporary capillary thrombosis or embolism is present in various areas of the cortex with exudation and consequent irritation of nervous elements.

Such capillary blockage might be produced by microorganisms or be the result of alteration in the coagulability of the blood.

Varieties of Rheumatic Chorea.-For purposes of convenience the varieties of chorea may be divided into two main groups :-

1. Sthenic or explosive chorea, in which the predominant characteristics are spontaneity, violence, persistence, and wide range of movements.

2. Asthenic or paretic (chorea mollis), in which the movements are less in evidence, and there appears to be loss of muscular power, or, at all events, loss of will power to execute voluntary movements.

These two main groups may be further subdivided into "severe" and "mild."

The sthenic not infrequently becomes asthenic in type, but the opposite sequence is rarely seen.

Severe sthenic chorea is characterized by spontaneous, uncontrollable, violent, irregular movements of the limbs and whole body, which movements are exaggerated by voluntary action, and when the patient is under observation. The movements are not due to spasm of individual muscles, but to complicated involuntary con- 
tractions of groups of muscles performed with unnecessary violence. The action of one group of muscles is continuously counteracted or replaced by the action of its opponent group. Often it seems as though an attempt were made to perform opposite and contrary movements at one and the same time. Attempted voluntary actions are accompanied and prevented by wild flourishes and jerky ataxy. It has been supposed that the performance of opposite or contrary actions is a voluntary attempt to counteract involuntary movements, but I am convinced that both alike are involuntary in this stage of chorea. The term "quasi-purposive" aptly describes the movements.

The facial contortions supply an admirable physiological study of the expression of emotions. The expressions of gladness, sorrow, pain, pleasure, disgust, fright, contentment, etc., follow each other in rapid succession, and one fades into the other as in a dissolving view. Moreover, conflicting expressions occur simultaneously in different parts of the face. The mouth may be widely opened, and the tongue shot out as far as it will go, with every appearance of disgust, but the eyes, instead of being tightly closed,* are open, placid and smiling, or the eyes are widely opened, the pupils dilated, the eyebrows are raised, and the hair bristles, with all the appearances of fright, whilst the mouth expands in an inane grin. Or, again, there are continuous sucking movements with smacking of the lips expressive of contentment, whilst the eyes look wild and the eyebrows frown with the aspect of surly discontent.

Movements of the legs, like those of the arms, are violent, continuous, and conflicting. The child is unable to stand or walk, and when supported in the erect position the lower limbs are thrown about as in the most extreme form of locomotor ataxy, or rather of ataxic paraplegia, for the ataxy is often associated with spastic rigidity. In such severe cases the patient is never still for a moment, except during deep sleep; and sleep may be prevented or dis- 
turbed (when not profound) by involuntary movements which affect both trunk and limbs.

Speech is frequently indistinct or impossible from incoordination and spasm of muscles concerned in articulation and respiration. But complete mutism is less common than in the paretic variety.

Mental symptoms are not generally pronounced, but there may be great irritability and fretfulness. Sphincter control is not lost, but there may be involuntary and sudden evacuations.

The sthenic variety may be regarded as an indication of spontaneous explosiveness of the motor centres, with complete absence of inhibitory power. Its duration is seldom longer than three or four weeks. The patient may then sink into the asthenic condition, which will be presently described, or one or other of the sub-varieties of sthenic chorea makes its appearance.

Sub-varieties of Sthenic Chorea.-1. The spontaneous movements cease entirely so long as the child is at rest and unnoticed, but they return directly one looks at him or approaches the bedside. They also reappear on volitional actions. In this condition spontaneous explosiveness of motor centres has ceased, but they are readily excited, and there is still great want of inhibitory control.

2. The spontaneous movements cease, the limbs are flaccid whilst the child is at rest, but on handling them they become stiff and rigid, and there is considerable inco-ordination on attempted voluntary action.

A peculiarity of the knee-jerk is often present in such cases. The response is somewhat exaggerated, and on repeatedly tapping the tendon the limb gradually rises to a position of extreme extension, with general rigidity and inversion of the foot, and remains so for a few seconds before becoming flaccid again. A response somewhat akin to this has been recently described by Dr. W. Gordon * as "the hung up knee-jerk."

* British Medical Journal, March 30, 1901, p. 765. 
The condition, as a whole, strongly resembles that of ataxic paraplegia, and possibly some passing affection of the postero-lateral columns may be present.

But in some cases I am inclined to think that the rigidity is due to a conscious voluntary attempt to control involuntary movements, for the spontaneous movements will recur if the child's attention is distracted. For instance, the child can hold out its hands steadily though stiffly, but if then asked to put out its tongue the hands and fingers begin to twitch at once.

3. Residual Chorea.-This is a condition often protracted for an unlimited time in which spontaneous movements continue, and in which there is great clumsiness and ataxy in using the hands, and a shambling, awkward, blundering gait. The child is constantly falling about and bruising himself; he stoops or keeps one shoulder higher than the other. He is nevertheless in perfect health, and the condition may be described as "residual chorea," for he can. overcome all his symptoms by an effort of will. The choreic movements occur chiefly when the child is unnoticed and ceases to take pains to control them. The chorea is cured but the symptoms still remain.

It must be mentioned that in all these cases chorea is frequently one-sided only.

Asthenic or Paretic form of Chorea (Chorea Mollis)As mentioned before, this form commonly succeeds severe sthenic cases. In severe cases of asthenic chorea the patients may become emaciated and prostrated. They lose the power of voluntary movements, and attempts to execute them only result in slight twists or shrugs of the whole body. There are seldom any facial contortions, but the expression is wild or imbecile. There is often well-marked retraction of the upper eyelid (Stellwag's sign), and the lips are constantly pursed and pouting. Often the tongue cannot be protruded, and speech is entirely lost. Not a word may be uttered for weeks together, and it does not appear that any attempt to speak is made. Mania or 
dementia is not uncommon. Control of the sphincters may be lost, probably on account of mental hebetude, but the condition may also point to implication of the lumbar centres.

In the milder forms of asthenic cases movements are again less in evidence than in the sthenic cases. They have rarely been observed by the patient's relatives. The children are usually supposed to be paralysed, commonly in one arm. The limb hangs limp and flaccid at the side. The child makes no voluntary effort to use it, and when asked to do so the attempts are small, abortive, half-executed, and fail.

Wishing to grasp an object or to shake hands, the child advances his hand a little, but drops it again at his side without completing the desired act. Objects placed in his hand almost immediately fall on the floor. When the leg is affected it gives way under him whilst walking, or he drags it after him as if hemiplegic.

Usually there is no rigidity nor ataxy, but simply weakness of the limb. But to this rule there are exceptions. The knee-jerks are often difficult to elicit and may be absent. In the asthenic group of cases there seems to be inhibition of movement rather than want of inhibitory control. There is not the hyper-excitability of motor centres which marks the sthenic variety. The muscular wasting which occurs in these cases may point to implication of the anterior cornual cells, just as the ataxy and rigidity present in the sthenic group afford evidence of involvement of the posterolateral columns. As in the sthenic group, the types of the asthenic pass into each other. The milder forms may usher in or may mark the approach of the severe, or mildness may prevail throughout.

I cannot recall a case in which the asthenic type gave way to the sthenic, but have no doubt that the sequence may occur. One such instance, in which choreic movements manifested themselves after a week of apparent 
paralysis of all four limbs, occurred in the practice of Professor Clifford Allbutt at the Leeds Infirmary.*

Mixed Cases.-Not infrequently cases occur in which the sthenic and asthenic types of chorea are present simultaneously. Thus one arm may be paretic whilst the other exhibits choreic movements

Mutism in Chorea sometimes occurs with such suddenness and completeness that one can hardly avoid the conclusion that Broca's convolutions are affected. I have not, however, noticed that in such cases the movements have been more frequently on the right than on the left side.

Complete mutism is I think more common in chorea mollis. In such cases the child evidently understands what is said, but makes no effort to utter a word.

The mutism of sthenic chorea on the other hand is akin to stammering. The child is unable to speak owing to spasm and inco-ordination of the articulatory and respiratory muscles.

It makes prodigious efforts to speak, but ceases to do so after a few unavailing attempts or succeeds only in blurting out a word or two.

Urine in Chorea.-Excess of urea and of uric acid may occur in proportion to the violence of muscular activity. Phosphates may be increased; Urohaematoporphyrin has been found by Dr. A. E. Garrod in fourteen out of twenty cases. Albumin is rarely present except in cases of nephritis. Glycosuria has been observed as an unusual complication.

Complications of Chorea.-Temperature is seldom raised in cases uncomplicated by arthritis and endocarditis or sepsis. But there may be considerable elevation in association with the acute mania of chorea, and hyperpyrexia is not unknown.

Sensory Disturbance in Chorea.-Pains in joints and limbs in various parts are not uncommon. They may be evidence of rheumatism, or they may be the result of fatigue induced by violence of movements. Hyperaesthesia in the

* Clifford Allbutt's System of Medicine, vol. vii. p. 852. 
course of nerve trunks or elsewhere, may be found, and in some cases there is general blunting of tactile sensations, especially about the hands and forearms. But such symptoms are frequently absent, and investigations as to the degree of altered sensations present are usually fruitless owing to the psychical condition of the patient.

Cardiac Affections.-True endocarditis and myocarditis are present in many cases of both mild and severe chorea. They are referable to rheumatism and, with few exceptions, fatality in chorea is attributable to heart disease.

Many most severe cases of chorea, however, run their course without any evidence of endocarditis. The same may be said of many cases of acute articular rheumatism.

Apart from cardiac bruits due to endocarditis, others are frequently heard in the course of chorea, and may be attributable to anaemia, or in some cases to abnormal respiratory movements, or to weakness of the cardiac muscle leading to temporary incompetence of the valves. They vary in locality, are fleeting in character and frequently disappear with convalescence.

The pulse in chorea is usually rapid in severe cases, and may be irregular and intermittent on account of the effect of irregular respiratory movements upon the heart.

Occasionally, especially in asthenic cases, the beat may be abnormally weak and slow.

Differential Diagnosis.-A typical case of chorea presents no difficulty.

The history of the case distinguishes true chorea from the chronic movements consequent on gross cerebral lesions in infancy.

Moreover, the slow athetoid movements, and also the wild jactitation of limbs which follow infantile hemiplegia bear no resemblance to the movements of true chorea.

Paretic chorea without obvious choreic movements may present difficulties, especially when endocarditis suggests unilateral cerebral embolism. But, almost invariably, choreic movements in the apparently paralysed limb and 
elsewhere will be found; the paralysis is less sudden and less complete than that which results from occlusion of cerebral vessels; the paresis never affects the face as in hemiplegia.

Hysterical Chorea is characterized by shakings or tremors of limbs and rhythmical spasms of individual muscles rather than by the irregular complicated alternating and conflicting movements of chorea.

The simulation of chorea is never complete. Hysterical chorea rarely occurs before puberty and at that time the usual hysterical stigmata may be found.

The distinction between chorea and habit spasms of various kinds may be considered separately.* Difficulty of diagnosis arises only when there is a combination of the two.

There is no danger of confusing paretic chorea with infantile paralysis, provided that the possibility of the latter be borne in mind. In cases of doubt, wasting of muscles and alterations in the electrical reactions will soon clear up the difficulty.

Psychical Conditions in Chorea.-Few cases of severe character escape mental disturbance altogether. In the majority it merely consists in mental dulness and apathy, or in fretfulness and tears. Sometimes fits of violent hysterical weeping occur without special cause. Night terrors with hallucination, mostly of vision, are fairly common, and such hallucinations may persist in waking hours. Acute mania is, I believe, rare during the sthenic stages of chorea. It mostly occurs after cessation of the movements, or when they arc extremely slight in character and hence the nature of the disease may be overlooked. "Chorea insaniens" is, I believe, unknown in children and is only met in young girls and women upwards of fifteen. It is doubtful whether such mania can be attributed solely to chorea. Usually there is a history of severe mental trouble, frequently associated with concealed pregnancy in subjects predisposed to insanity. 
Curious moral perversions are not uncommon in children after chorea, especially in protracted cases in which such movements as persist are more of the nature of habit spasms than of true chorea. Unwonted spitefulness, violent passion and general intractability may occur in children hitherto amiable.

Similar moral perversion may be experienced in children who have recovered from other long and exhausting illnesses, such as enteric fever.

A boy aged eleven after a long attack of chorea suddenly began to disturb the whole building by uttering piercing screams for hours together. Various sedatives were given in vain, and on one occasion I was preparing to administer chloroform in order to secure a little peace for all concerned. The boy had appeared to be unconscious, but I suddenly thought I detected a gleam of intelligence in his eye suggesting that the unconsciousness was feigned. So instead of giving chloroform I slapped his cheek smartly with a wet towel. He gave one cry of mingled surprise, rage and pain, and tried to bite my hand. But immediately the screaming ceased and did not recur. He seemed to be cured from that moment, the choreic movements had already practically ceased, and within a few days he was walking about the ward and making himself generally useful.

Such a mode of treatment is not to be recommended for general use, but the condition under which it succeeded is worthy of notice.

In rare cases, mental symptoms may become progressive, leading to partial dementia, but as a rule signs of feeble mindedness have been previously existent.

Treatment.-Sthenic Cases (severe).-Absolute confinement to bed is essential. The bed should have padded sides in order to prevent the patient from hurting himself or falling out. Or the bed may be made on the floor and surrounded by bolsters. It is often necessary to protect bony projections by cotton wool packing. Splints carefully applied to both arms and legs are sometimes useful. 
In feeding the patient, china or glass vessels should not be used, lest pieces be bitten off and swallowed. Enamelled metal feeding cups should be employed. When there is great difficulty in swallowing, the patient should be fed by nasal tube, lubricated with oil, not with glycerine. Sleep is often prevented as much by starvation as by violence of the movements, and may be secured by regular nasal feeding when sedatives are useless.

Special attention with regard to the evacuations should be paid to children suffering from choreic mutism. For almost invariably they are conscious of their desires though unable to express them, and accidents when they occur often excite paroxysms of hysterical weeping which aggravate the patient's sufferings. Complete tranquillity of mind is as important as physical rest in all cases.

The rule that in all primary attacks the patients should be absolutely confined to bed should be observed even in mild cases, at their onset, for they may quickly become severe. The rule is well recognized in cases of articular rheumatism, and should be equally so in chorea, for in both, the onset of endocarditis is to be feared. It is possible that endocarditis may be arrested or even staved off by enforced rest. The length of time during which confinement to bed is necessary varies according to circumstances. Generally speaking, no attempt should be made to get the patient out of bed until all spontaneous movements have ceased for at least a week. Also the period of rest depends on the extent to which the heart is implicated. A rapid or irregular pulse, signs of cardiac enlargement, and the presence of shifting bruits, are indications of active heart mischief and of the necessity for prolonged rest. So much importance need not be attached to the presence of simple mitral regurgitant bruits, unless of recent origin, and provided that signs of cardiac incompetence are absent. In mild cases of recurrent attacks the rule is not so absolute. Rest in bed for a week or two is often sufficient, and then the child may be allowed up for one hour or so out of every 
three or four. The child's own inclinations in the matter should be consulted. If he frets and rebels at enforced rest it is best to humour him within reasonable limits.

A child may often be in perfect health although suffering from "residual chorea," and such cases do not require treatment by rest. The treatment by rest may, in fact, be overdone. I have often noticed that children who have been kept in bed for many weeks on account of slight rises of temperature and rapid pulse, improve at once when allowed to get up. This applies to convalescence from diseases other than chorea.

Treatment of Sub-varieties of Sthenic Chorea.-The acute stage characterized by spontaneous movements seldom lasts longer than three or four weeks. At the end of this time the asthenic condition, or much more frequently one of the sub-varieties of the sthenic, makes its appearance. The sub-varieties may linger on indefinitely for many weeks or months, and the condition may in rare instances become chronic, unless appropriate treatment is adopted.

The methods of treatment of these subsiding forms of chorea, are "suggestion," physical exercises and rest, com-bined or used singly.

Suggestion (by which is not meant hypnotism) is useful in cases where movements only occur when notice is taken of the child, and on attempted voluntary action. Such children are naturally timid and self-conscious, and they require much patience, gentleness, and encouragement for their management.

1. Suggestions that the child should lie quietly should be repeated in the soothing manner used by the hypnotist. At the same time the flourishes and wriggles should be gently restrained, and the child will soon learn to lie completely relaxed and flaccid under observation, which is the first step gained.

2. Passive Movements combined with Suggestion.-It will be found that choreic movements occur directly the child's limbs are manipulated. To correct this condition the 
patient's hand should be placed between the observer's hands, and raised and moved in various directions, suggestion being made meanwhile that the child should keep its own hand quite still. At first it will be snatched away and flourished as usual, but soon the patient learns to control the involuntary movement by an effort of will which makes the whole limb rigid. This is an indication of improvement, though by no means of a cure; but by degrees the child discovers that its efforts to control involuntary movements need not be so strenuous whilst its limbs are guided and restrained, and accordingly the rigidity becomes relaxed. The measure of improvement is easily ascertained by the observer. Until the limbs can be passively moved freely in all directions without exciting either rigidity or spasm no other than passive exercises should be employed.

3. Voluntary Movements under Guidance.-The patient is then directed to perform the same movements as have been passively executed, whilst his hand is still controlled, guided, and helped by the observer.

4. When this can be done without exciting spasms or rigidity, but not before, voluntary movements without control, in imitation of the observer's, should be practised.

The movements should be of the simplest character at first, and gradually made more elaborate. They should be executed slowly and steadily without jerks and flourishes. The chief difficulty is, at this stage, inco-ordination rather than spasm, and the mode of treatment is adapted from Frenkel's system in the case of locomotor ataxy.

Elaborate apparatus is unnecessary. Simply bringing the fingers together from a distance and touching various parts of the body with them are admirable exercises. Precision of movement can be gained and the child kept amused by various toys and games. The kindergarten supplies simple and cheap apparatus which answer the purpose. Coloured balls hung by strings on a frame or strung on wires can be used. The balls can be made to swing, touched, and arranged in patterns under direction. Then solid 
squares or cubes can be built in various shapes and forms. Such games as draughts, dominoes, or solitaires can be used for older children, or "spilikins" (easily improvised with a box of matches), pegs to be fixed in the holes on a backgammon board, can be pressed into service. A child may usually be considered cured when it can build a twostoried house of cards.

The aim of exercises is to encourage freedom as well as precision in movement. For this reason it is inadvisable to allow the patient to write or thread needles or to sew. All these actions require much mental concentration, fixation, and tension of the various muscles employed. There is no objection to freehand drawing on a slate or blackboard and paper plaiting or weaving may be encouraged. It is important that all exercises should be carried out under supervision, otherwise the child becomes careless and ceases to take any trouble provided that it can amuse itself, and if neglected often drifts into what I have called " residual chorea." The treatment in this event is by a course of drilling, marching, wheeling, and standing at attention at word of command in particular, for the child's chief faults are inattention and carelessness, which have to be overcome. Ordinary calisthenic exercises are also useful in these cases. The important feature of "residual chorea" is that the movements are unconsciously performed, and can be immediately controlled by effort of will.

The treatment of the lower extremities is on the same principles as that of the upper. The patient should not be allowed to stand, or try to walk until all movements of the legs can be executed with fair precision whilst lying down. Such ataxy as still remains should be treated by making the child stand supported by the back of a chair whilst it places each foot separately in various positions. It is necessary finally to observe that exercises of any description, are inadvisable in all acute and recent cases of sthenic chorea. They are only of use when although heart, pulse, temperature, appetite and digestion are normal, 
all pains and aches have disappeared and general health has seemed fully restored for some woeks, choreic movements still continue.

I have only attempted to indicate the line of treatment which I have found useful. The principles are:-(1) That suggestion is of service where there is lack of inhibitory control over choreic movements. (2) Inhibition when acquired is often exaggerated, and has to be regulated by assistance before voluntary movements can be executed. (3) Inco-ordination has to be treated by exercises carefully graduated in the order of difficulty in their accomplishment.

Treatment by Drugs.-Chloral hydrate is the most valuable remedy for sthenic cases accompanied by much restlessness and want of sleep. It must be pushed until natural sleep is procured. Sometimes 5 grain doses, thrice daily, are sufficient (for a child of five or six), but it is usually necessary to increase the dose and to give it every four hours in order to bring the patient fully under its influence; 10 to 15 grains as a dose may thus be given to a child aged eight or ten. The bromides seem less serviceable alone but may be combined with chloral, and they are best administered per rectum.*

The pulse and heart should be carefully watched whilst the patient is under chloral, and if they show signs of failure, brandy and digitalis, strophanthus or caffein should be given.

The tincture of cactus grandiflorus, in doses of 2 or 3 minims, is useful when there is much cardiac disturbance or feebleness without definite signs of endocarditis. In very severe cases, in which even chloral hydrate fails to procure rest and sleep, inhalation of chloroform may be necessary. In milder sthenic cases, other nerve sedatives are of use. Antipyrin, in doses of $\mathbf{3}$ to $\mathbf{5}$ grains, for a child aged between five and eight is often efficacious, as also is monobromide of camphor, 1 to 4 grains three times daily with liquorice powder. Ext. physostigmatis, $\frac{1}{26}$ to $\frac{1}{6}$ grain,

* Chloretone, in doses of 4-5 grains upwards, has been recently recommended. It should be administered in petroleum emulsion. 
with ext. cannabis indicae, $\frac{1}{3}$ to $\frac{1}{2}$ grain, have been used with good effect. Hyoscine in $\frac{1}{100}$ gr. doses sub cutem may be beneficial in maniacal cases. But its use is not free from danger.

The Use of Arsenic.-It is to be regretted, I think, that the Newcastle quack who confessed on his deathbed* that his " chorea cure" contained large quantities of arsenic, did not die impenitent. Had he merely confessed to spells and incantations he would not have done much harm. But, as Voltaire said, "Spells and incantations, when combined with a sufficiency of arsenic, may destroy whole flocks of sheep."

I do not know that any choreic human sheep have been actually destroyed by arsenic, but I do know that many have been rendered extremely ill thereby. I believe that the practice of pushing arsenic until what are euphemistically called "constitutional symptoms" ensue, is mischievous, useless, and unjustifiable. Arsenic in poisonous doses is in no sense a specific for chorea. Yet it is an undoubted fact that choreic movements sometimes cease by the time that the accumulative treatment by arsenic has reached its height. What is the explanation? Dr. Rolleston asks, "Does arsenic cure chorea because it makes the patient ill in another way, and unable to manifest the original disease?" $†$ I deny that, given in this way, arsenic cures chorea at all; and I think the real explanation is that in such cases the sthenic form of chorea has given way to the asthenic, as commonly happens when arsenic has not been administered. The choreic movements have ceased, but the disease is in no sense cured, and arsenical peripheral neuritis may be superadded to the original complaint. In cases where enormous doses of the drug seem to be taken with impunity, it may be that they have not been absorbed. The rapid emaciation which often accompanies severe chorea

* Dr. W.Murray, Rough Notes on Remedies, p. 17. 3rd ed., 1899. $\dagger$ 'Some Remarks on the Uses and Abuses of Arsenic Treatment,' April, 1901, p. 83. 
shows that absorption is at a low ebb. In some cases symptoms may not disclose themselves until a fortnight has elapsed since the medicine was stopped (Railton, Medical Chronicle, February, 1900). Although I am strongly opposed to the routine treatment of chorea by heroic doses of arsenic, I yet believe that, given in ordinary amount, it is most valuable in all mild cases.

Aspirin in doses of about 5 grains appears to relieve pains and to lower temperature.

Salicylates.-One argument against the rheumatic origin of chorea has been that the movements do not seem to be checked by salicylates. This is not altogether true. I have found salicylates as beneficial in relieving the pains of chorea as the pains of ordinary articular rheumatism, and with the relief of pain the course and severity of the chorea is lessened.

Some deny that salicylates have any effect in shortening the duration of rheumatic fever. But the majority will admit, I think, that pain and swelling of the joints which had entirely ceased under salicylates often return directly the drug is withheld. In many cases of chorea there is evidence of disordered digestion, foul breath and tongue, loss of appetite, constipation, or diarrhoea. Salicylate of bismuth is useful in such cases, or salol in a castor oil emulsion after a dose of calomel.

Dr. D. B. Lees (Harveian Lectures, 1903) is in the habit of giving salicylate of soda in doses amounting to 100 to 300 grains a day to children from six to ten years of age. This method of treatment is apt to produce symptoms of poisoning by this drug. They resemble those of diabetic coma or acute acid poisoning with the presence of acetone in the breath and urine, and consist in airhunger, thirst, delirium, vomiting and drowsiness, which may end in coma and death.*

* Dr. Lees, however, claims that ill effects may be prevented by combining bicarbonate of sodium with the salicylates, and by 
The antidote in case of salicylate poisoning is bicarbonate of soda in large doses (Langmead and Willcox, Lancet, vol. i, 1906, p. 1822).

Aceto-salicylic acid has been considered useful by some.

Treatment of Asthenic Chorea.-The treatment should be recuperative and stimulant rather than sedative. In severe cases, which, as previously mentioned, are commonly the result of equally severe sthenic chorea, absolute rest in bed is essential, with an abundant and nutritious diet. Brandy should be given freely. It is of course necessary to reduce the amount as soon as improvement commences, otherwise a low state of semi-stupor, with delirium, furred tongue, and subnormal temperature, is apt to be induced. A similar condition of alcoholism sometimes delays convalescence from enteric fever in children. I have known it regarded as an indication for giving more stimulants; but, on the contrary less should be supplied. Needless to say, the treatment by large doses of alcohol is only applicable to cases in which exhaustion threatens life.

Quinine, which in the sthenic cases seems to aggravate the condition, as it often does in epilepsy, is useful in asthenic chorea. Salicylate of quinine, when there are muscular pains, cod-liver oil and maltine, nux vomica, and iron when anaemia is present, are better remedies than bromides and sedatives. Arsenic in small doses seems to be always beneficial. There is usually much prostration and emaciation. Massage and mild galvanism (not faradism) will improve the general nutrition.

Passive movements, and exercises under guidance and without, are as useful in these cases as in the sthenic subvarieties. But the rationale is somewhat different; for in asthenic cases voluntary movements are not so much hindered by spasms and ataxy as by inhibition of will power. Thus one has to teach the patient to use his limbs little by little, just as one coaxes a patient suffering from

reducing the amount of the latter directly symptoms of poisoning appear. 
hysterical paralysis to do so. The milder asthenic cases require treatment on similar lines, namely, tonics, exercises, massage, and prescribed amounts of rest in bed. Like cases of residual chorea, they are apt to be very tedious and even chronic unless taken in hand.

Reflex Chorea.-As may be gathered from preceding remarks, I believe that any condition which lowers general health may favour the flourishing of micro-organisms, and so give rise to chorea. Hence in every case of protracted chorea the presence of errors of refraction, naso-pharyngeal diseases, defective teeth, gastro-intestinal disturbance, parasites both internal and external, genito-urinary affections, and all sources of mental distress, must be sought and treated or removed if found. I do not contend that immediate relief is thereby procured, but so long as such conditions exist, the course of chorea may be prolonged.

There is no reliable cure, in the form of drugs, for chorea. Its vagaries in the way of sudden subsidence and recrudescence are well known. The most acute case tends towards recovery after a few weeks rest in bed under sedatives, and if precautions are taken to protect the child from emotional disturbance.

If after this period convalescence is retarded, the want of progress is usually due either to loss of will power to inhibit involuntary movements-in which case the will may be trained by suitable exercises, and recovery is soon effected-or to some continuous emotional disturbance which affects the child. A change of nurse, or even a change of room or bed may bring an immediate improvement. Children still choreic who fret at lying in bed may quickly lose their inco-ordination on being allowed to get up. A harsh or unsympathetic word, a disappointed desire, may bring about a relapse. Home-sickness will frustrate the kindest efforts of strangers to promote recovery in one case, whilst in another the desired result may be attained by satisfying the child's craving for a toy or an egg with its tea. 
The fact that the emotional or neurotic temperament plays a principal part in the production of chorea, is suffcient reason for condemning the practice of poisoning children with arsenic or any other drug. 


\section{CHAPTER XVIII}

\section{THE TICS.}

Tics or "twitches" are characterized by quick, sudden, involuntary co-ordinated movements of peculiar nature. They have been classified as Simple Tic or "Habit-Spasm" ; Convulsive Tic ; Psychical Tic ; and Co-ordinated Tic.

Etiology.-An inherited neurotic temperament is the predisposing cause of these complaints.

Any weakening illness will excite them. They frequently occur in children who are sent to school too soon, or are subjected to any kind of mental overstrain, after apparent convalescence from measles and other exanthemata.

Habit-spasms, like chorea, may be set up by traumatism, shock or fright, and by necessary or needless operations. Occasionally, especially in girls' schools, epidemics of habitspasm may result from mimicry, but such instances are rare. The old superstition that ordinary or Sydenham's chorea may spread in hospital wards by imitation is unfounded. Choreic children, however, should not be kept together, as each may aggravate the other's complaint. Children will sometimes imitate tricks, gestures and ugly habits which they observe in their elders, but these are not strictly speaking, habit-spasms.

The local causes which are held to excite habit-spasm by reflex irritation include refraction errors, conjunctivitis, decayed or erupting teeth, adenoids, intestinal parasites, adherent prepuce, phimosis, and a host of other minor irritants, which are only associated with habit-spasms in those who are of neurotic temperament. 
Varieties of Habit-Spasm or Tic.-No sharp distinctions can be drawn, but tics may be grouped in their order of severity.

In simple tic there is a rapid exhibition of isolated muscular twitchings in various parts of the face; a series of lightning-like blinks or nods or sudden turns of the head aside. The eyebrows may be elevated or corrugated, or the upper lips may be raised several times in quick succession as in a munching rabbit, or the nose may be wrinkled and the alae nasi expanded or contracted whilst half a dozen or more little ineffectual sniffs are produced, or a variety of grunts and queer guttural noises are heard.

The characteristic of all these simple tics is that they suddenly come and go, and each form will commonly give place to another. It is seldom that more than one trick or antic is present at a time.

In co-ordinated tic the movements are more complicated than in the simple variety, and as in simple tic, one set of movements may be suddenly replaced by another. For instance, after spending some days or weeks in repeating apparent efforts to twist his mouth round his nose, the child will suddenly relinquish the attempt and take to elevating his chin and stretching his neck as though his collar were too tight, or he will shrug his shoulders or writhe like an eel at short intervals ; or, whilst walking will suddenly execute a twirl, a hop, skip or jump, or he will stamp heavily on the ground with one or both feet or strike his head or body vigorously with his fist.

One child under observation would at half-minute intervals shut her eyes tightly, show her teeth in a disagreeable snarl, and protrude her tongue with quick vibration like a snake.

Sometimes the diaphragm descends deeply five or six times in rapid sequence, whilst the abdominal walls bulge and a sound resembling a combination of eructation, cough, and hiccough, or that of a rutting deer is emitted. Sometimes no sound is produced. 
Ignorant people may be alarmed in such cases lest the child be harbouring a live rat or frog or serpent in its abdomen. In more than one case I have known the diagnosis of pressure by tuberculous glands upon the phrenic nerve to be suggested by an anxious practitioner.

In convulsive tic the movements are more violent and severe than in the simpler varieties, whilst psychical tic (Gille de la Tourette's disease) is so called when in addition to imperative impulse to perform ridiculous and unaccountable actions, there are explosive utterances of obscene words (coprolalia) or imitation of animal sounds, or of the gestures and words of bystanders (echokinesis, echolalia). The mental symptoms in such cases are more in evidence than the motor. Agoraphobia or claustrophobia, acrophobia, mysophobia or arithmomania, fixed ideas or obsessions and signs of general mental impairment may make their appearance.

But the subjects are often physical and mental degenerates with neuropathic inheritance.

The first symptoms of these serious forms of Tic are usually seen between the ages of ten and fifteen, whereas the simple varieties usually occur in children after the age of four, and are most marked between the sixth and ninth year.

The incidence on the two sexes is about equally divided.

The term "habit-spasm" does not happily describe the curious contortions of face and body which characterize the tics. Habits are acquired by practice, but these start ready made. Moreover, it is extremely difficult to imitate by voluntary effort the rapid flickering of the eyelids which, for instance, is often seen, and it is impossible to produce at will the perverted and exaggerated action of the diaphragm which has been described. Some tics are neither habits nor spasms.

Habits again are usually unconsciously indulged, whereas, with few exceptions, the subjects of "tics" are fully aware of them. In many cases the tics are uncontrollable by force of will ; the impulse to perform them is irresistible, or 
can only be resisted by a continuous and exhausting effort, whilst yielding to the impulse affords a sense of satisfaction, the source of which it is difficult to understand. The movements of tic are not automatic or reflex actions of daily life, nor are they gestures of defence against some local causes of irritation. The movements are unlike any of the normal reflex acts which have protective ends. The weird guttural noises produced in the grunting variety of tic, for example, do not answer the purpose of clearing the throat in response to local irritation. The rapid blinks and sniffs, the spasmodic movements of the diaphragm in tic can afford no real relief to any supposed local cause of discomfort.

Undoubtedly in many cases slight local causes of irritation exist. But for the most part such causes are trivial and do not produce more than a passing uneasiness in any but neurotic subjects, in whom the origin of tics is in accordance with the general rule that "great events from little causes spring." The events may long out-last the causes.

Tics, in fact, are motor manifestations of psychical disturbance rather than indications of local disease.

Children will often lament bitterly that they cannot overcome their " habits," and each time they acquire a new one they will mournfully announce the fact to their sorrowing next of kin.

As in cases of "habitual" or " residual" chorea it will be noticed that, in some, the movements only occur when the child knows that it is under observation, whilst in others they occur only when it believes itself unwatched.

All these considerations seem to have an important bearing on the treatment of tics.

Treatment of Tics.-It is customary in all cases of tic to look for local causes, such as errors of refraction, decayed or erupting teeth, adenoid vegetations, intestinal parasites, and adherent prepuces. Whenever such conditions are obvious and pronounced and calculated to produce ill-health, even in ordinary healthy children, special treatment is necessary. But tics are suggested rather than caused 


\section{FUNCTIONAL NERVOUS DISORDERS}

by local irritation. A particular form of spasm may cease for a time after removal or correction of the supposed cause, only to recur in the same shape after the excitement of a children's party or a pantomime, or the introduction to a new and unpopular rule in arithmetic.

Tics are not invariably cured by the removal or correction of minor and trivial sources of irritation. Children with slight degrees of astigmatism will continue to blink through spectacles, and tics may be intensified, aggravated, and even produced by operations, such as removal of adenoids and extraction of teeth.

Palliative measures are therefore preferable to operations, unless the latter are urgently needed, as, for example, in cases of obstruction due to enlarged tonsils and adenoid vegetations.

In all text books it is very properly stated that scolding and any form of punishment are inadmissible, but the system of exhorting the child to control itself, and offering rewards if it succeeds in doing so is equally inadvisable, except in certain cases.

To a great extent tics are due to uncontrollable impulses, and the more the child's attention is drawn to them the more inveterate they become. In most cases the less notice taken of them the better. They soon subside when underlying causes of mental overstrain are removed. Habit spasms are in fact indications of nervous instability and emotional stress produced in any manner. They are frequently associated with fretfulness, irritability, fits of passion, night terrors, enuresis and dyspepsia. They are best treated by securing freedom from all emotional excitement; by wholesome diet and a quiet rational mode of life in a healthy open atmosphere, long hours of sleep, and periods of rest during the day.

A. Porot* recommends elaborate forms of moral and physical drill in cases of tic. He would train the child to stand like a statue before a looking glass, and teach it not 
to jump or wince when pricked or tickled, or when bright objects are suddenly brought close to its eyes.

It is doubtful whether Porot's measures are always justified in the case of neurotic emotional subjects of tic. They are certainly unjustifiable when tics are of recent origin.

There are cases, however, in which, although general health is good, tricks and antics are performed apparently from sheer inattention and carelessness. They are often associated with slouching, clumsy gait, ungainly attitudes, humped shoulders, dropped chins, and these should be treated by drills and exercises such as have been recommended in cases of "residual chorea." p. 231.

School life with all its trials to sensitive children is a frequent cause of tics, but they are perhaps as often produced by unsuitable environment at home. So the question as to fitness for school or home can only be decided by circumstances.

Whenever a child who is the subject of tic worries over his lessons, the obvious course is to stop them. Yet it often happens that a child though bright and intelligent and thoroughly enjoying his education as a whole, is harassed and vexed by some particular subject, usually simple arithmetic. In such cases the distasteful subject should be dropped, at all events for a time, from the curriculum.

Active minds will not lie fallow, so it is better to occupy them with interesting and useful information than to neglect their education altogether.

The treatment of the exaggerated forms of tic, in which psychical symptoms outweigh the motor, is unsatisfactory. The presence of unaccountable fears and obsessions, with signs of mental and moral deterioration, render future prospects gloomy, especially when neuropathic heredity prevails.

Yet sometimes many of the more serious symptoms may be closely imitated by hysteria, and the prognosis is then hopeful. When hysterical stigmata are found, isolation with 
moral discipline, followed by healthy pursuits and mental occupation, will usually yield good results.

Finally it may be observed that certain forms of coordinated tic and impulses are merely harmless eccentricities and not in any sense a disease.

Some individuals derive satisfaction from touching posts, some cannot pass a nutshell on the street without going out of their way to tread on it. Some stimulate thought by caressing their under lip or the lobe of the ear, or a lock of hair, or by playing with a button on their dress. The writer has known a highly gifted man who in early childhood would break off in the midst of any absorbing occupation, thrust his tongue into his cheek making a curious groaning noise, and thump his knees vigorously as though playing a drum for several seconds at a time. Such peculiarities of conduct not being morbid need no treatment beyond a little kindly ridicule.

Drug Treatment of Tics.-Tonics such as arsenic and strychnine are often of value, and whenever mental irritability and excitement are prominent, a course of bromides is indicated. No drug is a specific for the cure of tics. They are manifestations of psychical unrest, and should not be treated by atropin, conium and other poisons.

The "cumulative" treatment by those and other drugs simply serves the purpose of gaining time.

Iron and cod-liver oil may be given when required. Indigestion and constipation should be treated on ordinary principles. In weakly, emaciated children massage is often of use. Electricity may serve the part of mental therapeutics, but has no other value. When used, the currents should never be strong enough to hurt the patient.

Diagnosis of Tic.-The distinction between tics or "habit-spasms" and chorea is all-important from the point of view of treatment. For, acute rheumatic chorea must be treated at its onset by absolute rest in bed on account of the imminent danger of endocarditis, whereas 
in the case of tics or habit spasms it is the mind rather than the body which is in need of rest.

In chorea the movements of the limbs are the normal primitive actions of flexion, rotation, extension, etc., though performed without object, with needless vehemence, and constantly changing, alternating and clashing with each other. The movements in "tic" or habit-spasm are meaningless and complicated motor tricks, gestures or antics which are but a fantastic parody of normal actions. In habit spasm the child simply "pulls faces," whereas in true chorea the grimaces are exaggerations of normal expressions of emotion.

A difficulty in distinguishing chorea from the tics only arises when the two conditions are combined.

The slow, writhing, athetoid movements which occur during rest in cases of so-called "post hemiplegic chorea" and the laboured ataxy which accompanies attempts at voluntary actions, and also the tremors and violent jactitations of limbs which may be the consequences of infantile hemiplegia can hardly be mistaken for either tic or Sydenham's chorea.

Myoclonus (Paramyoclonus multiplex,-myokymia).-A rare disease which may be met with in children upwards of five years of age, consists in simple sudden spasms of individual muscles-not groups "of muscles, as in the tics and chorea. It usually affects the same muscles on both sides of the body, and the movements resemble those produced by faradic stimulation of the nerves which supply the affected muscles. The spasms do not occur rhythmically, and they do not resemble any volitional movements, whilst the face is rarely affected. Myoclonus, therefore, is easily distinguished from chorea and "habit spasm."

Head Rolling, Head Banging, Head Nodding, Nystagmus, and Body Rocking.-Head rolling occurs chiefly in infants under the age of two years. The head is slowly rolled from side to side as the infant lies in its cot, until in time the occiput may become bald from friction. 
The habit may suggest meningitis or brain trouble of one kind or another, but is rarely so caused. In some cases the movements are directly traced to earache, but more frequently they are unassociated with pain. Dr. Still however believes that latent catarrh of the middle ear accounts for some cases. Possibly vertigo is thus caused and gives rise to the movements. They have of course been attributed to dentition and other sources of peripheral irritation, but in most instances head-rolling is merely a habit which passes off after the second year.

Head banging is not uncommon in neurotic excitable children when in a fit of temper. In other cases the child seems to derive some unaccountable pleasure from striking the head with its fist or against the wall or floor. It is an alarming habit but I have never known injury to result from it. Nor as a rule is it associated with headache or pain. I have, however, known one instance in a boy aged six who would w frequently beat his head with considerable violence against the wall when suffering from cerebellar tumour.

Nystagmus and head-nodding (Spasmus Nutans). These affections with rotatory, horizontal,vertical, or oblique movements of head and eyes, appear to be due to want of correlation between the action of the ocular and cervico-cranial muscles. They have been attributed to residence in dark rooms in which there are one or more spots of bright light, the fixation of which exhausts the retina, also to intestinal toxaemia, rickets, and of course to dentition. The evidence of such causation is in each case insufficient. In a few instances, nystagmus and head-nodding are associated with feeblemindedness, and may be persistent, but in the majority, the movements cease spontaneously without special treatment towards the close of the first dentition.

Bromides and antipyrine, which have been recommended, are quite unnecessary, and indeed are contra-indicated if the condition is, as maintained, an instance of imperfectly established co-ordination. 
All that is necessary in most cases is attention to general hygiene, and provision of diet suitable to the ordinary child. The subjects of these affections are usually nervous and hypersensitive to noise.

Spasmus nutans should be distinguished from Eclampsia nutans, in which sudden nods or jerks of the head occur in series of fifty or more at a time. They do not resemble the slow deliberate movements of spasmus nutans. The expression looks vacant or there may be momentary loss of consciousness at the time of the spasms. In some cases the trunk as well as head are suddenly bowed, the hands extended palms downwards before the face (Salaam fits). Eclampsia nutans, in fact, is a form of epilepsy, whereas spasmus nutans has no relation to that affection.

Body rocking is another curious trick in which neurotic children sometimes indulge. When sitting they will sway to and fro and from side to side, twenty or thirty times a minute. Sometimes they will make a crooning sound meanwhile and appear to rock themselves to sleep. They are usually queer, odd children in other ways but by no means deficient in intelligence. Similar movements are however frequent in imbeciles. Bears, elephants and monkeys commonly practise swaying movements of the kind. The habit in horses is known to grooms as "weaving."

Body rocking in children is a harmless pastime in itself, but it may lead to or actually indicate masturbation, especially in little female children. Cf. p 109. 


\section{CHAPTER XIX}

\section{DELAYED WALKING. LOSS OF ACQUIRED WALKING POWER HYSTERICAL AND FUNCTIONAL PARALYSIS}

A NORMAL healthy infant usually tries to stand in the ninth or tenth month; by the beginning of the eleventh month it learns to stand with a little support, and by the end of the eleventh month it can usually do so alone.

Attempts to walk are commonly seen in the twelfth and thirteenth months, and in the fourteenth or fifteenth month most children can walk without assistance.

Even healthy children show great variability in this matter; some may start walking at ten or eleven months, others not till seventeen or eighteen months of age.

If a child has no idea of supporting itself on its legs or of walking by the age of two years, some morbid condition, either of the brain or spinal cord, or a general state of malnutrition and muscular weakness is present as a rule. If, in addition, there is inability to hold up the head, to sit up, to speak and to use the hands at this age, mental deficiency may be suspected; or if there is rigidity or spasticity of the limbs, birth palsy (cerebral diplegia) is the usual cause. But in the latter case mental powers may not be markedly impaired.

A prolonged or severe illness of any kind will necessarily postpone walking powers.

Rickets is, however, the most frequent cause of delayed walking. But this is not necessarily the case with children who show the most profound osseous changes of that disease. In some, the effects of rickets are shown in laxity of the 
ligaments, weakness and loss of tone in muscles rather than in enlargement of epiphyses and other well-known rachitic deformities, and therefore rickets may be unsuspected.

In such cases, there is excessive mobility of all the joints. The feet and hands can be dorsiflexed until the fingers and toes almost touch the backs of the forearms and fronts of the legs respectively. The knees can be hyper-extended. The child can lie with its face between its extended legs, and the lower extremities can be flexed until the feet touch the face and head. The child sits huddled up with bowed back, if it can sit at all. When lying on the back, the lower limbs fall outwards in frog-like or cadaveric position.

All the postures and subluxations of joints practised by the professional contortionist can be produced in this form of rickets without causing pain.

The condition is commonly attributed to relaxation of ligaments alone, but hypotonia or loss of muscular tone is undoubtedly present as well, and in some cases equals that met in tabes. The knee-jerks too in rachitic hypotonia may be absent, as in tabes. It is possible that the condition in rickets may depend upon some defect of development in the ascending cerebellar tracts. Of this, however, there is no post mortem evidence. Similar hypotonia may be seen in imbeciles, especially of the Mongolian type. The muscles, although weak and flabby, are not paralysed: all voluntary movements are possible. The electrical reactions, except when tetany is present, are reduced in activity. In extreme cases of rachitic hypotonia, if the child is held in the erect position, the legs and thighs are either kept flexed, or, if the child extends them, it is quite unable to support its weight on the feet. Nor does it attempt to move the limbs alternately forwards, as in walking.

The condition is one of pseudo-paralysis ; the prognosis is favourable.

Treatment consists in endeavouring to improve muscular 
nutrition and strength by massage and passive exercises. An intelligent patient can easily be taught to move its limbs against resistance, and so to strengthen its muscles.

It is important not to allow the child to rest its full weight on its feet, for, in the first place, want of muscular tone makes equilibrium difficult; hence attempts to preserve balance are made by standing with the legs wide apart, and this, together with muscular loss of tone, will inevitably result in flat feet and knock knee.

The old-fashioned "go-cart" is mostly condemned in these days, and is certainly not to be recommended for teaching healthy children to walk before their time, but in the cases mentioned it serves the purpose of encouraging the muscular movements of walking without the risk of inducing deformities.

Passive exercises and massage cannot take the place of normal movements entirely. Rickety children who have learnt to walk should not be kept off their feet indefinitely. Light side irons should be used to support their pliable softened bones when walking. The object of treatment is to strengthen the muscles whilst preventing the bones from bending.

Loss of Acquired Powers of Walking.- "Gone off his feet" is the common expression used to describe sudden or gradual loss of power to stand and walk from any cause.

Such loss of power may be due to pain, paralysis or weakness, and may affect one or both limbs. The onset may be sudden or gradual. If sudden, infantile paralysis or paraplegia from spinal caries may be suspected. If gradual, or not immediate, rickets, rheumatism, diphtheritic paralysis, scurvy, epiphysitis and incipient tuberculous disease should be borne in mind. Brain diseases such as hydrocephalus, tumour, abscess, encephalitis, cerebro-spinal meningitis, may cause inability to stand or walk, whilst difficulty in doing so may be due to myopathy, or Freidreich's disease, and other affections of the cord. 
But all these diseases have distinctive features which cannot be overlooked, and need not be considered here.

Pain as a Cause of "Going off the Feet."-Inability to stand or walk has to be distinguished from reluctance to try to do so. Pain, or dread of pain, will always prevent a child from any exertion which causes or increases its sufferings. Whereas, provided no pain is excited, a child will usually make the effort to stand or walk, although it may be quite unable from paralysis to do either. Hence whenever a child has "gone off its feet," pain is the probable cause.

In cases of rickets, the common history is that the child, aged two or three, has tired itself by running about at play, and has begged to be carried. Next day it refuses to put one or both feet to the ground, and cries piteously if compelled to do so. On examination, there is obviously no paralysis of muscles, but certain passive movements of the ankle, knee or hip excite resistance and screaming. No signs of inflammation are discovered in the joints, nor as a rule is there any tenderness or hyperaesthesia of the limbs. The supposed general tenderness of bones and limbs in rickets is seldom found.

The cause of this loss of walking power in rickety children seems to be a simple strain of certain tendons or muscles which are too weak to support the child's heavy frame.

Under a few days treatment by rest, gentle massage, and with diet suitable for rickets in general, the pseudo-paralysis passes off.

In children upwards of three years of age, slight muscular or tendinous rheumatism will produce similar effects. But in infants under eighteen months rheumatism can practically be excluded. Symptoms ascribed to rheumatism in young infants are generally due to scurvy, or to acute epiphysitis. In scurvy the infant lies absolutely still but screams in characteristic terror of being disturbed when any one approaches. The history, cachectic appearance, spongy 
gums, pectechial and subperiosteal haemorrhage in scurvy, the exquisite tenderness, redness and swelling present in epiphysitis will easily distinguish these causes of pseudoparalysis in infants.

Acute osteomyelitis, and epiphysitis, in older children should not be confused with rheumatism. In rheumatism the swelling is of the joints, in the other diseases, it is outside the joints.

The arthritis of acute rheumatism affects several joints symmetrically, and seldom severely in children, and it quickly subsides, though it may recur. Cardiac symptoms or chorea may be present. In acute suppurative arthritis, osteomyelitis and epiphysitis it is seldom that more than one joint or part is affected. The pain and local inflammation are severe and increase rapidly, cardiac symptoms are less common, fever and constitutional disturbance are usually far more grave than in rheumatism.

Tuberculous Disease of Joints and Bones is more gradual in onset than other inflammatory conditions. It often causes limping and pain in early stages, but seldom prevents walking except in very young children.

Infantile Paralysis, when severe, always gives rise to fever and other signs of acute illness such as languor, drowsiness, headache and vomiting, with pain and tenderness of the limbs involved. Mild cases, in which a single muscle group is paralysed, may occur without constitutional disturbance.

The onset may be sudden or gradual. The pains may simulate those of rheumatism, and the paralysis may at first escape detection : but in the course of a few days it becomes obvious.

It is impossible at first to ascertain the extent of the lesion in the anterior cornual cells. It always seems, judging from the degree of paralysis present-more widely spread than it really is. But within a few weeks, power is regained in all but certain groups of muscles which remain palsied, and waste rapidly, whilst the affected limbs become 
cold and blue. The activity of the knee-jerks is not lessened unless the anterior group of thigh muscles is affected.

Electrical testing of the muscles is needless for diagnostic purposes, and harmful because the strong currents necessary are painful and therefore, by alarming the child, make treatment by electricity difficult. Electricity is useless when applied to muscles paralysed in consequence of total destruction of the anterior cornual cells which innervate them. It is only serviceable in hastening return of power in muscles which are merely functionally disabled. A certain degree of functional disablement of non-paralysed muscles is apt to persist, unless treated by mild electricity, massage and encouragement to make use of powers regained which would otherwise remain in abeyance.

Diphtheritic Paralysis, when the legs are affected, causes staggering and weakness of gait, but seldom in early stages prevents walking altogether. The diagnosis is completed by absence of knee-jerks, the presence of a weak nasal voice, a loose ineffectual cough, regurgitation of fluids through the nose on swallowing, and sometimes a squint. A history of diphtheria or sore throat is often absent. Recognition of such cases is all-important as the danger of rapid death from cardiac or respiratory paralysis is imminent. Absolute rest in the recumbent position is essential.

Multiple Neuritis.-A condition of generalized paralysis simulating diphtheritic paralysis but unattended by bulbar symptoms is sometimes seen in children. It is probably due to multiple neuritis of obscure toxic origin. It may succeed influenza or any of the exanthemata, or it may occur spontaneously. The onset is usually sudden, with pyrexia and pain in the back and limbs.

Hyperaesthesia or tenderness in the course of the nerve trunks in the lower extremities may be present. The child lies motionless and after the first few days is usually free from pain except on passive and active movements. Attempts to make it stand or sit up, or to flex the hips, hyper- 
extend the knees or dorsiflex the feet cause shrieks of pain. Complete facial paralysis or of some of the ocular muscles sometimes occurs, but the muscles of the limbs are paretic rather than paralysed. The knee-jerks are often absent but may be exaggerated; the muscles waste. Recovery may be complete though tedious. In one case, contraction of the calf muscles on both sides resulted, but after division of the tendo Achillis full powers of dorsiflexion of the feet returned showing that the anterior muscle of the leg had recovered. In another, slight talipes valgus with flat feet and wasting of calf muscles, drooping of the two mid fingers of the right hand and paresis of the right superior rectus oculi remained. In yet another case, in which complete right-sided facial paralysis, trigeminal neuralgia, ataxy and tremors of both arms, staggering "cerebellar" gait, loss of knee-jerks and weakness of back muscles were present, complete recovery ensued at the end of three months.

Polyneuritis resembles the severe form of anterior polio- * myelitis, but recovery is far more complete in the former than in the latter disease. Some think that poliomyelitis, polio encephalitis and polyneuritis are instances of the same disease affecting different parts of the nervous system.

Paretic Chorea as a cause of apparent paralysis, and also the paralysis of the lower limbs due to treatment of chorea by large doses of arsenic, have been mentioned elsewhere (pp. 234-235).

Hysterical and Functional Paralysis.-An unqualified diagnosis of hysterical paralysis in children-and in adults too-should never be made in haste. Even when manifestations of hysteria are obvious, almost invariably some antecedent morbid condition, which may still remain uncured, has set them up. Worse still, hysterical symptoms may be caused by incipient organic disease, which most careful examination at the time fails to detect. For instance, the writer has known typically hysterical contracture of a lower limb to occur in a girl aged ten who three 
months later was found to have tuberculous disease in the neighbourhood of the hip joint.

On the other hand one sometimes meets with cases of purely hysterical paralysis which have been treated for non-existent spinal caries.

Further, functional paralysis may be the first indication of gross cerebral disease, whilst it may perpetuate loss of power in a limb once paralysed or injured, but long since cured. Sensational reports of miraculous cures of long standing paralysis at the shrines of saints and quacks would seldom put our profession to shame, were not functional symptoms mistaken for those of organic disease.

The stigmata of hysteria-restriction of visual fields, local anaesthesia, or hemi-anaesthesia, and contractures of limbs-are rarely met with in children under puberty, but are fairly common at or about that period.

Functional Asthenopia, with loss of conjunctival reflex and sensitiveness, and deficient use of the muscles of accommodation, has been described. But the condition has to be distinguished from diphtheritic paralysis. Absence of kneejerks with a nasal voice and loose ineffectual cough will complete the diagnosis of the latter affection.

Functional Amaurosis.-Acute amaurosis may be the consequence of posterior basic meningitis which has given rise to internal hydrocephalus, and therefore to pressure on, inflammation, or perhaps stretching of the optic nerves. In such cases there will be sooner or later atrophy of the optic nerve. Signs of optic atrophy distinguish them from cases of acute amaurosis following encephalitis, in which as a rule no changes in the optic nerve take place. The amaurosis here may sometimes be due to toxic affection of the cortical visual centres in the occipital lobes. The prognosis is therefore fair in amaurosis arising from encephalitis, whereas it is mostly gloomy when blindness is due to the results of posterior basic meningitis. But even in the latter disease, vision is sometimes recovered to a remarkable extent.

Post-Convulsion Amaurosis, again, may depend on 
organic mischief, in which case recovery is doubtful, but sometimes it seems due to temporary exhaustion or anaesthesia of the cortical visual centres. A similar condition of exhaustion may produce transient aphasia or hemiparesis. When the amaurosis and paralysis depend upon organic disease, recovery is seldom complete. The amaurosis in such cases is hemianopic in type. Amaurosis due to exhaustion of visual centres is as a rule not hemianopic but affects the whole of the fields of vision. Vision is usually restored in a few hours.

Amaurosis following prolonged Blepharospasm is somewhat rare. After long disuse of one or both eyes, the child seems literally to have forgotten how to see, and before vision can be regained he must re-educate his cortical visual centres. (Sydney Stephenson.)

Leber regards amaurosis in these cases as due to cortical changes of functional character.

The treatment simply consists in encouraging the child to use its eyes.

Another cause of "fleeting amaurosis" in children is migraine, to which reference has already been made.

Functional Dysphonia is fairly common. It usually follows catarrh, and may be associated with any local pharyngeal disorder. The child will not raise its voice above a whisper, but can cough loudly. The palatal reflex is lost and pharyngeal anaesthesia is revealed by the ease with which laryngoscopic examination is effected. The vocal cords are normal, but on phonation they are only approximated anteriorly and posteriorly, leaving an elliptical space in the centre.

Under strong emotion, or application of the faradic current, the voice is at once regained, and the good effect is maintained more constantly than is usually the case with adult sufferers from hysterical mutism.

Functional Dysphagia may be met in neurotic infants at or about the time of weaning. Sometimes the difficulty is with semi-solids, sometimes with fluids. In some cases it is 
due merely to the child throwing its head back in the effort to avoid swallowing food it does not like. The difficulty is soon overcome by patience and perseverance. Sometimes it is due to hurry and may be prevented by feeding slowly and in small quantities at a time. In some instances it may be akin to "stage fright," which prevents the débutante from eating and drinking in face of an audience. Or the child may have once suffered from the discomfort of food going the wrong way, and dreads that it should do so again. This infirmity passes off if confidence is restored by encouragement.

Dysphagia due to inco-ordination or stammering of the muscles of deglutition has been described, but it is decidedly rare.

Cases of dysphagia in young infants have, however, been recorded in which the defect seems to be spasm or absence of relaxation of the cardiac sphincter, leading to regurgitation of food before it reaches the stomach. It must be treated by passage of bougies and feeding by nasal tube, in hope that in time the affection may wear off. It seems to be analogous to spasm of the pylorus. (John Thomson.)

Hysterical Dysphagia is characterized by prodigious though unavailing attempts to swallow. The patient complains that she cannot get the food out of her mouth, and that it goes down but returns before it is half swallowed, or that a ball rises in her throat to meet food as she swallows. (St. Clair Thomson.) This difficulty is only with solids or semi-solids. Treatment is by isolation, encouragement, and as a last resource, forced feeding.

Functional Paralysis of the Limbs may be associated with rigidity or flaccidity. The upper or lower extremities may be affected. When rigidity is present there is almost always complaint of pain. The knee is most commonly involved. It is kept rigidly extended or semi-flexed and all attempts to move it are met with resistance and piercing shrieks. Sometimes a mild attack of rheumatism or slight injury accounts for the condition. Existing local disease of knee and hip must of course be excluded. The flaccid 
form may affect one or both lower limbs. The apparent loss of power usually occurs suddenly, but may be gradual. In the paraplegic variety, although, on examination, proof of voluntary power of executing all movements may be elicited, no efforts to stand or walk are made. If the child be placed upon its feet it treads on the inner or outer side or even on the dorsum of the foot, and at once collapses on the ground if unsupported. When one limb only is affected the child will not rest upon it. The limb is trailed like a dead weight, often with the toes or dorsum of the foot scraping the floor, behind the patient.

In cases of long duration the diagnosis is often difficult owing to wasting of the limb from disuse. Sometimes after an undoubted attack of infantile paralysis it may be difficult to decide how much of the disability is functional, and how much dependent on organic disease. But this can be ascertained by electrical tests when other methods fail.

Condition of Tendon Jerks and Reflexes in Functional Disease.-Apparent exceptions to the following rules may be met, yet they are evidence of temporary organic mischief, and not of purely functional disorder. The knee jerks, and Achilles jerks are never absent except in organic disease. They are usually active in functional disorders. True ankle clonus is never present in functional paralysis. The plantar reflexes are most frequently absent, they may be flexor in type, or they may be unduly active, with drawing up of the entire limb, expansion and extension of the toes in functional paralysis. But the slow "Babinski" extensor response of the great toe is not seen except in cases of organic affection. The condition therefore of reflexes and tendon jerks is of great assistance in arriving at a conclusion.

Treatment of Functional Paralysis and Neurasthenia.-Hysterical paralysis seems to depend rather on inappreciation by the cortical cells of the brain of peripheral afferent stimuli, which usually excite motor action, than upon exhaustion of the cortical cells themselves. An unwonted and extra-powerful stimulus will excite the cortical 
cells to activity. Hence the treatment of functional paralysis consists in waking the sleeping cortex by strong Faradic shocks to the periphery, and by rousing dormant powers of will by persuasion, moral discipline and encouragement.

Isolation from relatives and friends is almost always necessary in hysteria, for the environment has usually been, and may be still, unwholesome. Isolation may also be necessary in neurasthenia, but on different principles. Hysterical patients are isolated in order to rouse them, whereas in the case of neurasthenics, the purpose is to rest them. Needless to say, success in either case depends on the personal influence of those in charge.

Electricity is useful in both hysteria and neurasthenia, but in the former, every application which does not cause pain or emotional wonder and excitement is useless, whereas in neurasthenia it must be painless and soothing in order to produce good effects.

Drugs.-Strychnia and nux vomica, though valuable in most cases of simple nervous debility, often do harm when given in hysteria and neurasthenia coupled with emotional excitement, restlessness and irritability; they may aggravate these symptoms and induce headache, increase hypersensitiveness, and cause insomnia.

The hypophosphites are better borne. I have never discovered any particular advantage in patent preparations of glycerosphosphates over the officinal mixed hypophosphites of sodium, calcium, and potassium.

The bromides are useful in all cases where strychnia and nux vomica are contra-indicated, and they may be given with hypophosphites. Large doses of bromides, however, should not be given for lengthy periods. They have no selective action on different areas of the brain, and hence, whilst doing good in diminishing hyperaesthesia and irregular nerve discharges in one area, they may do harm by lowering the powers of normal function in another. Hence motor and sensory paralysis may be increased, and powers of inhibition and control may be decreased by bromides. 


\section{CHAPTER XX}

\section{STAMMERING AND OTHER DEFECTS OF SPEECH}

Stammering is due partly to spasm, and partly to incoordination of the muscles concerned in the production of speech. Spasm may affect the articulatory muscles, namely, those of the lips and tongue, or those which govern the air supply necessary for the emission of sound, to wit, the muscles of the glottis (true and false vocal cords) and the respiratory muscles in general, the diaphragm and abdominal muscles in particular.

Inco-ordination 'may exist between the sets of articulatory muscles, or between those of the respiratory muscles, or it may interrupt the harmonious action of the two main sets, and thus prevent the equable flow of vowels and consonants.

Stammering may be briefly defined as a spasmodic arrest of utterance due to one or more of the causes mentioned.

Stuttering consists in spasmodic repetition of initial syllables of words.

Owing to imperfect vocalization and respiratory force, utterance of the initial syllable is weak and abortive. The stutterer is aware of this and repeats the syllable over and over again without taking breath in the effort to make it audible.

Stuttering is less common than stammering, and is more amenable than is stammering to treatment by respiratory exercises.

In any case of stammering it is necessary first to ascertain the part of the mechanism which is at fault, and in order to do so, the physiology of speech must be understood. 


\section{STAMMERING AND DEFECTS OF SPEECH 263}

Speech is composed of words, and words of vowels and consonants.

Vowel-sounds are produced in the glottis by vibrations of the true vocal cords, which are set in action by currents of air passing over them.

The different forms of vowel sounds-A, E, I, O, U (Ah, $\mathrm{Eh}, \mathrm{Ee}, \mathrm{Oh}, \mathrm{Oo}$ ), arise from modifications of original tones produced in the larynx, by alterations in the capacity and resonance of the oro-nasal cavities.

Consonants are so called because several of them cannot be sounded properly except consonantly with a vowel.

All consonants are formed by interruption of the current of air in some part of the air passages above the larynx.

Consonants are divided into:-

Voiceless-oral (P, F, Wh, T, Th, K, S, Sh.).

Voiced-oral [B, V, W, D, Th (Dh), L, R, Z, Zh, Y, G.]

Voiced (with nasal tone) (M, N, Ng).

Consonants are also divided into explosives (B, P, D, etc.) and fricatives ( $\mathrm{F}, \mathrm{S}, \mathrm{H}$, etc.).

The obstruction to the current of air which causes formation of consonants may be due :-

1. To closure of the lips (first stop position). Thus are produced the consonants $\mathrm{B}, \mathrm{P}, \mathrm{M}$.

2. By pressure of the tip of the tongue against the back of the upper teeth and forepart of the hard palate (second stop position). The consonants E. D, Th, (dh.) are thus formed.

3. By approximation of various parts of the back of the tongue to the soft and hard palate (third stop position). Thus are produced the consonants [K, G, (hard) S, Z, Sh, Zh, Y].

Finally spasm of the false vocal cords may prevent exit, whilst spasm of the true vocal cords prevents entrance of air, and thus renders vowel sounds inaudible (fourth stop position).

The consonants $\mathrm{F}, \mathrm{V}$, are formed by pressure on the lower lip by the upper teeth.

$L$ is formed by partial contact of the tip of the tongue 
with the forepart of the palate, the sides of the tongue remaining free.

$R$ (trilled) is produced by vibration of the tip, not sides of the tongue.

Bearing these elementary facts in mind it is seldom difficult to ascertain at which of the four stop positions the difficulty in a case of stammering occurs.

In some cases there is "want of harmony between the respiratory and laryngeal mechanism. The patient has no notion of governing the exit of his breath; he emits it in a gust, without making use of the glottis as a waste preventer, and he attempts to speak when breathless; sometimes he may even try to talk without first intaking air.

But, as Dr. Cathcart points out,* in the great majority of cases the want of co-ordination is between the oral and the laryngeal mechanisms. The patient does not know that consonants are formed within the oral cavity, and vowels within the larynx, and that clear articulation depends on harmonious relation between the vocalizing organs and those of articulation. He is not aware that consonants are merely interpolations into vocalized vowels, and he makes frantic efforts to pronounce the consonants without the vowel sounds which should precede, accompany, or follow them.

As in Kussmaul's celebrated description of a stammerer :-

"He closes the oral canal at one or other of the closing points, according to the nature of the letter to be articulated, and this he does as well as a man who possesses the faculty of speech could do it; instead, however, of allowing the vowel to follow without delay, he presses his lips, or his tongue and his teeth, or his tongue and palate, more firmly together than necessary; the explosive escape of breath does not take place, the other muscles of the face and those of the glottis and even the muscles of the neck, become spasmodically affected like those of articulation; gesticulatory movements are made, the abdomen is retracted, the head is drawn backward, and the larynx is drawn

* (Vol. xi., Encyclopaedia Medica). 


\section{STAMMERING AND DEFECTS OF SPEECH 265}

forcibly upward, until he finally works himself into a state of frightful agitation; his heart beats forcibly, his face becomes red and blue, his body is bedewed with "perspiration, and he may present the picture of a complete maniac."

In such pronounced cases the patient attempts to speak without vocalizing his words. His energy is devoted to the oral mechanism of speech, the laryngeal and respiratory mechanisms are ignored.

The spasmodic movements which may affect the whole body are due to overflow of misdirected nervous energy into various parts.

When spasm of the false vocal cords which control exit of the breath takes place, the patient may stand speechless, and with widely opened: mouth and an agonized expression for several seconds ${ }_{4}^{\mathrm{x}}$ together, then when spasm relaxes, he pours forth his words in one continuous exhalation until he becomes breathless. After each inspiration, spasm and subsequent volubility recur.

This variety of stammering in which the difficulty is in vocalizing initial vowels is uncommon, but Dr. Cathcart has shown by an apt quotation that it was known to Shakespeare. "I pr'ythee tell me who is it quickly, and speak apace. I would thou could'st stammer, that thou might'st pour this concealed man out of thy mouth, as wine comes out of a narrow-mouthed bottle, either too much at once, or none at all. I pr'ythee take the cork out of thy mouth that I may drink thy tidings." *

Etiology of Stammering.-Heredity appears to have less bearing on the causation of stammering than is the case with other functional neuroses. The habit is more frequently imitated than inherited. It may be associated with the neurotic temperament, and when this is so, stammering causes untold misery, and treatment is difficult because the fear of displaying his affliction in company always makes the stammerer lose his head and forget to put into practice the principles which would bring him relief.

* As you Like It, Act iii. Scene 2. 
The local causes of stammering are any of those which produce naso-pharyngeal obstruction, and hence, faulty methods of respiration and diminished respiratory capacity.

Some have laid stress on the presence of phimosis as a cause. When the condition is an obvious source of local and general irritation, it should be removed. But circumcision is probably only indirectly beneficial, the enforced rest which the operation entails affords an opportunity for carrying out treatment of the stammering.

Shock or fright have immediately preceded stammering in some cases, and the affection has been known to follow severe illnesses of many kinds.

Boys are said to develop stammering five times as frequently as girls, and this discrepancy remains unexplained.

The affection does not occur until the power of fluent speech has been acquired.

Treatment.-Any general condition of ill-health needs attention, and local mischief due to adenoids, enlarged tonsils, decayed teeth, etc., should receive appropriate treatment. But stammering is rarely produced solely by local causes, and is seldom cured by their removal alone. As in the case of the tics, stammering is suggested rather than produced by local irritation. The mouth and naso-pharynx in many cases are normal. Nervous instability and emotional strain account for many cases of stammering, and these are not cured by correction or removal of minor local defects.

Stammering children make each other worse, and should not therefore be kept together.

Education at school is in most cases unsuitable, but in some, home life is more detrimental than that at school. The general effect of environment on health has to be considered as well as its bearing on stammering.

Stammering may make a nervous boy's life unendurable to him at school; but many stammerers are not nervous 


\section{STAMMERING AND DEFECTS OF SPEECH 267}

in the ordinary sense; they are callous and indifferent to their affliction, and may indeed deliberately exaggerate it in order to conceal the fact that lessons are unprepared.

The timid, nervous boy cannot be treated, and the indifferent careless boy will not be treated at school. Therefore each should be removed for treatment.

It is necessary to gain the confidence of the one and the co-operation of the other.

In undertaking the treatment of stammering, the first thing is to ascertain which part of the mechanism of speech is at fault. Does the difficulty arise at the first, second, third, or fourth stop positions ?

Is the trouble with the consonants-explosives, voiced and voiceless ; with the fricatives ; with the nasal resonants, or with the vowels?

Alliterative sentences illustrating all the speech sounds can easily be constructed and used as tests.

In the great majority, the fault is respiratory. The patient must therefore be instructed in the first place how to increase the vital capacity of his lungs, by breathingexercises, especially those which exercise the diaphragm. $\mathrm{He}$ must also be taught to control the exit of his breath, first without, and secondly together with vocalization.

He must learn to vocalize his vowels with steady prolonged resonance, and to direct his attention to this, rather than to articulation. Also he must grasp the important fact that the voice need not be intermitted in order to interpolate consonants.

He must intone the vowels, and be shown how to introduce the consonants meanwhile, as for instance in uttering the sound $\overline{\mathrm{O}}-\mathrm{M} \overline{0}, \overline{\mathrm{O}}-\mathrm{D} \overline{\mathrm{o}}, \overline{\mathrm{Q}}-\mathrm{T} \overline{\mathrm{o}}$, etc. $\mathrm{He}$ will thus learn that vocalization of vowel sounds aids in giving utterance to the consonants over which he stumbles.

Exercises in the methods of supplying and controlling his breath, without reference to their practical bearing on speech production, should be first mastered. Then should 
follow exercises in vocalization of vowels. Lastly, instruction in the art of framing consonants in conjunction with phonation should be given.

By following the course of exercises in this order, one may hope to render speech an automatic process and not a conscious and laborious effort. Stammerers, however, are seldom able to attain this power of automatic speech until, after unswerving attention to the principles of speech production, their practice becomes a matter of habit.

Many stammerers learn the principles with care, but fail to practice them in daily life, and so are never cured. Their speech is only fluent in the presence of their teachers.

Dr. R. A. Worthington in a valuable article* has dwelt upon the fact that rhythmical or metrical speech is easier for stammerers than prose. The reason is that the de-s livery of verse, when stress is laid on the metre, demands orderly management of the breath and so, in reading poetry, the stammerer diverts his attention from articulation to respiration. From the elocutionist's point of view it is of course a heinous offence to dwell upon the metre of verse in recitation, but in the case of the stammerer the fault may be encouraged.

The treatment of stammering passes necessarily into the hands of lay-specialists, for few medical men can devote the amount of time and attention to this affection which it merits. Therefore in the interests of the public it is desirable that all who profess to cure defects of speech should be licensed after proper training and examination.

Lalling (from the German "Lallen" - to speak as a child) and Lisping consist in substitution of consonants for each other.

Both conditions are characteristic of "baby language", which may be persistent in the feeble-minded and imbeciles. Minor degrees of lalling and lisping, in which the difficulty is only with consonants such as $\mathrm{S}$ and $\mathrm{R}$, do not of course

* Lancet, September 22, 1906. 
indicate want of intelligence. They may be due to defective formation of the mouth or teeth, or arise from habit. Lalling and lisping are met in their extreme form in so-called idioglossia, which again is compatible with full intelligence. 


\section{CHAPTER XXI}

\section{ON IDIOGLOSSIA}

The name Idioglossia was given by Dr. Hale White and Mr. Golding-Bird * to a defective condition of speech, so peculiar as to give the impression that the speaker used a language of his own. They exhibited to the Royal Medical and Chirurgical Society two cases of the kind occurring in brothers aged nine and ten and a half years. At the same meeting of the society, Dr. Frederic Taylor reported another instance of idioglossia in a boy aged eight and a half years. The late Dr. Hadden had previously given a very full account of three similar cases, all males, aged eleven, seven, and four years respectively, in the Journal of Mental Science, January, 1891.

Professor Wyllie met with two imbeciles at the Larbert Institution, who presented the same defect of speech. One was a boy aged eight, the other a girl of twenty. $\dagger$ Dr. W. S. Colman reported two cases in boys aged six, and had met with six others. $\ddagger$ The present writer has seen a number of children and adults in whom the defect existed in a minor degree, and two children in whom it was well marked.

The first of the latter was a girl aged seven, of whose case unfortunately the notes are incomplete; $\S$ the second forms the subject of this chapter.

* “Med.-Chir. Trans.," March 10, 1891.

† Wyllie, Disorders of Speech, 1894, p. 122.

I Lancet, vol. i., 1895, p. 1419.

§ This girl, whose alphabet is given in phonetic form on p. 277, was not unintelligent ; she could read words of one or two syllables and could write fairly well. Her speech presented most of the 
This patient, H. P., a bright and intelligent-looking boy aged seven and a half, was under the writer's care for the treatment of pseudo-hypertrophic paralysis. An elder brother had died of this affection at the age of fifteen. No other members of the family are known to have suffered from it.

The association with idioglossia was probably quite accidental, but it must be mentioned that the brother who died of Duchenne's palsy is said to have spoken exactly as the present patient does until shortly before death, when his speech became clear and distinct. I cannot vouch for the truth of this. A sister of the patients, aged five or six, is said to speak more indistinctly than either of her brothers,but as yet she has shown no signs of pseudo-hypertrophic paralysis.

In order to give a general idea of the defect of articulation under which he labours, the alphabet as phonetically pronounced by him may first be considered.

The alphabet, perhaps, does not best illustrate his speech imperfections, because the sounds of the letters when uttered singly are not the same as when combined to form words; but it is difficult to devise a better scheme for demonstrating his defects, and at least the knowledge of the particular letters which he mispronounces has been of service in rendering his speech intelligible. At first he could not be understood at all, but this was largely due to slurring and indistinctness of utterance. When he could be persuaded to raise his voice, and speak slowly and plainly, the fundamental defects of pronunciation were easily recognized, and his language could then be interpreted.

Alphabet as pronounced by H. P.-A-ah, Bbee, C-tee or dee, D-dee or tee, E- $\bar{e}, F-\bar{a} \bar{a}, G-d$, characteristics presently to be described. She also showed in a marked degree the tendency to "mind-wandering," so common in this affection. Whilst her attention was engaged she could repeat most words correctly at dictation, but she soon looked vacantly round the room, and her speech became gibberish, although she still continued mechanically to utter words after me. 
$\mathrm{H}$-ah, I-ah, J-day, K-kay, L-āā, M-em (sometimes, but more often âhǐ), $\mathrm{N}$-air, $\mathrm{O}-\overline{\mathrm{o}}, \mathrm{P}-\mathrm{p}, \mathrm{Q}-\mathrm{koo}, \mathrm{R}$-ah, $\mathrm{S}-\bar{a} \bar{a}, \mathrm{~T}-\mathrm{t}, \mathrm{U}-\bar{o} \bar{o}$ or dōă, V-bee, W-dădoo, X-ak, $\mathrm{Y}$-bāā, Z-dair.

Of the vowel sounds, A alone is always sounded as in " ah," but the sound " $\overline{\mathrm{a}}$ " appears for $\mathrm{F}, \mathrm{L}$, and $\mathrm{S}$, all pronounced as " $\bar{a} \bar{a}$, , also for $\mathrm{Y}$ (bāa) and J (day). E and $O$ have their natural sounds. $\mathrm{U}$ is ōō or dōa, $\mathrm{I}$ is ah. $\mathrm{Y}$ again has a vowel sound, $\bar{a} \bar{a}$, preceded by the sound of $b$ or $d$. "Yes" becomes dāā or bā̄a (ā as in day).

Of the consonants, $\mathrm{B}, \mathrm{D}, \mathrm{P}, \mathrm{T}, \mathrm{K}$, are correctly given, except that $\mathrm{D}$ is sometimes pronounced $\mathrm{T}$. But they are substituted for other consonants. $C$ becomes $d$ or $t, G$ becomes d. He says "do " for " go," but oddly enough the G in "God" is pronounced with perfect clearness.*

$P$ and $B$ appear as initials, but not as terminals.

Sibilants, such as $\mathbf{S}$ or $\mathrm{C}$ soft or $\mathrm{X}$, have no place in his spoken language, but are represented by the sound $t$, or by vowel sounds. Thus "sheep " is rendered tēe ; "slipper," tēēĕr ; "stool," tooâ ; "biscuit," bickēē ; "stocking," tockēè.

Yet he imitates the sound of hissing quite easily when shown how to produce it, although he does not use it in speech.

" $\mathrm{L}$ " is represented by vowel sounds $\bar{a} \bar{a}$, sometimes with the addition of consonants $d$ or $p$. Thus lion becomes " dâî," fly is "pâri," (a as in " ah ").

Nevertheless he can produce the sound of " $L$ " when at the end of a word, for dog becomes "dol."

Similarly $\mathbf{M}$ is usually represented by the vowel sound " ahi," but by an effort, and when instructed how to frame his lips for the purpose, he can pronounce it perfectly. $\mathrm{N}$ also has a vowel sound, but he can say " no " quite clearly.

* In explanation it may be mentioned that he is a very devout little person. Doubtless more pains have been taken to make him pronounce the name of the Deity correctly than in the case of other words. 
"Pinafore" becomes "pēēafoh." Here the sound of " $f$ " is produced, although if asked to say the letter " $f$ " he again emits a vowel sound. $R$ is not trilled, but pronounced "ah"; needless to say he does not aspirate the letter " $h . "$

To sum up, his vocabulary consists almost entirely of consonant sounds $\mathrm{B}, \mathrm{P}, \mathrm{D}, \mathrm{T}, \mathrm{K}$, and of various vowel sounds.

He does not make use of the labio-dentals $F, V$, at the beginning of words, nor of the linguo-dentals Th, S, Z, and C (soft).

Of the anterior linguo-palatals, $\mathrm{T}$ and $\mathrm{D}$ are given clearly, but substituted for each other. $\mathrm{L}$ is used only when terminal. Sh, $\mathrm{Zh}$, and $\mathrm{R}$ (mid linguo-palatals are absent).

Of the posterior linguo-palatals $\mathrm{K}$ and $\mathrm{Ch}$ (hard) appear. $\mathrm{G}$ is variable, but is usually $\mathrm{D} . \mathrm{Ng}$ is absent. $\mathrm{N}$ is variable.

Of the labials, $\mathrm{P}$ and $\mathrm{B}$ are freely used when initials, but not as terminals. $\mathrm{W}$ has only a $\mathrm{D}$ sound. $\mathrm{M}$ is variable.

Mental Condition.- - He looks and is intelligent, but owing to his physical infirmity his education has been much neglected. He cannot read, but knows his letters, and can count up to 100 .

$\mathrm{He}$ is able to form most of the letters of the alphabet correctly, but there are some capitals, such as K, M, which he cannot draw. If asked to copy one of these from a print held a little way off, he carefully traces the printed letter with his pencil, as if to fix it in his memory, then hurries to his slate to reproduce it ; by this time, however, he seems to have forgotten its appearance, and he can only draw a hieroglyphic which does not in the least resemble the letter in question. But if the copy is held so that he can keep his eye upon it and his pencil at the same time, he imitates it fairly well.

From this it would seem that his visual memory is defective.

In confirmation of this may be added the fact already mentioned, that if he can be made to watch a speaker's face and frame his lips and tongue as he (the speaker) does, he is 
able to produce sounds such as those of M, S, and F, which he does not ordinarily use. But if his attention wanders, and he looks away (as he usually does after a few moments), the sounds are no longer produced correctly, although he goes on trying to imitate the speaker.

There are, I believe, no elementary sounds of letters, or of letters combined in words, which he cannot utter if his attention can be gained sufficiently to make him observe the mechanics of their production. Yet he does not seem to know whether he has uttered them correctly or not.

He has no physical deformity of any part of his vocal apparatus. His fauces, palate, teeth, and tongue are normal.

Hence it may be concluded-

(1) That he has no defect in his motor apparatus of speech.

(2) That his visual memory is bad, in the sense that he does not remember the mechanism for producing certain sounds unless aided by his eye.

(3) That want of attention and mental concentration are largely concerned in perpetuating his faulty articulation. The matron of the hospital (Miss Oldham) states that when he is in bed, preparing to go to sleep, he can be made to say words which he seems unable to pronounce when up and about. Perhaps his mind is less actively employed and his attention less liable to be distracted at these times than during the day. Parrots are more easily taught to speak when quietly roosting than when engaged in clambering about their cages and otherwise diverting their minds after the manner of parrots. Yet parrots learn to speak by "ear," and in this respect he differs from them.

(4) As there is no physical deformity which prevents him from producing all the sounds necessary for intelligible speech, and as he is obviously not conscious whether he produces such sounds correctly or otherwise, we must conclude that the defect is not in his motor vocal apparatus, but in his ear.

It is not that he is deaf, but that he lacks the power of discriminating shades of difference between sounds. 
In favour of the view that audition rather than articulation is at fault is that the child has but little ear for music. At first it seemed that he had none at all. He made no attempt to imitate the sound of a note when struck on the piano or sung to him. He had a large repertoire of nursery rhymes, but if asked to sing one to a simple well-known tune he merely recited it in his usual fashion, without any suggestion of singing. He said that he did not know any songs or hymn tunes, and this appeared at first to be the case. But he was subsequently overheard crooning to himself sounds which distantly resembled those of a carol called "When shepherds watched their flocks by night." The carol, however, was recognized more by the child's rendering of its rhythm than of its melody, for he showed the utmost impartiality as to key, which he changed almost at every bar when singing alone.

When the accompaniment was played for him in $\mathrm{F}$ he sang more or less in C. But on transposing it to $\mathrm{C}$ and various other keys his obligato was ad lib. to a generous extent. He kept time fairly correctly, but was never by any chance within a tone or so of the note desired. Sometimes, quite by accident, he would sing nearly a third below the accompaniment. Evidently the musical sense is singularly wanting in his case. It is true that the singing voice of children at his age is commonly tuneless owing to ataxy of their vocal apparatus from want of training. Their musical intervals are often faulty, and they may sing sharp or flat. But for any one with a trace of musical ear, it is an extremely difficult feat to sing in $\mathrm{C}$, for instance, to an accompaniment played in so remote a key as $\mathrm{F}$. It was subsequently ascertained that great pains had been taken by his family to teach him this particular carol, and that he had never shown any sign of acquiring another tune.

Auditory Memory.-It is not easy to decide whether his auditory memory, or memory for sounds, is at fault as well as his visual memory, or memory for the seen mechanism of sound production. But it may be that this is so, and that he 
neither remembers sounds nor their mode of production, nor discriminates between them.

Children learn to speak by imitation. They imitate sounds which they hear, and movements of the lips, tongue, and mouth which they see. Setting aside the difficulties in controlling and co-ordinating their vocal apparatus which have first to be overcome, the power of speech is developed quickly or slowly in accordance with the accuracy of perception, both visual and auditory, which may be present. The imitative faculty is not possessed by all in the same degree, and when it is deficient the loss must be compensated by a greater amount of mental concentration than is necessary in those in whom the imitative faculty is prominent.

But increased mental concentration is also still more necessary in those who, although able to imitate mechanism of sound production which they see, are nevertheless unable to reproduce sounds which they only hear. And this is the case with the present patient. $\mathrm{He}$ can only produce certain sounds so long as his visual attention-which soon" wanders-can be commanded.

It may be asked how can his visual and auditory memory be deficient considering that he has committed to memory a large stock of rhymes, short poems, and hymns, which he repeats glibly in his own tongue?

It is generally true that a good memory is either auditory or visual. Those who possess a good auditory memory seem to hear the words which they have memorialized dictated to them, whilst those of good visual memory are able to visualize the printed page, and literally read it aloud.

Most learned anatomists and also artists possess the faculty of visual memory to a marked extent, whilst the auditory memory is perhaps more commonly met in uneducated people. The accuracy with which the latter will often repeat the exact words of a long conversation, which could only be recalled in substance by those of higher social position, is astonishing. Doubtless the visual memory 
in educated folk has increased at the expense of the auditory, by the artificial aid of writing and reading.

Those who neither possess a good auditory nor a good visual memory are compelled to rely on the association of ideas for their power of recollection, and this will be more or less accurate as the association is logical or arbitrary.

The patient, H. P., understands everything that is said to him. Words, whether spoken in his own tongue or correctly pronounced, convey a definite meaning to his mind which he remembers, although he seems not to remember the exact sound which he hears, or the method of producing it.

He appears to act on the principle advocated by that whimsical philosopher the late Lewis Carroll-" Take care of the sense, and the sounds will take care of themselves."

Neither his eye nor his ear aids him. He remembers the meaning of words, but not the sounds of the words themselves, nor the mechanism of their production, nor their appearance in print, as he cannot read.

Comparison with Other Cases.-For the purpose of comparison, the following table, showing letters of the alphabet as pronounced by six cases, is appended.

Letters of Alphabet as pronounced in Six Cases of IDIOGLOSSIA.
A
(ia(Guthrie)
ah (Guthrie.
ah (Hale-White, Golding-Bird)
ahsee ( , , ) )
ädě (Fred. Taylor)
ah (Hadden)
$C\left\{\begin{array}{l}\text { tsee } \\ t \text { or d } \\ c \\ c \\ \text { dëder } \\ \text { ve }\end{array}\right.$
$D\left\{\begin{array}{l}d \\ t \text { or d } \\ d \\ \text { gee } \\ \text { dēder } \\ \text { te }\end{array}\right.$
B $\left\{\begin{array}{l}b \\ b \\ b \\ b \\ \text { bēder } \\ \text { be }\end{array}\right.$
$E\left\{\begin{array}{l}e \\ e \\ e \\ e \\ \text { ēyer } \\ e e\end{array}\right.$ 

FUNCTIONAL NERVOUS DISORDERS

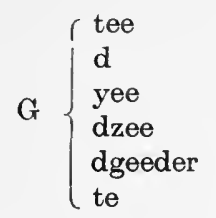

I $\left\{\begin{array}{l}\text { ai } \\ \text { ah } \\ \text { ah } \\ \text { aee (a as aye) } \\ \text { aider } \\ \text { ah }\end{array}\right.$

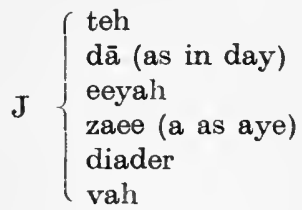

L $\left\{\begin{array}{l}\text { al } \\ \text { a a } \\ \text { ahl } \\ \mathrm{L} \\ \text { aider } \\ \text { ve }\end{array}\right.$

$\left\{\begin{array}{l}0 \\ 0 \\ \bar{u}\end{array}\right.$

O

$\mathrm{O}\{$

ōër

(vah

cah

R ah

$\mathrm{R}\{\mathrm{ah}$ arder ah

( $u$

U $\left\{\begin{array}{l}\text { ōō or dōa } \\ \mathbf{u} \text { (as in few) }\end{array}\right.$

$U\left\{\begin{array}{l}u \text { (as in frugality) } \\ \text { u }\end{array}\right.$ ūer ve

$\mathrm{X}\left\{\begin{array}{l}\text { ats } \\ \text { ak } \\ \text { aht } \\ \text { ěs } \\ \text { aidow } \\ \text { fitch }\end{array}\right.$

bëder
$H\left\{\begin{array}{l}\text { aitch } \\ \text { ah } \\ \text { ahsee } \\ \text { aisee (a as aye, } \\ \quad \text { i as aye) } \\ \text { aidow } \\ \text { vatch }\end{array}\right.$

$K\left\{\left\{\begin{array}{l}\text { tã } \\ \mathbf{K} \text { (normal) } \\ \text { talı } \\ \text { kee } \\ \text { dader } \\ \text { vah }\end{array}\right.\right.$

( ain

$\mathbf{N}\left\{\begin{array}{l}\text { air } \\ \text { ahdi } \\ \mathbf{n} \\ \text { en } \\ \text { ve }\end{array}\right.$

r too

koo

Q

$t \bar{u}$

pe

(ats

$\bar{a} \bar{a}$

S $\left\{\begin{array}{l}\text { ahsee } \\ \text { ees }\end{array}\right.$

aidow

fish

wee

b

yee

wee

veder

ve

$\mathbf{Y}\left\{\begin{array}{l}\mathbf{Y} \\ \text { bēā } \\ \text { eeyah } \\ \mathbf{y} \\ \text { whyde: } \\ \text { vah }\end{array}\right.$ $q$

l ve

$T\left\{\begin{array}{l}\mathrm{t} \\ \mathrm{t} \\ \mathrm{t} \\ \mathrm{kee} \\ \text { deder } \\ \text { te }\end{array}\right.$

$W\left\{\begin{array}{l}\text { dubbleyew } \\ \text { dădoo } \\ \text { dahbeyew } \\ \text { dahbeeyew } \\ \text { doubbeouer } \\ \text { dedorch }\end{array}\right.$

$\mathrm{Z}\left\{\begin{array}{l}\text { dads } \\ \text { dair } \\ \text { yahdd } \mathbf{i} \\ \mathrm{z} \\ \text { diader } \\ \text { ve }\end{array}\right.$

It will be seen that they all bear a general resemblance to each other, but the individual peculiarities are so many that it would be tedious to analyse the list in detail. 
The general resemblance consists in the fact that sounds of which the mechanism of production is obvious, presented the least difficulty, whilst the difficulty in most cases increased in accordance with the obscurity which attends the visible method of formation of each individual sound. Dr. W. S. Colman (op. cit., p. 1421) sums up the characteristics as follows :

"Letters which cannot be pronounced include in almost all cases the posterior linguo-palatals, the labials and linguodentals nearly always escaping. Next, the gutturals F, $\mathrm{V}, \mathrm{R}$ appear to give most difficulty. The average number of consonants which patients failed to pronounce was eight, and for these nearly all substituted $\mathrm{T}$ or $\mathrm{D}$, the former for voiceless and the latter for voiced consonants. In some cases it was easier to pronounce consonants when they were terminal than when they were initial. ... In all cases pronunciation of vowels has been good, and there has been no attempt at substitution."

In the main this summary holds good. The explosives $-\mathrm{B}, \mathrm{P}$, for instance-the labial $\mathrm{M}$, and the linguo-dentals $\mathrm{T}, \mathrm{D}$, were more frequently heard than the sounds $\mathrm{G}, \mathrm{H}$, J, K, F, V, R, C (soft), X, S, and Z, the mechanical production of which is obscure, but the same sounds were not substituted by all alike for those most difficult of production.

In all cases consonant sounds were substituted for each other, but the consonants were not in all cases the same. Sometimes they were pronounced when terminals but not when at the beginning of a word, sometimes the reverse. The cases which show the greatest individual peculiarities are those of Dr. Hadden and Dr. Frederick Taylor.

In Dr. Hadden's case the sound V (ve) stood for the consonants $\mathrm{C}, \mathrm{L}, \mathrm{M}, \mathrm{N}, \mathrm{Q}, \mathrm{Z}$. It also appeared in $\mathrm{H}$ (vatch), $\mathrm{K}, \mathrm{O}$, and $\mathrm{Y}$ (vah). F and S appeared as the word " fish," and $\mathrm{X}$, as "fitch." This peculiarity may have been traceable to the habit of biting the lower lip, common in children. This would lead to the production of $\mathbf{F}$ or $\mathrm{V}$ sounds amongst those first articulated. Generally, but not invariably, 
labials and linguo-dentals are first heard-in children learning tó talk. In rare cases gutturals are earliest.

In Dr. Frederick Taylor's case, in addition to mispronunciation and substitution of consonants for each other, there was the addition of a suffix "aider" or "er" to each letter or word. It was noticed when he first began to talk at the age of two. After careful instruction had been given, Dr. Taylor says, "It was chiefly when he repeated a string of words or a phrase after me that he became unintelligible, and the apparently involuntary affix 'eeda' or 'ida' was produced."

Somewhat similar suffixes are common enough in those who drawl, whether from affectation or from a paucity of words. There is always, however, a pause between the word and the suffix, which prevents their speech from being unintelligible, as it would become were they to speak fast, and add the suffix without the intervening pause.

In this connexion Dr. Taylor alludes to the schoolboys' game in which a meaningless syllable is added to each * word. Dr. Wyllie,* quoting Kussmaul, says that amongst German children the practice is known as the "Erbsen speech game," from the addition of the syllable "erbsen" to each monosyllabic word.

It is possible that in Dr. Taylor's case the suffixes arose from an attempt to emphasize final consonants.

In singing, the necessity of prolonging the final sound of a consonant ending a word is sometimes inevitable; for instance, "and" and "yet" become "ahnd-der" and "yet-ter," thus affording some parallel to the employment of the suffixes "ida," "eda," by Dr. Taylor's patient.

Finally, the general effect produced on listening to the speech of these children is that of hearing an unknown tongue, until one is initiated into the mysteries which underlie it. It then is discovered to be merely the King's English, the words of which are mangled and distorted, but English all the same. The language flows easily and without hesitation from their lips. It is polysyllabic, and 
in the patient $H$. P., at all events, each syllable can be clearly uttered. In most, however, there is a tendency to slur over words, which renders their sounds difficult to imitate. One of Dr. Hadden's patients was unable to understand his own language when spoken by others, doubtless because it was difficult to imitate. H. P. understands the meaning of words whether pronounced correctly or as he renders them. He calls a lion "dâi," and a sheep "teeĕr," but if asked to find one of these animals by either designation in a picture-book he points it out at once.

The vocabulary is extensive; inflections are indicated, and grammatical construction is correct in form. Every word in a sentence is represented by a separate sound. In these respects it differs from "baby English," which it resembles, however, in the substitution of consonants for each other. Gestures are not used except when the child finds it impossible to make itself understood, and even then the pantomime is feeble.

Use of Term Idioglossia._-Objection may be raised on the ground that this is not a peculiar language, but, as already stated, imperfectly pronounced English. Yet practically the result is the same as if a new language were heard, and so the term may pass. It is not found in Greek classics, but it is quite legitimate to coin it from the word 'I $\delta \iota^{\prime} \gamma \lambda \omega \sigma \sigma o s$ (of distinct, peculiar tongue), found in Strabo.

Professor Wyllie prefers to use the word "lalling" (German, lallen, "to speak as a child") to include idioglossia amongst all imperfect performances of the oral articulative mechanism. But, as already mentioned, idioglossia is not simply "baby English."

One may exclude the notion that idioglossia is a species of "atavism" or a "sport in language," by a study of which we may obtain a glimpse of the early evolution of speech as it occurred amongst our prehistoric ancestors.

This possibility has been dear to philologists since the days of Psammetichus, who, Herodotus tells "us * caused

* Book II, ch. ii. 
two new-born infants to be isolated for two years and suckled by goats. At the end of this time the only word the children could say was "bekos," the word "bek" being Phrygian for "bread." Hence Psammetichus concluded that Phrygian was the most ancient language in existence. The Scholiast, however, takes the commonplace view that the children were merely trying to imitate the bleating of the goats, which is probably correct.

In more recent times other attempts have been made to trace in childish utterances the germs of language, and to show that children in using "words of their own invention" hark back to the speech of their ancestors. Thus Horatio Hall* gives an elaborate account of twin children of German extraction who spoke a language of their own, in which their family detected a German accent, although the German language was never spoken in the household. Similarly, Dr. E. R. Hun $\dagger$ records the cases of a girl aged $4 \frac{1}{2}$ years, and her younger brother, who invented a language, some of the words and phrases of which had a resemblance to French, although it seemed unlikely that the children had ever heard French spoken. Whether this was so or not, the resemblance to French in the instances given does not seem particularly striking. Nor do the examples cited of the other children's diction suggest a German origin. Romanes $\ddagger$ says in reference to Hun's cases, "Amongst the words showing this resemblance are feu (pronounced, we are expressly told, like the French word), used to signify fire, light, cigar, sun ; too (the French tout), meaning all, everything ; and nepa" (whether pronounced as in French or otherwise we are not told), "signifying not. Petee petee, the name given to the boy by his sister, is apparently the French petit (little), and ma (I) may be from the French moi (me)."

Of these it may be said that feu is just as likely to have

* Proceedings of the American Association for the Advancement of Science, vol. xxv, 1886.

$\dagger$ Monthly Journal of Psychological Medicine, 1868.

$\ddagger$ Origin of Human Faculty, p. 141. 
been an attempt to say fire as its French equivalent. Too, signifying all, everything, is as much English as French. Petee petee is as likely to be an attempt to say pretty, pretty (an expression commonly used in talking to babies), as the French word petit. Ma might equally well stand for me as moi.

Ne pa or "not" is more difficult to explain. But ne or neh is commonly used for " no " by children. Do children ever really invent language, and are "words of own invention" used by the subjects of idioglossia? Children oftenperhaps always-when learning to talk appear to use words of their own invention. Yet I believe that for the most part their words are but imperfect attempts to imitate those which they hear. After the period of "echolalia," as it is calledin which sounds are imitated parrot-like-has passed, children begin to attach a definite meaning or connotation to the words they use. Frequently the connotation of the name of an object, or its attributes, are used as the name of the object itself, and of all other objects between which the child detects a fancied resemblance. The connotation may exist only for the child, and unless one knows what it is, the child will appear to have coined a new word, especially when the word which it wishes to utter is imperfectly pronounced. Thus a little boy aged two years called grapes bazoons, and on first seeing a signpost asked whether it was not a zebra. He had recently been playing with a toy balloon, and the signpost happened to be covered with striped advertisements. Hence the association of ideas based on superficial resemblance. His name for umbrella was bessersole, evidently a combination of umbrella and parasol.

A good example of the use of attributes for the names of objects is given by Taine.* A child aged eighteen months was told of everything hot "ça brule." After playing "cou-cou" with its mother it saw the red sun sink behind a hill, and said " a bule cou-cou," i.e. "the sun is playing hide and seek."

* De l'Intelligence, vol. i, p. 48. 
It will often be found that the supposed new terms are but misapplied and mispronounced words which children have actually heard and imperfectly understood.

Thus in the instances given by A. Crane in Nature, April 9,1891, p. 534, a child is said to have called an ordinary chair lakail, a great arm-chair lukull, whilst a little doll's chair was likill.

Obviously the word likill was the child's version of little. The doll's chair would inevitably have been introduced to the child's notice as "a little chair," and the attribute little or likill would be regarded as the name of the chair itself, whilst in trying to discriminate between this and other chairs various vowel sounds were interpolated.

It is not surprising that the term little should have had such wide significance for the child, because in the nursery it is accustomed to hear every portion of its person, its clothing, and all that concerns it referred to as "little."

The second instance given in support of the view that children invent language is that the root for all round objects was " $\mathrm{m} \mathrm{m}$ "- a watch, plate, and the moon were mem, a large round disc or table was mum, whilst the stars were mim, mim, mim. Here, again, the explanation is obvious. " $M$ " is one of the earliest sounds which a child learns to articulate, and its attention is sure to be drawn to the full moon on occasions when its male parent endeavours to soothe it during the silent watches of the night. Thus it soon learns to associate the recently acquired " $m$ " sound with the moon, and therefore with all round objects. The various vowel sounds, which are also soon learnt, were doubtless used in order to distinguish differences in magnitude of circles. The repetition of $\mathrm{mim}, \mathrm{mim}, \mathrm{mim}$, for "stars" obviously was an attempt to express the idea of plurality.

The origin of some of the words drawn from the vocabulary of children to whom Romanes has alluded is obscure, but had not the clue been lost it is probable that, however 
meaningless or arbitrary the words used may have seemed they admitted of explanation.

They may have been derived-

(1) Simply from imperfect articulation of the real names of objects.

(2) From imperfect articulation of attributes, real or imaginary, of objects used as the names of the objects themselves.

The origin of some may have been purely onomatopoetic -e.g. migno, migno signifying "water ;" ni si boa, "carriage," etc.

Hence it is open to doubt whether children ever actually invent language, rather than distort such language as they hear. The strongest argument against spontaneous evolution of speech is the fact that deaf-mutes never talk at all unless taught to do so. Idioglossia is not baby language, neither can it be strictly regarded as a new tongue, although many of the words used seem absolutely unlike those which the child has heard. The words dâi and pâi used by the patient H. P. do not in the least resemble lion and $f y$, yet they are not invented names for these creatures, but are the child's own version of their names as heard by him. I do not believe that children ever, except perhaps in play, invent new words, and am convinced that idioglossia is not an instance in favour of a contrary supposition.

Nature and Causation of Idioglossia.-Idioglossia seems to be simply an exaggeration of defective modes of speech, which are extremely common in minor degrees -without being regarded as in any way morbid.

For instance, the sound of " $\mathrm{s}$ " is commonly rendered "th" by ordinary lispers, Jews or Gentiles ; occasionally as " $t$ ", more rarely as " $k$." Thus I remember a certain hairdresser who used to mystify all new customers by remarking, "Kamkoo, kir, oo kave, kir ?" when they entered his shop, until they realized that he merely desired to know whether he should shampoo or shave them. His s's were. all $\mathrm{k}$ 's, but he had no other marked defect of speech. $\mathbf{R}$ 
is often represented by "y" or "w." Rabbits becomes " yabbit" or "wabbit." Sometimes $\mathrm{R}$ has an " $\mathrm{L}$ " sound. This is especially noticeable amongst the Chinese, but is not uncommon amongst English.

At times amongst the lower class the custom of mispronouncing vowels as well as consonants appears to spring up, becomes universal, and then gradually dies out.

Most of Dickens' characters drawn from the uneducated class, substituted $\mathrm{v}$ for $\mathrm{w}$; but the error is now practically extinct. In our own time we can all remember a period when the vowel sounds were substituted for each other, a became "ai," o "ow," y "oi," etc. But this confusion, again, was more common fifteen years ago than it is of late. More recently there has been a tendency to substitute the sound $\mathrm{v}$ for th. Mother, father, Thursday, become " muvver," "farver," and "Fursday," with adults and children alike. Oddly enough, what is regarded as a vulgarity of pronunciation in one age becomes fashionable in another; for instance, the termination "ow" becomes "er "_- "fel-" low" is "feller; "-or final g's are dropped— "shilling" is "shillin." Thirty years ago these abuses of the King's English were only heard amongst the uneducated.

It is unnecessary to enlarge on the vicissitudes which the letter ' $\mathrm{h}$ ' has undergone.

Many of these common defects of speech are but minor instances of those which obtain in idioglossia.

Idioglossia is only a comprehensive example of them all.

Predisposing Causes of Idioglossia-Wyllie * concludes that "lalling" upon a single consonant should not be regarded as an indication of defective intellect, although persistent "lalling" upon many consonants is always very strongly suggestive of such a defect.

In the case of imbeciles it is only natural that widespread defects of articulation should be present, but it will always be found in such cases that not only articulation, but syntax and grammar are in fault. An imbecile 
is mostly a crystallized infant, and his powers of language stop short when his intellect ceases to grow. His vocabulary is limited in a few words, and he makes little use of inflections. His sentences, like an infant's, are primitive in form. In idioglossia, on the other hand, the vocabulary is extensive, inflections are used, and the grammatical form of sentences is correct. Every sentence is complete, and each syllable of a sentence is represented by a separate sound.

Mental Condition in Individual Cases of Idioglossia.-One of the patients of Dr. Hale White and Mr. Golding Bird, aged nine years, had acquired a character for sharpness and ability; the other, aged $10 \frac{1}{2}$ years, had always seemed an intelligent lad.

Dr. Taylor's patient, aged $8 \frac{1}{2}$ years, had an intelligent face, and understood everything that was said to him. His palate presented rather a high arch, but he was otherwise well formed.

Dr. Hadden did not regard any of his cases as being deficient in intelligence. Indeed, the great improvement which some of them showed after a systematic course of treatment proves that they could not have been so.

Dr. Colman says,* "Although the children are often intelligent and quick, the difficulty of making themselves understood gives other people the impression that they are idiots."

The patient H. P. is bright and quick in understanding, but, as already mentioned, he cannot concentrate his attention for more than a brief space of time. He soon tires, and looks bewildered and worried; then ceases to make any effort to speak properly when pressed to do so. This may be partly due to lassitude occasioned by his physical condition (pseudo-hypertrophic paralysis). But it also depends on the mental confusion induced in this and other cases by prolonged effort. My second case exhibited it in a marked degree if one attempted to regain her attention after it had wandered.

Dr. Hadden mentions that one of the patients would * Op. cit., p. 1420 . 
begin to write well at dictation, but after a time would go on writing up and down strokes with no meaning, or, at all events, words which would suggest the language which he usually spoke. He also got confused if he attempted to speak quickly. This was apparently so in Dr. Taylor's case.

I conclude, therefore, that although not actually unintelligent, the subjects of idioglossia have some inherent inability to make prolonged use of the faculties of attention and observation which are necessary for the acquisition of correct speech.

Family Antecedents.-Several of the cases occur in members of the same family. In some instances there is a family history of insanity.

The father of one of Dr. Hadden's patients died in Colney Hatch. Two uncles of another were insane ; in his third case the father's brother did not speak until seven years of age, and the patient's cousin on his mother's side stammered slightly.

The father of Dr. Hale White's and Mr. Golding-Bird's three patients was said to have spoken badly until the age of twenty, when he was cured by some American process. His mother was in a lunatic asylum. A paternal uncle of the children talked indistinctly many years ago, but subsequently he spoke distinctly. Their mother was a nervous, emotional woman.

A cousin on the mother's side of Dr. Frederic Taylor's patient was an idiot.

In my own case, however, there is no family history of insanity, imbecility, or any other nervous disorder.

Yet I think it must be more than a coincidence that a family history of insanity obtained in so many cases. Its significance has yet to be seen in association with idioglossia.

Other Diseases and Conditions associated with Idioglossia .-Many of the patients are healthy and sound, but Dr. Colman met with infantile hemiplegia in one case, and heart disease (? congenital) in another.

Some of the patients are left-handed, and others not. 
One is said to have been ambidextrous. This was the case with the maternal grandmother of my patient. Cerebral disturbance in early life may lead to arrested development of speech centres or aphasia associated with hemiplegia, but the defective speech in such cases does not resemble that which characterizes idioglossia.

Part Played by Defective Audition in Producing Idioglossia.-Dr. Hadden mentioned in his paper * that " the evolution of speech depends on integrity of auditory perceptive centres." At the discussion on Dr. Hale White's and Dr. Taylor's paper $\dagger$ Mr. Spencer Watson and Dr. Langdon Down attributed the condition to defect of hearing short of deafness. Mr. Spencer Watson suggested that adenoids and naso-pharyngeal complaints might account for defective utterance. Such complaints may certainly lead to indistinctness of speech, but will not alone account for idioglossia. The patient H.P. is quite free from any disease of the sort. In none of the cases was hearing anything but acute so far as mere audition of sounds is concerned. Yet some defect of auditory perceptive centres is probable.

Absence of Musical Ear.-I have already laid stress on the singular absence of musical ear in H. P.'s case. With the exception of Dr. Colman, who mentions that one of his patients "sang fairly well," none of the writers on the subject alludes to the point. Yet I think it has an important bearing on the nature of idioglossia.

If the patient has not the ear to discriminate between spoken sounds, it is probable that he will not appreciate differences between musical sounds.

It will probably be found that people who have literally no ear for music in the sense that they do not appreciate distinctions between sounds, have learnt to speak on the oral and visual method rather than on the auditory. This implies greater exercise of concentration and observation 
than is needful in those who learn to speak by ear. The acquisition of their own as well as foreign tongues is usually slow, although by sheer hard work they may learn to converse with considerable fluency, yet with a barbarous accent, in languages used abroad.

Good musicians, on the other hand, are almost invariably good linguists. There may be apparent exceptions to the rule, but they admit of explanation.

Many people profess to have no ear for music, yet have no difficulty in articulation. The late Dean Stanley, although a fluent speaker, was accustomed to say that he did not know one tune from another.

Charles Lamb, if his "Chapter on Ears" * is to be taken seriously, and not as good-humoured badinage at the expense of his musical friends the Novellos, might be another instance in point. Yet on his own showing he was singularly susceptible to the emotional effects of music, which he actually disliked.

Many are like Charles Lamb in this respect; not a few are absolutely indifferent to the charm of music, and so have never taken the slightest pains to cultivate it, but it by no means follows that an ear for music is completely lacking in them as in the patient, H. P.

Indeed, they may possess a far finer and more correct ear (if they had chosen to train it) than others who profess

* " I have no ear. . . . I even think that sentimentally I am disposed to harmony. But organically I am incapable of a tune." "Scientifically I could never be made to understand (yet have I taken some pains) what a note in music is, or how one note should differ from another. Much less in voices can I distinguish a soprano from a tenor." "I am constitutionally susceptible of noises. A carpenter's hammer in a warm summer noon will fret me into more than midsummer madness. But those unconnected unset sounds are nothing to the measured malice of music. I have sat through an Italian opera till for sheer pain and inexplicable anguish I have rushed out into the noisiest places of the crowded streets, to solace myself with sounds which I was not obliged to follow, and get rid of the distracting torment of endless, fruitless, barren attention."(Essays of Elia, 1884; Macmillan, p. 52, et seq.) 
to be fond of music. The latter often only like the rhythm of a tune, but the richest harmonies which accompany it are disregarded, or, it may be, unheard by them. They enjoy a cornet or violin solo, but would willingly dispense with the band. To the musician these are the swine before whom he casts his pearls. However, they readily pick up simple melodies and distinguish one from another, and so cannot be absolutely devoid of ear.

Another apparent exception is in the case of semi-imbeciles who have often a keen appreciation and a quick ear for music, but whose powers of speech are limited to a few illpronounced words. I have already mentioned that the speech of imbeciles is that of infants, and bears only a superficial resemblance to idioglossia. Such cases are not in the same category. Lack of intellect prevents the imbecile, and lack of ear prevents the idioglossic from speaking correctly.

I see no reason, therefore, for doubting that idioglossia in H.P's case depends on defective audition, in the sense that distinctions between sounds are not appreciated or not heard ; further, that the absence of musical ear in his case is in accordance with such a view. I have already mentioned the evidence that his visual memory is faulty, and that his auditory memory is so too; whilst the difficulty in concentrating his attention for more than a short time, and the mental confusion induced by prolonged efforts at concentration, seem largely accountable for the perpetuation of his peculiar form of speech.

A similar explanation probably holds good for all cases of idioglossia.

The other conclusions which have been drawn as to the nature of idioglossia are-

(1) The term idioglossia is legitimate as representing the condition of a well-marked group of cases.

(2) Idioglossia is neither a spontaneously invented language nor an example of atavism, nor a "sport " in language.

It is not to be confounded with baby language nor with 
the language of imbeciles, although it bears a superficial resemblance to them. It is not evidence of weakened intellect, but may possibly indicate hereditary taint of insanity.

(3) It is an exaggerated form of minor and extremely common defects in speech.

It does not depend upon malformation or imperfection of the motor organs of speech, but probably is chiefly due to congenital deficiency of audition-not amounting to deafness.

As such it has no more pathological basis than has the absence of a liking for sport, or a taste for art, or a sense of humour.

Treatment.- The chief point to be borne in mind is that in all cases hitherto recorded-I believe without exception -correct articulation is possible when the child's attention can be gained sufficiently to make him imitate the mechanism necessary for production of various sounds. If his eye wanders, his ear is no help to him. He must therefore be taught, as the deaf-mutes are taught, to imitate by eye what he cannot do by ear. Also in order to learn the mode of production of sounds such as gutturals, the mechanism of which is not obvious to the eye, the sense of touch must be used. One of the child's hands should be placed on the teacher's throat, and the other on his own, whilst the desired sounds are uttered.

It is first necessary to ascertain which sounds are most faultily produced. Then, monosyllabic sentences should be constructed, in which the sounds occur both as initials and terminals-as Dr. Colman suggests-and the patient should be made to reproduce them by the aid of eye and touch.

It is best that the sentences should be meaningless, otherwise the child will learn them with ease in his own jargon, and will cease to take pains to repeat them correctly.

Few medical men have leisure to devote the time and patience necessary for the treatment of these cases, so 
instruction must be left to a relation or friend intelligent and persevering enough to carry it out on the lines laid down. In some cases it may be desirable to isolate the patient from all but his instructor. Relapses are not uncommon when teaching is lax and intermittent.

In addition, exercises should be devised to train the visual memory, e.g. the patient should be taught to draw from memory, simple, and by degrees more elaborate, figures, after carefully studying their copy.

Probably the ear may be cultivated by systematic musical training. Many people become creditable executantsvocal and instrumental-by industry, although by nature they have no musical proclivities. After much trouble my patient learnt to render a recognizable tune; but when seen two months later, instruction having lapsed meanwhile, the faculty had apparently deserted him.

The success which follows systematic instruction, and the serious bar to prospects in life occasioned by idioglossia, warrant prolonged endeavours to overcome this cacoethes loquendi. 



\section{INDEX}

Abnormal Conscientiousness, 19,42

Acetonuria, 162

Acrophobia, 194

Adenoid Vegetations in night terrors, 73

in enuresis, 156

Agoraphobia, 194

Albuminuria, Cychical, 161

Alcohol, Evils of, 118

Amaurosis, Functional, 257

Post-convulsive, 257

Anaesthesia, 16, 257

Andersen, Hans, 47

Andrewes, F., 216

Appetite, 24

Ascham, Roger, 47, 60

Ashby, 31, 201

Asthma, see Spasmodic, 200

Attitudes, Effects of, on mind and body, 120

Atropin in enuresis, 159

Audition colorée, 33

BABINSKI, 260

Bacon, Lord, 128

Bacchiadae, 3

Bacteriuria in enuresis, 156

Baginski, 200

Balanitis in enuresis, 157 in masturbation, 109

Balzac, de, 60

Baratiére, 125

Batten, F. E., 214

Berkeley, 128

Berlioz, 107

Bird, Golding, 277

Bladder, Hypertrophy of, 15

Disorders of, see Enuresis, 155
Blepharospasm, 258

Boyer, Rev. J., 60

Breton, Jules, 192

Bromides in epilepsy, 197

in night terrors, 84

in hysteria and nourasthenia, 261

Burns, 129

Byron, 129

Cantharides in enuresis, 160

Carbohydrates, 27, 157

Cardan, Jerome, 27, 69, 100, 193

Carlyle, T., 22

Catarrh, Gastro-intestinal, 13

in dentition, 169

Cathcart, 264

Cerebro-spinal system, 13

Chorea, 14, 15, 212

Anatomy, morbid, of, 219

Cardiac conditions in, 227

Complications of, 226

Diagnosis of, 227

Duration of, 212

Fright and shock as causes of, 215, et seq.

Knee-jerks in, 223

Microbic origin of, 216

Paretic-asthenic-mollis, 221-4, 235, 257

Psychical conditions in, 228

Reflex, 218, 238

Relation of, to rheumatism, 213

"Residual" Chorea, Treatment of, 229-31

Urine in, 226

Circulation, Disorders of, 141-5

Claustrophobia, 194

Clench, 125 
Clothes, ill-fitting, 36, 121

Cod liver oil, 27

Coleridge, 60, 129

Colic, mucous, 143, 206

Colman, 33, 270

Colours, dislike for certain, 31

Comby, 200

Complaints of neurotic children, 19

Constipation, 19, 159, 169

Control, deficient, of higher over lower centres, 13

Convulsions, 13, 166, 169, 176, 182

Causes of, 83-5

Definition of, 182

Dentition, 169

" Inward," 184

Pre-dentition, 183

Prognosis in, 187

Post-dentition, 183

Reflex, 185

Treatment of, 186

in Rickets, 179

Co-ordination, Defective, 13

Corvisart, 55

Cruelty, 87, 89

Cypselus, 35

DaNa, 216

Darwin, 98, 131, 138

Davies, 36

Day, 38

Day terrors, see Terrors, 78

Dead fingers, 145

Deformities, Neurasthenic, 121

Dentition, Disorders during, 166 Painful causes of, 168, et seq. Symptoms"of, 168 Treatment"of, 174

Dennis, Laurence, 45

Descartes, $128=$

Dickens, 22, 134

Diet, 25

Dishonesty, 96

Down, Langdon, 44, 124

Dreams, Psychology of, 72

Dreamy mental states, 16, 61, 192
Dysphagia, 14, 258

Dysphonia, 258

ECCheVERRIA, 192

Echolalia, 283

Eclampsia, Neonatorum, 186, see Convulsions

Nutans, 249

Eliot, George, 7, 22, 104

Eilis, Havelock, 32

Electricity in enuresis, 157

in functional disorders, 261

Emotions, moral and religious, 45

Emotional temperament, 14 See Temperament

Encephalitis, 185

Enteroptosis, 161

Entero-spasm, 142, 161

Enuresis, 14, 155

Environment, 17, 87

Epilepsy, 15

and Eclampsia, 189

" Accidental," Reflex, symptomatic, 190

Etiology of, 190

Parental drunkenness as cause, 191

Idiopathic, 190

Treatment of, 195

Bromides in, 197

Erythema exudativum, 145

Erythromelalgia, 145

Evangelists, Child, 45

Evelyn, John, 126

Ewart, W., 200

Exaggerated views, 44, 114

Exercises in chorea, 231

Exhaustion, 15, 123

Explosiveness of nerve centres, 15

FAT, Dislike of, 25

Fears, 38, et seq.

Feet " going off," 253

Fever, Hay, 207

Fichte, 51

Fingers, Dead, 145 
Fleming, Marjorie, 104, 133

Fluids, Dislike of, 26

Flushing, blushing and pallor, 144

Food fever, 27, 162

Fretting, 62

Fright and chorea, 215

Galen, 7

Garrod, A., 226

Gautier, Théophile, 53

Genius, Longevity of, 128

Glaisher, 77

Goodhart, 81, 209

Grand Mal, 190

Gum lancing, 167, 176

Graves's disease, 161

Gordon, W., 223

HaBIT, Spasm, see Tic, 240

Hadden, 270

Haematuria from healthy kidneys, 145

Hall, Horatio, 282

Hallucinations, complex dream, 74

Hart, Ernest, 32

Hawkins, H. P., 143

Hay asthma, 207

Headaches, 149-54

Head, banging, nodding, rolling, 247

Heinecken, 125

Henoch, 200

Heredity, 89

Teaching of, 114

in Epilepsy and eclampsia, 191

Herodotus, 35, 281

Hodge, 16

Holmes, O. W., 39

Home-sickness, 50

Horder, 216

Hugo, Victor, 106

Hunter, John, 171

Hun, 282

Hunt, Leigh, 41, 44, 45, 131

Hysteria, 15

Hysterical paralysis, 256
Hyperaesthesia, Cutaneous, 36 in rickets, 253

Hypotonia in rickets, 251

Hypersensitiveness of special senses, 24

IdIOGLOSSIA, 270

Idiots savants, 124

Inco-ordination of sphincters and detrusors, 15

Inheritance, Neuropathic, 16

Insanity after enteric fever, 100

Instability, Nervous, 15

Physiological, 14

Individual, 14

Intellectual precocity, 125

Ireland, W., 29

JACKSON, Hughlings, 182

JUNOT, 54

KaNT, 128

Keats, 129

Knee jerks in functional disease, 260

Küssmaul, 264

LALIING, 268

Lamb, Charles, 22, 41, 71, 77, 290

Laryngismus, 178

Laryngeal stridor,Congenital, 181

Leathes, J. B., 165

Leber, 258

Lees, D., 236

Lewes, G. H., 51

Lewis, Percy, 157

Lisping, 268

Ling, 32

Liver, Fatty, in acetonuria, 164

Locke, John, 128

Loves, Early, 107

Lucas, Clement, 216

Luther, Martin, 102

Lycopodium in enuresis, 160

Macaulay, 128

Malkoff, 216

Mal petit, 192 
Marcet, 77

Martineau, 40, 71, 135

Massage in enuresis, 157

Masturbation, 108

Medicine and milk, 25

Memory, 133

See also Idioglossia, 270, et seq.

Mendelssohn, 129

Mental dreamy states, 61, 192

Migraine, 150

Mittiz, von, 52

Montford, Simon de, 77

Moon, R. O., 192

Moral failings, 86

Causes of, 86

Varieties of, 87, et seq.

Morley, H., 194

Mozart, 129

Murderers, Infant, 95

Murray, W., 235

Myers, W. H., 43

Myoclonus, 247

NARCOLEPSY, 82, 138

Nephritis, Chronic, as cause of enuresis, 157

Nervous system in childhood, 13

Neurasthenia, 15

Cerebral and gastric, 153

Exciting causes, 17

Eye strain in, 152

Outcome of neurotic temperament, 17

Sexual, 113

Neuroses, Functional, of psychical origin, 23

Neurotic temperament, 8

Types of, 18

Complaints associated with, 19

Nicknames, 93

Night-mare, 69

Night-terrors, see Terrors, 65

Nostal'gia, 56

Nutrition, 16

Nystagmus, 14, 247

Odours, Hypersensitiveness to, 35
Oldfield, 127

Overstrain, Méntal and educational, 123, 133

Oxyurides in enuresis, 157

Paget, Sir J., 110

Palpitation, Cardiac, 141, 161

Paralysis, Hysterical, 256

Functional, 256

Parish, 32

Passion fits, 81, 91-4

Passive movements in chorea, 231

Pepys, 125

Petit mal, 192

Phillpotts, 97

Phimosis as cause of enuresis, 157 of Stammering, 266

Pianese, 216

Pica, 28

Pitres, 16

Plato, 38, 103

Poe, 129

Polyuria, 157

Porridge, 28

Porot, A., 244

Poynton and Paine, 216

Psammetichus, 281

Puberty, Splenic pain in, 144

Pulsation of carotids and abdominal aorta, 142

Punisliment, fear of, 46, 105

Pylorus, Stenosis of, 146

Pyrexia, Cyclical, 27, 162

Pyrexia, cause of night terrors, 76

QUINCEY, DE, 53

RaynaUD's Disease, 145

Refraction, Errors of, 152

Remorse and apprehensions, 42

Residual chorea, 224, 245

Rhinorrhæa, Paroxysmal, 207

Richter, 216

Rickets, Neuroses associated with, 178

as cause of epilepsy, 191

Convulsions in, 179 
Rickets, (continued)

Laryngismus in, 180

Tetany in, 178

Hypotonia and pseudo-paresis in, 181, 251

Rocking body, 247-9

Romance weaving, 98

Romanes, 282

Rousseau, 108

Rubbing, Thigh, 109, 249

SAENGER, 101

School life, effects of, 50

School masters, 47, 49, 59, 112, 138

Schubert, 129

Scott, Sir W., 39, 104

Screaming fits, 81, 91-94, 195

Scurvy, 177, 253

Sense, Moral, 86

Limited development of, 102

Sexual aberrations, 108

Information, 104

Shock and chorea, 215

Sight, development of, 28

Silbermann, 68

Sleep, hours of, 64

Disorders of, 64, et seq.

Smith, Eustace, 27

Noble, 122

Sneezing, paroxysmal, 207

Sommerville, David, 149

Sounds, fear of, 29

Southey, 48, 129

Spasm of pylorus, 15

Habit, see Tics, 240

Spasmodic asthma, 200

Analogy with mucous colic, 206

Alternation with other complaints, 204

Causes of, 202, 208

Diagnosis of, 206-7

a habit, 202

Idiosyncrasy in, 203

Pathology of, 205

Periodicity of, 204

Treatment of, 207

Speech, defects of, 262
Sphincter, atony of, 157

Spinoza, 128

Stafford, Viscount, 35

Stammering, 14

of bladder, 14

of vocal organs, 14, 262

Causes of, 262

Treatment of, 266

Stanley, Dean, 290

Steele, Richard, 51

Stephenson, Sydney, 258

St. Leger, 35

Still, 81, 103

Stridor, Congenital, 14

Stuttering, 262

Sturgis, 213

Suggestion in Chorea, 231

Suicide, 100

Supernatural, Fear of, 41

Sutherland, 200, 215

Swift, Dean, 10, 21

Sympathetic System, Disorders of, 141

emotion as cause, 142

Synaesthesia, 34

TACHyCaRdia, 141

Taine, 283

Taylor, Frederick, 270

Temperament, Emotional, 14

Restrained and unrestrained,19

Tennyson, 36

Terrors, Night, 65

Asphyxia in, 76

Astigmatism in, 75

Causes, 73

Calculus in, 76

Cyclical albuminuria, 76

Ghost tales and, 77

Heavy bedclothes, 76

Hip disease in, 76

Idiopathic and symptomatic, 68

Migraine in, 75

and nightmare, 69

Mucous disease and, 81

Nasopharyngeal obstruction in, 76 
Terrors, Night (continued)

Night sweats in, 76

Pyrexia as cause, 76

Skin eruptions and, 76

Symptoms of, 67

Treatment of, 83

Varieties of, 74

Terrors, Day, 78

and epilepsy, 81

Mucous disease, 81

Narcolepsy and, 82

Somnambulism and, 84

Tertullian, 43

Tetany, 14, 178

Electrical reactions in, 179

Treatment of, 179-81

Varieties of, 180

Thackeray, 93

Theresa of Castile, 42

Thigh rubbing, 109, 249

Thompson, John, 148, 259

Thymic asthma, 207

Tics, 14, 240

Causes, 240

Diagnosis, 246

Treatment, 243

Varieties, 240

Tissot (note), 125

Tobacco, evils of, 116

Tolstoy, 37

Traumatism as cause of neurasthenia, 17

Triboulet, 216

Trollope, Anthony, 58

Types of neurotic subjects, 18
Unemotional Person, The, 9

Untruthfulness, 98

Uric acid diathesis, 161

Urine, Alkalinity and hyperacidity of, in enuresis, 156 in chorea, 226

Urticaria, 19, 145

VASO-Motor NeUroses, 141 et seq., 161

Venesection in convulsions, 184

Versatility and vanity, 135

Vomiting, Cyclical, 162

Vulvitis in enuresis, 157

in masturbation, 109

WALKING, DELAYED, 250

Rickets in,

Loss of power of, 252

Causes of, 252-3

Wagner, 22, 129, 131

Warner, Francis, 99

Wasserman, 216

Weak hearts and weak digestions, 142,146

Wesley, Mrs., 92

White, Hale, 270

Worry and morbid apprehensions, 44

Wotton, 125

Wright, 201

Wyllie, 270, 280

Zola, Emile, 132 


\section{Date Due}

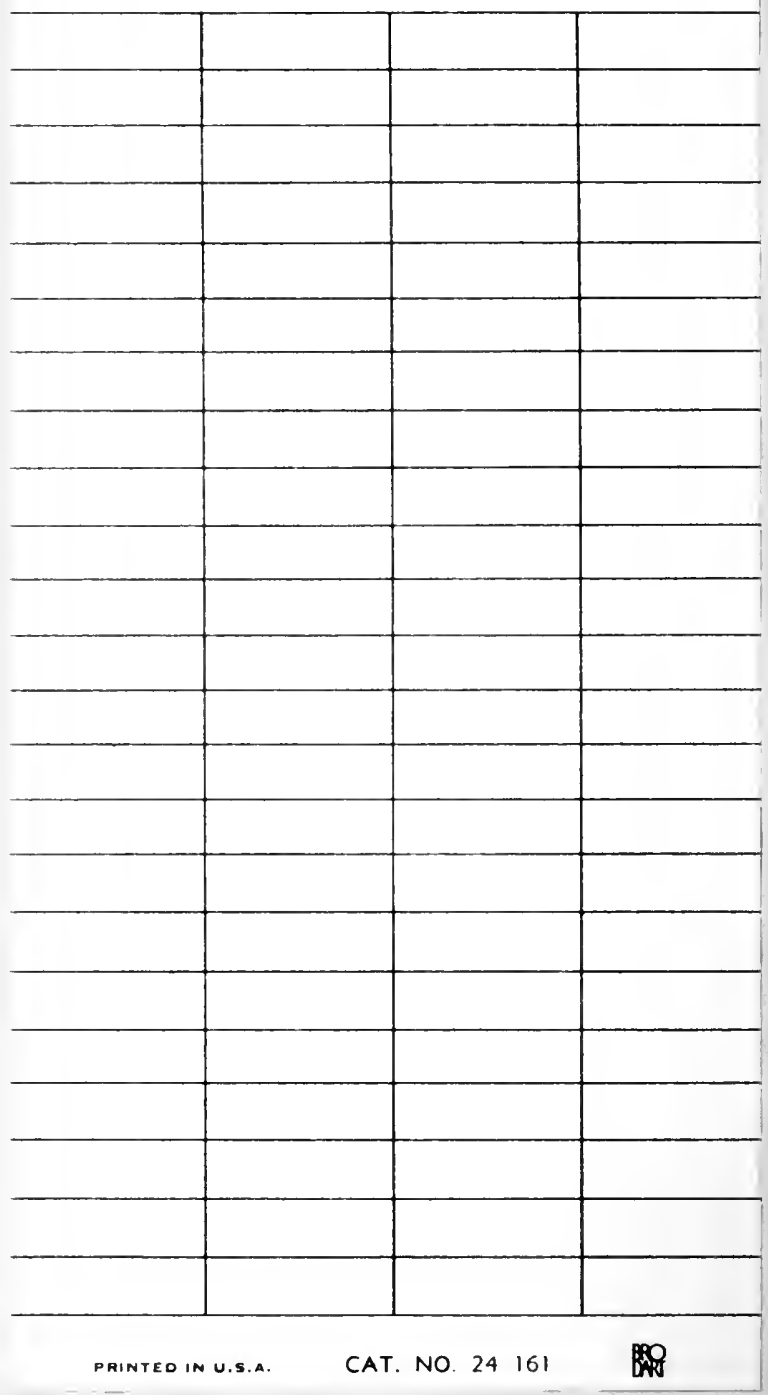


A $000432626 \quad 0$

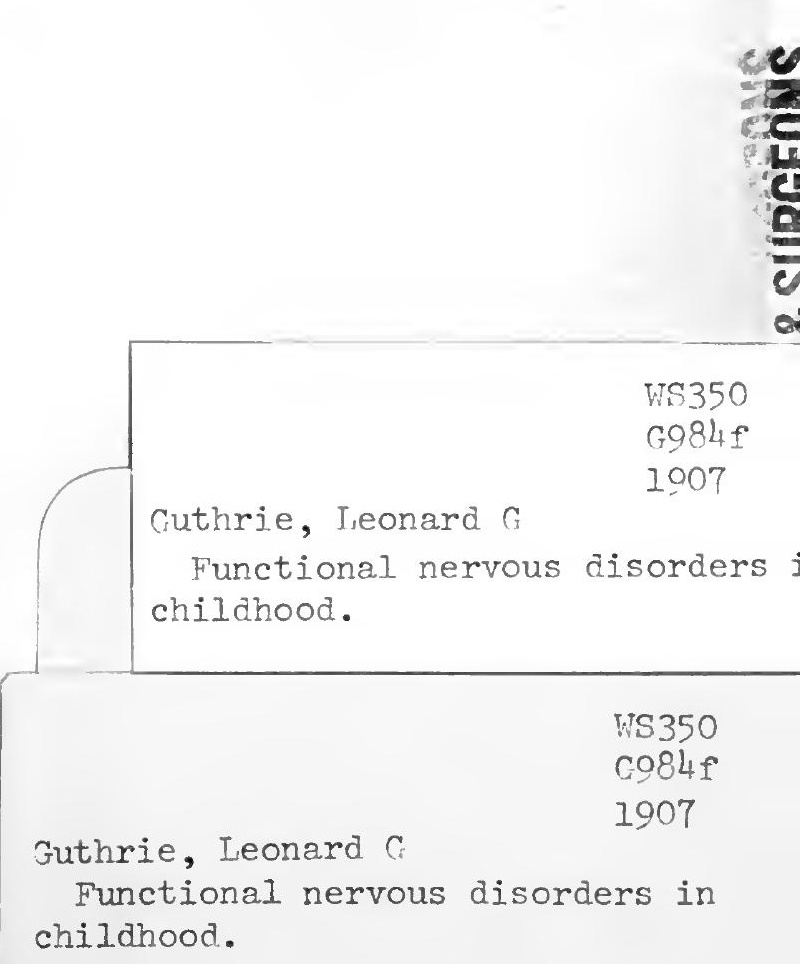

MEDICAL SCIENCES LIBRARY UNIVERSITY OF CALIFORNIA, IRVINE IRVINE, CALIFORNIA 92664 
